The School of Media, Creative Arts and Social Inquiry

\title{
Remembering Excombatientes: A Visual Enquiry into the Social Memory of Colombia's Former Combatants
}

Larry Defelippi

0000-0001-5823-8781

This thesis is presented for the Degree of Doctor of Philosophy

of

Curtin University

August 2021 


\section{Declaration}

To the best of my knowledge and belief this thesis contains no material previously published by any other person except where due acknowledgement has been made.

This thesis contains no material, which has been accepted for the award of any other degree or diploma in any university.

Signature: $\square$ Date: August 302021 


\begin{abstract}
Situated within the field of visual arts practice inquiry, this creative thesis consists of an exegesis and a creative component titled Recordando Excombatientes, through which it investigates the mediation of trauma and social memory in the photographic depiction of former combatants from Colombia's lasting internal armed conflict. Given the highly contested field of historical memory in Colombia, the thesis examines diverse strategies in photographic practice emerging in this South American nation in response to the personal, social and cultural aftermath of decades of internal violence, while also offering an original work of creative photographic research into the legacy of the Colombian conflict as seen through the eyes of former combatants. The thesis seeks to elucidate the manner in which alternative photographic portraiture intended to represent and mediate the trauma and lived experience of the Colombian conflict might help to interrogate notions of cultural memory and identity through the subjective choices made in its production. Methodologically the thesis seeks to reveal the memories of former combatants through a practice-led creative project intended to elicit an empathic viewing of the work. The exegesis interrogates theories of photography, social memory and affect as a means to support the analysis of the work of contemporary Colombian visual artists and inform the creative project. The creative project consists of a series of assisted self-portraits of Colombian ex-combatants from diverse groups taken over a period of 18 months of fieldwork in Colombia, which culminated in four exhibitions held in Colombia in 2018 and 2019, in addition to the production of a photography book of the exhibited work. The thesis seeks to produce insights conducive to an enhanced understanding of the plight of former combatants, with potential applications to memory theory and cultural memory work both in Colombia and other contexts of political violence.
\end{abstract}




\section{Acknowledgements}

I would like to thank Antonio Traverso for his untiring feedback, support, and encouragement for the project. I would also like to thank Suvendrini Perera for her feedback at the last stages of writing this exegesis. I would also like to thank George Karpathakis for his guidance. I am also highly appreciative of the technical support and advice from Joe Landro. The photographs taken in Colombia would not have been possible without the advice and support of David Caneva Akle and Gonzalo Galvis, to whom I am eternally grateful. Last, but not least, I would, most deeply, like to thank the men and women who trusted me to photograph and share their stories, for this project could not have proceeded without their participation and collaboration. 


\section{Table of Contents}

Declaration $\quad$ i

$\begin{array}{lll}\text { Abstract } & \text { ii }\end{array}$

Acknowledgments $\quad$ iii

Table of Contents $\quad$ iv

General Introduction 1

Chapter 1

Mobilising Indexicality, Memory and Affect in the Photographic Representation and Mediation of Traumatic Histories

1.1 Introduction

1.2 Representing Reality: The Indexical Before the Camera

1.3 Social Memory and Post-Conflict

1.4 Traumatic Histories and Affective Representation

1.5 Conclusion

Chapter 2

La violencia: The Colombian Conflict and Its Photographic Representation

2.1 Introduction

2.2 Photography and Affective Memorialisation

2.3 Erika Diettes and the Memorialisation of Grief

2.4 Juan Manuel Echavarría and the Photographic Metaphor

2.5 Jesus Abad Colorado's Exposure of an Invisible War

2.6 Miguel Angel Rojas: Affective Appropriation

2.7 Conclusion 
Chapter 3

Photographic Mediated Remembrance in Ongoing Traumatic Histories in Oscar Munoz's Aliento and Libia Posada's Signos Cardinales

3.1 Introduction

3.2 A Return to Death in Muñoz's Aliento (Breath)

3.3 The Act of Disappearance

3.4 Photography, Death and Mourning Mirrored

3.5 Libia Posada’s Signos Cardinales (Cardinal Signs)

3.6 Affective Portraiture: The Indexical Traces of Adversity

3.7 Cartographic Signs of Diasporic Trauma

3.8 Conclusion

General Conclusion

105

Appendices

Appendix A Fieldwork: The Act of Producing Recordando Excombatientes

Appendix B Chronology of an Intractable Conflict

Appendix C Interview with Colombian Artist Libia Posada (English translation)

Appendix D Entrevista a la artista colombiana Libia Posada

(Interview with Colombian Artist Libia Posada) (Spanish transcription)

References

139

List of Illustrations

Digital copy of the printed book: Recordando Excombatientes 


\section{General Introduction}

For the better part of the twentieth century and up to the present day, Colombia has experienced an uninterrupted and incapacitating internal conflict whose current status combines elements of conflict and post conflict (Uribe, 2009). Though typically described as beginning in the 1940s with a decade-long bloodbath known as La violencia (The violence), even positing the date when hostilities commenced becomes problematic, as assigning a date means implying culpability in the highly contested field of Colombian historical memory. For much of the conflict's history, visual representation has been mostly the domain of a hegemonic visual regime that serves the interests of the Colombian government and the traditional elites. However, in recent years, Colombian visual artists, who have increasingly focused their work on the conflict combined with the development of more diverse practices and forms of representation, have played an important role in the portrayal of previously silenced or omitted narratives of the conflict. Long denied a

permissive environment to exhibit politically charged art because of the constant threat of violent consequences, numerous contemporary Colombian artists since the 1980s have centred their work on the creation of empathic portrayals of the victims and survivors of the conflict. This relatively newfound freedom to represent the conflict has allowed artists to address the pervasiveness of amnesty and official oblivion, and the cultural background of Catholicism, race and class hierarchies, and their role in the fabrication of the notion of natural, cyclical violence in Colombia (Cabrera, 2009).

If it were not for an invitation to visit Colombia I received from a Colombian photographer with whom I had exhibited my photographic work in Japan in 2013, I would likely remain largely ignorant today about the long and violent history of Colombia's internal conflict. One of the first places I visited in Colombia after arriving in this country in 2014 was Palomino, a small town on the Caribbean coast, where the Palomino River meets the ocean. It was in this town that I started to consider the implications of the drawnout conflict within Colombian society. While in this space, I observed the incongruity of a military outpost with machine guns that I walked past on the way to the beach, contrasted with young families frolicking in the river mouth, and this first brought the omnipresent yet disregarded nature of the conflict into focus for me. It happened during this time in Colombia that I developed an interest in this country's history, which, combined with an 
admiration of the social activism featured in much contemporary Colombian art, was the genesis of this project of creative research. While exploring Colombian art that centred on the conflict, I noticed a lack of artistic representation of those who fought, particularly the guerrillas, and with this in mind, I decided to focus on documentary photography that mediated their lived experiences.

One of the first trips I took to photograph ex-combatants in Colombia in 2017 was to one of the Espacios Territoriales de Capacitación y Reincorporación (Territorial Spaces for Training and Reincorporation). These were the camps to which the recently demobilised FARC (Fuerzas Armadas Revolucionarias de Colombia - Revolutionary Armed Forces of Colombia) had moved for the purpose of reintegration in 2017. One evening my Colombian assistant and I went into a small town with the commander of the camp and some of his men for drinks. While there, some other men came in whose belligerent behaviour concerned the ex-FARC, which was understandable as an ex-combatant had been assassinated in the area only days earlier. We quickly left and returned to the camp. It may have been nothing, but no one was taking any chances given the palpable sense of trepidation that exists in Colombia's remote regions that is not found in the cities. When I returned to the capital Bogotá from the camp it felt like I had re-entered a bubble far removed from the conflict, with the ongoing violence in rural areas seemingly rendered invisible for many urban dwellers. For a country like Colombia ${ }_{2}$ with a history of civil wars and violence that goes back roughly 150 years, the local and fragmentary nature of the modern Colombian conflict, and its chronic form of violence at a very slow pace, seemingly makes it easy for oblivion to flourish.

A characteristic defining the process of demobilisation was that the violence did not end with the peace agreement signed by the FARC in 2016. This can be seen in the facts that since then a total of 253 ex-combatants have been killed, including four in the first two weeks of 2021 (Aljazeera, 2021). Furthermore, killings of human rights defenders in Colombia's remote communities increased as armed groups swiftly filled the power vacuum left by the FARC, warring for control over territory for coca production and other illegal activities that have led to the death of over 400 rural human rights activists since 2016 (Human Rights Watch, 2021), not to mention the ongoing forced displacements and disappearances throughout the country that continue to this day. This is a reality that hit 
home with the recent news that someone I know, Sebastián Antonio Restrepo Sierra (figure 1) disappeared in the San Sebastián de la Castellana Nature Reserve near Medellín on May 17, 2021 during a hike in an area he knew well. Although Sebastián’s disappearance may have been accidental given the rough terrain in the park, one hypothesis is that he ran into individuals or groups engaged in illegal activities in the area ${ }^{1}$ (Héctor Abad Faciolince, 2021). It should be noted that since the national strike held on April 28, 2021 against the policies of the government, 327 people have been reported missing in Colombia (Telesur, 2021). Although Sebastián did not take part in these protests, until answers are found he numbers as one of the tens of thousands of Colombian who have disappeared in the country's violent history.

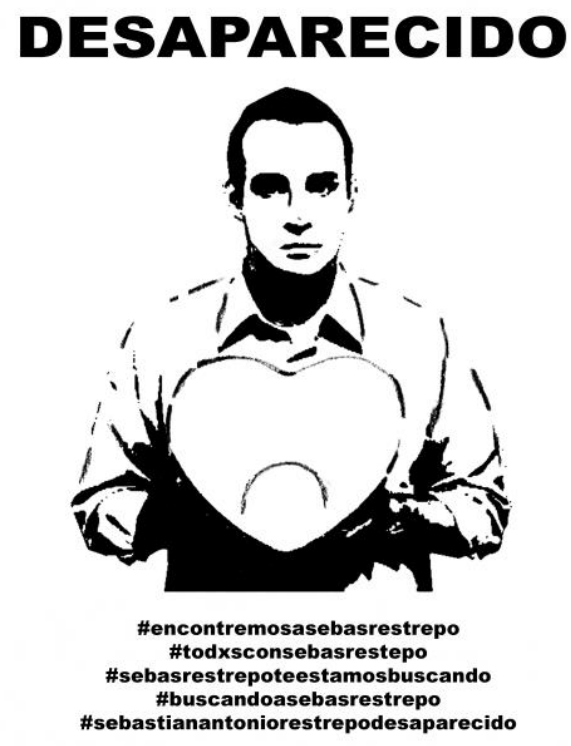

Figure 1. María Marcela Patiño Upegui. Carte Desaparecido Sebas (Missing Poster Sebas). (2021). [Poster] Courtesy of the artist

This thesis includes two components, an exegesis and a creative work, which both respond to the same central research question regarding the photographic representation of the Colombian conflict. As a practice-led $\mathrm{PhD}$, this thesis follows the model of the central research question articulated by Barbara Milech and Ann Schilo (2004). In terms of this model of postgraduate creative research, this thesis' exegetical and creative components

${ }^{1}$ All translations from Spanish are by the author unless otherwise noted 
both seek to answer the same research question, namely, how alternative photographic practices can mediate the trauma of the victims and survivors of the Colombian conflict. A central theme of the thesis is the contention that typical mass media depictions of the conflict have rendered the victims of the conflict somewhat invisible. This is not to say that the constant stream of massacres, forced disappearances, forced displacement, violence, and assassinations that occur in Colombia go under reported. Actually, it is quite the opposite, particularly from the late twentieth century, but to suggest that the saturation of conventionalised and sometimes violent mass media imagery of the conflict lacks the capacity to engender much empathy, reflection, or remembrance of those whose trauma and suffering simply becomes relegated to a statistic. As a riposte to traditional hegemonic depictions of the country's violence, this thesis argues that alternative photographic approaches intended to mediate the trauma and the lived experiences of those most direly affected by the Colombian conflict can act as a means to interrogate ideas of memory and historical identity through the subjective choices made in its production. For this to happen, it is necessary that the work shown have the capacity to elicit an empathic response. The thesis' exegetical component consists of three chapters. The first chapter outlines a conceptual and theoretical framework for both the production and analysis of photographic representations of the traumatic histories of the conflict. The last two chapters apply these conceptual and theoretical tools in an analysis of the photographic work of contemporary Colombian artists whose practices focus on specific aspects of the Colombian conflict.

The first chapter, 'Mobilising Indexicality, Memory and Affect in the Photographic Representation and Mediation of Traumatic Histories', begins with a discussion of photographic theory, specifically ideas derived from Roland Barthes' seminal text Camera Lucida (1980), which posits that the indexical and mnemonic nature of photography that facilitates the memory of events and histories not witnessed firsthand is a function of photographic historicity. Of note is the photograph's capacity to produce, supersede, and shape memories, and to provide material evidence on which declarations of truth are based. It is this notion of indexicality, the idea that something actually appeared before the lens, which Barthes describes as imbuing the photograph with an evidential force that provides confirmation that an event occurred. Although no media are more equated with mnemonic experience than those that are lens based, such 
as photography, memory is not contained in a photograph so much as it is mediated by it. While both photography and memory concern the practice of recording images that can be used to recall past events, memory does not take material form. Instead, it is mediated, and what is remembered and forgotten within a culture is determined not by individual memory, but by those with a shared past, although not necessarily a shared interpretation of said past. This concept of social memory, which is introduced in this chapter with an emphasis on the phenomenology of memory put forward by French philosopher Paul Ricoeur in the book Memory, History, Forgetting (2004), conceptually interrogates the connection between social identity and historical memory, and addresses the problematic of representing the past in a post-conflict environment. Ricoeur's treatise on memory seeks to answer questions regarding what is remembered and by whom, which he posits in a framework of Husserlian phenomenology as a means to become aware of conscious processes that usually go by unnoticed, to suggest "all consciousness is consciousness of something" (2004, p. 3). Therefore it is necessary to ask, "Of what are there memories? [prior to] Whose memory is it?" (p. 3) before it is possible to arrive at a phenomenology of memory.

These are questions of immense relevance to the countenance of hegemonic compositions of social memory, which contemporary Colombian visual art seeks to address. As mentioned earlier, there is no shortage of images depicting violent events in Colombia and, increasingly, memories of those events start to merge around a small number of images that can be described as iconic. These are often images that have the capacity to elicit affect and potentially to move people to action, empathy, and critical thought as part of the interpretive nature of the photograph derived from cultural understanding, and the subjective intervention of the artist in its production. The importance of affect, a concept that is also discussed in in the first chapter, interrogates the notion that the affective quality of art can potentially provide alternative ways of looking and thinking about the represented event, potentially eliciting an empathic response from the viewer. The application of the aforementioned theories of photographic indexicality, social memory, and affect is an essential component in the articulation, theorisation, and analysis of photographic mediation of traumatic histories that take place in the following analytical chapters. 
The second chapter, La violencia: The Colombian Conflict and its Photographic Representation, furthers the central theme of the necessity for affective depictions of the conflict, and argues that alternative forms of photographic representation are better able to elicit empathic affect and articulate memory in their interrogation of historical violence through a reflective distance from the horror. This chapter continues the discussion started in Chapter 1 concerning photographic affect and the importance of the role that images play in the mediation of memory and affect. This second chapter further argues that violent imagery succeeds to elicit neither reflection nor empathy. To demonstrate this proposition, the chapter interrogates the work of four prominent Colombian photographers: Erika Diettes (b. Colombia, 1978), Juan Manuel Echavarría (b. Medellín, 1947), Jesús Abad Colorado (b. Medellín, 1967), and Miguel Ángel Rojas (b. Bogotá, 1946), whose respective practices, in order to elicit empathic affect from the viewers, shun the use of violent imagery, while addressing some of the most shocking and violent acts of the Colombian conflict. These artists are featured because they all share an aesthetic distance, or an aestheticisation of violence, through imagery that incorporates metaphor, metonym, and iconography, and which provides greater potential to move the viewer as opposed to graphic mass media depictions of violence and atrocity. This elicitation of an empathic response creates a space for superior reflection on what they have seen, and greater potential to share their experience of the work, and knowledge of the event. This in turn allows these formerly neglected narratives to become part of the fabric of social memory, and counteract the hegemonic visual regime by giving visibility to the individuals and subjects that have been rendered forgotten by both official and social oblivion.

The final chapter, Photographic Mediated Remembrance in Ongoing Traumatic Histories in Oscar Munoz's Aliento and Libia Posada's Signos Cardinales, further explores the problematic of memory in a country with a longstanding history of conflict and post-conflict such as Colombia, and reiterates the important role of art to generate socially affective responses with crucial cultural, political and aesthetic implications. At issue are the combined effects of hegemonic representation and oblivion, both official and otherwise, that result in memory being as unstable a commodity as compassion is in the face of recurring exposure to violent imagery (Sontag, 2003). The two prominent 
Colombian artists to be considered in this chapter, namely, Oscar Muñoz (b. Popayán, 1951) and Libia Posada (b. Andes, Antioquia, 1959), not unlike the artists discussed in Chapter 2, also reject traditional representational approaches to the conflict through a practice of critical creative mediation of the violence of the conflict. In doing so they close the distance between urban viewers and a predominantly rural conflict that can easily go unnoticed by those most removed from the violent events. This chapter discusses how Muñoz's Aliento (1995), work on forced disappearance, and Posada's Signos Cardinales (2008), work on forced displacement, promote a call to empathy and remembrance that cannot be elicited through simply showing either images of the violence or tired visual clichés of the conflict, but through affective strategies that allow both a reflective distance from the violence, yet allow a proximity to the experience of victims and survivors. The ability to do so, the chapter argues, is a direct result of the artist's formulation of the work and the productive practices involved. In addition, this chapter provides a deeper analysis of the subjective choices the artists make to generate truly affective works that are as relevant today as when first exhibited. This_point is a continuation of ideas developed in the previous two chapters that shocking images anesthetise, and that alternative representations that elicit greater empathy and remembrance are required. This is an important notion as both Muñoz and Posada mediate through their critical photographic practice the memory of atrocities that have been happening over decades on a grand scale in Colombia, which sadly continue in a vicious circle of repetition and oblivion.

This exegesis is followed by the creative component of this thesis. This work is composed of a series of assisted self-portraits of ex-combatants from various armed groups from different periods of the conflict taken with calotype film, a nineteenth century paper based film. The series of photographic portraits, which has been exhibited multiple times in Colombia between 2018 and 2019 (see Appendix A, Fieldwork), is presented here in the form of a photography book, entitled Recordando Excombatientes. The creative production of the photographs displayed is one grounded by notions of agency that allow the participants to be the arbiters of the creation of their self-image (see Appendix A). The method of production and the resultant images is predicated on theories of photographic affect, and phenomenological concepts of social memory. It is 
the intent of this work to enable an empathic reading of the lived experiences of an under-represented group of people, often seen pejoratively by many in Colombian society, whose actions need to be better understood in the context of a violent conflict. As for many ex-combatants, this is not necessarily a conflict they asked for, but a conflict they were compelled to join, often because of horrific circumstances that are a legacy of an ongoing violent civil conflict that spans the entire history of Colombia (see Appendix B, The Chronology of an Intractable Conflict). 


\section{Chapter 1}

\section{Mobilising Indexicality, Memory, and Affect in the Photographic Representation and Mediation of Traumatic Histories}

\subsection{Introduction}

In his seminal text on photography, Camera Lucida (1980), Roland Barthes discusses the portrait of a man taken by the photographer Richard Avedon (b. New York, United States, 1923) titled 'William Casby, born in slavery' (figure 2).

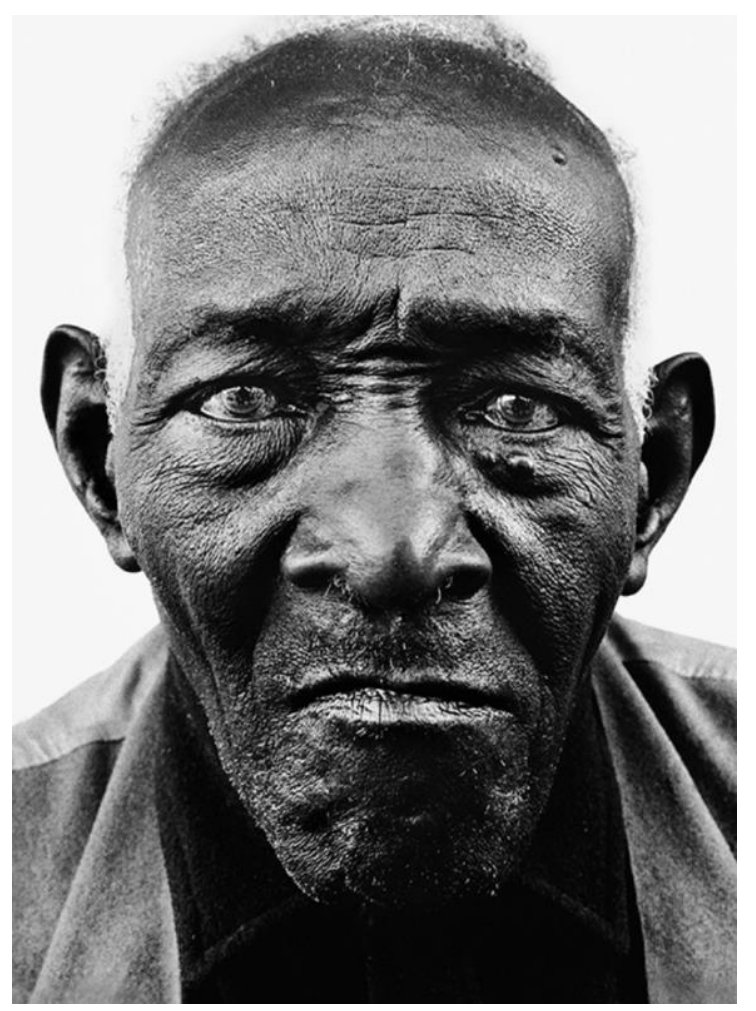

Figure 2. Avedon, R. (Photographer). (1963). William Casby, born in Slavery, Algiers, Louisiana, March 24, 1963. [Photograph] (Richard Avedon Foundation (1963) (C) The Richard Avedon Foundation)

Barthes posits this image as a demonstration of photography's power as proof, and as a record of a reality that had existed, adding that "the man I see here has been a slave: he certifies that slavery has existed, not so far from us; and he certifies this . . by a new, somehow experienced order of proof' (p. 79, emphasis in the original). For Barthes this particular image is evidence of the existence of slavery. The photograph of William Casby is a closely cropped portrait of a face registering the ravages of time via an indexical medium that leaves no doubt that this man had existed. His relation to slavery, 
other than race, is provided by the accompanying text. For photographs are not only seen, but also typically explained with text. How photographs are framed, how they are produced, how they are described, function together as part of an interpretive matrix. Even the subjective choices behind the production of photographic work, particularly what matters within the frame, can also be seen as interpretive. And interpretation takes place by virtue of the inherent traits of a photograph, namely, its mnemonic function and the communicability of its intended affect. No media is more equated with mnemonic experience than those that are lens based, in particular the photograph. The photograph seems to encapsulate memory and history, to construct and recount the past and situate it in the present. Yet memory is not contained in a photograph, so much as it is mediated by it. Photographs have the capacity to produce, supersede, and question both individual and social memories. They can shape memories, and provide the material evidence on which declarations of truth are based. William Casby was born in slavery. In Regarding the Pain of Others, Susan Sontag suggests "being a spectator of calamities taking place in another country is a quintessential modern experience" (2004, p. 17), and argues that there is an incessant exposure to images, and an overexposure to the same kinds of images seen again and again that are soon forgotten. Despite there being no shortage of images depicting traumatic events, increasingly, memories of those events start to merge around a small number of images. Those images that have the capacity to elicit affect, that is, to potentially move people to action, empathy, and critical thought. This chapter argues that theories of photographic indexicality, the phenomenology of social memory, and affect theory are essential in the articulation, theorisation, and discussion of photographic mediation of traumatic histories. In this exegesis the discussion is focused on art that depicts the Colombian conflict (see Appendix B, Chronology of an Intractable Conflict). The indexical and mnemonic nature of photography facilitates the memory of events and histories not witnessed firsthand as a function of photographic historicity. Shared images become part of the fabric of social memory, however, that is not to say that the most widely disseminated images are representative of the entire truth. As within a hegemonic visual regime, such as in Colombia, that can be seen to predominantly serve government interests, what is shown and subsequently what is remembered, often does not reflect the entire scope of narratives. 
In recent years a number of photographic projects have sought to illuminate silenced or omitted histories of the Colombian conflict. A task made possible by a more permissive environment. This thesis' subsequent chapters will discuss select photographic works and images by contemporary Colombian photographic artists that draw upon elements of art and documentary photography to represent and mediate traumatic histories and memories of an enduring conflict. This chapter's discussion of photographic indexicality, the phenomenology of social memory, and affect theory is used in Chapter 2 to inform the critical analysis of the elicitation of affect in the work of four contemporary Colombian artists, Erika Diettes, Juan Manuel Echavarría, Jesús Abad Colorado, and Miguel Ángel Rojas. These critical theories are further employed in Chapter 3 in a more detailed interrogation of affective qualities in the work of Óscar Muñoz and Libia Posada. Both of these chapters form the analysis of photographic mediation of the conflict's violence in contemporary Colombian art. These chapters demonstrate how the respective critical practice of each artist contributes to an empathic response that enhances the remembrance of victims and survivors of past and present atrocities.

This chapter's Section 2, Representing Reality: The Indexical Before the Camera discusses the indexical nature of the medium in photographic theory and the subjective choices in photographic production, and defines documentary photography and photojournalism. These are important considerations in the discussion of how the photographic image relates to the notions of authenticity, historicity, and the mediation of memory, particularly in the context of contentious historical events, such as the violent internal conflict of Colombia. As mentioned previously, although both photography and memory concern the practice of recording images that might be used to recall past events, memory does not take material form. That is, it cannot be retrieved, held or viewed like a photograph. Rather, it is always mediated. In other words, what is remembered and forgotten within a culture is determined not by individual memory but by a community who upholds a shared past, although not always a shared interpretation of said past. This notion is known as social memory, a concept used to interrogate the connection between social identity and historical memory. It calls attention to the social contexts in which people shape group identities and contest conflicting perceptions of the past. This theory, 
introduced in Section 3, Social Memory and Post-Conflict, discusses phenomenological theories of social memory and the problems of representing the past in a post-conflict environment. This is followed by Section 3, Traumatic Histories and Affective Representation, which addresses theories of affect, interrogates the idea that the affective quality of art can potentially provide alternative ways to look at, and think about the represented traumatic event, with the potential to elicit an empathic response, not through the shock of graphic images of the violence, but through images that engage the viewer.

\subsection{Representing Reality: The Indexical Before the Camera}

Since its inception much has been written about photography in terms of its 'blunt factuality' and its role in culture as mnemonic device. The $19^{\text {th }}$ century French novelist and amateur photographer Émile Zola's often quoted suggestion that, "we cannot claim to have really seen anything before having photographed it" is one of the earlier occurrences of notion of photographic truth (Silver, 1998, p. 449). American curator and art historian Beaumont Newhall, in his book The History of Photography, further posits that through a chemical and physical process, the photograph "gives nature the ability to reproduce herself" (Newhall, 1964, p. 17). It is this reproduction that originally saw photography regarded an objective tool for recording reality. Phenomenological theories of photography have seen much written about the notion of the 'referent' and the inherent originality in photographic works (Barthes, 1980; Bazin, 1960; Mitchell, 1992; Newhall, 1964; Sontag, 1977). In discussing the idea of originality in The Ontology of the Photographic Image, André Bazin (1960) points out that:

Originality in photography as distinct from originality in painting lies in the essentially objective character of photography. For the first time, between the originating object and its reproduction there intervenes only the instrumentality of a nonliving agent. For the first time an image of the world is formed automatically, without the creative intervention of man. The personality of the photographer enters into the proceedings only in his selection of the object to be photographed and by way of the purpose he has in mind. (p. 7)

For Bazin, the objective nature of photography has a quality of trustworthiness lacking in other mimetic reproductions in that the lens produces an image, which he posits as a substitute for the object in being "something more than a mere approximation, a kind of decal or transfer" (Bazin, 1960, p. 8). Suggesting that filmic representations are 
unrivalled at revealing objective reality due to a direct link to the subject. That the object had existed before the lens imbues the photograph with a certain credibility with this transference of reality from the thing to its reproduction. Furthermore, Bazin suggests that:

The photographic image is the object itself, the object freed from the conditions of time and space that govern it. No matter how fuzzy, distorted, or discoloured, no matter how lacking in documentary value the image may be, it shares, by virtue of the very process of its becoming, the being of the model of which it is the reproduction; it is the model. (1960, p. 8)

This idea of the 'truthfulness' of photography was further advanced by Roland Barthes's discussion of the referent. For Barthes (1980), a specific photograph can never be distinguished from its referent, the object that which it represents. For him the photographic referent is not the referent of other sign systems. It is not an "optionally real thing to which an image or a sign refers but the necessarily real thing which has been placed before the lens, without which there would be no photograph"; the photograph, he states, "is literally an emanation of the referent. From a real body, which was there, proceed radiations which ultimately touch me, who am here; the duration of the transmission is insignificant [...] From a real body which was there" (Barthes, 1980, p. $76 \& 80$ ). Unlike painting or language "which can feign reality", photography can never deny that the thing has been there in front of the camera, but that actuality is lost the instant the photograph is taken superimposing reality and the past. Barthes terms this the noeme, the something "that-has-been" (p. 77), positing it as the very nature of photography. Barthes's interest in photography arises from this relationship between a photograph and its particular referent. In Barthes's view, the categorisation of photography as a copy of nature could be stated using the theoretical sign of indexicality, whereby the photographic image is a trace or the effect of the object that was photographed. Indexicality is a concept developed by philosopher Charles Sanders Peirce that has come to characterise the relation between artwork and world that occurs in visual arts. Considered "the 'father' of semiotics", the philosophical study of signs, Peirce is "widely influential in cultural studies and anthropology, and widely cited in art history and art criticism" (Elkins, 2003, p. 5). For Peirce, the correlation between the photographic signifier and the object that it represents is established by the indexical and 
iconic nature of photography. As Peirce explains, photographs correspond to the depicted world by their iconic nature because "we know that they are in certain aspects exactly like the objects they represent" (Peirce, 1965, p. 281). In addition to this correspondence by similarity, photographs also better represent reality by their closeness with the referential object at the instant of their production. There exists a "physical connection" between the signifier, a sign's material form, and the object it represents, since as Peirce argues "photographs have been produced under such circumstances that they [are] physically forced to correspond point by point to nature" (p. 281). It is this relation of productive causality that defines the photographic depiction as an indexical sign. The tendency to see the photographic signifier as an affirmation of the existence of the object before the lens is primarily a function of this indexical relationship. Unlike Barthes's referent, Peirce's indexical sign is not limited to a discussion of photography, as paintings and drawings too possess an indexical relation to the world. The difference is that photographs possess a sense of certainty and authority, lacking in painting and drawing, because they fulfil a semantic criterion of correlation to the facts. Take for example a comparison of Eddie Adams's photograph of Brigadier General Nguyen Ngoc Loan shooting a Viet Cong prisoner (figure 3), and a painting titled Civilian Massacre by the Paramilitaries in Vergel (figure 4) by an ex-guerrilla in a social memory project partly organised by Juan Manuel Echavarría, a Colombian artist whose photographic work will be discussed in the next chapter.

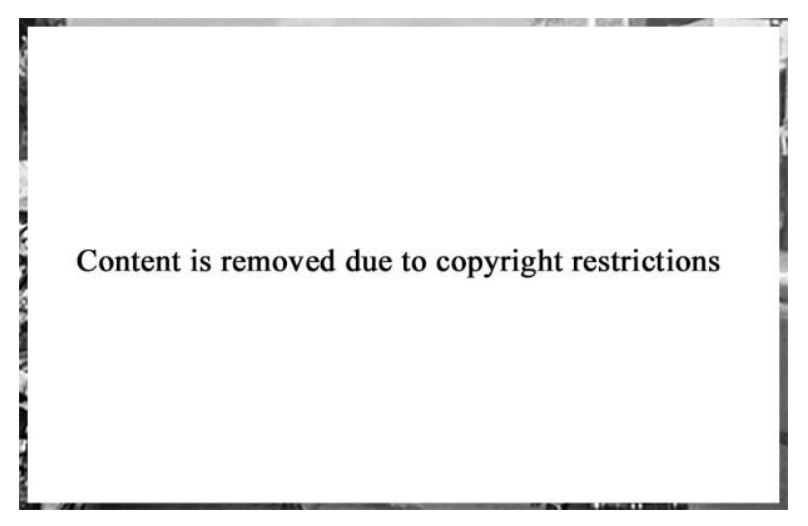

Figure 3. Adams, E. (Photographer). (1968). Brigadier General Nguyen Ngoc Loan shooting a Viet Cong prisoner. [Photograph] Retrieved from: https://www.bbc.com/news/world-us-canada-42864421 


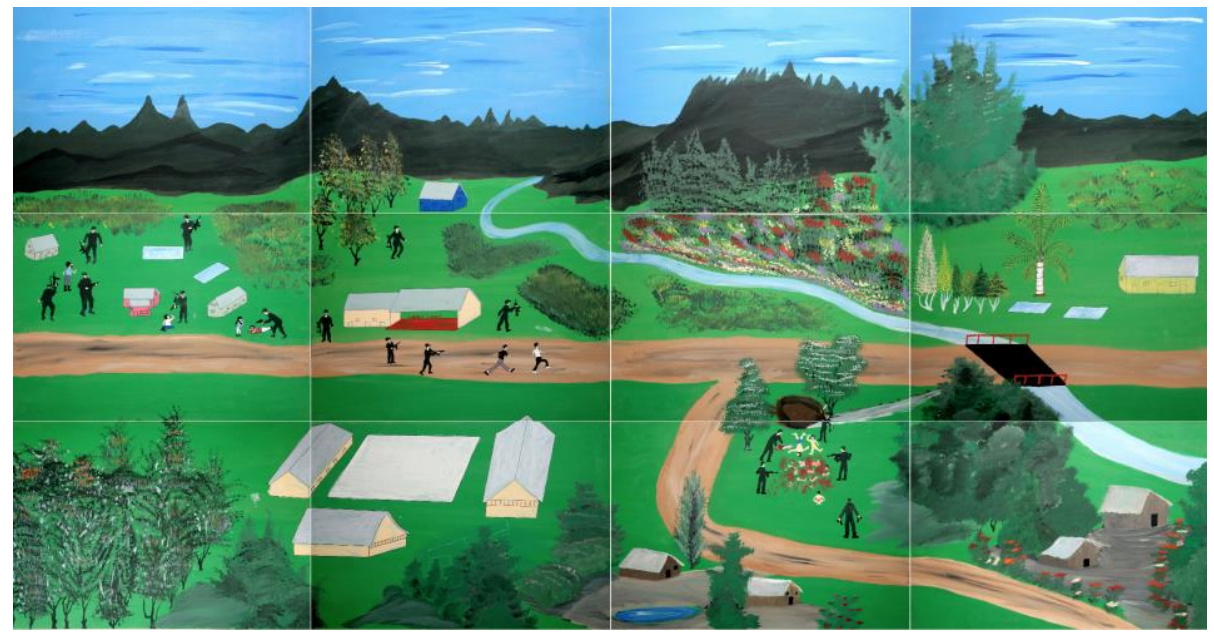

Figure 4. Anonymous. (Artist). (2008). Civilian massacre by the paramilitaries in Vergel. [Painting] Retrieved from: https://laguerraquenohemosvisto.com/en/civilian-massacre-by-the-paramilitaries-in-vergel/

Both images represent the atrocities of war, more precisely the depiction of summary executions. Whereas a photograph can be seen as documentary evidence from a semantic point of view, a painting, though an indexical trace or imprint of the world, cannot lay claim to the same level of objectivity as a photograph. Photography theorist David Campany further argues this point, as "the photograph's strength is its objective, mechanical quality that turns the existing world into a sign of itself, not a symbol of ego or creation (2003, p. 23). This concept of the transparency of authorship contributes to minimalise the subjectivity of the photographer as it emphasises a mechanical reproduction of reality. However, this is an assertion extensively questioned in photographic theory.

Although it had been argued that "subjects can be misrepresented, distorted, fake, [this] still cannot shake our implicit faith in the truth of a photographic record" (Newhall, 1964, p. 91), this idea of the photograph as an absolute 'truth' has been disputed at least since the 1970 s by photography theorists who interrogate the alleged objectivity of the photograph (Becker, 1978; Berger, 1974; Burgin, 1977; Sekula, 1984; Mitchell, 1992, Haley, 2008). This notion of objectivity was questioned more so with the advent of digital photography in the 1990s, particularly given that digital photography does allow a far greater degree of manipulation, for a digital image could be "part scanned photograph ... and part electronic 'painting' - all smoothly melded into an apparently coherent whole" that never existed before the lens (Mitchell, p. 7, 1992). 
With the growing emergence of digital photography and its inherent ease of manipulation, theorists in the 1990s began to question the certainty of the indexical relationship between the subject and the photograph in regards to digital capture. These new forms of digital photographic manipulation allow photographers to combine digital and analogue methods to produce work that is often demonstrably altered, and typically abstains from an adherence to representing photographic reality. This practice became known as post-photography. Nonetheless, in his discussion of post-photography, Stephen Haley (2008) describes what he calls 'normative' photography:

It is a form of representation that, like perspectival representation, emulates the vision seen in a planar glass mirror. In the contemporary period it has become so hegemonic it is often simply (and absolutely erroneously!) equated with human vision. In this sense, normative photography is almost 'transparent' - so entrenched as a mode of depiction that naive viewers often assume there is little or no difference between what is pictured and the actual subject. (p. 39)

This idea of normative photography can be applied to an argument that although images may be digitally produced they can still adhere to a notion, or degree, of indexicality. Koray Değirmenci's article, Photographic Indexicality and Referentiality in the Digital Age (2017), argues that the differences between analogue and digital photography do not necessarily suggest that either is a neutral process free from ideology, and that the object before the camera is not brought to the photographic surface without subjective interference. In this view, the photograph is conceived as a "certificate of presence of a thing and carries traces of it, rather than encapsulating a specific association between the photographic representation and truth" (Değirmenci, 2017, p. 111). It is important to note that the entirety of the photographic work analysed in the next two chapters, alongside the images in the creative component, observe normative photographic practices.

Although the truthfulness of any photograph, analogue or digital, can be questioned, there remain certain photographic genres that function on a presumption of truthfulness. In this respect, certain genres can be regarded as normative. Notwithstanding the fact that both analogue and digital photographs can be manipulated, often unperceptively in digital photography, Barthes's noeme remains relevant in discussing digital photography. Although developments in photographic editing software have made it easier to create an image that can differ substantially from what appears before a lens, there remain those genres in photography that are generally considered to adhere to perceived notions of 
objective factuality. The family photograph is a good example, although, one typically constructed to represent idyllic memories. The family's members are typically moved around within the frame; instructed to smile, perhaps look directly at the camera. This act of construction is clearly interpretive, and yet certifies the presence of those pictured. Although not as arguably objective as a passport photograph, one needs to consider both the intent and subjective choices made by the photographer when interrogating photographic work.

When deciding to take a photograph a number of choices are available to the photographer. The first being the decision as to what is worth photographing. As John Berger (1974) notes:

A photograph is a message about the event that it records. The message is; I have decided that seeing this is worth recording. The photograph is an automatic record through the mediation of light of a given event; yet it uses the given event to explain its recording. Photography is the process of rendering observation selfconscious. (p. 46)

In capturing an image, framing or composition is one of the key decisions faced by a photographer. The inclusion or omission of elements within the frame influences the potential reading of an image through the photographer's subjective decisions of what, where, and how to photograph. Combined with the choice of focal length, depth of field, camera angle, and lighting, these choices provide a connotative element. For example, according to visual conventions, a level angle, which is a photograph taken at the eye level of the subject, encourages the viewer to identify with the subject, and therefore this technique is predominantly used in documentary photography. The decisions that individual artists make in the creation of their work will be discussed at greater length in Chapter 2 and Chapter 3 through the analysis of select photographic works. For example choices such as framing, composition, materiality, and exhibition location, to name a few, are detailed in these chapters to describe how the artists critically construct photographic imagery to impart an interpretation of their message. Although Barthes (1977) posits the photograph as only having a denoted meaning with no code, and therefore devoid of cultural determination, the subjective interventions of the photographer provide a personally, culturally and historically invested connotative reading that is ideological in nature. Photographer and theorist Allan Sekula (1984) 
considers that photography is an explicitly ideological production and that a photograph is a sign of someone's investment in the sending of a message. In his theorisation of photographic meaning Sekula suggests, "that a photograph is an utterance of some sort, that it carries, or is a message. However, it is an incomplete message that depends on some external matrix of conditions and presuppositions for its readability" (1984, p. 84). That is, the photograph communicates meaning by culturally determined signs that enable the image to be read, as the photograph derives its semantic qualities as a function of cultural elements within the image (Sekula, 1984). This idea of cultural codification of the image will be taken up again in Chapter 2 and Chapter 3, which discuss the work of contemporary Colombian artists depicting the conflict's violence. For example, the importance of the artist's codification of the image is evidenced in Chapter 2's discussion of Colombian artist Juan Manuel Echavarría's use of culturally encoded metaphor and metonym to represent and communicate a message about the violence of the conflict. It is important to note here that these critically transmitted meanings seek to be mobilised in the production of social memory resistant to hegemonic depictions, where shared knowledge and information about a common past become significantly associated with a collective identity.

It is essential to consider at this point that memory is not entirely dependent on firsthand experience. The concept that distant contemporaries or subsequent generations bear witness to the personal, collective, and traumatic histories of others is known as post-memory. Firstly introduced by Marianne Hirsch in her article Family Pictures: Maus, Mourning, and Post-Memory (1992), this term has subsequently become an influential concept in memory studies. Hirsch defines postmemory as "the relationship of the second generation to powerful, often traumatic, experiences that preceded their births but that were nevertheless transmitted to them so deeply as to seem to constitute memories in their own right" (2008, p. 103). The term was originally used primarily to refer to the relationship between the children of Holocaust survivors and the events they 'remember' or know, and the memories of their parents. A crucial element to Hirsch's conception of post-memory as it relates to the Holocaust in particular is the phenomenology of photography. Hirsch (2008) contends that: 
The technology of photography itself, and the belief in reference it engenders, that connects the Holocaust generation to the generation after. Photography's promise to offer an access to the event itself, and its easy assumption of iconic and symbolic power makes it uniquely powerful medium for the transmission of events that remain unimaginable. And, of course the photographic meaning of generation captures something of the sequencing and loss of sharpness and focus inherent in post-memory.

(p. 108)

In effect, memory is not "entirely our own" and derives from "a combination of our own lived experiences and the experiences transmitted to us by others (whether those "others" are individuals or images from the collective archive of the mass media, popular culture, or politics)" (Lazzara, 2009, p. 156). This transmission of memory has become "one of the most recurrent themes in contemporary art", particularly in Latin America where cities "have become huge memorials ... full of sites ... to delineate the return of different experiences of violence", and in particular the representations of the victims (Giunta, 2014, p. 321). The act of exposure to overwhelming events such as political violence and war atrocities represented in works of art can be reconceptualised as an experience of the event itself, in that this historical trauma of others can become part of one's own experience and identity even through successive generations. This artistic representation of trauma can be concerned "with the content or subjects of the works in which trauma [can] be both directly and indirectly present [and] sometimes [...] with the history and the background or the context of the works that [can] exist as underlying reasons for the origin of those works" (Kulasekara, 2017, p. 35). The represented transmissibility of trauma occurs because it is not a past event or experience that is remembered, rather it is the repetition or acting out of aspects of a past experience in a perpetual present. Trauma is in effect a wound "resilient in its persistent and timeless inhabitation of a subject who does not, and cannot know it [or] that it happened or what it is that happened, the eventless event, unremembered. Yet this happening is not in the past" (Pollock, 2009, p. 40). There are parallels to be made between trauma and photography, given that the latter too collapses the past into the present.

Arguably, the two photographic genres most associated with the aforementioned transmission of traumatic history are photojournalism and documentary photography. Even 
though documentary photography has been variously linked with photojournalism, they both, arguably "convey very different messages" (Kratochvil and Persson, 2001, p. 27). Photojournalism, as Kratochvil and Persson argue, "neither has the time [...] nor the space to display [the] complexity" of the situation photographed, whereas "through documentary work, the photographer has a chance to show the interwoven layers of life, the facets of daily existence and the unfettered emotions of the people who come under the camera's gaze" (p. 27). Documentary photography can be further differentiated by its desire to advance social and historical understanding, and potentially reveal social issues. According to Andy Grundberg, modern documentary photography is frustrated by problems "to find a subject matter that has not already been exhausted by previous photographs, and to find a style that can maintain at least a modicum of documentary authority without merely repeating the conventions of the documentary tradition" (1999, p. 196). In recent years, there has been an "intensified interest in a genre of documentary photography variously referred to as late photography, after-the-fact photography or aftermath photography" (Tello, 2015, p. 555). The aftermath photograph is said to express:

Temporal, technological, and formal belatedness [and] an overall focus on absence and ruin. The centrality of absence is obvious: because these images are taken in the aftermath of a war, conflict, or atrocity, it is precisely this momentous event that is missing from the frame. (Lisle, 2011, p. 876 - 877)

The many photographers today that photograph the aftermath of violent conflict "desire to be as neutral as possible, and the prioritizing of restraint and detachment are the hallmarks of a particular aesthetic style" (Herschdorfer, 2011, p. 17). Though typically described as primarily focused on spaces devastated by violence (Campany, 2008; Herschdorfer, 2011; Tello, 2015), aftermath photography does not preclude portraiture. The method of aftermath photography or 'late photography' in its act of photographing human tragedy after, often well after, the event has occurred, is not without criticism. In his discussion of aftermath photography, Campany (2003) remains critical about the ability of aftermath photography to elicit the empathic function of documentary photography, suggesting that it is "not so much the trace of an event as the trace of the trace of an event" (p. 124, emphasis in the original). This dismissal of aftermath photography as primarily a form of removal by aestheticisation does not consider that the representation of trauma is "more likely determined by the complicated historical, ideological, and aesthetic contexts of the 
photographer" (Dong-Yeon, 2015, p. 82). Therefore, however distant the momentous events may be, photographs taken long after the fact can still arguably provide an indexical relation to the past in their evocation of individual and social memory. A quality that becomes important in connecting the photograph and historicity to the formation of social memory, an issue that will be discussed in the next section. This indexicality is indelibly linked with a capacity for mnemonic representation, one that can mediate trauma both expressively and metaphorically with an element of evidentiary certainty of that past moment. This transmission of memory is of particular importance when discussing the Colombian experience, as it will be covered in the next section, which has seen an absence of symbolisation and the repression of past traumatic events, which has made the representation of the past problematic (Uribe, 2009).

\subsection{Social Memory and Post-Conflict}

From its epochal expansion over the last two decades, "the study of memory has assumed a pivotal place in the humanities, especially history, and has also risen to prominence in some of the social sciences, most notably sociology and anthropology" (Bell, 2009, p. 345). Of particular importance is French philosopher Paul Ricoeur's phenomenological theory of memory, principally his reflection on the "problematic of representing the past" as he discusses in Memory, History, Forgetting (2004, p. xvi.). Within this text, Ricoeur identifies what he calls a 'common problematic' "[flowing] through the phenomenology of memory, the epistemology of history, and the hermeneutics of the historical condition: the problematic of the representation of the past" (p. xvi). A desire to address questions of how to represent the past has become prevalent in post-conflict Colombian society. Ricouer's theories of social memory posit that shared memories are predicated on social and cultural determinants, and that this process includes shared ideologies. The polarised nature of Colombian society along political and ideological lines partially determines what is remembered and by who. This is compounded by a hegemonic visual regime responsible for the production and circulation of the majority of conflict imagery seen by Colombians. These images and the historical narratives they support often provide a one-sided memorialisation of the conflict. Their prolific nature and exposure have a direct effect on what is socially remembered, particularly given the mostly unseen and unexperienced nature of the war to large numbers of the population. The artists discussed in the next two 
chapters seek to memorialise through affective critical practice the traumatic experiences of the often neglected or forgotten narratives of the victims and survivors of the conflict. In exhibiting their works, these artists provide a counterpoint to hegemonic narratives and a space for inclusive social memories. The articulation of traumatic memory through documentary photography incorporates the problematic of memory at a group level in a post-conflict environment, and therefore it is important to note the "internal relations between individual and collective memory" (p. 96). This section focuses initially on theories of social or collective memory, particularly Ricoeur's phenomenological theories, and the role of memory during intractable conflict.

Ricoeur's contributions to the study of collective memory were greatly influenced by the work of Maurice Halbwachs. Indeed, Ricoeur acknowledges the debt owed to Halbwachs's "bold intellectual decision to attribute memory directly to a collective entity, which he names a group or society" $(2004$, p. 120). The contemporary use of the term "collective memory" can be attributed to Halbwachs, with the publication of his book The Social Frameworks of Memory in 1925 (Olick, 1999, p. 334). Likewise, Wulf Kansteiner (2002) states, "most historians who study collective memories take the work of the French sociologist Maurice Halbwachs as their primary theoretical reference point" (p. 181). In his seminal text, Halbwachs ([1950] 1992) suggests that memories are "recalled to me externally, and the groups of which I am a part at any given time give me the means to reconstruct them, upon condition, to be sure, that I turn toward them and adopt, at least for the moment, their way of thinking" (p. 38). Furthermore, he purports that we need others to remember, suggesting "there exists a collective memory and social frameworks for memory; it is to the degree that our individual thought places itself in these frameworks and participates in this memory that it is capable of the act of recollection" (p. 38). Discussing the history of collective memory, Jeffrey Olick (1999) states, "collective memory challenge[s] the very idea of an individual memory. It is not just that we remember as members of groups, but that we constitute those groups and their members simultaneously in the act (thus re-member-ing)" (p. 11). More recently, Olick (2008) concludes:

The role of 'images of the past' in political legitimation - was best handled as a problem of 'collective memory' was by no means much more obvious than that it should be handled as a problem of 'political culture', 'narrative', 'symbolic politics', or any number of other concepts circulating at the time. (p. 24) 
The collectivist approach, as forwarded by Halbwachs's On Collective Memory, presents theoretical problems (Leichter, 2012). In discussing collective memory, Ricoeur's (2004) analysis goes further than Halbwachs's work in his inclusion of individual memory (Dessingué, 2011). In considering individual alongside collective memory:

Ricoeur is closely linked to a hermeneutics of the self [that replaces] the traditional paradigm between individual and collective memory [...] by the necessary affirmation of the dialogical nature of memory related to the dialogical nature of the being as a self and as an other. (Dessingué, 2011, p. 169)

What Ricoeur (2004) is proposing is the existence of a "level of reference between the poles of individual memory and collective memory, where concrete exchanges operate between the living memory of individual persons and the public memory of the communities to which we belong" (p. 133). In his article Collective Identity and Collective Memory in the Philosophy of Paul Riceour, David Leichter (2012) states:

While memory is central to selfhood, it is nevertheless a complex phenomenon and ought to be understood in at least two distinct senses: it is our only access to the past and that memories are of the past. We remember persons we have met, events that have happened, places we have seen, and things we have done. We also remember events that we did not personally witness but have become part of the symbolic order of the heritage with which we identify. (p. 122)

These unwitnessed events and their retelling have particular resonance when discussing the problematic of memory during the course of an intractable conflict. Recent commentators have discussed the role of memory during conflict (Nets-Zehngut, 2014: Oyola, 2015). Discussing Colombia's internal armed conflict, Rios Oyola (2015) explains that despite the conflict remaining mostly unseen, "polarised versions of the conflict have impeded the creation of a collective memory of past atrocities", that has created an "impediment in reaching a consensus ... about the conflict" (Oyola, 2015, p. 52). Rafi Nets-Zehngut (2014) in his discussion of the Israeli-Palestinian conflict concludes that "holding biased, selfserving narratives inhibits peace. Therefore, on the psychological level, the more that this phenomenon is prevalent in a society, the stronger its psychological inhibition will be in its progress towards peace" (p. 115). The resulting enmity makes forgiveness difficult and raises questions about forgetting. Sontag (2003) suggests, "too much remembering (of ancient grievances) embitters. To make peace is to forget. To reconcile, it is necessary that 
memory be faulty and limited" (p. 103). However, Sontag's view raises questions about what is remembered and what is forgotten.

Ricoeur's phenomenology of memory begins with asking: "Of what are there memories? [and] whose memory is it?" (p. 3, emphasis in the original). These two questions adhere to a tradition of thought indebted to Husserl's phenomenology, whereby, as Ricoeur points out, "priority has been given to the assertion expressed by the wellknown adage that all consciousness is consciousness of something” (p. 3). According to Ricoeur, we have traditionally posed the question 'Who?' before the question 'What?' and this “primacy long accorded to the question 'Who?' has had the negative effect of leading the analysis of mnemonic phenomena to an impasse, when the notion of collective memory was to be taken into account" (p.3). Ricoeur suggests that "if the 'I' in the first person singular is too hastily declared the subject of memory, the notion of collective memory can take shape only as an analogical concept, even as a foreign body in the phenomenology of memory" (p. 3). For memory, as Leichter puts it, is a phenomenon shared with others:

Recounting one's own past necessarily refers to others. In so doing, remembering articulates further possibilities for acting and offers testimony of actions that have been carried out or suffered, thereby enabling one to constitute a sense of oneself as sharing a common life with others. (Leichter, 2012, p. 114)

Therefore, to understand the notion of collective memory it is important to explore how memory mediates and upholds inter-subjective associations among individuals and the groups with which they identify.

On the topic of whether memory should be ascribed to either the individual or the collective in traditional memory studies, Ricoeur contends that behind the interpretation of recalled events there is always an impenetrable, opaque, inexhaustible ground of personal and cultural motivations that can constitute the subjective side correlative to the objective side of historical knowledge. In his words:

Whether we consider the sociology of collective memory or the phenomenology of individual memory, neither has any greater success than the other in deriving the apparent legitimacy of the adverse positions from the strong position each, respectively, holds: on one side, the cohesion of the states of consciousness of the individual ego; on the other, the capacity of collective entities to preserve and recall common memories. (p. 124) 
Seeking to establish a clearer connection between individual and collective memory, Ricoeur queries the existence of an "intermediate level of reference between the poles of individual memory and collective memory, [whereby] concrete exchanges operate between the living memory of individual persons and the public memory." (p.124). Ricoeur purports that this intermediate level of reference can be constituted by the closeness of relations, suggesting, that "these close relations, these people who count for us and for whom we count, are situated along a range of varying distances in the relation between self and others" (p. 124). This notion of closeness as a function of social memory is evidenced in a study that concludes that family political leaning is a strong indicator in attitudes towards the leftist and rightist narratives of the Colombian conflict (Ugarriza and Craig, 2012). The study also reveals, not unexpectedly, that "former paramilitaries tend to have higher levels of negative attitudes toward leftist armed groups than former guerrillas" ( $p$. 464), while those on the left felt the opposite. In the epilogue to his phenomenological enquiry into the nature of memory, Ricoeur (2004) discusses notions of forgiveness. Here Ricoeur considers forgiveness in "the tone of an eschatology of the representation of the past. Forgiveness - if it has a sense, and if it exists - constitutes the horizon common to memory, history, and forgetting. Always in retreat, this horizon slips away from any grasp. It makes forgiving difficult: not easy but not impossible" (p. 457). In the context of the Colombian conflict, the task of forgiveness is potentially more attainable with the advent of social memory projects in Colombia that seek to represent and foster understanding of the individual motivations of armed actors not traditionally represented empathetically in the decades long conflict.

The Colombian conflict, and its intractability, has made memory a "battlefield unto itself [incorporating] hegemonic, subordinate, and contradictory memories, [that] there are as many memories as power relationships" (Uribe, 2009, p. 4). Pervasive thinking in terms of friend and foe, particularly in a prolonged situation of political conflict, confers an importance to the role of memory within post-conflict society. This enmity amongst groups which individuals identify is "why both observers and participants have attributed such significance to collective memory in recent decades: historical narratives such as these run deep in academic, social, and political spheres" (Olick cited in Nets-Zehngut, 2014, p.104). 
The important role collective memory has played academically, socially, and politically is demonstrated in its capacity to galvanise public sentiment. According to Olick:

Images of the Vietnam War limit support for American military activities; memories of the Nazi period constrain German foreign and domestic policy; recollections of dictatorship shape the activities of transitional and post-transition regimes from Eastern Europe to Latin America. (Olick, 1999, p. 333)

The theory of collective memory provides a language to discuss the memorialisation of traumatic histories, and the importance these discussions have in a post-conflict period. Colombian academic enquiry into the various dimensions of violence, including the memory of the violence and its representation, has similarly risen in prominence in its "attempt to order the chaotic experience of violence in Colombia, [whereby] knowledge about the topic was professionalized to the extent that it resulted in a very particular kind of sub-discipline of the social sciences, popularly known as Violentología” (Riaño-Alcalá, 2002, p. 225). In discussing the lived experience of violence, and historical memory, RiañoAlcalá (2002) describes how “violence modifies and creates new cultural and social realities" (p. 222). Riaño-Alcalá asserts that:

History and memory continue to be key elements in understanding the Colombian situation; history not understood as factual and linear, but as a dynamic process where past, present and future are mutually determined by complex historical and cultural relations. (p. 224)

Riaño-Alcalá concludes that history should be approached as a social discourse, one that is "tainted by power ... with the function of legitimizing certain social orders", and furthermore, that it functions "not only as a source of understanding causes and preconditions of violence, but as a narrative where certain images, metaphors and codes have been selected and others excluded" (p. 224). This idea will be taken up again in Chapter 2, which discusses the hegemonic depiction of the Colombian conflict. Therefore, it is important to consider the inclusion of photographed subjects in the construction of their own image, identity, and omitted histories. Of particular note is the selection of locations and objects significant to the photographed subjects, and their relation to their memory and experience.

Memory is arguably "shaped by embodied and embedded narratives, located in particular places and times" (Carter, Donald, \& Squires, 1993, p. x), and these places ground identifications. These places being either architectural or landscape embody the 
memories of a population. In her discussion of landscape and memory, Birksted (2000) posits that landscape is historically linked to memory in how it is viewed. In Birksted's words:

The interaction between vision and memory in the landscape [generates] a narrative vision that cuts across the very basic distinction between the textual and the visual [...] transporting the past into present, blurring past and present, recreating the present as past (p. 3)

Location and memory are inextricably linked to each other. Both location and the mind function as a repository of images that recall past events. With the photograph enabling the recollection of a past that one has not witnessed. A photograph of the Justice Palace in Bogotá could arguably have many Colombians, or any foreigner familiar with Colombian history, recall the Justice Palace siege of 1985, one of the few massacres of the Colombian conflict caught on film. Therefore, prior knowledge of the location's historical and cultural significance and its iconography determine how it is viewed. It can be argued that collective memory is a function of personal memories being reshaped into the collective by forms of social and "political intervention through commemoration", such as the reconstruction of the Justice Palace (Moore \& Whelan, 2007, p. 6). Though this commemoration is typically discussed within the realm of monuments and spaces constructed to invoke memory by a nation, it also includes the unofficial commemoration found in the graffiti and murals of a place. These places of commemoration, particularly murals depicting left wing iconography, often feature in this thesis's creative component, which makes use of a methodology centred on assisted self-portraiture, and participant agency. This approach enables photographed subjects to be actively involved in the creation of their own representations, for, as Pierre Nora suggests, "the less memory is experienced collectively the more it will require individuals to undertake to become themselves memory individuals", particularly in instances where memories are often omitted or silenced (1989, p. 16). There are, however, ongoing efforts in Colombia to be more inclusive in the construction of historical memory. A more inclusive approach came into effect by the passing of Law 975 in 2005. This law detailed the parameters of the demobilisation of armed groups, and subsequent transitional justice measures. As part of this law, the Grupo de Memoria Historica (GMH) (Historical Memory Group) was formed and tasked with producing a report on the origins and causes of Colombia's political violence, which 
allowed for previously silenced and omitted narratives to enter public discourse. As part of its approach to historical memory the GMH facilitated collective memory workshops around Colombia that used a research methodology that included conducting visual art projects for the articulation of memory (Riaño-Alcalá, 2016). This increased permissiveness to the representation of the conflict in the latter years of the conflict, which is discussed further in Chapter 2, has been instrumental in the depiction of forgotten or ignored traumatic histories through artistic means by those previously disenfranchised.

The photographic representation of 'different truths and memories of violence' can potentially elicit new ways of seeing and understanding the conflict and its participants. As discussed earlier in this chapter, the mnemonic qualities of photography, particularly the indexical nature of the photograph as it relates to historicity, can mediate new perspectives. Often guerrillas in the conflict were primarily photographed by photojournalists as either dead or captured for newspaper headlines. Resulting in a distorted, and mostly hegemonic view of the conflict. For much of the conflict has been witnessed after the fact with "images of towns bulleted and shelled down to the last house, ... of women and children mourning the loss of their husbands and fathers, [and] the corpses of guerrilla leaders abated by the national army [being] all too common" (Yepes, 2012, p. 1). Colombian filmmaker Federico Atehortúa Arteaga's documentary Pirotecnia (Mute Fire, 2019) details that many of the photographed corpses presented as dead guerrillas were actually the bodies of innocent people killed to be disguised as guerrillas in response to demands for results by the government and the public. As discussed earlier in this chapter, photographs can in fact misrepresent. However, as a medium closely related to historicity and memory, social documentary and art photography can be mobilised to express counter narratives that resist hegemonic representation. The photograph has the capacity to mediate omitted or silenced memories and narratives to potentially affective experiences that illuminate different truths. As suggested earlier, documentary practice needs to maintain its documentary authority while developing new approaches to remain relevant. Therefore, it is just as important, if not more, to consider how images are received and how they move the viewer. 


\subsection{Traumatic Histories and Affective Representation}

When it is framed as art, photography can prepare the viewer for the different truths of a contentious history through its representational and affective qualities. In the last twenty years "under the rubric of the interdisciplinary area of trauma studies, a substantial critical literature on affect, trauma, memory, and representation has emerged" (Bennett, 2002, p. 333). Subsequently, differing approaches to artistic representation of violence and trauma, and discussions about art's relation to memory are featured in a growing number of texts (Bennett, 2005; Gregg and Seigworth, 2010; Pollock, 2009; Ray, 2005). In the context of theories of representation influenced by psychoanalysis, the concept of trauma is often understood in relation to an extreme event that "overwhelms a subject's capacity to integrate what has happened to him or her in their lives" (Pollock, 2009, p. 44). Expanding on Sigmund Freud's theorisation of trauma as a "defensive measure" by the psychic apparatus against an external "disturbance on a large scale (1961, p. 23), Jacques Lacan proposes to understand trauma in his notion of tuché or hit as the impossible encounter of the subject with a missed real. For Lacan, trauma operates through unchangeable truths that function retrospectively, which, in turn, symbolise the "encounter with the real as the exposure of real subjective limits [that are] not recuperated into the representation of trauma except as the now exposed wound" (Ray, 2005, p. 6). Therefore, trauma as defined in psychoanalytical theory is not the past event but a belated and repetitive reconnection between a subject and an overwhelming event.

It is important to note that memory is distinguished from narrative memory since trauma cannot be recalled as a past event. In other words, trauma is not remembered within the framework of a narrative of past but is simply revisited and felt as a 'real time' experience (Bennett, 2002). That is, trauma is not a past event or experience that could be remembered, even as a flashback, but it is rather a repetition of a disturbing past experience in the present. French writer and Holocaust survivor Charlotte Delbo, in her book Auschwitz and After (1995), further differentiates between narrative memory, which is derived from language and thought processes, and what she describes as sense memory, which is centred on the processes of trauma and its affective impact. This distinction made between narrative memory and sense memory also resonates with French novelist Marcel Proust's concept of voluntary and involuntary memory, the first a deliberate effort to recall 
the past, and the second, a memory unconsciously evoked by cues encountered day to day (Kaplan, 2001). Yet Proust does not consider that memories triggered by sense experience necessarily need to be traumatic, as they are also linked to nostalgia. Although Proust does not directly answer the question of how to represent the worst, "his illumination of the way in which the oddest, tiniest moments contain whole pasts goes a long way towards describing the involuntary nature of much post-traumatic remembering" (Kaplan, p. 327). In discussing the aesthetic rendering of traumatic memory, Delbo (1995) suggests that this was precisely what made sense memory valuable, the fact that it resisted historicisation and preserved within memory the affective experience itself. From Delbo's insights, we might infer that an art form that seeks to bear the imprint of sense memory must operate in these terms, thus making the experience of trauma present. In other words, rather than removing the experience to the field of analysis, sense memory art should confront traumatic experience within the realm of the senses. This sensory reaction is dependent on the affective nature of art. Therefore, an important aspect of the production and representation of trauma cannot take place without considering affect. Trauma as represented in art can be considered in many ways, "sometimes it has to do with the content or subjects of the works in which trauma could be directly and indirectly present [and] sometimes it has to do with the history and the background or context of the works" (Kulasekara, 2017, p. 35). As mentioned earlier, Lacan defines the traumatic as a missed encounter with the real, and as such, the real is non-representable, it can only be repeated. In this regard, American art critic Hal Foster argues:

This repetition serves to screen the real understood as traumatic. But this very need also points to the real, and at this point the real ruptures the screen of repetition. It is a rupture less in the world than in the subject-be-tween the perception and the consciousness of a subject touched by an image (1996, p. 132).

Whereby trauma is considered as a complete and irreducible other, moreover, it is the other of the subject. On the problematic of the representation of trauma, Pollock (2013) suggests that trauma should not be perceived as an event that we cannot know but as an encounter with a trace of the event. This encounter with trauma presents a kind of lateness, which potentially can expand meaning to allow the trauma of others to enter the domain of art. This rupture or tuché potentially elicits a bodily affect, a sense affect that points to the traumatic. Through the exploration of various methods that integrate 
processes of memory, mourning, and working through trauma into their respective practices, the artists discussed in the next two chapters, endeavour to elicit affect as a means to critically mediate the ongoing impact of violence on Colombian society.

Although affect has found application in numerous disciplines, there exists no single general theory of affect, however, it is most commonly defined as a human or nonhuman "body's capacity to affect and be affected" (Gregg and Seigworth, 2010, p. 2). Gregg and Seigworth posit that affect:

At its most anthropomorphic, is the name we give to those forces - visceral forces beneath, alongside, or generally other than conscious knowing, vital forces insisting beyond emotion - that can serve to drive us toward movement, toward thought and extension. (p. 2)

Put simply, affect is considered a spectrum of subtle to strong forces or feelings that pass body to body, from artwork to viewer. Jill Bennet (2002) describes the artist as a mediator or 'secondary witness' to the trauma, which elicits:

The sense memory of grief embodied in the other that touches the onlooker who understands at a certain point the implications of his/her presence at the scene. The affective "prick" occurs when one has the realization "I am in this scene," it affects me, I am a witness. (p. 348)

As discussed previously, memories can be transmitted, as memory itself is not necessarily experienced firsthand. In this case, memory is being revisited and replayed for others not present. Bennett further suggests that trauma related art is "best understood as transactive rather than communicative" in that "it often touches us, but does not necessarily communicate the 'secret' of personal experience" (2005, p. 7). To understand its transactional nature, Bennet draws on French philosopher Gilles Deleuze's 'encountered sign', "the sign that is felt rather than recognized or perceived through cognition" (p. 7). Bennet (2000), in her reading of Deleuze's Proust and Signs (1964), empathises with Deleuze's focus on the creative production of affect rather than reception. In Proust and Signs, Deleuze interrogates Proust's opposition to the philosophical idea of 'method', and his insistence that "truth is never the product of a prior disposition but the result of a violence in thought” (1964/2000, p. 16). In his exploration of signs within Proust's In Search of Lost Time, Deleuze concludes:

Truth depends on an encounter with something that forces us to think and to seek the truth. The accident of encounters and the pressure of constraints are Proust's two 
fundamental themes. Precisely, it is the sign that constitutes the object of an encounter and works this violence upon us. It is the accident of the encounter that guarantees the necessity of what is thought. (p. 16)

As the source of traumatic art, sense memory has the potential to affect and trigger emotion in the present. This disruptive hit or force of traumatic history can be replayed through the "artistic mimesis of the structure of trauma, [where] disturbance is reinstalled in the scene and put into play" to elicit affect (Ray, 2005, p. 6). Deploying a Kantian concept of 'negative presentation', Ray argues that:

Art can mark those points at which Auschwitz, Hiroshima, and other collective traumas exceed conventionalised representation. By negatively evoking such crimes and testifying to their unrepresentability through the positivities of traditional representational and narrative means, art can avow the damage they have wreaked. (p. 6)

In communicating a level of bodily affect, art places the viewer, the 'secondary witness in the scene, and this spectatorship of one's own feelings creates a "spectacle of feeling by which the gap between representation and affect is somehow bridged" (Bennet, 2000, p.

82). Traumatic art can further be regarded as a motivated practice, in that:

It aims to constitute a language of subjective process to complement history and to work in a dialectical relationship with common memory. Its production thus becomes a contingent and culturally situated practice - linked to social histories that requires framing against a backdrop of cultural knowledge. (Bennet, 2000, p. 83)

This necessity of cultural knowledge can be illustrated with the photographic work of Colombian artist Erika Diettes (b. Bogotá, 1978) whose work Silencios (Silences, 2006) attempts to capture the faces and memories of thirty Jewish Holocaust survivors in Colombia (figure 5). 


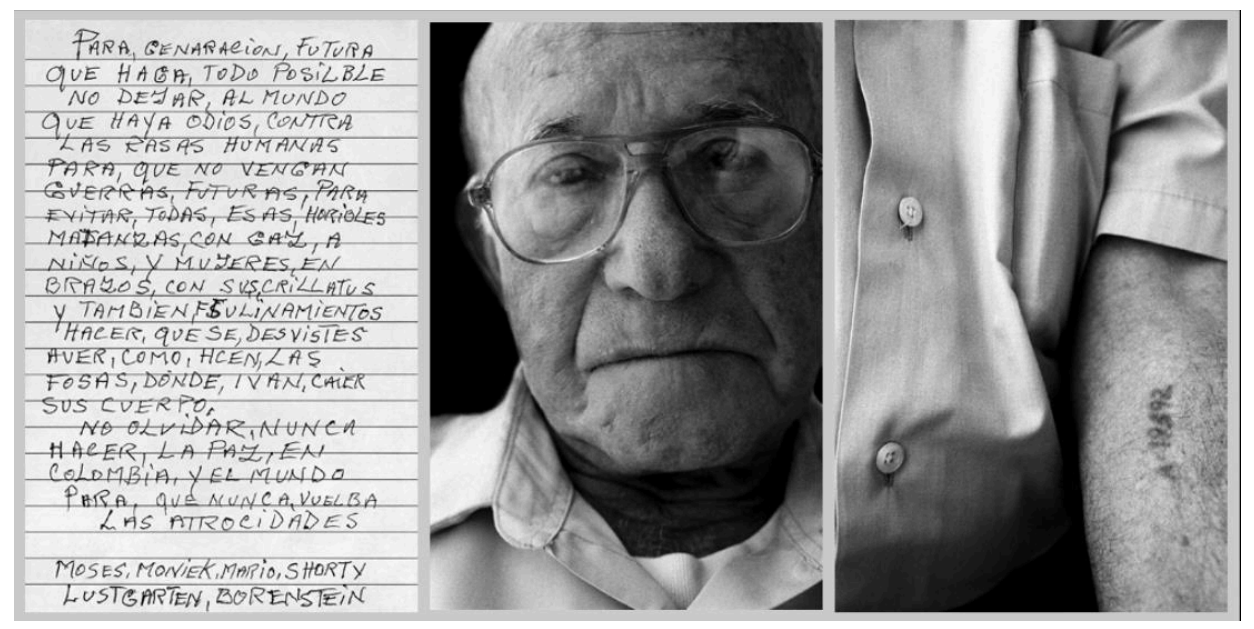

Figure 5. Diettes, E. (Photographer). (2005). Silencios. [Photograph] Courtesy of the artist

Diettes's work seeks to introduce the topic of the Holocaust to Colombia, "as well as explore the silence that these immigrants had regarding their history, which shows itself as a space for enunciation that opens through the image, objects and words" (Cardona, 2017, p. 133). Just as Barthes had posited the portrait of 'William Casby, born in slavery', discussed in this chapter's introduction as a 'record of reality that had existed', the same can be argued of Diettes's work. For her images, too, can be considered evidence of the existence of another terrible history. Similarly, Diettes's portraits do not require many words to contextualise the trauma being represented. Arguably, they require none, for in some photographs can be seen the tattooed numbers used to identify those held in concentration camps. Similarly, one of the photographs analysed in Chapter 2 by Jesús Abad Colorado, which depicts a young girl with the acronym of a paramilitary group carved into her arm by her attackers, needs no explanation for Colombian viewers, who are aware of what those initials connote.

However, many of Diettes's portraits from Silencios are still somewhat reliant on accompanying text identifying the sitters as Holocaust survivors, as are her later photographs of women who have survived Colombian atrocities, as presented in Chapter 2. The arguable primacy of the use of captions is worth mentioning given that it has been argued that photographs cannot "speak for themselves" (Sontag, 2003, p. 9), and though images can give a visual record of something that has been, Sontag argues they cannot 
provide an interpretation of that event but must "wait to be explained or falsified by their captions" (p. 9). Countering this view, Judith Butler argues that photographs are always already interpretations of the events portrayed (2007 p. 952). As mentioned previously, photographs are always a function of subjective choices, and Butler explains "prior to the events [...] represented within the frame, there is an active, if unmarked, delimitation of the field itself, and so a set of content and perspectives [...] not shown" (p. 953). These frames control what can be seen and not seen, also helping to mediate how images are seen and understood. Although Butler's discussion is focused primarily on what wider factors are at work to strengthen visual hegemonies, and the regulation of affect, the interpretive nature of art allows alternative visualisations of traumatic histories. But how is affect transmitted in the work of art? Deleuze (1964) argues that the artist's engagement with the medium generates sensations, although, his focus is on painting, and as discussed earlier, painting is essentially non-referential (although Deleuzian theories provide a framework for considering affect, they do not discuss the photograph specifically). Yet the innate attributes of the photograph do provide insight into what is known as photographic affect.

As discussed in Section 1 of this chapter, a key attribute of photography is its indexicality, an attribute that serves as an agent of affect. Adrian Kear's article Restaging the Anxiety of the Image (2005) in discussing traumatic images describes how the photograph's affective potency "derives directly from its authenticity as an index of lived experience" (p. 108). He argues that the photographic representation of traumatic histories engenders emotions such as 'anxiety' because its materiality cannot be questioned. Reliant on Barthes's theory of the noeme, Kear posits:

To the extent that 'the photograph is literally an emanation of the referent' - a capturing of an actual instant - it provides an indisputable record of presence. The bodies of the oppressed contained within it offer self-evident testament to the simple fact of their having been there, subjected to the violence of exploitation [...] What is seen with the eyes is directly felt in the body: a gut wrenching, stomach-churning, physical encounter with the sheer fact of history. (2005, p. 108)

Here, the indexicality of the photograph creates an encounter with the historicity of the image, in that "a real body, which was there, proceed radiations which ultimately touch me, who am here" (Barthes cited in Kear, 2015, p. 109). For from the moment the viewer encounters the photograph, the photographic image serves to: 
Reanimate the moment of the event itself, albeit at a representational remove; to allow the moment of viewing to open up and renew its disjunctive presence within the 'now time' of historical memory even as it repeats the codification of the relations that have 'seared the subject' with the historical index of its materiality. (Kear, 2015, p. 53)

Barthes termed this piercing emotional affect within photographs, the punctum, which he describes as an "element that rises from the scene, shoots out of it like an arrow, and pierces me" (1980, p. 26). In theorising the punctum, Barthes differentiates between the relative importance of what he terms the studium, or the cultural-historical 'meaning' of the image, which corresponds to what is happening within the photo on a discursive level, and the interruptive punctum, the emotional 'affect' which cannot be completely explained discursively. This sudden affective reaction and the "potentially wounding sensation [that] the act of looking at photographs may afflict on the viewer. It is the affect contagion that photographic authenticity and singularity can cause" (Haustein, 2012, p. 153). It is arguable that the most common responses to photographs are based not on aesthetic value but rather on identification in that viewers' interest is more referential than formal. Furthermore, it can be argued that this interest is sustained primarily "through presenting, rather than representing, the historical reality of another. The disruptive experience of being 'pricked' by the image therefore works against the grain of its frame's distancing effect, 'rupturing' subjectivity whilst simultaneously figuring and embracing alterity” (Kear, 2005, p. 109). Although the theorisation of affect in photography has for the most part focused on images that could be best described as normative, the malleability and materiality of photography does provide numerous aesthetic and interpretive approaches that may contribute to how it is read and received. Although referentiality is just part of the interpretive matrix of affect in photography, it is nevertheless a substantial part. 


\subsection{Conclusion}

This chapter has advanced a theoretical framework that is to be used in the subsequent analysis of photographic art in Chapter 2 and Chapter 3, which detail the efforts of contemporary Colombian artists to generate critically affective work to counter hegemonic representations of the conflict that contribute to the nation's endemic oblivion. In discussing these theories, it has been argued that photographic indexicality, the phenomenology of social memory, and affect theory are essential in the articulation, theorisation, and analysis of photographic mediation of traumatic histories. This chapter's Section 2, Representing Reality: The Indexical Before the Camera, posited that despite recent criticism that questions the objective nature of photography within normative practice, the idea of photographic truth remains pervasive as it relates to historicity. The theories of the indexical nature of the photograph and its mnemonic capacities discussed in this chapter are an important consideration in the interrogation of photographic affect as it relates to the representation and mediation of traumatic histories and memories. It is precisely its mimetic attributes that enable the photographed image to function as a powerful repository of social memory, a topic that was discussed in this chapter's Section 3, Social Memory and Post-Conflict. In this section it was noted that memories can be transmitted by others, and need not be firsthand. These others may be contemporaries or people from past generations, their memories transmitted from individual to individual or through mass media and public culture. In this sense, individual memories can become collective memories in an exchange between the recorded living memory of individual persons and public memory. The chapter's Section 4, Traumatic History and Affective Representation, provided an insight into theories of affect, and argued that art can potentially communicate a level of bodily affect as it places the viewer as a secondary witness to trauma transmitted through affect. Essentially the spectatorship of one's own feelings creates a spectacle of feeling bridging the gap between mediation and affect. Put simply, affect physically and emotionally moves viewers, and through this function, transmits and mediates trauma that may elicit critical enquiry and thought, and an empathic response from the viewer.

In considering the nexus of photographic indexicality, social memory, and affect theory, one should consider how they operate conjunctively in the production and reception 
of photographic representations of traumatic histories. The phenomenology of photography plays an important part in understanding photographic affect as it relates to historicity. The photograph, though clearly a mediated object, makes an affective impact on viewers partly because it is seen as an index of lived experience. It is precisely its mimetic attributes that enable the photographed image to function as a powerful repository of social memory. To facilitate a social memory of traumatic histories, it is not necessary for the photograph to be traumatic. It should, however, endeavour to repeat a trace of the trauma through affect. This thesis' subsequent chapters will focus on the work of noted Colombian artists who have taken a reflective approach to representing the conflict's violence. The artists to be discussed in Chapter 2 and Chapter 3 utilise visual strategies that affectively communicate atrocities that have taken place and sadly continue in Colombia. They do so not by presenting explicit depictions of the violence, as photojournalists often do, but by invoking a creative mediation of the violence that transmits the affect of trauma, yet without producing a re-enactment of the trauma-inducing event. 


\section{Chapter 2}

\section{La violencia: The Colombian Conflict and its Photographic Representation}

\subsection{Introduction}

The term La violencia (The violence), derived from a period of civil war that lasted more than a decade, has been appropriated by Colombian contemporary artists to refer to the subject of violence without the historical specificity of the term. Although this period of violence from the 1940s to the late 1950s was known to have "hindered political engagement by artists [...] and indeed, a significant number of the country's intellectuals became exiled during that period" (Yepes, n.d., p. 1), it should be noted that there has been a tradition of representation from the beginning of La violencia ${ }^{1}$. In the subsequent decades, acute violence suffered in Colombia since 1948 has become part of the social fabric, and, as a result, this has become a theme that has inspired significant works in the fields of literature, film, theatre, and visual arts (Medina, 2019). In the 1970s, artistic repression worsened with the organisation of the first paramilitary groups, which quickly began to target left-wing intellectuals and artists, with the result that "artists turned towards formal aesthetic problems of the expression of their own interior" (Yepes, n.d., p. 2). Beginning in the 1980s, larger numbers of Colombian artists began returning their attention towards political art and representation of the conflict. This trend also coincided with a shift away from figurative realism, which had the realistically depicted human figure as the principal focus of the work. In Colombian visual arts, this shift was "evidenced by an interest in moving beyond this realm of unambiguous images as well as in interrogating the role of images and narratives of violence in the construction of Colombian cultural memory" (Cabrera, 2009, p. 204). The increased focus on the conflict, combined with more diverse artistic practices can be seen to play an important role within the realm of cultural or social memory in its interrogation of images and

\footnotetext{
${ }^{1}$ M.Cabrera (personal communication, November 18, 2020) notes that there is a well-documented artistic production around La violencia, its founding event, the assassination of Jorge Eliécer Gaitán and the subsequent uprising known as El Bogotazo (9 April 1948), which had repercussions throughout the country. Well-known painters such as Alipio Jaramillo, Alejandro Obregón, Débora Arango, Enrique Grau and many others represented these events. These figurative dynamics of representation extended throughout the 1950s, creating an archive of this period of La violencia. ). In the 1960s, there are also emblematic paintings refering to La Violencia such as Piel al sol (1963) by Luis Ángel Rengifo, La cosecha de los violentos (1968) by Alfonso Quijano, La horrible mujer castigadora (1965) by Norman Mejía and El martirio agiganta a los hombres raiz (1966) by Pedro Alcántara. In the 1970s and 1980s, the artistic depictions of violence shifted, as they had to deal with the rise of paramilitarism, urban violence, and the emergence of drug trafficking.
} 
narratives (and omissions), the prevalence of amnesty and official oblivion, and also the cultural background of Catholicism, race, and class hierarchies and their role in the production of the notion of natural, cyclical violence in Colombia (Cabrera, 2009). This gradual shift towards more inclusive and diverse representations of the conflict was also bolstered by institutional changes, such as legislative steps to promote the production of knowledge about a violent past to articulate comprehensive and plural narratives about violence in Colombia. The memorialisation and representational shift from predominantly traditional mass media depictions of the Colombian conflict to the emergence and greater inclusion of artistic representations of the violence in the subsequent decades since La violencia have led to not only alternative aesthetic responses, but also alternative narratives of the conflict.

This chapter argues that alternative forms of photographic representation of the Colombian conflict are better able to elicit an empathic affect and articulate memory in their interrogation of historical violence through a reflective distance from the horror. The chapter's first section, Photography and Affective Memorialisation, continues the discussion of photographic affect, and the importance of the role that images play in the mediation of memory and affect, started in Chapter 1 . This section shows that violent imagery succeeds in eliciting neither reflection, nor empathy. To examine this point, the remaining sections of the chapter interrogate the work of four prominent Colombian photographers whose practice eschews the use of violent imagery, while at the same time representing some of the most shocking and violent acts of the Colombian conflict, to elicit empathic affect. The first artist discussed in this chapter, Erika Diettes (b. Colombia, 1978), experiments with photographic techniques and materials to explore memory, pain, and absence in response to a violent death, often through the appropriation of religious iconography. The next section focuses on the artist Juan Manuel Echavarría (b. Medellín, 1947), who incorporates metaphorical and metonymical elements_in his photographic work to represent both the omnipresence of violence and its invisibility. Furthermore, the chapter discusses the work of Jesús Abad Colorado (b. Medellín, 1967), a former photojournalist turned social documentary photographer, and arguably Colombia's most famous photographer, who focuses on the violence experienced by the peasants and residents of the most remote and forgotten 
parts of the country to bring attention to the often omitted narratives of Colombia's poor and forgotten. The final section focuses on the work of Miguel Ángel Rojas (b. Bogotá, 1946), who reflects upon the educational and cultural inequalities in Colombia that can be seen as a determinant in the continuation of armed conflict. These artists are discussed in this chapter because they all share an aesthetic distance or an aestheticisation of violence through imagery that incorporates metaphor, metonym, and iconography that has theoretically greater potential to move the viewer as opposed to graphic depictions of violence and atrocity such as journalistic photographs of bloodied bodies. The figurative devices to be analysed in the artist sections, such as metaphor and symbolism, provide a reflective distance not offered in gruesome imagery that potentially enable the viewer to greater reflect on what they have seen, become an empathetic witness, and share their experience of the work. This allows these formerly neglected narratives to become part of the fabric of social memory. In this way, these images can be seen to counteract the hegemonic visual regime by providing visibility to the individuals and subjects that have been rendered invisible by both official and social oblivion.

\subsection{Photography and Affective Memorialisation}

Although artistic representations of the Colombian conflict were quite limited until the latter part of the twentieth century, there was no shortage of images in the media displaying the aftermath of violence. Given the nature of the guerrilla conflict in Colombia, the majority of battles between insurgents and government troops took place in sparsely populated rural areas, and subsequent media depictions of the conflict were typically images of the aftermath. These images, which often showed the corpses of guerrillas killed by the Colombian army, were published in the media to promote a government narrative of military success. As discussed in Chapter 1, some of those

pictured were innocent Colombians whose deaths were staged by the Colombian army. One such media depiction is a photograph of a purported guerrilla killed in combat according to the army, who on closer inspection can be seen to be wearing new rubber boots on backwards (figure 6). 


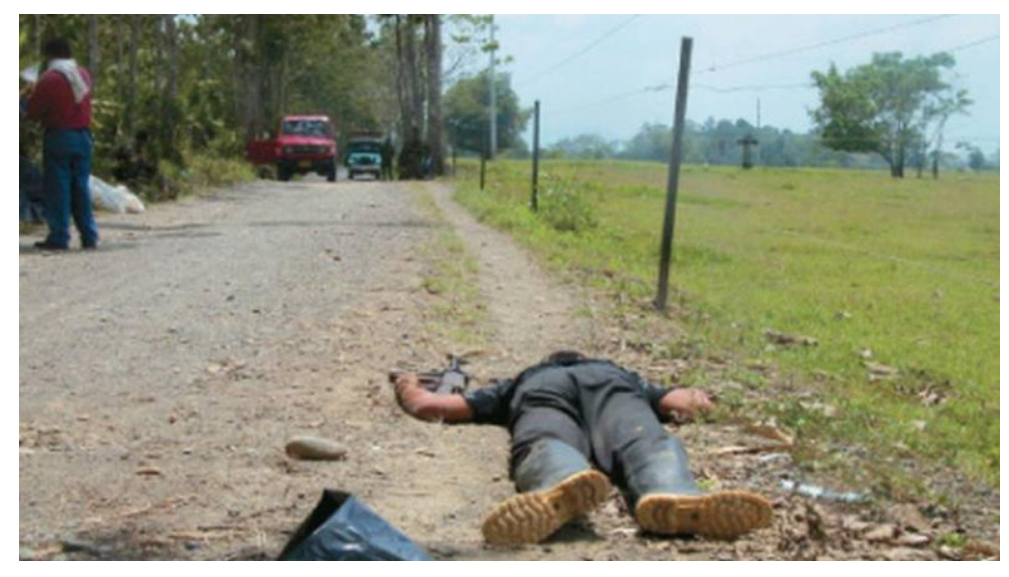

Figure 6. Unknown photographer. Purported guerrilla killed in Urabá, Antioquia. (2011).

[Photograph] Retrieved from: https:/www.semana.com/nacion/articulo/lentos-positivos/234804-3/

Numerous theorists have argued that images such as figure 6, through their overabundance render the viewer unreceptive to the depiction of violence. Julia Kristeva (1982), in the book Powers of Horror: An Essay on Abjection, argues that continual exposure makes it difficult to attribute meaning to explicit images of violence. Kristeva suggests that horror is a pain that has escaped the limits of intelligibility; horror is a reaction to that which escapes the symbolic order that is difficult to make sense of in the light of unintelligible suffering (Kristeva, 1982). Adriana Cavarero further elucidates this notion of horror in visual representation in Horrorism: Naming Contemporary Violence (2009), where she suggests that contemporary instances of violence, particularly those directly linked to human lives and bodies, can be better explained within the context of horror rather than terror. According to Cavarero, terror "acts immediately on the body, making it tremble and compelling it to take flight", where terrorised bodies seek to escape from fear $(2009$, p. 5). In contrast, Cavarero intimates that horror stops the body, and denotes "a state of paralysis [...] where the movement of flight seems to be excluded" $(2009$, p. 7). Although there is something of the fearsome in horror, she further argues, "horror has to do with repugnance" (2009, p. 7). To invoke horror is to be in the presence of something unbearable to look at: something that "aims to destroy the uniquenesss of the body [and] its constitutive vulnerability" to provoke repugnance or disgust (Cavarero, 2009, p. 8). Furthermore, Cavarero notes:

Horror has to do precisely with the killing of uniqueness, in other words; it consists of an attack on the ontological material that [transforms] unique beings 
into a mass of superfluous beings whose 'murder is as impersonal as the squashing of a gnat', [that] takes away from their own death. (2009, p. 43)

It is important to note that the aim of horror in photography is not to elicit empathy but precisely the opposite, to immobilise, and, as Cavarero suggests, to stop people in their tracks and impose sovereignty. Both Kristeva's concept of abjection and Cavarero's theorisation of horror provide similar insight to the nature of horror in photography. However, Kristeva's concept of abjection also implies that attraction or fascination is as much a part of disgust as the compulsion to turn away from the horror depicted (Debrix and Barder, 2011). For example, the photograph Purported guerrilla killed in Urabá, Antioquia (figure 6) is not an image that in the context of its original dissemination fails to elicit empathy, but rather one that is intended to engender apathy. This image was originally a trophy photograph of the Colombian army intended to represent military success against the guerrillas, and not the depiction of state violence subsequently evidenced. Although the knowledge of the actual circumstances of the death portrayed in this photograph may engender empathy, the aesthetics of the image does not. The prolific use of images of dead guerrillas by the Colombian government and an ideologically aligned media manifest a desire to capture, elicit and order a preferred reading of the violence of the conflict. In Formations of Violence: The Narrative of the Body and Political Terror in Northern Ireland (1991), Allen Feldman argues, "political violence is a genre of 'emplotted' action [where] narrativity and emplotment [are] the organisation of events into a configurational system, a mode of historical explanation, and a normative intervention". And Feldman adds, "The event is not what happens. The event is that which can be narrated" (p. 14, emphasis in the original). The killing of innocent people to be paraded as examples of the Colombian army's effectivess in countering the guerillas, and the subsequent photographs of these 'kills' is demonstrative of Feldman's assertion that "narratives are enacted as well as written" (1991, p. 14). Furthermore, public images of massacres, assassinations, the disappeared, and other forms of extreme violence cause a rupture of meaning and order. In the case of Colombia, this constant exposure has resulted in a society largely traumatised by the horrors of war, and numbed and stifled by a decades-long legacy of violence (Yepes, 2016). In these cases, viewers often fail to engage with the implications of the images, 
and consequently become desensitised to such violent imagery of conflict. The extent to which photography can represent conflict, and either succeed or fail at eliciting an empathic affect is a crucial consideration in the photographic representation of extreme violence. As Susan Sontag (1977) argues, a conflict with seemingly no end simply has people become less responsive to the horror. In Sontag's words:

To suffer is one thing; another thing is living with the photographed images of suffering, which does not necessarily strengthen conscience and the ability to be compassionate. It can also corrupt them. Once one has seen such images, one has started down the road of seeing more - and more. Images transfix. Images anesthetize. (p. 20)

Sontag is primarily discussing the photograph as typically seen in conflict reportage, in which, she argues, typical representations of violence and violent histories do not sustain compassion, for "compassion is an unstable emotion. It needs to be translated into action, or it withers" (2003, p. 79). Sontag's idea can be illustrated by considering another media depiction of the Colombian conflict, namely, a journalist's photograph of one of the many individuals killed during the course of the conflict, in which a young girl is seen as she walks past the dead body (figure 7).

Content is removed due to copyright restrictions

Figure 7. Ferry, S. (Photographer). A young girl passes the body of a man assassinated in Cucuta. (2011). [Photograph] Retrieved from: https://time.com/3782831/ 
This photograph of a young girl not looking at the horror before her can be read as representative of the prevalent oblivion in Colombian society discussed in Chapter 1. This state of being forgotten is particularly problematic within the Colombian conflict, which has mostly taken place in rural zones, and it can be argued that such images have contributed towards apathy of the conflict in urban areas. The images of the dead, irrespective of whether they are soldiers, guerrillas, or peasants are seen as depictions of the other, and bear no relation to the everyday lives of those in urban zones. Therefore, not only does the constant exposure to violent imagery engender apathy, but also, if the images represent people and places detached from the lived experience of the viewer this also diminishes the affective power of the images. Unlike Kristeva (1982), Sontag does not necessarily suggest that graphic depictions of violence erode all emotional impact, but that the quality of such impact changes. Sontag argues that a familiarity with the tropes of suffering in photographs diminish their "quality of feeling, including moral outrage" (1977, p. 19). Indeed, she argues, "the photographer is always trying to colonise new experiences, or find ways to look at familiar subjects - to fight against boredom. For boredom is the reverse side of fascination: both depend on being outside rather that inside a situation, and one leads to the other" (p. 42). The former is a sentiment shared by Griselda Pollock (2012), who posits that the full horror of photographic depictions of appalling suffering and death is "pacified by the pathos of well-known tropes of war", that symptomise the displacement of atrocity (p. 71). Therefore, it becomes necessary to counter depictions of extreme violence with the production of aesthetic works that seek to promote engagement and an affective response. While the unmediated experience of horror and violence tends to be immobilising, the representation of violent histories does not have to be. The intimation of violence in art allows the viewer to experience the horror obliquely, in terms of reflective distance, and potentially elicit an empathic affect that may have direct bearing on the viewer's lived experience. As Jill Bennet (2005) argues, what matters is not what art represents, but what art does, namely, to generate socially affective responses with crucial cultural, political and aesthetic implications. Herein lies the role for alternative methods of the representation of political violence. 
Therefore, it is important to derive an elicitation of affect that is not solely a function of indexicality, such as in most conflict photojournalism, but also of how the topic is approached given that violent imagery over time neither succeeds to elicit reflection, nor empathy. Therefore, a key aspect of constructing empathic photographs is not only the capacity to function as a historical document but also the construction of alternative ways of mnemonic representation at the service of affect. This critical construction allows a more empathic reading so that viewers may engage with both the trauma, and the implications of it. The mnemonic qualities of photography can contribute much to the task of memorialising traumatic history in its capability to represent what 'has been'. As discussed in Chapter 1, the photograph is invested with both an indexical quality and an interpretive and expressive capacity whose status as 'truth' is less disputed than other artistic media. Although photographic affect is distinct from empathic affect, the two are not mutually exclusive. The art photograph can both function as a historical document providing testimony to actual lived experience, and elicit empathic affect through well considered constructions of interpretive and symbolic elements, whereby its overall affective nature is a function of both mnemonic representation and the subjective choices made in its production. The alternative representational methods employed by the photographers discussed below stand out in their opposition to the mainstream media's dominant approach to generate socially affective responses.

\subsection{Erika Diettes and the Memorialisation of Grief}

Erika Diettes (b. Colombia, 1978) is a visual artist from Bogotá known for her experimentation with photographic techniques and materials to explore memory, pain, and absence in response to violent deaths. Her work questions how particular memory making processes and grieving experiences arise in the context of having lost a loved one to violence. Particularly, her work investigates how the victims of violence are remembered, and by what objects they are remembered. Since her first work, Silencios (Silences, 2005), a series of portraits, still-lifes, and testimonies of survivors of the Holocaust who relocated to Colombia after the war, Diettes's process has included in-depth conversations with the survivors to understand 
people's response to bearing witness to indescribable horror. Her work, though printed on alternative materials, still adheres to notions of photographic realism. This is the idea that photographs would excel in their representation of the real by virtue of being photographs, that is, by virtue of their mechanical origins, and their indexical relationship with the subject regardless of what they look like. According to Andre Bazin "no matter how fuzzy, distorted, or discoloured, no matter how lacking in documentary value the [photographic] image may be, it shares, by virtue of the very process of its becoming, the being of the model of which it is the reproduction; it is the model" (Bazin, 1967/2005, p. 14). As mentioned previously, while this notion of photographic indexicality is a key aspect of photographic affect, the photograph is however also imbued with signs that contribute to the affective nature of the image. This physical connection between the signifier, the photograph, and the object it represents is enhanced by photographic indexicality, as argued in Chapter 1 in reference to Peircean semiotics. The sign, as defined by Peirce, is anything, which is determined by something else, called its Object. This determines an effect upon a person, where effect is called its Interpretant. This understanding of the sign/object relation is thought of as the translation or development of the original sign. The idea is that the Interpretant provides a translation of the sign, allowing a more complex understanding of the sign's object (Peirce, 1965). The signs embedded in Diettes's work relate to specific cultural and social memory Interpretants of the object. These signs function as a crucial element of eliciting an empathic affect.

Diettes's first series on aspects of the Colombian conflict, Río Abajo (Drifting Away, 2008), is focused on forced displacement. This is a strategy aimed at clearing territories, thus allowing illegal armed groups to increase their areas of control and develop illegal activities. Forced displacement covers nearly every region of the country and disproportionably affects the most vulnerable parts of the population (Ibáñez and Vélez, 2003). Strategies adopted by illegal armed groups to force civilians to flee include death threats, massacres, forced recruitment, and selected murders. Forced displacement is discussed in further detail in Chapter 3. Diettes's Río Abajo is a series of digital photographs of clothing that belonged to the 
murdered and disappeared photographed in water, as the bodies were thrown into the river. The clothes, however, are photographed floating in clear and clean water, not the muddy water of a river, as if they are ready to be worn by those who never returned home (figure 8 ).

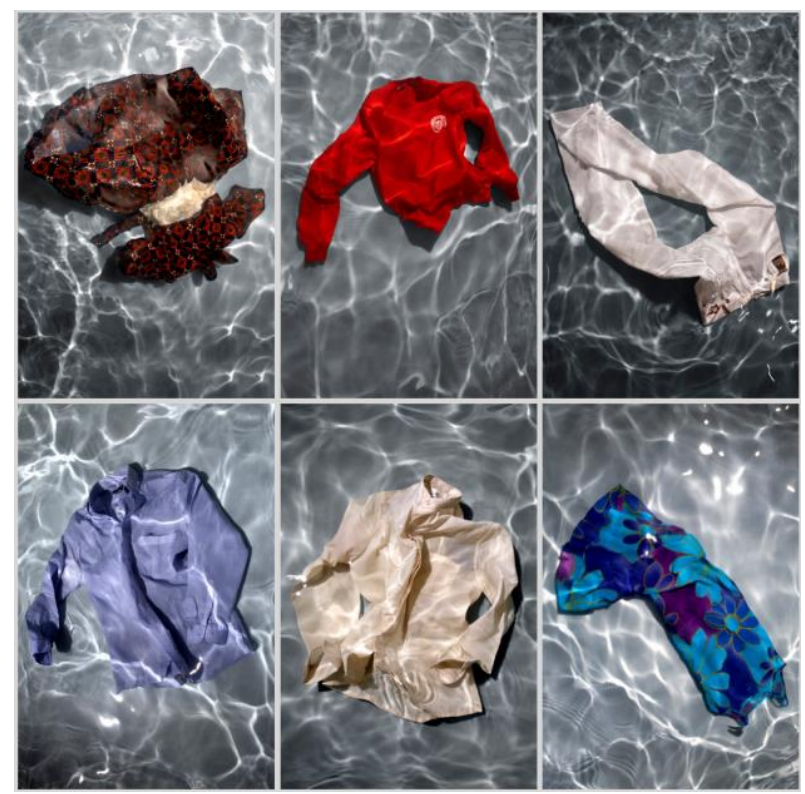

Figure 8. Diettes, E. (Photographer) Rio Abajo. (2008). [Photograph] Courtesy of the artist

In the case of forced disappearances these clothes are kept in the hope that those they await may wear them again (Diéguez, n.d.). Memory and grieving compose Rio Abajo through the absent body, "for those who live with the sorrow of not being able to mourn properly, the personal items of their loved ones attain the value of a holy relic: they are venerated, they stand in the place of the missing" as metonymic remains (Diéguez, n.d., p. 6). The rivers of Colombia have been described as the world's largest graveyard given how well they are known as a dumping ground for those murdered by armed groups; within the context of the Colombian conflict, they have come to signify death. The clothes held with reverence by the families of the disappeared, photographed in water, represent not only the tragic circumstances of the disappearance but also an existential theme of hope and despair. This work may lead the viewer to question how it is possible to endure such trauma, which is a recurrent theme in Diette's creative_production. Given the known aspects of the 
atrocities being mourned, asking oneself what it must be like to live with such grief contributes to the work's mediation of loss.

Diettes's following work, A Punta de Sangre (All Blood and Guts, 2009), also speaks to the issue of the forced disappearance of victims of the armed conflict into rivers. This work is a triptych with equal sized $2.00 \mathrm{~m} \times 1.00 \mathrm{~m}$ digital prints comprising an image of a woman conveying grief over the disappearance of a loved one, another image of an expressionless vulture with blood on its beak, both looking at the image of clear water in the middle with different intent (figure 9).

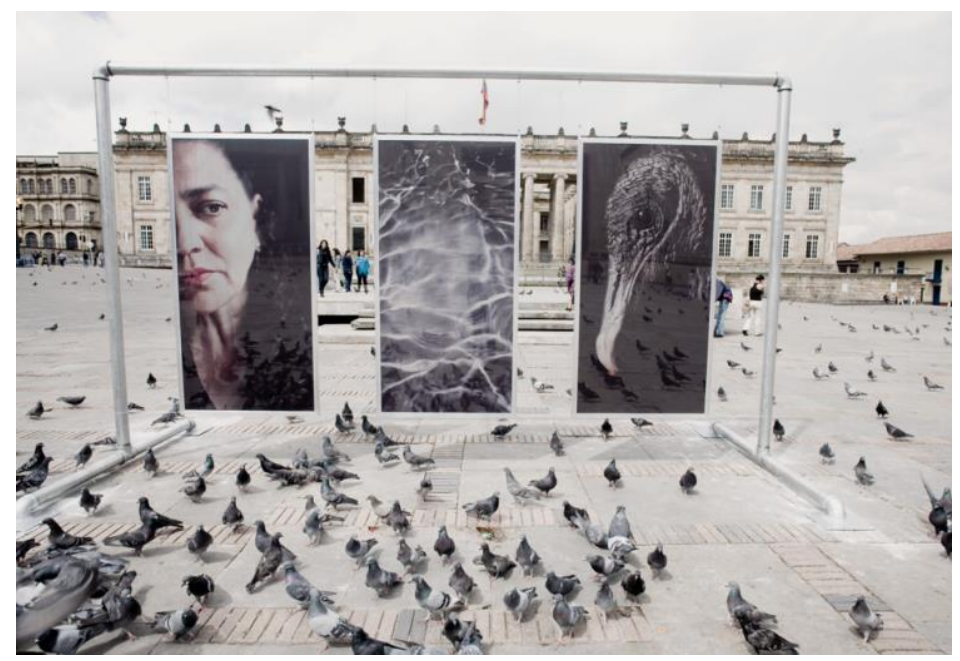

Figure 9. Diettes, E. (Photographer) A Punta de Sangre. (2008). [Photograph] Courtesy of the artist

The vulture becomes an unfortunate ally in alerting people about the presence of a body in the riverbanks where corpses usually float. As Diettes notes:

In various parts of Colombia, forcibly disappeared persons end up in rivers, which are symbols of life and of the wealth of our nation. From time to time the corpses float to the riverbanks and people gather because of the hassle the vultures cause - they become allies when it comes to alerting others of the presence of a body, unfortunately dead. (Diettes, n.d.)

As with Rio Abajo, this work also utilises the culturally specific sign of the river. Given that vultures typically arrive after death has taken place or is imminent, this large bird of prey, like the river, is also a signifier of death. In the Scriptural proverb Luke 17:37, "Where the corpse is, vultures will gather", in reference to the Parousia, the second coming of Christ, this proverb can be understood to mean that the where 
and the when of the Parousia will be known after it occurs, not before, as it is only after a body is dead that one sees the gathering vultures (Topal, 2003). This is not the only biblical allusion that can be read in A Punta de Sangre. In Latin America the religious experience is often characterised by a strong devotion to the Virgin Mary. One of the preeminent representations of the mother of Christ in Catholicism is that of the grieving mother, such as in the painting Pietà (1876) by the French painter William Adolphe Bouguereau (b. Paris, 1825). A pietà (Italian for piety) is a subject in Christian art depicting the Virgin Mary embracing the dead body of Jesus (figure 10).

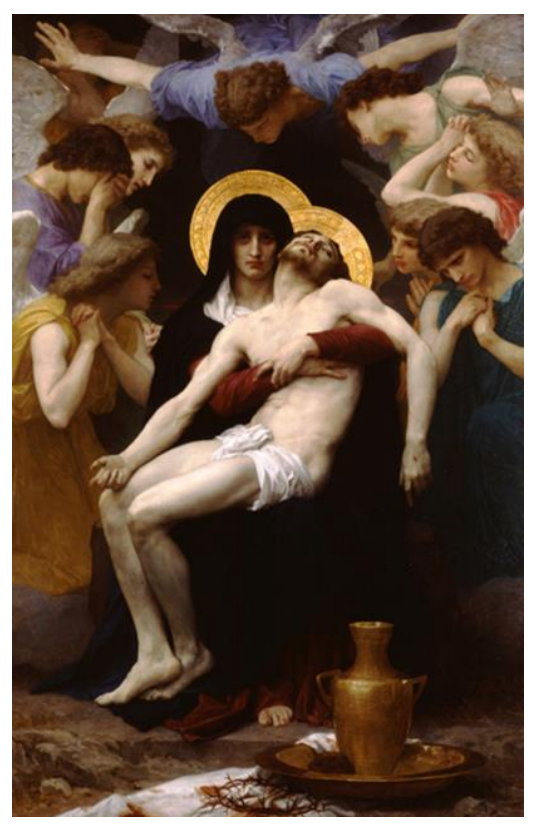

Figure 10. Bouguereau, W.A. (Painter). Pietà. (1876). [Painting] Retrieved from: https://commons.wikimedia.org/wiki/File:William-Adolphe_Bouguereau_(18251905)_-_Pieta_(1876).jpg (Public domain)

Like the representation of the Virgin Mary in Bouguereau's Pietà, the woman's expression in A Punta de Sangre is not one of acceptance, but sorrow and incomprehension as to why a loved one has been torn away from her. Diettes only describes the woman as having lost a loved one, however, given the potential allusion to the grieving Virgin Mary, it can be read to depict one of the most intensely personal, devastating and incomprehensible events: a mother's loss of a child. Also of significance is the place this work was exhibited. This triptych was 
exhibited in the centre of Plaza de Bolívar in Bogotá, the main square in the capitol city surrounded by the Palacio de Justicia de Colombia (The Palace of Justice of Colombia), the seat of the judiciary; The Capitolio Nacional (The National Capitol), home to both houses of Congress; and La Catedral Nacional (The National Cathedral). These landmarks symbolise the power of the nation, and the strategic location of A Punta de Sangre alludes to a relationship between nation building and bloodshed in Colombia. Colombian art historian Christian Padilla, in his analysis of A Punta de Sangre, argues that the indifference of many Colombians engendered by what he describes as the traditional pseudo-journalistic approaches to the conflict give reason for Diettes to make these real situations evident, for "Colombia has been built itself by the force of their people's bloodshed, and denying the facts has been our defence mechanism to survive. For convenience we are gullible whenever we want to voluntarily believe or ignore our history" (Padilla, 2007, para. 3). Although, Padilla's analysis can be read as a generalisation of viewer indifference as it imagines an audience devoid of agency, or differential readings, which seemingly necessitate artistic intervention, it does underscore the significance of public exposure to unheard, forgotten or silenced histories through non-mediatic actors. Therefore it is an extremely apt location to obligate a large number of viewers to see a depiction of Colombia's violent history in the place where the trajectory of the nation has been determined as it involves a specific subjective involvement in space and place. The landscape can be conceptualised as place where "several simultaneous modes of action, information, remembrance, and alteration" moderate each other (Gibson, 2010, p. 26). The viewer is necessarily involved in the space, moving "back and forth instantaneously connecting the past with the present, connecting received momentum with whatever is immanent so that one can perceive historical continuities operating in concert with chance and change (Gibson, 2010, p. 32). And it may not go unnoticed that the same institutions that drove much of the bloodshed now allow previously suppressed and omitted truths and narratives to be publicly expressed.

The next project of Diettes's, Sudarios (Shrouds, 2011), is underpinned by the two previous works, Río Abajo and A Punta de Sangre. Many subjects in the 
new exhibition were women she had met during the production of Río Abajo with whom she made a connection (Miller, 2016). Also Sudarios continues the practice established in A Punta de Sangre of photographing subjects as they recount their stories. This work is composed of twenty portraits, together with testimonies, of women who have been victims of the Colombian armed conflict in Antioquia. These women were photographed as they remembered and narrated how their loved ones were tortured, murdered, and mutilated as they were forced to watch. Contemporary art historian and curator Ileana Diéguez, in Cuerpos sin duelo: Iconografías y teatralidades del dolor (2016), describes how the images and testimonies of these women speak of "the enormous horror and extreme degradation at which we have arrived in these times, where killing someone is not enough, but the body and the sight must be punished, and the memory of the other must be made insufferable" (p.13). The women were photographed during interviews held in sessions with a grief therapist that focused on the experience they had when their loved one was murdered. As they reached a moment of deep pain through their account, the photograph was taken. These sessions took two to three hours per person, because Diettes "wanted to capture that exact instant when they are remembering the moment when their life was torn apart" (cited in Miller, 2016, p. 2). In further discussing the therapy process, Diettes describes how "they remembered not only the tragic event, but also their loved ones. It's this particular moment that's a conjunction of love, pain, unbearable horror and memory. It's all these stages that are being portrayed here" (cited in Miller, 2016, p. 2). The subsequent photographs from these sessions were printed on lengths of translucent silk over two metres long about the length of a shroud, which can be seen from both sides (figure 11). 


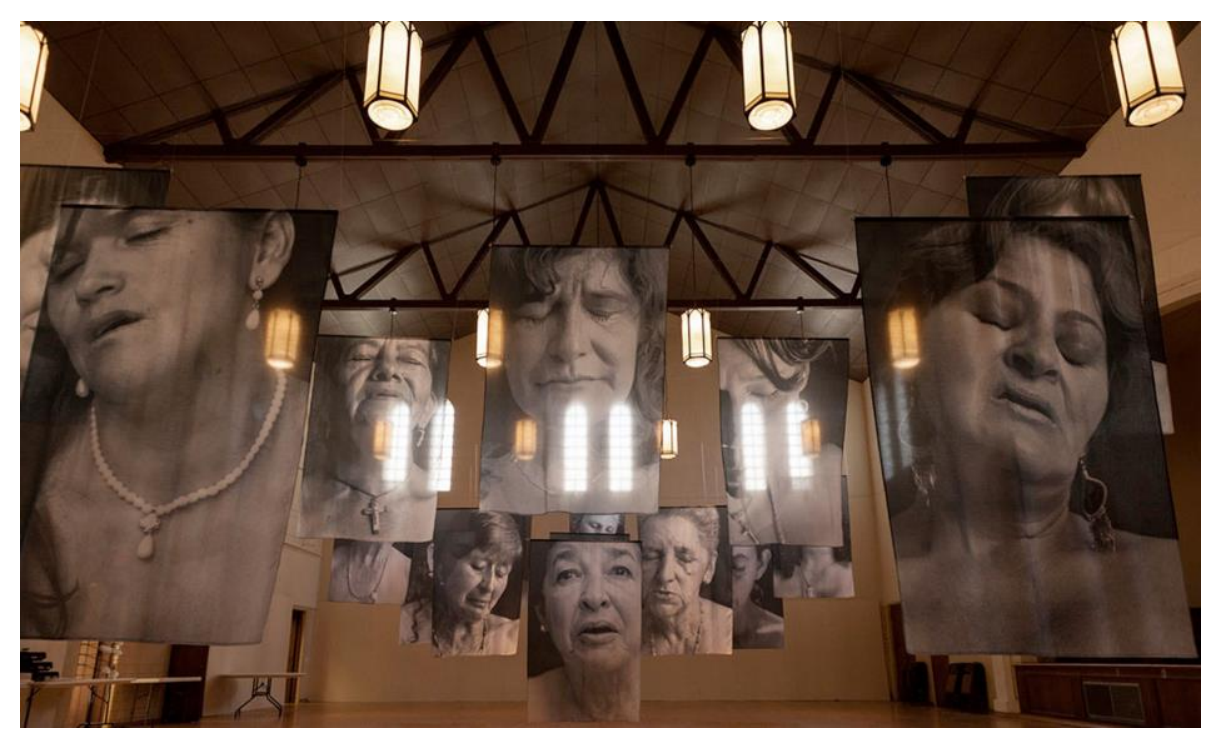

Figure 11. Diettes, E. (Photographer) Sudarios. (2011). [Photograph] Courtesy of the artist

A shroud is a piece of cloth which is wrapped around the body of the deceased, but as Diéguez notes, "it is also the fabric which becomes contaminated once it is in contact with the face and is subject to a phantasmagoric impregnation by the decaying body, a trace which results from a kind of photographic process" (n.d., p. 9). Beyond the religious allusion of the shroud, these works too can be read to allude to the iconography of the pietà. This a reading reinforced by the significance of the exhibition's location. Sudarios was exhibited in churches in Colombia, initially the Iglesia Museo Santa Clara (Santa Clara Church Museum; a deconsecrated church) in Bogotá, and the Capilla de Jesús Resucitado (Chapel of Jesus Resurrected) in Barichara, as well as being exhibited internationally in several churches. Similar to A Punta de Sangre, the exhibited location of this series is integral to how it is received by the viewer. Diettes describes why these images are exhibited in churches, in that such sacred places are "conducive to contemplation, where the architecture and the meaning of these environments guide the observer to consider the shrouds not in a passive manner, but to amalgamate with them from their own beliefs and their own humanity understood as empathy and not pity" (Head On, 2014).

Of the twenty images exhibited, all taken at a moment to immortalise the instant they experience and convey deep pain, all but one of the women has their 
eyes closed, as if "each closed pair of eyes, draws a veil across these gruesome chronicles of depravity, degradation and death to focus instead on the inward grief of the living" (Foster, 2013). As for the one woman whose eyes are open, Diettes says:

What really surprised me was that it was like she didn't need to remember. This woman was present in the horror the whole time. For me, she's the anchor of the whole exhibit. You see the violence. We can't understand, and we really don't want to understand. The only question you can ask is how they can rebuild from that. How do you go on? (Cited in Miller, 2016, p. 2)

In an article written for the 2014 Sydney Head On Photography Festival, which featured Sudarios, Diettes recounts several horrific testimonies she had been exposed to, "one of these ladies, while pregnant, was forced to watch the assassination of her father. This left her engulfed in the inevitable tragedy: her son's life would be forever tarnished by the painful memory of this tragic loss" (Head On, 2014). In listening to these women's testimony about witnessing the death of their loved ones, Diettes also becomes a witness to such horror, although to a different extent. As exhibited, the twenty silks on which the women are printed are suspended from the ceiling, spread out, free to sway, exposed to contact, either voluntary and involuntary, giving a tactile dimension to the work touching the spectator; themselves a witness to the women's embodied remembrance and pain. Ultimately forging what had been described in Chapter 1 as post-memories (Marianne Hirsch, 1992), namely, those traumatic events that live on through the generations to mark the lives of those who were not there to experience them. For instance, the woman's son, upon learning of the circumstances of his grandfather's murder, also becomes a witness to the violence, just as the viewer becomes a witness to the trauma. As Ileana Diéguez states: if these "artistic images and events do not salvage the past, do not return what is lost and barely help us to recognize what has been inevitably lost" (cited in Head On, 2014), and instead reveal an apathetic and silent viewer, then they are in some way an accomplice of the atrocities. The events themselves, such as innocent Colombians being murdered solely for some small patch of land at the behest of the rich and powerful, can only elicit empathy. However, Diettes's images through photographic authenticity, uniqueness, and a deft and intelligent use of 
iconography, magnify the affective memorialisation of these traumatic histories. These artistic images invite reflection and conversation that adds to the Colombian social memoryscape with some viewers experiencing their own post-memories of the traumatic event. The work of Diettes, alongside the work of the other Colombian photographers discussed in this chapter, is driven by a desire to break through the pervasive cultural and official oblivion that in the past had left the many alternative narratives to that of the official line, omitted, silenced or simply forgotten. Each of the artists discussed here, within their own practice use alternative approaches to the representation of the conflict, with their own appropriation and application of signs, metaphor, metonym, and iconography.

\subsection{Juan Manuel Echavarría and the Photographic Metaphor}

Juan Manuel Echavarría (b. Medellín, 1947) is a Colombian visual artist whose work recounts memory and historicity by photographs of spaces and objects that function as metaphor or metonym. Photographs of abandoned objects and rural spaces, which have often seen displacement, symbolise violence and its nameless victims. Echavarría's work often involves the incorporation of non-human elements into the discursive formations of violence and memory. Just as landscape embodies the memory of a population (as deliberated in Chapter 1), objects also become part of a sensual memory landscape where relationships with objects are relationships of affect (Raffles, 2002). These non-human elements in his work are often a metaphor or metonym for the human body, whereby "this comes to signify the omnipresence of violence exerted over individual bodies as well as on the social body" (Cabrera, 2009, p. 206). Echavarría's predilection for metaphor and metonym shapes his work, and results in a certain aestheticisation of the violence represented. This strategy is intentional, as explained by Echavarría:

There is a conscious purpose behind my aestheticising of violence. In a country like Colombia, where the media has been giving us sensationalism as a routine through photographs, journalism, television news ... we have become totally anesthetised by this sensationalism. (cited in Reid, 2000)

As mentioned in this chapter's introduction, the idea that continual exposure to explicit violent images might lead to apathy is an argument made by numerous theorists. The 
work discussed in this section, like all the work in this chapter, is both sober and provocative because of an alternative approach intended to elicit reflection and affect. Echavarría first photographic exhibition, Retratos (Portraits, 1996), comprised of silver gelatin prints of broken and mutilated mannequins found on the street damaged by use and time (figure 12).

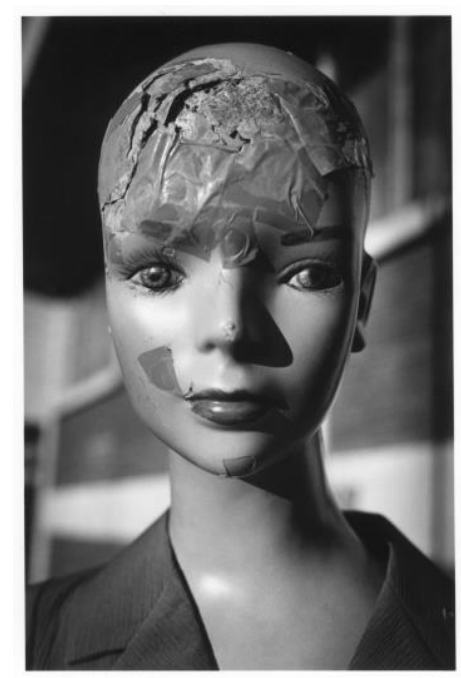

Figure 12. Echavarría, J.M. (Photographer). Retratos \#5. (1996). [Photograph] Courtesy of the artist

This early series presents Echavarría's ongoing interest in "the social decomposition embodied in the decomposition of objects" (Rubiano, 2017, p. 46). In Retratos a relationship is articulated between the decomposition of the mannequins and the indifference of the passers-by, which metaphorically represent the indifference of Colombians with respect to the armed conflict in Colombia. The key effect in Retratos is that these mannequins are permanently exposed but at the same time ignored (Rubiano, 2017). Echavarría in his own words discusses how these mannequins represent a violence that many Colombians have perhaps come to ignore during the course of a decades long conflict:

I always saw people go by and never look at those mutilated faces. And I said: "I have been one of these passers-by who have never wanted to look at the violence in my country." After doing that series I understood that from now on I was going to investigate through photography, through video, the violence of my country. (Pacifista, 2015) 
The black and white photographs in the Retratos series have an ethnographic aesthetic devoid of obvious manipulation that produce "metaphors within the linguistic and cultural conventions embedded in Colombian culture where the notion of circular, omnipresent violence persists" (Cabrera, 2009, p. 206). The result is reminiscent of surrealism, where a juxtaposition of unconnected objects creates a disturbing effect on the viewer. Echavarría's use of metaphor is a distinctly different affective approach in comparison to the embedded symbolism in Diettes's work. It is important to note how metaphor functions differently from signs. Whereby signs depict a real object with culturally defined meanings and associations, metaphors bridge a gap in language and give expression to something that defies comprehension. As truly horrific events cannot be easily expressed because a referent does not necessarily exist in normal society, therefore the metaphor establishes a gap in expression between the unfathomable and the normal. In his discussion on metaphor, Karsten Harries (1978) suggests that, "metaphors speak of what remains absent. All metaphor that is more than an abbreviation for more proper speech gestures towards what transcends language. Thus metaphor implies lack" (p. 84). The lack that the metaphor points to is that of an inability of language to provide a full expression to articulate something that defies comprehension, like traumatic events. The metaphor consists of the tenor, the referenced thing, and the vehicle, the image that refers to the tenor. It should be noted that metonymy shares the same two constituents, however, metaphor is based upon substitution and similarity, and metonym upon predication, contexture and contiguity (Jakobsen, 2003). Ines Mzali, in her discussion of metonymy, suggests that "representations of war and the materiality of war itself do not stand for one another; rather, they coexist in discrepant yet linked realms, [...] which illustrates the principle of contiguity in metonymy" (Mzali, 2010, p. 86). This is to suggest that photographic representations of conflict can be read through displacement as associated with metonymy and not just substitution as in metaphor. This idea follows an argument that "many metaphors are based on, or derive from metonymies" as opposed to the idea that there is no connection between the two (Kövecses, 2013, p. 75). Therefore, the works considered here could be argued to function through operations of metaphor, metonym, or correlation metaphors (metaphors that emerge from and are dependent on metonymy). However, unlike culturally encoded 
imagery, the relatively abstract nature of Echavarría's metaphors does not function independent of the didactic, which is necessary to provide the topic of the metaphor. Furthermore, Retratos is not to be seen as historically specific, but a commentary on the overall violence of the conflict, a violence that includes the displaced, the disappeared, the mutilated and the massacred. This is an incomprehensible level of violence that has plagued Colombia for many decades. To represent this violence literally, that is, in actual images of lifeless and mutilated bodies would perhaps initially elicit some shock and disgust, however, this shock value has limits over time, and can eventually lead to general apathy. Echavarría's use of metaphor enables a reflective distance not present in the traditional journalistic approaches of the Colombian media, whose traditional images of the conflict provide little room for either reflection or empathy.

In Echavarría's next exhibition, Corte de Florero (Flower Vase Cut, 1997), there is a specific relation to the 1948-1958 civil war known as "La violencia". In this series, the artist "humanized flowers by photographing them like botanical specimens, replacing the stems, leaves, flowers, and berries with what look like human bones" to represent the bodily repertoires of killing and mutilation during this period (Taussig, 2003, p. 98) (figure 13).

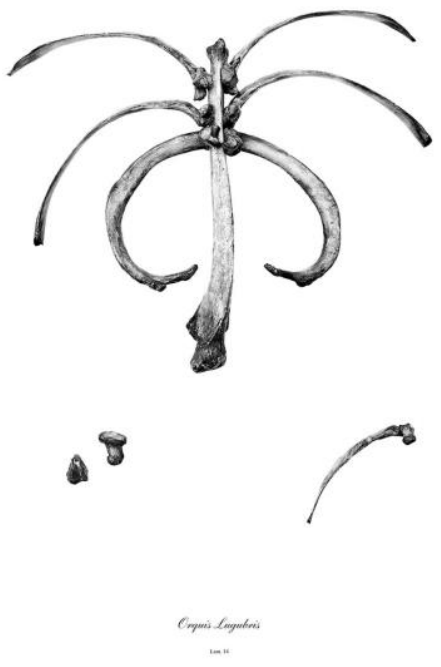

Figure 13. Echavarría, J.M. (Photographer) Corte de Florero. (1997). [Photograph] Courtesy of the artist 
The title of the exhibition refers to the name of one of the mutilations practiced during La violencia. In an interview, Echavarría talks about his aesthetic and representational approach to this specific act of violence:

Throughout the '50s there was this violent language of cuts [...]. One is called the Colombian Necktie [...]. A hole was made in the throat of the victim and the tongue pulled out through the hole. They perform this ritual on the corpse. In the Flower Vase Cut, the head is removed and the legs and arms are cut and the dismembered body parts are put inside the torso as if it were a flower vase. My purpose was to create something so beautiful that people would be attracted to it. The spectator would come near it, look at it, and then when he or she realizes that it is not a flower, as it seemed, but actually a flower made of human bones something must click in the head, or in the heart. (cited in Reid, 2000)

In Corte de Florero, Echavarría continues with making a record on the decomposition of objects, but with what appear to be human bones of decomposed bodies which metonymically stand in for a different form of violence; post-mortem mutilation. Additionally, Echavarría makes a connection to the importance of flowers in Colombian colonial history and the present day, where Colombia is the world's second largest exporter of flowers after the Netherlands. Colombia's geographical situation makes it very rich in flowers and biodiversity, "and at the end of the 18th century Spain sent a commission to study the flowers of Colombia. [...] That botanical expedition ushered in the independence of Colombia. It was a moment of reflection, and I wanted to make that connection with the botanical expedition [...]" (cited in Reid, 2000). This connection that Echavarría makes to the botanical expedition suggests that contemporary violence in Colombia can be traced back to Colombia's colonial past. Although, there is some continuity between the two periods, conflation between the two periods can be viewed as problematic. Marta Cabrera notes that without "historical detail and specificity, violence seems [to be] linear, and inescapable" in Echavarría's Corte de Florero (personal communication, November 18, 2020).

His next series El Testigo (The Witness, 1997) is in response to a more contemporary event, the Mapiripán massacre that occurred earlier that year. This massacre in a coca-growing village in southeastern Colombia was committed by paramilitaries known as the AUC (Autodefensas Unidas de Colombia or United SelfDefences of Colombia). During the massacre, the paramilitary killed at least twenty people. Witnesses testified that the AUC branded some villagers as leftist guerrilla 
collaborators and then proceeded to torture, kill, and dismember them. The case became especially infamous after it was reported that the Colombian army not only delayed assistance but had also provided munitions and communications to the paramilitary. $E l$ Testigo, not unlike Retratos, comprises non-human elements to stand in for human beings. In this case a number of black and white photographs of farm animals. In one of these photographs a skeletal horse looks directly at the viewer from a desolate landscape (figure 14).

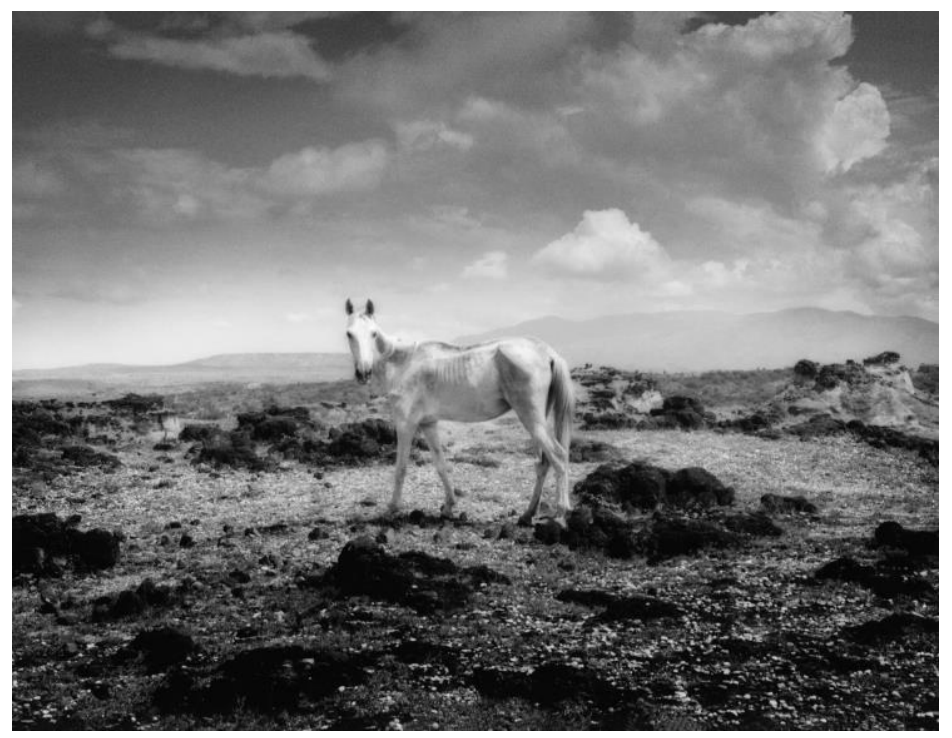

Figure 14. Echavarría, J.M. (Photographer) El Testigo. (1997). [Photograph] Courtesy of the artist

This series, like Retratos, symbolises the omnipresence of death and violence, this time as metonym. "In order to kill one must reduce the other to an animal", Echavarría explains. "Sometimes the victims of Colombian massacres, such as Mapiripán, have been taken by their aggressors to the public slaughter house" (cited in Herzog, 2004, p. 197). Echavarría's metonymical construction of violence in The Witness as a massacre is quite significant as it points to the importance and consciousness of this occurrence in narratives of violence since the time of La violencia (Cabrera, 2009).

In a later series titled Requiem $N N$ (2006-2014), Echavarría photographed a mausoleum in the town of Puerto Berrio over several years, where within its tombs "lies a corpse or part of a corpse that the people ... rescued from the Magdalena River. Most are victims of massacres from the drug war, many mutilated, ... discarded for 
convenience, for anonymity, to feed the vultures" (Echavarría, 2007, p. 297). These corpses are referred to as NNs (Ningún Nombre or 'No Name' in English). Their identities have been lost by the practice of throwing their corpses in rivers in an attempt to disappear them. The bodies would be pulled out of the river, buried within the mausoleum, and locals would often name the $\mathrm{NN}$ giving them an identity. Echavarría suggests that:

Collectively and perhaps unconsciously, the people of Puerto Berrio are saying: we won't let the violence erase you, we snatch you away from those who want you to disappear, we take care of you, we baptized you in death, you become part of us. The pact with the dead resists the violence and reconstructs the social fabric. I have made many journeys to document the changing tombs. Among the death and destruction of more than 50 years of violence in Colombia, the NN tombs of Puerto Berrio are a unique gesture of humanity. (2010, paragraph 4)

In this town, as in many other towns along Colombian rivers, fatal victims of the conflict frequently wash ashore. Though no one seems to know exactly where these corpses come from, anyone who encounters them undoubtedly understands their presence as "one of the many visible sides of the violent reality" of the Colombian conflict (Acosta López, 2014, p. 82). Of the more than eighty thousand forcibly disappeared and presumed dead from 1958 to 2017 (Colombia Reports, 2019), there is no way to know how many ended up in the rivers of Colombia.

The Requiem NN series is a departure for Echavarría with a use of colour that subscribes more to tropes of modern documentary photography, particularly the genre of aftermath photography (figure 15).
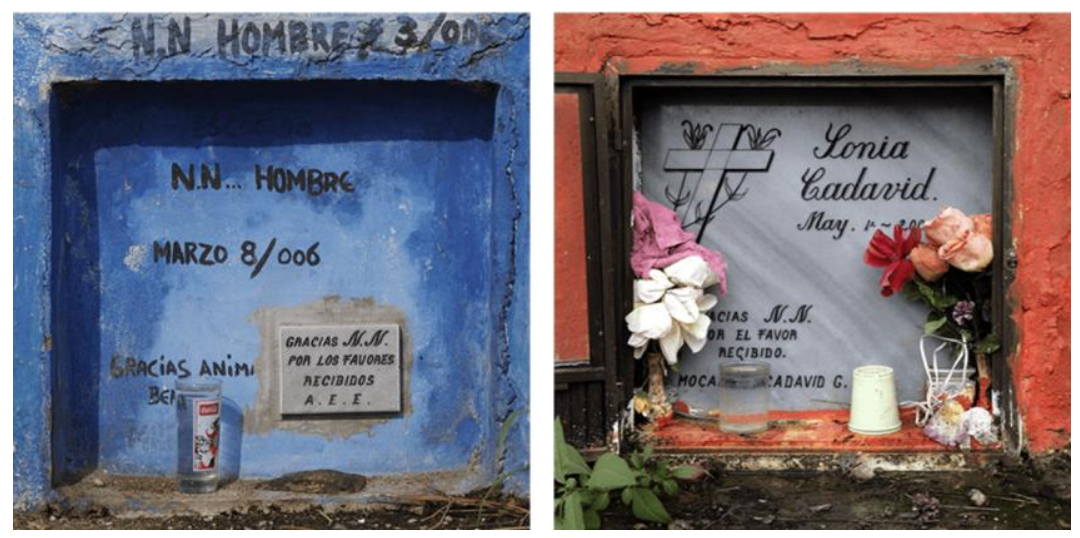

Figure 15. Echavarría, J.M. (Photographer) Requiem NN. (2006). [Photograph] Courtesy of the artist 
Again, the images seem devoid of manipulation, and elicit a strong indexical relationship with the subject. The series acts as documentation that the villagers collectively responded in this way to the aftermath of violence brought by the river. Their actions and the work of Echavarría can be seen as acts of resistance against oblivion, a state of forgetting or having forgotten, to ensure remembrance of this heinous history. As previously mentioned the mnemonic nature of photography posits a relationship between image and memory. Traditionally, the photographic image is associated with the possibility of remembrance. Therefore if "post-mortem memory is a certain kind of pledge we take when faced with the absence of someone who has passed away, image and mourning are essentially related", and the image becomes a sign of loss and absence (Acosta López, 2014, p. 84). Those bodies named, buried, and remembered by the people of Puerto Berrio not only represent a part of the violence of the conflict, but also the threshold between memory and oblivion. Those who knew them and loved them no doubt keep photographs of them when they were alive, yet the possibility of their mourning is unquestionably denied. In other words, their "absence cannot be compensated through an image because what is absent is not the dead but death itself", something that only the perpetrators can attest to (Acosta López, 2014, p. 85). Instead it is this absence of death that evokes mourning in the present as it keeps the promise to mourn those lost. The temporality of Echavarría's photographs both interrupt and record the passing of time, and allow the images of the NN graves in Puerto Berrío to elicit sorrow in the viewer. This absence, the indescribable torment of families never having resolution, the atrocities, and the fact that finding bodies is almost a daily occurrence are representative of the conflict, has these works echo unspeakable realities. In his work, Echavarría uses visual language to elicit an affective response to foster postmemory of traumatic histories often through the use of metaphor and metonym. The reflective aspects of his work enable the viewer to intuit and feel tragedy, in a way that a photograph of a corpse in a river cannot. His latter use of documentary photography as art is not unprecedented in Colombia, particularly with the sometimes shift from photojournalist to social documentary photographer. 


\subsection{Jesús Abad Colorado's Exposure of an Invisible War}

Jesús Abad Colorado (b. Medellín, 1967) is a Colombian photographer who has dedicated more than twenty years of his life to covering the violence of the conflict. His practice differs from those of the artists previously discussed above, and those to be discussed in subsequent chapters, in that he does not organise his work around individual artistic projects but around the events he covers as a photojournalist. His work focuses on the "tragedies of the peasants and residents of the most remote and forgotten municipalities of the country", and their testimonies (González-

Combariza, 2019). Indeed, it would be an oversight to talk about the images of the conflict in Colombia without mentioning Jesús Abad Colorado. His most recent exhibition, El Testigo in Bogotá (The Witness, 2019), is perhaps one of the most impactful exhibitions held in Colombia, best evidenced by the more than 280,000 people who attended the exhibition. El Testigo is composed of more than 550 images that cover the entirety of his photojournalist career. They were displayed in the Cloister of San Agustín, next to the Palacio de Nariño, the official residence and workplace of the President of Colombia, being perhaps "a direct message to the ruling class of this country, that Jesús regards with so many reservations" (EncisoNoguera, 2019).

His method differs from that of many Colombian photojournalists in regards to both his aesthetic, and a decidedly non-partisan approach to the conflict. In a recent interview in a Colombian magazine Pacifista, he explains the intention behind his photographs:

It is that photography - or memory or orality - have many functions. I am one of those who say that a picture is not worth a thousand words. I am one of those who say that these images need many words. It is an ethical and aesthetic exercise and a commitment to the truth. What you see there is an exercise in putting yourself at the service of a society. Journalism has to help us find that truth. Because there is no single truth, the truth is like a broken mirror. And we have to help put those fragments together. Not so that we look at ourselves under the same face. But to understand that this country is multiethnic and multicultural, and that there are many truths [...] and [that] journalists cannot be aligned to one side or another, we have to help understand all this. Not only to leave a good story, but also to leave a memory that makes us reflect. And not just to make the armed forces reflect, but also to make this ruling class reflect. Pacifista (2019) 
His images are mostly photographed in black and white, as an aesthetic choice to represent "the pain, the mourning of the mothers and what they are experiencing... putting the dead in colour, nope" (Pacifista, 2019). Many of the images function as a synecdoche, a kind of metonym where a part stands for the whole, along a chain of signification in a syntagmatic relationship. Consider the photograph of a young woman's arm (figure 16).

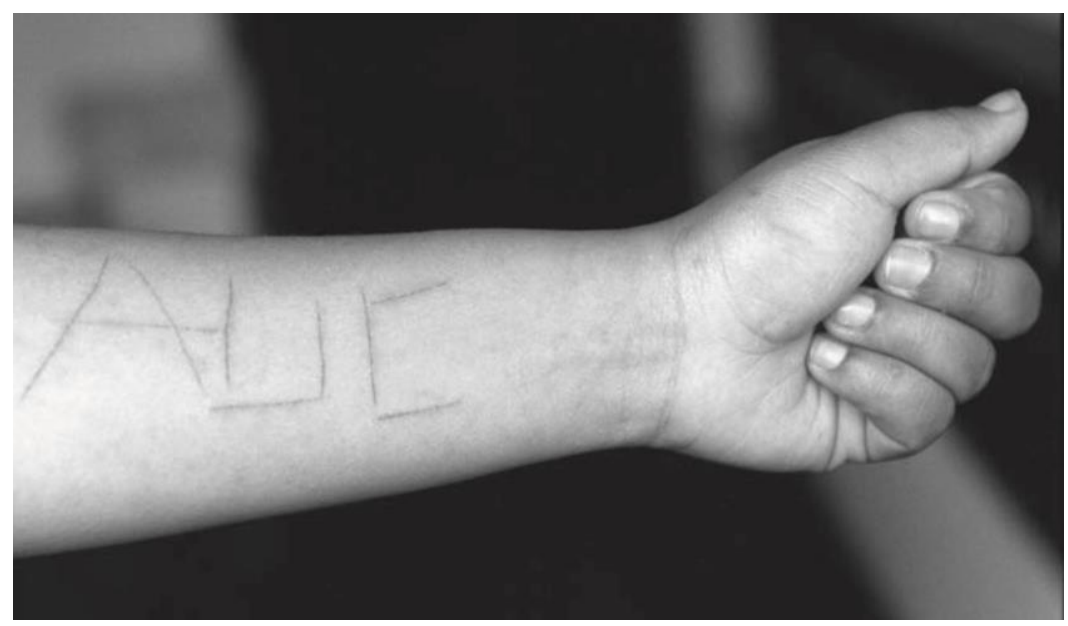

Figure 16. Colorado, J.A. (Photographer) AUC. (2002). [Photograph] (Grupo de Memoria Histórica, 2013, p. 307) C Jesús Abad Colorado

Figure 16 depicts the photograph of an 18-year-old girl that was kidnapped by paramilitaries in the North Eastern part of the city of Medellín. She was gang-raped, burned on various parts of her body with cigarettes and marked with a sharp object. The paramilitaries responsible were members of the AUC. The photograph can be seen as a metonym for the unthinkable acts the young girl endured at the hands of the AUC, the mark as an ever-present trace of the trauma, a constant trigger. Beyond her experience it can also be viewed as a sign for the extreme brutality of the paramilitaries throughout Colombia, and indeed the conflict itself. The acronym AUC, widely known in Colombia, stands in for the violence and brutality of the paramilitaries.

The next image shows the remains of a bombed out church, a result of an event known as the Bojayá massacre. In the foreground of the image can be seen the remains of the altar crucifix. The crucifix placed upon the altar is intended to serve 
as a reminder to the people in attendance of the believed nature of the Eucharist as the actual body of Christ; except, here, the body is dismembered, leaving only the head and torso (figure 17)

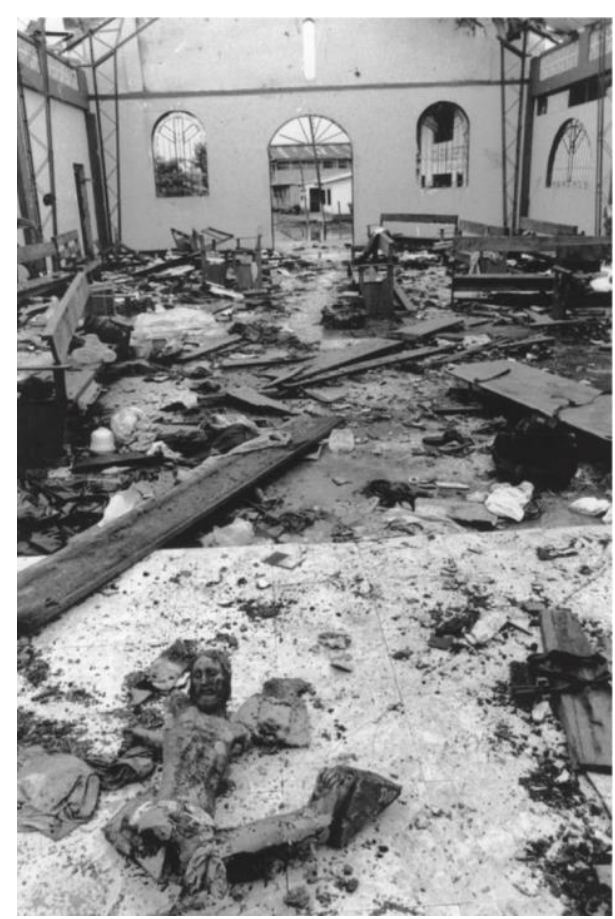

Figure 17. Colorado, J.A. (Photographer) Bellavista. (2002). [Photograph] (Grupo de Memoria Histórica, 2013, p. 88) C Jesús Abad Colorado

This mise-en-scène effectively stands in for the absolute devastation wrought upon the church inhabitants at the time of the explosion. The Bojayá massacre was part of a continuous and bloody confrontation between the FARC and the AUC that took place between April 20th and May 7th 2002 in the municipal capital of Bojayá, in a town called Bellavista. During the fighting a cylinder bomb (known in Spanish as a pipeta or cilindro bomba) was launched by the FARC with a mortar at the paramilitaries who were hiding behind the church compound where most of the town was sheltering. Of the approximately 300 inhabitants of the town who had taken refuge in the church, 79 died, including women and children. Human Rights Groups determined that the guerrilla group understood the levels of destruction and death that were derived from the use of prohibited weapons such as pipetas, "since this group had caused the death of at least 12 civilians and the wounding of 45 
others, including 10 children, as a result of the use of gas cylinder bombs similar to those used in the combat of May 2, 2002" (Bojayá: La guerra sin límites, 2010, p. 36). The tragic outcome it caused in Bojayá was not a simple mistake or a product of chance, and its devastating impact on the population could have been foreseen and avoided (p. 36). This image would require no explanation to the majority of Colombians, as one of the deadliest, and most infamous massacres in Colombia. As with the first photograph, the girl's arm, the image of the church can be read as being normative (as defined in Chapter 1). The photojournalistic approach used, and the apparent absences of image manipulation have the images function on a presumed level of objective factuality. Therefore, the photographs presented in this work provide documentation of the presence of a thing before the lens and carry strong indexical traces of it. This inherent authenticity imparts a certain photographic affect, but this alone does not explain the affective nature of these photographs. One has to consider the framing of the image, the subjective choices of the photographer. Although the work of Jesús Abad Colorado has a carefully considered aesthetic quality, his work does not convey an aestheticism devoid of content, but develops an incisive idea, of a symbolic, political, social order, embodied in an image. The distinctive elements specific to its Colombian context are also very present. Not only at the level of the contents that refer to its context, but through iconography and metonymy that speak of the unspeakable. Although these photographs are photojournalistic in nature, given that they respond to a specific event as part of a news cycle, the deliberate aesthetic approach used has parallels with more artistic endeavours. Subsequent works, after he became an independent photographer in 2001, continued an aesthetic approach as it shifted its focus to the survivors of violence, and those that have lost loved ones, and their testimony, as he says in his own words, "I'm not making breaking news, I'm telling the story of the people of my country" (Enciso-Noguera, 2019). This assertion corresponds more to notions of documentary photography, as it concentrates on an ongoing issue or story, than to breaking news, as it seeks to draw attention to issues that require some form of remedial or political action. 
One such story forms part of a series of portraits of those who had lost a loved one to extrajudicial executions by the Colombian state, known as Falsos Positivos (False Positives). The false positives scandal concerned the arbitrary execution of mostly, poor, marginalized male civilians by the military, sometimes in collaboration with paramilitary groups. Those murdered were 'falsely' presented as guerrilla fighters lawfully killed in combat to inflate operational results for benefit, such as promotion and cash bounties on guerrilla casualties (Gordon, 2017). In 2010, Jesús Abad Colorado photographed Doña Fabiola, the mother of Luis Fernando Lalinde, who was killed by the army, and now known to be one of over 3000 false positives.

On October $3^{\text {rd }}$ 1984, Luis Fernando Lalinde was detained and tortured in front of the village school in the presence of children. Members of the National Army later executed him in the village of Ventanas. He was presented as a guerrilla fighter killed while attempting to escape under the alias Jacinto. Afterward, Doña Fabiola and her family began a tireless twelve-year search for Luis Fernando. In the end, they found part of his remains on the mountain where he was buried. Three decades after Luis's murder, the family was still waiting for justice, and the enforcement of a court decision that mandated reparation (Chaparro, 2015). The photograph of Doña Fabiola portrays her holding a wooden carving of a Sirirí, a small bird that pursues sparrow hawks who steal their chicks, and are sometimes able through persistence to force the sparrow hawks to return them (figure 18). 


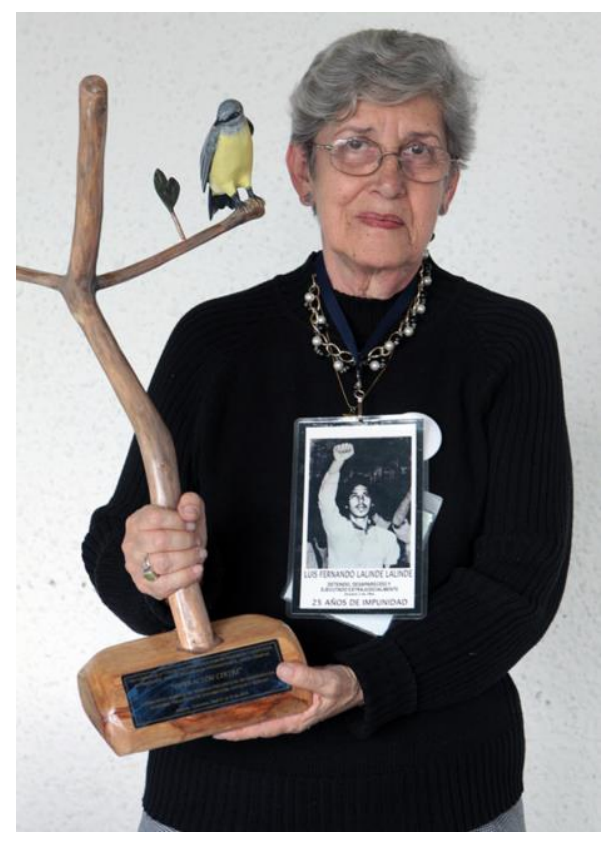

Figure 18. Colorado, J.A. (Photographer) (2010). [Photograph] Retrieved from: http://www.amphibiousaccounts.org/\#!/en/publicacion/anti-war-the-mothers--party C Jesús Abad Colorado

This bird came to symbolise both her persistent search for her son, and the name for a group of mothers whose children had been disappeared by the military she cofounded. She is also wearing a portrait of her son around her neck in the photograph. This is symbolic of the many mothers who everyday throughout the country wear portraits of missing loved ones hanging from their necks, searching busy public areas carrying their children's portraits, and distributing handwritten flyers recounting unceasing searches, while carrying an eternal pain. This is a grief that is further explored in a Chapter 3 discussion about the grievability of forced disappearances.

Although this photo is a departure aesthetically from the earlier black and white work, particularly in its use of colour, it too is reliant on notions photographic authenticity. There is no doubt that Doña Fabiola appeared before the lens, as did her son decades before. Both images present an indexical relation with their subject. The difference between the two photographs, the portrait within the portrait, one knows that Luis Fernando is dead. The portraits these women carry can often be decades old. Though they search relentlessly for many years, perhaps never accepting the idea that their child could be dead, these portraits of los desaparecidos 
(the disappeared) are typically the last photographs taken of a person who was killed many years ago, and whose remains will likely never be found. And just as with Diettes's La Punta Sangre and Echavarría's NNs, this portrait can be seen as a contemporary pietà, again with no body to be held, but with an absence of death, resolution, and mourning. Furthermore, just as the personal items photographed in Diettes's series Rio Abajo have become venerated, these portraits too are holy relics. The portrait hung from the neck functions on a metonymic level, standing in for the entirety of the disappeared, as it has become an icon, literally and figuratively, for a mother's indescribable loss. All of the photographers discussed so far mediate the lived experience of what are seen as the traditional victims and survivors of the conflict as part of their practice. This is indicative of an almost singular focus on these groups in contemporary Colombian conflict art, which does leave a gap in the representation of other actors. That is, the former combatants, although not what could be considered innocent players in the conflict, many of those who fought, did so because of extenuating circumstances that also need to be understood. This lack of representation is something that is spoken to by the work in the next section on Miguel Ángel Rojas's mediation of a soldier's trauma, and within the creative component.

\subsection{Miguel Ángel Rojas: Affective Appropriation}

During the 1990s, numerous Colombian artists began to turn their attention to the role of cocaine trafficking associated with the Colombian conflict. The effects of trafficking undertaken by both guerrilla groups and paramilitaries, exacerbated the internal armed conflict and led to an enormous loss of life, and the forced displacement of millions of farmers as the groups took control of coca plant cultivation in the 1980s. Miguel Ángel Rojas (b. Bogotá, 1946), a conceptual artist, painter, photographer and architect, in an ever changing aesthetic practice has come to "address conceptual, symbolic and political themes such as marginality, sexuality, indigenous politics, social displacement and, most recently, the unchecked violence related to drug abuse and trafficking that grips Colombia" (Project Video, 2013). At times working with people maimed by the violence that 
has plagued Colombia in recent years, Rojas's work acts as an indictment against the violence brought by international drug trafficking, with portrayals of the tragic consequences of the conflict.

This is certainly evident in his series of twelve $2.00 \mathrm{~m} \times 1.00 \mathrm{~m}$ black and white photographs titled David (2005). They portray a male nude reflected in a young and athletic body, in a pose that visually references the marble sculpture David (1501-1504) by the Italian Renaissance artist Michelangelo (figure 19).

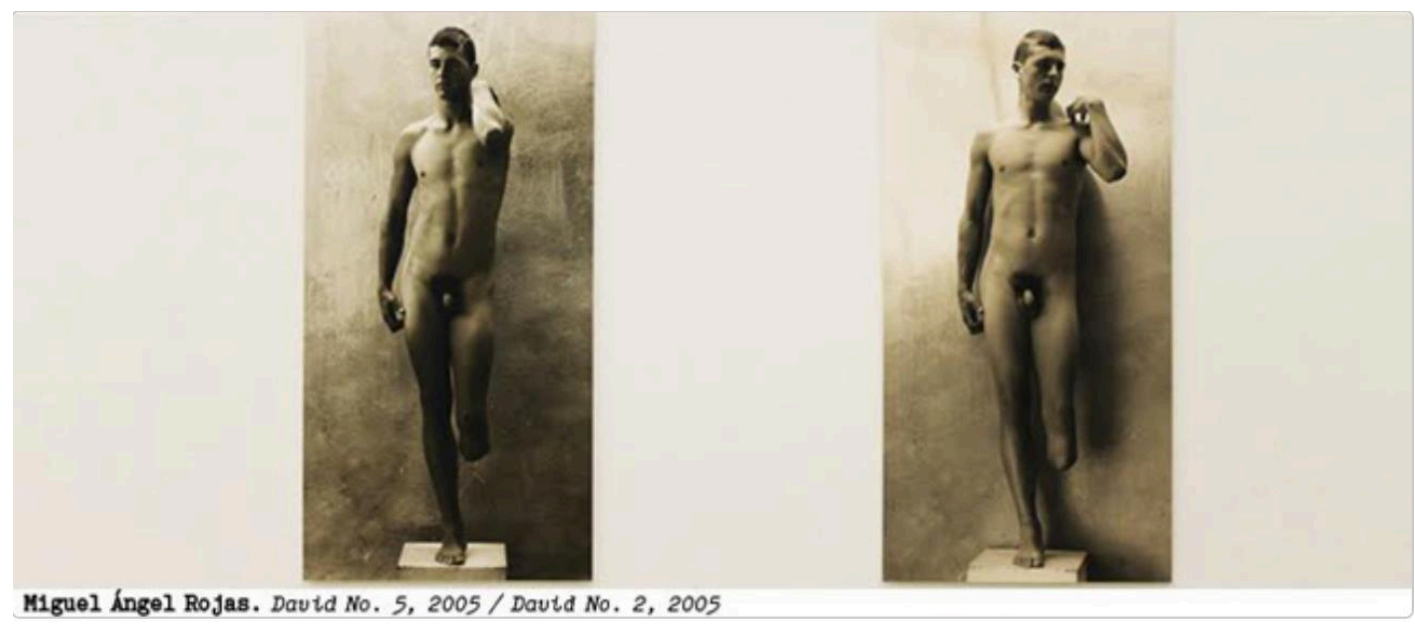

Figure 19. Rojas, M.A. (Photographer) David. (2005). [Photograph] Retrieved from: https://www.arte-online.net/Notas/La_coleccion_Daros_Latinamerica_hace_pie_en_Proa

This sculpture is considered an iconic work of the male aesthetic ideal in the history of Western art that becomes a referential index for the viewer in Rojas's David. Like the pose utilised in Michelangelo's David, Rojas's series stages a real body to achieve a posture in which it is possible to establish direct opposites between both sides of the body. The left part of David shows his limbs fully extended, exhibited, while his right side is represented with a bent arm, in action, and an incomplete limb. This fragmentation can be initially read by many as a bend in the leg at the knee, similar to a pose known as contrapposto (opposed in Italian) in which the standing human figure is composed such that the weight rests on one leg, allowing the other leg to be bent at the knee, but here it is a real absence, an amputation as a result of a landmine explosion. Like a sculpture, Rojas's David is standing on a pedestal, albeit not one immortalised in marble, but in a more contemporaneous 
medium, the photographic image. Although both works communicate aesthetic beauty, the body of Michelangelo's David represents an aesthetic ideal sculpted in cold white marble that does not correspond to that of a real body, in marked contrast to the photograph of Rojas's David which is the indexical trace of a living body impacted upon by violence. Even though the photographed soldier is missing a limb and his pose does not exactly replicate the Renaissance David, the resemblance is strong enough to encourage viewers to complete the image.

It is here that Rojas's David subverts the stylistic norms determined by art history, whereby "a male nude articulated through the contrapposto cannot be incomplete, [are] used to make sense of the image, however, [...] this conceptual and historical scaffolding [are] shaken by the David series" (Montenegro Rosero, 2018, p. 117). These initial aesthetic similarities might perhaps conceal the injury, making it invisible, and the shock recognition of the injury, the amputation, becomes doubly mobilising for the viewer. The young man, a former member of the National army, photographed naked before the camera undeniably exists or did exist. It is here that the photographed former soldier appears as both testimony and witness. Initially the image seems to represent the classic ideal of the male body, however, what first appears to be compliance to an aesthetic ideal, surprises the viewer when they realise a leg is missing. This denial of aesthetic pleasure by sudden realisation that the young man's leg has been violently severed off can be experienced as the Barthian punctum, that is, the element that pierces the viewer. While the photographic claim 'this has been' indicates a presence before the camera, the missing leg is signified through its absence. The amputated leg is an index of the violent force that severed the leg. To a Colombian viewer, it is likely that have some awareness of the nature of the injury as landmines present a serious problem in Colombia. Anti-personal mines and Improvised Explosive Devices (IEDs) kill or injure approximately 1,000 Colombians each year, more than any other country in the world (Arango-Domínguez, 2009). Rojas's David elicits an empathic reading of the plight of soldiers wounded in the conflict. This is something that has been largely ignored in Colombian society. Even though Colombia has a serious problem with landmines, the images of those affected, are far less frequently seen in the 
media compared to the images of dead peasants and dead guerrillas that function as the hegemonic images of the conflict. The affective nature of Rojas's David stems from the tension between an expected classic aesthetic and the sight of the amputated leg, an absence that points to a presence, not that of the disabled body, but the horrors of a conflict that has always disproportionately affected the poorer and more marginalised members of Colombian society. Rojas reminds the viewer that it is not only the more traditional victims of the conflict such as the disappeared and displaced that require empathy and remembrance, but also those whose circumstances led to little choice but to take up arms. In doing so, Rojas re-signifies an icon of Western culture from a local context, and a specific local history to make visible the tragic consequences of an internal conflict most often experienced by the rural poor.

As Rojas points out, his model, a young Colombian soldier, was unaware of the existence of Michelangelo's David. When asked, "Would you like to pose like David?" the soldier answered, "Which David?" (cited in Barrios, n.d.). At that moment, the artist realised that he was talking to a poorly educated campesino (peasant), and that the difference between himself and the young man was a reflection of the disparity in education levels between the poor and the more affluent in Colombia. From there he began to further his mandate to reflect on educational and cultural inequalities in Colombia, which are seen as a determinant in the continuation of armed conflict (Barrios, n.d.). Rojas differs from the photographers discussed in this chapter, and the next chapter, in that he posits former combatants as victims of the conflict. To understand the simulacrum that is Rojas's David suggests a level of education not afforded the former young soldier that signals the viewer's privilege. His wounded visage is not only representative of the violence, but the price disproportionately paid by the poor, uneducated, and marginalised of Colombian society. Rojas's work interrogates the idea of inequality in Colombian society. Between the viewer and the subject there exists an inequality, and the empathic nature of the work is a result of its depiction of one of the tragic consequences of being poor in Colombia. That is being drawn into the conflict through lack of education and poverty in a conflict that seemingly never ends. 
And here Rojas, like Erika Diettes, Echavarría and Colorado, mediates a horrific past event that draws attention to a present reality that is very much the same as the past.

\subsection{Conclusion}

During the course of the Colombian conflict it was not until the latter part of the twentieth century that Colombian artists were able to produce works representative of the conflict without fear of retribution. Prior to the 1980s, photographic depictions of the conflict were typically photojournalistic, and often included photographs taken of the dead long after the fighting had subsided. With graphic photographs of dead guerrillas and dead soldiers essentially propagandistic to serve state narratives, with stereotypical representations of the combatants from opposing factions as either terrorists, criminals, or heroes. Subsequently, these images leave no space for the viewer to reflect on the implications of the image, the causes of the conflict, and ultimately desensitise the viewer to violent imagery of the conflict. In response to such hegemonic violent imagery, as this chapter has argued, Colombian artists, Erika Diettes, Juan Manuel Echavarría, Jesús Abad Colorado, and Miguel Ángel Rojas eschew literal depictions of the violence through the use of metaphor, metonym, symbolic content, and composition to create works intended to affect the viewer. Their images seen as normative possess a strong indexical relationship to the subject that imbues the images with a level of authenticity. However, this photographic authenticity, also shared with photojournalistic images of the conflict, alone does not guarantee an empathic response. It is the subjective choices made by the photographer that elicit an empathic response.

The relationship viewers have with objects is also a relationship of affect, and the photograph as object is no different. Photographs are invested with affect, partly as a function of their indexical nature, but more importantly their content, composition, and aesthetic. And, in this sense, the works discussed in this chapter are each thoughtful artistic representations of the unintelligible that are socially affective through alternative and diverse artistic approaches to their subject. The respective aesthetic approaches employed by these four Colombian photographers promote greater reflection and empathy than imagery that excessively references the 
violence. This aesthetic distance or an aestheticisation of the violence through figurative devices such metaphor or symbolism have the potential to elicit thought, reflection, and empathy. The impact of this work may have it shared or spoken about. This allows those formerly neglected narratives to become part of the fabric of social memory. In this way, these images can be seen to counteract a hegemonic visual regime by providing visibility to the individuals and subjects that have been rendered invisible by both official and social oblivion. The success these artists have experienced both within Colombia and abroad have drawn much needed attention to previously omitted histories of the conflict. As Jill Bennett (2005) suggests in her discussion of empathic affect, this is what art does; it generates socially affective responses with crucial cultural, political, and aesthetic implications.

The next chapter provides a more detailed analysis of the work of two Colombian artists, Óscar Muñoz's Aliento (Breath, 1995), and Libia Posada's Signos Cardinales (Cardinal signs, 2008). Both artists represent ongoing violent practices; Muñoz depicts forced disappearance, and Posada, forced displacement. Chapter 3 will discuss and analyse how both artists, through their uniquely different approaches, promote a call to empathy and remembrance that cannot be elicited through simply showing images of the violence, but through affective strategies that allow a reflective distance. 


\section{Chapter 3}

\section{Photographic Mediated Remembrance in Ongoing Traumatic Histories in Oscar Munoz's Aliento and Libia Posada's Signos Cardinales}

\subsection{Introduction}

In a country with a longstanding history of conflict and post-conflict, such as Colombia, memory is constantly experienced as a problem. At issue are the combined effects of hegemonic representation and oblivion that result in memory being as unstable a commodity as compassion, according to Susan Sontag (2003). As mentioned in Chapter 1, a lack of symbolisation and a suppression of traumatic events have made forgetfulness pervasive in Colombian society in regards to the conflict (Uribe, 2009). This continual oblivion has been a decisive factor in the ability of armed groups to reprise the atrocious crimes committed since the period known as La violencia. The continual nature of this internal war and its constant omnipresence has resulted in an overexposure to the horrors of a seemingly unsolvable conflict that, not unlike the continual exposure to violent imagery, has shaped an image of Colombia that has grown exhaustive. The mnemonic phenomenon of what is remembered is provided as an image of events previously seen, heard, experienced, learned, and acquired. In terms of representation what memory proposes can be formulated insofar as it is held to be about the past (Ricouer, 2003). However, the events to be discussed in this chapter, and their representation, are not only of past but ongoing events that signal their own invisibility and Colombia's societal unwillingness to engage with the past. In this regard, Ricoeur's two questions central to his phenomenology of memory, what is remembered, and by whom can be resynthesised to inquire who cares to remember.

As argued in the previous chapter, one role of art is to generate socially affective responses with crucial cultural, political and aesthetic implications (Bennet, 2005). Accordingly, the two prominent Colombian artists discussed in this chapter, Oscar Muñoz (b. Popayán, 1951) and Libia Posada (b. Andes, Antioquia, 1959) eschew traditional representational approaches to traumatic histories through mediation rather than a representation of the violence of the conflict. In doing so, they close the distance between their viewers and a predominantly rural conflict, which is described by Juan Manuel Echavarría as the 'war we have not seen' (see Chapter 2). Therefore, this 
chapter argues that Muñoz's Aliento (Breath, 1995) and Posada's Signos Cardinales (Cardinal Signs, 2008) promote a call to empathy and remembrance that cannot be elicited through the simple depiction of images of the violence or tired visual clichés, but through affective creative strategies directed to allow both a reflective distance from the violence and a proximity to the experience of victims and survivors. This assertion is a continuation of ideas developed in the previous two chapters that shocking images anesthetise. This makes it necessary to provide alternative approaches that can elicit remembrance and empathy. The ability to do so is a direct result of an artist's formulation of their work and the productive practices involved. Both Muñoz and Posada create photographic work that mediates atrocities that have happened over decades on a grand scale, yet remained somehow invisible. Both artists express in their art a desire to elicit greater remembrance and empathy for the victims.

The first half of the chapter discusses Muñoz's Aliento (1995), a critical photographic work that focuses on los desaparecidos (the disappeared) in three sections. Section 2, A Return to Death in Muñoz's Aliento, gives an overview of the work, and a discussion of its central themes. This section is followed by a discussion of the act of disappearance and its denial of the ability to mourn in Section 3, The Act of Disappearance. Though this section focuses on the disappeared, and the psychic toll on the families, it also discusses what Judith Butler (2006) calls 'ungrievable' violence, which also relates to Posada's work. Put simply, ungrievable violence refers to the forgotten, disregarded, or silenced suffering of the other that these artists seek to readdress. Section 4, Photography, Death and Mourning Mirrored, analyses the specific aspects that mediate Aliento's articulation of affect. The remaining half of the chapter looks at Posada's Signos Cardinales (2008), a series of unorthodox portraits of women that mediates the lived experience of los desplazados (the displaced). Section 5, Libia Posada's Signos Cardinales (Cardinal Signs), introduces both Posada's work and its political context. There are two elements in Signos Cardinales, the indexical, and the metonymical intervention of the artist's hand, where their confluence is essential for affect. The next two sections discuss these elements. Section 6, Affective Portraiture: The Indexical Traces of Adversity analyses photographic affect, and Section 7, 
Cartographic Signs of Diasporic Trauma, demonstrates how Posada's re-appropriation of cartographic symbolism is used to show places, and experiences.

\subsection{A Return To Death In Muñoz's Aliento (Breath)}

Oscar Muñoz (b. Popayán, 1951) is regarded as one of Colombia's most significant contemporary artists, having exhibited prolifically both at home in Colombia and throughout the world over the last four decades. Muñoz is known for a multi-faceted approach to his work that includes photography, video, printmaking, and drawing. His varied use of alternative photographic processes is central to his exploration of two recurring themes: the narcissistic contemplation of the self versus a concern for the other, and the capacity of an image to recall memory. The first theme, the contemplation of self, is sought with the use of reflective surfaces such as mirrors, glass, water and metal disks to have the viewer appear in the work. María Margarita Malagón-Kurka (2019) suggests that the concepts of 'reflection' and 'identification', both visually and psychologically, are "essential when examining spectators' engagement with his art of the viewer's engagement with his art", as the reflective surfaces in his artworks allow viewers to see both their own reflection and that of another (p. 761). Muñoz describes his use of reflective devices in the following terms:

I [...] work with the idea of the self-portrait, keeping in mind that the person who will see my work is looking at him/herself; it's a mirror. My image becomes the image of the other, which is a theme that has interested me; how we see ourselves and the other, and how we recognise ourselves in the other. (cited in Herzog, 2004, p. 239)

The second theme, the interrogation of the capacity of an image to recall memory, is a function of photographic techniques that conform to notions of proto-photography. Muñoz's embrace of alternative photographic processes contrasts with the work of artists discussed earlier, and with Libia Posada's Signos Cardinales, to be discussed below, in that his work is an event that takes place as an experience. This happening comes about as a presentation through the artistic device as opposed to the visual image being the primary conduit of meaning. Therefore, if the ontology of photography relies on the fixed image, Muñoz's work is consequently located in the 
temporal space prior to that decisive moment when an image is fixed. This is the space between proto-photography and filmic representation. Although 'photographic effect must necessarily have been observed in 'proto-photographic' substances - that is those in which the action of light alone suffices to produce a permanent image", it is the negative and the chemical processes required to permanently affix images that signals the invention of photography (Ware, 2015, p. 10). The surprising temporality of Muñoz's work either in its deterioration or disappearance of the image provides a mediatory function via an affective relation to the subject. In an interview with Hans-Michael Herzog (2004), Muñoz suggests:

The idea of making a portrait is to congeal a moment in time and fix it. One of the most important things about photography is what is called the index; the moment at which contact is made with reality [...] But there is something else, which is very significant in another sense, which is the fixing of photography, what makes it a document that can be archived, what transforms it into the past [...] By reflecting on the fixing of time, the relationship to the moment, the passing of time - all key elements of photography - have also been reflection upon our own relationships to the past. (p. 242)

In contrast to painting or drawing, the photograph is able to capture an image from a moment in time through an optical, mechanical, and chemical process without the intervention of the human hand, and fix it materially in order to abstract it from the passing of time. Thus it can be said that the essence of photography is not the capture of an image but its permanence. This notion raises questions about the status of the image in the instant prior to the moment when it is permanently fixed. In Muñoz's work, absence is marked by a fleeting presence, rather than by permanence.

In his work Aliento, Muñoz arranges ten eye-level greased metal disks on the wall separated as stations for individual contemplation. In order to view the work the viewer must first gaze upon their own image reflected in one of the ten mirrorlike disks with their reflection slightly distorted by the curves of the disks. The viewer is then directed by a small written sign accompanying the disk to lightly exhale onto its surface. As the moisture from their breath covers the surface of the disk, it blurs it with an opaque stain that slowly spreads to reveals an image of a man's face (figure 20). 


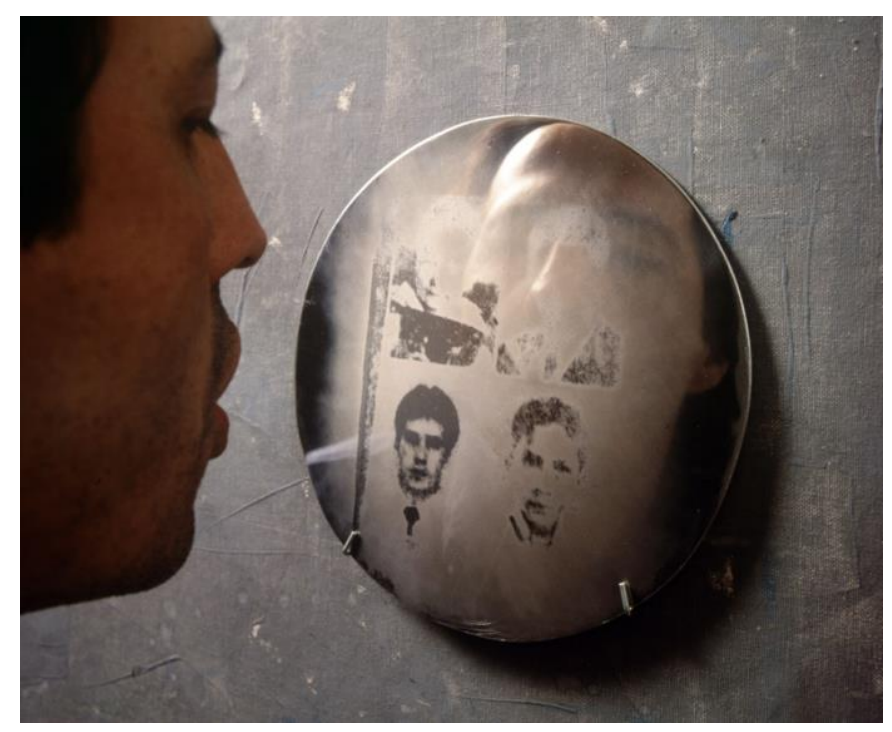

Figure 20. Muñoz, O. (Artist). Aliento. (1995). [Photo-serigraph]. Courtesy of the artist

The images that appear in Muñoz's Aliento are fused to the metal mirrors through a photo-serigraph technique, which creates a rendition of the photographs that is commonly used in silk screening. Following exhalation, from the edges of the previously unnoticed layer of grease, the silkscreen traces emerge from a seemingly invisible background to temporarily suspend the viewer's mirror image. Although the viewer loses their reflection, the breath that diffracts the light enlivens the image of a foreign face. The breath infuses a transitory life into the face of a man that is only visible for a matter of seconds before the moisture from the breath evaporates and the metal disk reflects the viewer's face again.

The images that appear before the viewer are read as old. As Mary Ann Doane "another kind of indexicality allied with $[\ldots]$ contingency and that has to do with the traces of time on the photographic emulsion, the scratches and fading and chemical deterioration" (p. 18). A visible degradation of the image from either the condition of the emulsion or the printed image points to the duration of existence, and unlike digital media, the photograph carries this imprint of time. In Doane's words:

The age of photographs and of films is traced not only in their deterioration but in the type of film stock, lighting, colour system, etc. In the viewer's recognition of an old photograph or film as old, the fact of the medium's 
materiality is foregrounded, not escaped. The historicity of a medium is traced in the physical condition of/within its objects. (p. 18)

At this point as the viewers move from disk to disk, each face becomes slightly larger than the one before. Each man is wearing a collared shirt, and appearing quite expressionless. The pixilation of the images posits an imprint of time, as they appear to be half tone printed as in old newspapers; photographs that were made up of a series of large and small dots to make up the black and grey looking areas. The photographs themselves are from newspaper obituaries that the artist has been collecting for many years. Muñoz explains his interest in these photographs as due to the fact that those represented are deceased. In an interview with Hans-Michael Herzog discussing Aliento (2004), Muñoz states:

I think that Roland Barthes' idea is very relevant: that the true function of photography is fulfilled when the referent disappears; it is at that point that the photograph acquires all its force and value. Of these individuals that have disappeared and died, the only document that can testify to their existence - in addition to those mementos sometimes preserved by families, like articles of clothing or certain objects - is photography. (p. 246)

The provenance of Muñoz's appropriated images or the fact that they are indeed photographs of the disappeared is not indicated until the end of the exhibition. However, given the association between photography and mourning, it is likely that the viewer perceives that they are looking at the dead. The images on the disks are photographic in origin and therefore as they appear, no matter how briefly, they bring forth photographic indexicality, and elicit an acknowledgement that the individuals that appear and disappear actually existed. The images of the anonymous men exposed to the viewer posit questions about the identity of the men and the nature of the artistic device of appearance and disappearance. If recognised as the disappeared, these images amongst Latin American viewers may infer a bad death, and the imagined horror it implies. 


\subsection{The Act Of Disappearance}

In order to understand the mediatory function of Aliento with any degree of depth, one must consider the irretrievable and ungrievable nature of the systematic disappearance of people and the resultant never-ending anguish of their families and communities. In Colombia, the forced disappearance of people became a common strategy used by all armed actors, including the military, throughout the 1980s to the present day. This practice ultimately became one of the main tactics of paramilitaries often with the tacit approval or direct collaboration of Colombian authorities. A combined pressure to maintain control over territories through violent means and also restrict visible violence led to the wide scale use of disappearing people in Colombia. To this effect, the paramilitary group Autodefensas Unidas de Colombia (AUC) (1997-2006) changed from using overt forms of violence, such as massacres and exhibition of mutilated bodies, to obliterating the evidence of violence by disappearing the bodies of their victims. Although the violence became less visible to broader Colombian society it was clearly perceptible to the affected communities. The use of forced disappearances not only endeavours to hide any evidence of the killing but to make the very act unknowable. In addition to unseen physical violence, there is also an added psychological pain, given forced disappearances are often dismissed by official narratives that deny the experience of the victims, and diminishes the ordeal of their families. The lack of the victim's body, and an official discourse that repudiates and invalidates their experience create a crisis of identity, reality and grieving. Gatti and Blanes (2021), in the article The Deviated Mourning of the Disappeared: Reimagining Disappearance and

Transcending its Tropes (original italics), suggest that:

After the disappearance, those left behind inhabit a space of eternal instability, a death that never comes to a close, that lacks the materiality necessary to be firm: there is no grave, no body, and therefore no mourning, as there is nothing to fix on to in order to do the work that is required. Without a body on which to focus the work of mourning, with absence turned into a never-ending moment, the institutions with which death is normally managed naturally crumble. (p. 57)

This idea of continual uncertainty as to the fate of the disappeared is mediated in Muñoz's Aliento with his application of a photographic like process that also is 
unable to be permanently resolved. This never-ending absence effectively renders the violence ungrievable, particularly as many families never get closure. Judith Butler (2006), in Precious Life: The Powers of Mourning and Violence, details how the differential allocation of grief has considerable socio-political implications, arguing that:

We have to consider how the norm governing who will be a grievable human is circumscribed and produced in these acts of permissible and celebrated public grieving, how they sometimes operate in tandem with a prohibition on the public grieving of others' lives, and how this differential allocation of grief serves the derealising aims of military violence. What follows as well from prohibitions on avowing grief in public is an effective mandate in favour of a generalized melancholia (and a derealisation of loss). (p. 37)

Although Butler is specifically talking about what she describes as the nameless victims of American and European aggression in Afghanistan, questions of who gets to mourn and who is mourned are just as applicable to the Colombian conflict. This denial of the ability to mourn is an act of dehumanisation, where the victims are either seen as troublesome to official narratives or simply just unacknowledged as a life lost which makes such deaths ungrievable. Through Aliento, Muñoz seeks to draw attention to this lack of recognition of the unresolvable absences of the disappeared, and provide a space for symbolic and communal grieving. The chasm between the narrative of those disappeared and the official repudiations of the event not only exacerbate the fear and trepidation experienced in rural zones but, with the media focused on guerrilla violence, it strengthens the false narrative that guerrillas are responsible for the majority of the violence as disappearances performed by paramilitary groups go largely unnoticed.

The use of forced disappearances to subdue populations is not unique to Colombia, as Latin American governments have long "made use of the anguish caused by forced disappearance and attempted erasure from society of identities" (Crowder-Taraborrelli, 2013, p. 389). Dictatorships in Chile, Argentina, Paraguay, Brazil and Uruguay during the 1970s left tens of thousands of disappeared throughout Latin America as a legacy of their genocidal practices (CrowderTaraborrelli, 2013). Since the late 1970s, the fate of the disappeared had become an international political symbol of the ruthlessness of authoritarian state repression in 
Latin America, in no small part due to the activism and resistance to erasure by groups trying to learn what happened to their loved ones. However, the disappeared in Colombia, as Humphrey (2018) explains, are not as easily categorised:

The human rights subject categories of perpetrator and victim on opposing sides. The scale of disappearance, the heterogeneous political geography of victimhood, the stigmatization of the disappeared as blameworthy (i.e. not innocent victims but leftist guerrillas or their sympathizers), their social invisibility as a consequence of racism (many were from Afro-Colombian and indigenous background) and the complex historiography of the Colombian conflict make it difficult to turn the disappeared into a homogeneous symbol of the political victim. (p. 454)

Therefore, the disappeared in Colombia have not become the emblematic victim and focus of human rights accountability that they are in other Latin American countries, particularly Argentina. As mentioned previously, the use of forced disappearance and displacement in Colombia was in fact a common tactic used by all sides to seize control of territory and terrorise the population. However, unlike Argentina and Chile, these tactics continue to be used on a large scale in Colombia. The disappeared in Colombia are not a closed category produced by past acts of violence, but a present reality. The affective construction of Aliento is predicated on social memories of prior events of disappearance, and with the prevalence of this violent act well known in Latin America, Muñoz can safely assume that Colombian viewers will know something of this atrocity.

In Latin America today, it would be difficult to find individuals who do not know about forced disappearances or what the figure of the disappeared represents (Gatti \& Blanes, 2021). Beyond the legal and institutional recognition of the disappeared as a human rights violation, the disappeared have attained tropes, in the sense of a common, recurring theme or convention associating those forcibly disappeared to "an individual's removal from the rule of law by state or para-state forces and the plunging of that individual into a space of negation" (Gatti \& Blanes, p. 55). 'Disappearance' is typically seen as a situation that challenges the deployment of conventional forms of representation and language, which prove inadequate in the face of this 'death in life', this 'present absence', this 'permanent death', where "problematic art and mourning passes through the problematic of the 
absence of the body, through the challenges around the ways of accounting for those absences" (Diéguez, 2016, p. 31). The lack of a body on which to focus the work of mourning creates a never-ending moment of absence and waiting for the families and communities of the disappeared. This condition of permanent deferral is mirrored by the duration it takes for Muñoz's images to reappear, and the uncertainty as to whether they will resurface. This sense of hopelessness, metonymically delivered by Muñoz's process in Aliento, mediates what Gatti and Blanes (2021) describe as one of the leading tropes of forced disappearance:

A bad death that blocks any possibility of structurally managing the definite absence of a loved one, plunging those who suffer it into a mourning that is difficult to manage. The most widespread response to this was the deployment of an enormous effort aimed at repairing the wound and filling the absence, an effort that sought to rebuild the fractured bonds with materials similar to those that were broken: identity, family, community, body. (p. 57)

Faced with the tragedy of the kidnapping, the shock penetrates family histories, and the search begins. It is precisely the set of actions deployed to find some resemblance of closure that causes the collapse of that world they inhabited before. Personal and public meanings become charted around the disappeared; the mementos they keep, and the publicly displayed banners, bills, and carried portraits all express the absence of the body and the insistence on pointing out its lack. The search for the victims of an ongoing conflict that imposes the anticipated memory for the disappeared of whom there is no news, only the assumption and the imagination that perhaps their demise is only knowable within the unbreakable passage of time, the only witness to their death. The photographs in Muñoz's Aliento, like family photos of the disappeared kept as mementos, function as proof of a life lived, while the metonymic elements within the appearance/existence and evaporation of the image allows the viewer to intimate an embodied experience of disappearance that renders the death visible, and witnessed. For the Colombian viewer, it is the implications of what they know, that brings home the affective weight of the work. 


\subsection{Photography, Death and Mourning Mirrored}

Although those who view Aliento might not be specifically aware that more than 124,000 Colombians have been disappeared throughout decades of conflict (Comité Internacional de la Cruz Roja), they certainly should be able to discern that the sheer scale of this ongoing atrocity demands their attention, and activism. Since the 1980s Muñoz has shifted from archival and purely representative photography to an exploration of the photographic process in his interrogation of connections between the photographic process and the subjective process of identity and memory. Given the duration of a conflict that both precedes Muñoz's birth, and continues in some capacity today, he endeavours to make sense of a yet to be resolved conflict that is akin to "living through an eternal present or in a past present" (Muñoz in Herzog, 2004, p. 242). This concern suggests a repetition of daily events that are similar but not identical, and as noted by Muñoz (Herzog, 2004), this repetition is not dissimilar to that depicted in Andy Warhol's serial prints of the same automobile accidents reprinted in different inks. It can be said that Warhol's repetition of a traumatic event are "more than a patient release from the object in mourning [...] but an obsessive fixation on the object in melancholy" resulting in not only the reproduction of traumatic events but their production (Foster, 1996, p. 132). A similar repetitive affect is evident in Aliento's appearance of ten identical disks that reflect the viewer and their surroundings, and the recurrent appearance of anonymous images of similar looking dark haired Latino men that are literally brought to existence by the viewer's breath (figure 21). 


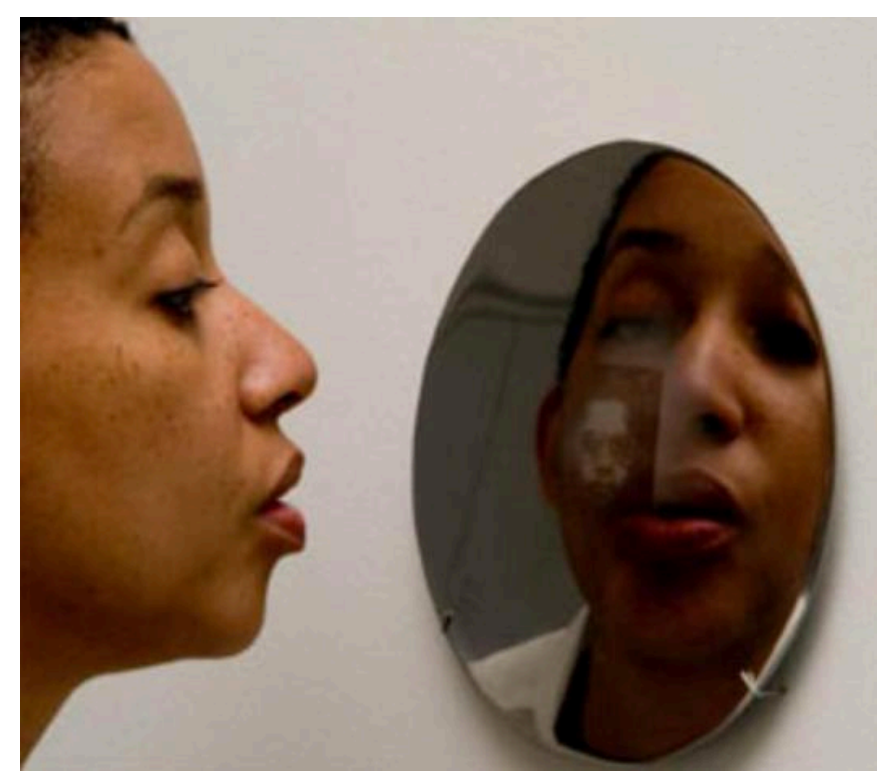

Figure 21. Muñoz, O. (Artist). Aliento. (1995). [Photo-serigraph]. Courtesy of the artist

In Aliento, Muñoz produces an image that remains unstable and unfixable. Despite the initial photographic site of the work, the affective nature of the work takes place in a constant reveal of the latent image in which absence takes presence as an event. As previously described, the viewer must approach the discs to be able to activate the process that the artist has arranged, otherwise the work remains dormant as the metal discs only reflect the image of whoever observes them. The image is activated by the viewer's breath and the object loses its reflective state to reveal the image made by screen-printing grease onto the metal surfaces. Once the image surprisingly appears, it is lost again, as the viewer moves away to observe it in detail, at which point it begins to fade. In this way, the work presents an image in process in which the inability of the photographic apparition to contain and fix time is staged as an unstable and unanticipated image subject to the presence or absence of the viewer. This involvement of the viewers to make something visible beyond reproduction is a fundamental element in the reading of this work. In this way, Muñoz creates a work in which the perceptual experience of the viewer is crucial, not only through the gaze but corporeally with the act of breathing. The back-and-forth appearance and disappearance that occurs between the viewer and the work is mediated by the work. Breath becomes as necessary a material component of Aliento as the metal discs on 
the wall. As the photo-serigraph it reveals cannot exist without the embodied agency of the viewer as co-creator of the piece. With this breath comes all that it metaphorically represents, notably life.

However, it is not life that is being represented in the images of Muñoz ' $\mathrm{s}$ Aliento. Though originally in photographic form, these images are latent and the instant the viewer's breath activates the screen-printed grease to reveal the other is much like the moment a photograph image becomes visible as an effect of chemicals in the darkroom. The viewer's breath is what exposes, and recalls the image. The viewer who frames and composes the image can therefore be likened to the photographer who "determined upon the capture of actuality, do not know that they are agents of Death" (Barthes, 1980, p. 92). As mentioned in the previous chapters, the photograph is referential, in the sense of the index, as it carries the referent or the thing in itself. This ontology of the photograph as a trace of the subject that appeared before the lens continues to shape how photographs are understood and viewed and how the relationship between material reality and images is theorised. It is exactly these ontological particularities of the photograph as a representational media that help explain the efficacy of the photographic portrait as a memento. Since its inception photographs have become a principal media of mourning. As Sontag explains, "photography has kept company with death. Because an image produced with a camera, is literally, a trace of something brought before the lens $[\ldots]$ superior to any painting of the vanished past and the dear departed" (2003, p. 21). As part of mourning and memory, the images appropriated by Muñoz's Aliento function as a metonymic trace of corporeal absence, as the photograph is culturally understood as an object of memorialisation of the dead. As discussed in the previous section, the representation of the disappeared has attained tropes, whereby the photographic portraits of the missing have become pivotal in both the personal and public memorialisation of forced disappearance. In her book No habrá flores en la tumba del pasado (2001), an ethnographic investigation on the relatives of the disappeared from La Plata, Argentina, Ludmila Catela da Silva suggests that the use of photographs play a key 
role in helping mediate loss. With no body to bury, no knowledge of the moment of death, and no gravesite, mourners have looked to new spaces to handle their grief:

The use of photographs to remember an absence recreates, symbolises, and recuperates a presence that establishes links between life and death, the explicable and inexplicable. Photographs 'vivify'. Like a metonymy, they contain part of the referent to summate a system of meanings [...] The photos of the missing constitute one of the most frequently used forms to remember them. They oppose and complement the category of the disappeared in the sense that they return a notion of personhood, that which our societies condense the most essential features: a name and a face. (p. 129)

These portraits instill the disappeared with both a corporeality that had been negated and an opposition to their erasure. This situating of the departed and a material artifact, one that connects the lost to the living, engenders the photograph with an innate potency for the memorialisation of those lost, and for processing a profound sorrow. Although, each of the anonymous photographs in Muñoz's Aliento provide a face, they do not provide names, as these pictured men are representative of the tens of thousands of Colombians disappeared. They do, however, create a space to collectively mourn the truncated lives of these unknown men, granted, it can never be comparable to the grief their loved ones experienced, but the transmitted sense of loss these images enact serves to counter their erasure.

This relation between the photograph and death is notably theorised in Barthes's seminal text Camera Lucida, written after the death of his mother. In this book, he directs his grief into a search for the ontology of the photograph driven by a desire to find an image of his mother that affectively corresponded to his memory of her. In his search for his mother in old photographs he finds images that objectively look like her, but ultimately discovers her true likeness in a photograph of her taken when she was five in a winter garden, the so called Winter Garden photograph. This singular image refocused Barthes's ontology of the photograph, in his own words:

At the time [...] when I was enquiring into my attachment to certain photographs, I thought I could distinguish a field of cultural interest (the studium) from that unexpected flash which sometimes crosses this field and which I called the punctum (another "stigmatum") than the "detail". This new punctum which is no longer a form but of intensity, is Time, the lacerating emphasis of the noeme (that-has-been), its pure representation. [...] In front of 
the photograph of my mother as a child, I tell myself: she is going to die: I shudder, like Winnicott's psychotic patient, over a catastrophe which has already occurred. Whether or not the subject is already dead, every photograph is this catastrophe. (pp. 94, 96)

By capturing a subject in time, portrait photography adopts a posthumous relation to both the subject and the moment in time. As a record of a moment and subject that no longer are, portrait photography provides the viewer access to the ongoing psychic work of mourning loss. This punctum is that the subject is going to die, and interpreted at the same time as "this will be and this has been" (p. 96) to which Barthes elaborates, "by giving me the absolute past of the pose (aorist), the photograph tells me death in the future" (p. 96). For Barthes death is the nature of photography. This is a death in which the own viewer's death is inscribed. As the viewer moves from disk to disk, the brief appearance of the image becomes anticipatory, and with each exposure a death is repeated as the 'photograph' is taken over and over again. Muñoz's juxtaposition of the photograph as a sign of death and mortality, and breath as a symbol of life and embodiment is key. As the viewer endeavours to resuscitate the image they can only temporarily expose the dead object: the photograph of a presumably deceased individual. He has each and every viewer participate in resuscitating the image. By seemingly breathing life into the image, the viewer only manages to create an "asymbolic Death, outside of religion, outside of ritual, a kind of abrupt dive into literal Death" (Barthes, 1980, p. 92). The reflective surface makes it possible for the viewer to attempt bring the dead back to life again as the reflection shows the living. However, the image is unfixable, and the frustration implied in the futility of the desire to bring someone who has died back to life is noted in an interview with Muñoz by María Wills (2011). In this interview Muñoz states:

I did the work Aliento at the time I was studying Barthes, reading Camera Lucida. I was studying about photography and the referent, how photography, due to its character as a testimonial mark, becomes so important when the referent disappears. [...] As a result of reading Barthes and looking at these collected portraits, without reference, it was taking on a special meaning to confront them before the image of a spectator reflected in a mirror, of the one who is there. I was not thinking of doing a work about the disappeared, with the burden and the meaning that we give to the term disappeared. The action 
had more to do with the fruitless impulse to reclaim the one who is no longer there. (question. 5. para. 5)

The innate temporality that is evident in Muñoz's proto-photographic process can be read as a metaphor for the disappeared. However, the process also illustrates the irretrievability of an event that is forever lost. The indexicality of the image exposed by the viewer's breath can be better understood as a death made visible. Although to a Colombian viewer it may be an inescapable truth that they are most likely looking at old newspaper photographs of los desaparecidos before Muñoz reveals the identity of the anonymous images. This realisation should not be surprising, in the same way Jesús Abad Colorado's portrait of Doña Fabiola with a photograph of her murdered son is not, as discussed in Chapter 2.

As the practice of publicly displaying family portraits and unassuming ID photos to protest the horrors of state sanctioned violence has been commonplace in Latin America since the 1970s. Ángeles Donoso Macaya, in her book The Insubordination of Photography: Documentary Practices under Chile's Dictatorship (2020), describes how the public display of photographic portraits is/was critical to providing a face to the crime of forced disappearances, because of the ID photograph being seen "as an almost exclusively denotative object, a sign of the purest visual empiricism" (p. 41). The ID photos used by Muñoz operate like the family portraits that Donoso Macaya discusses, in that they appear un-coded and devoid of artifice, and "compel a gaze that is affiliative and 'indentificatory' and instantly familiar $[\ldots]$ in the context of human rights activism $[\ldots]$ across a range of Latin American countries" (p. 44). As indicated earlier, it should be stressed that at the time Aliento was first exhibited in Colombia in 1995, the disappeared were not a homogeneous symbol of political victimhood, as they were in such countries as Argentina and Chile. In Colombia, such groups as Las madres de Soacha (The Mothers of Soacha) mirrored the recognition brought by activist groups of forced disappearances in other Latin American countries, although at this point the Colombian conflict had been raging for decades. That is not to say that people were previously unaware of forced disappearances in Colombia, but a situation persists where "memory loss [that] is characteristic of Colombians [through] both a lack of 
symbolisation and the suppression of traumatic events" has rendered the disappearances as mostly forgotten (Uribe, 2009, p. 5). Muñoz clearly expects that many Colombian viewers would have some knowledge of the practice of forced disappearances, however, the potential for a revelatory shock still exists, and this revelation may speak to the extent to which they had thought about the disappeared previously. This belated knowledge that they are indeed images of the disappeared is exactly the punctum that exists outside the photograph, as detailed by Barthes (1980) in his discussion of the Winter Garden photograph. Although in this case, this is as much about how they must have died, as it is that they are dead and they are going to die. The viewer, like those whose loved ones were disappeared, may not want to imagine the circumstances of an act considered to be "one of the most brutal things that can exist [...] It is the inhumane of the inhumane" (Elsa Sanchez de Oesterheld cited in Robben, p. 261). It is enough that the viewer now understands that the anonymous men that appeared before them died horribly. Acknowledging that the men are dead gives an element of closure, something previously denied. This so called photographic death returns an element of grievability to the disappeared, as Butler explains in Frames of War: When is Life Grievable? (2009).

In Butler's words:

The photograph is linked through its "tense" to the grievability of a life, anticipating and performing that grievability. In this way, we can be haunted in advance by the suffering or deaths of others. Or we can be haunted afterwards, when the check against grief becomes undone. It is not only or exclusively at an affective register that the photograph operates, but through instituting a certain mode of acknowledgment. It "argues" for the grievability of a life: its pathos is at once affective and interpretive. (p. 198)

In this dead image - the photograph - the viewers reveal the death of the disappeared, and their own future death, although not a death as horrific as those of the men revealed in Aliento. The imagined death of the disappeared in Aliento, the details of which will probably never be known, is the punctum. By means of the process fashioned by Muñoz, the image is no longer the witness but the viewer, since this is only the vestige from which it is possible to activate the perception that allows, so to speak, witnessing. As Butler (2009) suggests, "grievability is a presupposition for the life that matters", and in the thoughtful application of proto- 
photographic process in Aliento allows a space for both reflection and mourning of the now 'dead' disappeared (p. 14).

The next section discusses Signos Cardinales (2008) by Colombian artist Libia Posada, a work that also responds to a collective need to recall the consequences of the conflict within social structure. In contrast to Muñoz, Posada's work is much closer to the studium, those details that Barthes (1980) suggest comprise the material of ethnological knowledge and, as discussed in Chapter 1, address the photo on a discursive level. In Posada's Signos Cardinales, it is the way the photographs are decoded to reveal symbolic meanings that present a message that is inscribed in a manner that is understandable to any Colombian viewer.

\subsection{Libia Posada's Signos Cardinales (Cardinal Signs)}

Libia Posada (b. Andes, Antioquia, 1959) is a doctor/surgeon and contemporary artist from Medellín, Colombia, whose professional training is a key element in the realisation of her artistic practice. Posada first graduated in Medicine in 1989 from the University of Antioquia, and later returned to the same institution to graduate in Plastic Arts in 1996. As a doctor, she specialises in emergency and social medicine. She cares for patients that suffer from physical and psychological trauma as a result of Colombia's long running internal conflict, particularly those affected by gender violence, forced displacement, and violent crime. Her art ranges from photography, drawing, installation, and video with a focus on public health, gender violence, forced displacement, traditional medicine, and trauma. Posada relates her work as an artist interested in representations of social issues to her medical practice, and the treatment of individual patients. In Posada's words:

In what I do I work on issues that have to do with human beings [...] Definitions about what humanity is, what it is to be a human being, about what death is, what life is, struggle, let's say that they occur while one lives through situations that are expressed often in people's bodies as disease. As a doctor, I have to see these types of situations, so when I see, when I face a sick body, I think of the subject who is expressing a situation in this body. That situation or a certain situation has to do with culture, with society, with the historical moment, with the economy, because that disease made a body speak to us about a historical and socio-cultural moment, and that seems to me very important, very interesting. (L. Posada, personal communication, November 25, 2017) (see Appendix C) 
For Posada, her artistic practice raises questions that originate from her medical practice, and the connection that takes place between these two disciplines is the body in its different representations and how it is constructed by culture (Ramírez Mejía, 2013). In Signos Cardinales (2008), Posada exposes the vulnerability of the body in contexts of violence and memory that critically address the theme of forced displacement. Signos Cardinales is an installation comprised of a set of twelve large black and white photographs of women's legs and feet on which maps have been drawn to show the route followed by each woman from her home territory to escape violence (figure 22). In its entirety, the installation can be read as a larger map as the photographs are placed within a grid reference system according to the Cartesian coordinate system composed of longitudinal and latitudinal lines. This cartographical element provides a specific location for each of the photos within this larger map that is also accompanied by an unconventional map key titled Mapa Físico - Sistema de Ruta (Physical Map - Route System) that has a map scale that uses both the length of a foot, and steps taken as a measure of distance (figure 23).

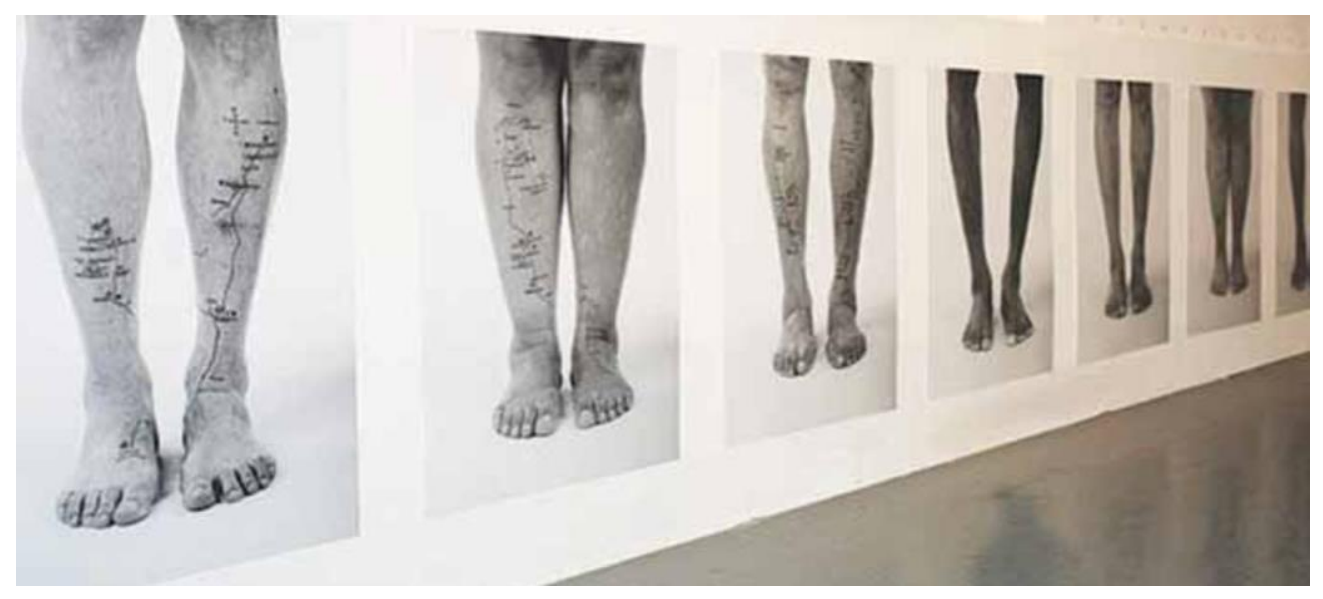

Figure 22. Posada, L. (Artist). Signos cardinales. (2008). [Photograph]. Courtesy of the artist 


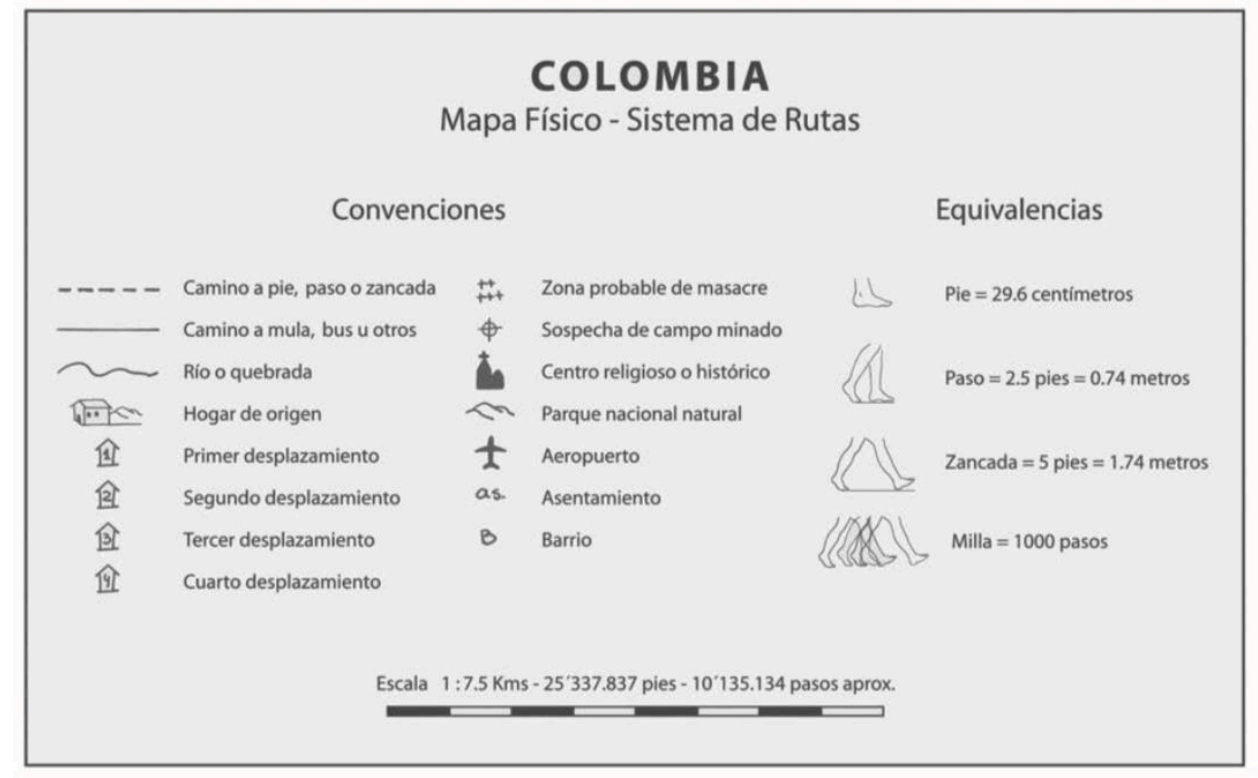

Figure 23. Posada, L. (Artist). Signos cardinales. (2008). [Map key]. Courtesy of the artist

The socio-political context of Signos Cardinales is the ongoing armed conflict that has engulfed Colombia over the past sixty years, during which an estimated six million people, mostly women, have been forced to migrate from their native homes to other regions or neighbouring countries (Centro Nacional de Memoria Histórica, 2015). Whether their lives were subjected to endless violence or guerrillas, paramilitaries, or the military forced them from their homes, for many, forced migration was a choice between life and death. In order to comprehend the mediatory function of the photographs in Signos Cardinales, it is important to understand the circumstances they represent. Forced displacement is not only a material tragedy for the victims who have been dispossessed of their lands and personal effects, but also an emotional tragedy where they are forced to forfeit their social heritage and way of life. In the words of one of the displaced:

It is that the displaced do not care so much about the material they lose, but the loss of their social base, their roots, their environment [...] It is that the uprooting of the communities, the fact that ... I would even say that I was poorer there than here, but richer in every way there. In every sense, because there I was with my people, with my community [...] It was a way of life that is priceless, well ... that is priceless: you can live here in a house of gold, but uprooting does not have it [...] And for me, the most painful in that sense is uprooting: moving away from your environment, your landscape, your usual perspective. (cited in Grupo de Memoria Histórica, 2013, p. 73) 
This phenomenon of a forced diaspora within or sometimes outside Colombia, gives rise to a specific way of relating to territory, which can only be demonstrated affectively through memories of an arduous journey to flee from violence. These are the memories that are inscribed in maps on the legs of the displaced women of Posada’s Signos Cardinales.

The viewer of Posada's piece knows before seeing the photographs that they are images of the displaced as that information is posted beforehand. As with Muñoz's disappeared, the displaced have received relatively little recognition, and almost rendered unseen by a hegemonic image establishment. Even so, it is likely that a Colombian viewer has seen numerous depictions of those displaced in the media. However, as Sontag $(1977 ; 2004)$ argues, continual exposure to either shocking imagery or an overexposure to the same kinds of photographs renders the images both unmemorable, and with a diminished capacity to affect the viewer. Vladimir Olaya and Martha Cecilia Herrera, in their article Fotografía y violencia: la memoria actuante de las imágenes (2014), an analysis of two decades of Colombian mass media depictions of the conflict's victims, suggest the images typically seen render invisible many of the actors of these events, produce an anonymity around the dead, and remove a sense of the conflict. They suggest that the often seen media image "despite the visibility that it proposes to us, blinds us, obscures any type of historical-argumentative rationality and enhances, on the other hand, the power of the other victimiser and their capacity to do and to be" (Oyala \& Herrera, 2014, p. 103). In other words, the diminished empathic affect and oblivion engendered by repetitive exposure to colourless images enables violent perpetrators to repeat past crimes in the present. The typical representation of the "victim in the public arena is that of silence, since the suffering is [their] state and it is what makes [them] visible" (Oyala \& Herrera, 2014, p. 104). However, these representations do not ensure that they be seen as a subject in history contextualised with sufficient attention to socio-political history. Therefore, as Oyala and Herrera determine, it is necessary to construct images within narratives that reveal a voice that makes their place explicit (2014). The media images Oyala and Herrera discuss, consequently, only present knowledge as a means of ordering the logic of an inconceivable past 
and present, which results in a repudiation of the potential to view the victim as a political subject. Without offering specific narratives or the circumstances of individuals' traumatic histories, these images only establish a standardised archive that generalises the human toll of victimisation.

Herein lies the importance of the inclusion of testimony, as part of the documentary process, to represent the lived experiences of those most adversely affected by the conflict. This testimony better allows an authentic and affective documentation of historical truth, whereby "history is constituted not merely by the events of the past but by the scribe's interpretation of those events" (Nowrojee, 2005). Not unlike Erika Diettes's practice, as discussed in Chapter 2, Posada's photographs were shaped through a series of meetings and workshops that the artist held with the participants in the project. Those who volunteered to take part in Signos Cardinales were asked to plot the routes of their displacement onto maps of their regions of origin and to speak about their personal experiences of displacement. In recounting the project, Posada describes how prior to the photographs being taken she met with the displaced, individually at first, to discuss the nature of the work:

We worked a lot on the idea of the trip, not on the idea of recreating the violent events, but on the idea of the trip, and on the idea that the trip they had made was a heroic journey, a historical journey, a journey that no one else had made. They had made maps, and they had drawn a geography, which was an absolutely real geography, but one not in books [...] Those bodies were very important, the bodies of heroes, the bodies of the survivors, so they work on that idea, and for them it was very important. The photographs took place after several conversations, workshops, preparation for the lines, a tracing session, drawing on the legs, all prior to the photography session. (L. Posada, personal communication, November 25, 2017)

These women's testimonies are the driving force behind Signos Cardinales. There is a notion of agency behind the work. The maps drawn on their legs, and later photographed, mediate an emotional cartography; the severe experiences of being forced from ones' territory, and the ordeal to find a place to settle. The photographs function as representations and the maps as metonymical metaphor. This is the story within a story. Their capacity to elicit an affective engagement with the plight of the displaced is a product of intentionality on behalf of Posada to harness the image to 
serve an affecting narrative. In doing so, they reveal social and political circumstances beneath the appearance of the image to represent a deeper understanding. Similar to Muñoz's work, they counter mainstream representations of violent histories by their ability to compel the viewer to consider their role in forgetting.

\subsection{Affective Portraiture: The Indexical Traces of Adversity}

Unlike Muñoz's Aliento, the viewer of Posada's Signos Cardinales is made aware that this is an exhibition about the displaced prior to seeing the work. The affective nature of Posada's images is a function of their indexicality. As they enter the exhibition, the viewer comes across twelve larger than life photographs of women's legs mounted on cartographic lines. Although at first glance the images seem repetitive, a closer look reveals that they are all quite different. Some legs are shorter, thinner, stockier, and all differently shaped. These legs are evidentiary in the same way as the closely cropped portrait of William Casby discussed in Chapter

1 (figure 2), which shows his age ravaged face with an indexical medium that leaves no doubt of his existence. Like this portrait, the twelve photographs of women's legs also certify both the women's existence and their experience. Although these images refute ideas of a portrait orthodoxy that privileges the face, these images are nevertheless portraits given that each one is representative of a particular person. As discussed in Chapter 1, the photograph is the result of a series of subjective choices made by the photographer that include context, topic, focus, the precise moment, and composition, among other things. In Posada's work, the choice of framing is noteworthy as here we have the legs cropped by the image frame just below the knee. Posada describes this decision thus:

I came to this project to think about the body, to think about the idea of the portrait, to make some portraits, to also question the idea of the portrait, to wonder what a portrait was, how could I do portraits of the displaced, of the dispossession of the lands. I also question the idea of the portrait because that typically will start from the head along the body and reach the feet. If there is someone who is mobile, who can traverse territory, it is because they have legs and feet. (L. Posada, personal communication, November 25, 2017) 
Taken in isolation, the photographed legs of the displaced women reveal a life of struggle that is not as contingent on written contextualisation as in Richard Avedon's portrait of William Casby (Chapter 1, figure 2), whereby the relation to slavery, other than to his ethnicity, is provided by the title William Casby, born in Slavery. Consider for instance the legs in the following image (figure 24). Thick, short, and battered, these legs testify to a life of hard work, the impermanence of displacement, and less than perfect health. If the viewer is to look closer, they can see that the skin is discoloured, scarred, and bruised, something that further speaks of hardship. These are clearly the legs and feet of a campesino (peasant farmer) and not those of an urban dweller. They are illustrative of the lived experiences of these women. As Posada has mentioned, the poor condition of a body, in this case the legs and feet of displaced women, arise from circumstances that have to do with culture, society, the economy, and history, because physical disorder makes a body express a historical and socio-political malaise. 


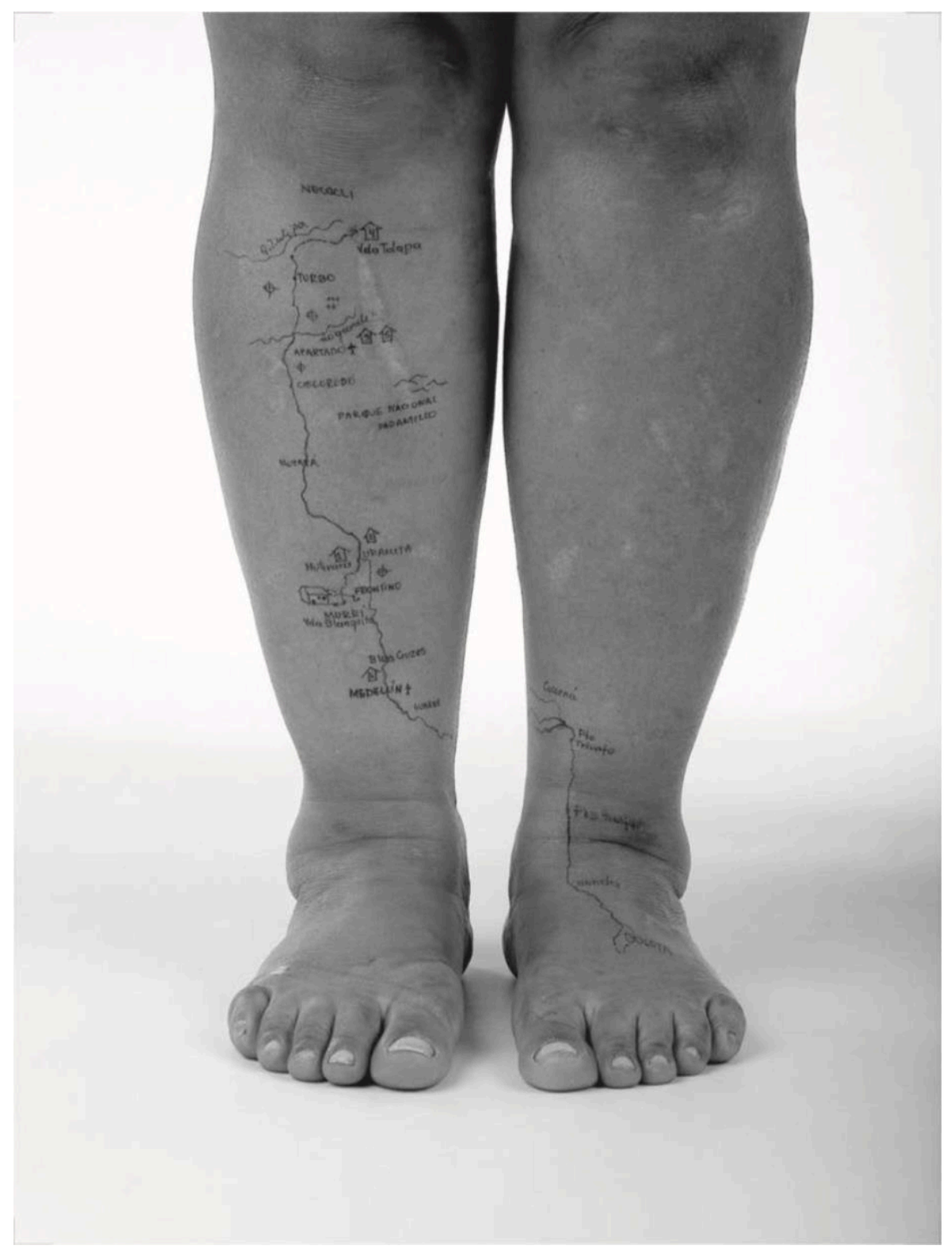

Figure 24. Posada, L. (Artist). Signos cardinales. (2008). [Photograph]. Courtesy of the artist

As discussed in Chapter 1, the photograph is considered to have a primitive core of meaning that, as Barthes (1980) suggests, is the denotative function of the photograph, and a second level of invested, culturally determined meaning, a level of connotation. Alan Sekula (1982) argues that, "the meaning of a photograph, like that of any other entity, is inevitably subject to cultural definition" (1982, p. 84). Therefore, as described in previous chapters, the photograph can be read discursively in that it carries, or is a message. However, it is a message that depends 
on an external matrix of cultural knowledge for its readability. Thus, to read a photographic message the viewer requires context. As Sekula suggests:

A photograph communicates by means of its association with some hidden, or implicit text $[. .$.$] that carries the photograph into the domain of readability. (I$ am using the word 'text' rather loosely; we could imagine a discourse situation in which photographs were enveloped in spoken language alone. The word 'text' is merely a suggestion of the weighty, institutional character of the semiotic system that lurks behind any given icon). (1982, p. 85)

Generally the image is contextualised first by descriptive text to locate the subject, and although Posada does foreshadow the nature of the photographs, the photographs surprise in their capacity to represent lived experience. The scarred and battered legs are signs that are read as the weight of a tough existence inscribed on the body. The photographed condition of the legs alone signifies the physical toil of the rural poor. But, in addition the hand drawn maps on the legs further codify the lived experience within a semiotic system of cartographical representation that maps the women's testimony. The act of mapping is described as "the act of conceiving spatial relationships in the milieu", and these relationships of the hills, valleys, and rivers they observe and their conception of things within a spatial relationship is the critical nature of maps (Head, 1991, p. 237). These maps, however, show the spatial relationship of the women to the territory they were forced to traverse to escape from violence. A journey that was often undertaken on foot.

\subsection{Cartographic Signs of Diasporic Trauma}

Since the 1980s the use of maps and cartographic elements as means of artistic expression as a practice has gained great strength and has been developing worldwide (Ramírez Mejía, 2013). Many artists have used these elements in varying ways and for different purposes to make maps, subvert maps, perform itineraries, imagine territories, chart the invisible, and modify physical, virtual, and hybrid spaces in the name of cartography (D'Ignazio, 2009). Maps are understood semiotically, pertaining to their signs and symbols, not unlike a medical diagnosis that is also read by signs and symptoms. In any map, an important part of its signs are symbols of objects, and their origins and characteristics, are clearly influenced by their referents (Schlichtmann, 2013). In Signos Cardinales, geographical 
mapping functions as a metonymy based metaphor of forced displacement framed by the scarred and bruised skin of the women's legs. As noted in Chapter 2, the distinction between notions of metonym and metaphor are particularly difficult both theoretically and in application. To reiterate, metonym is a mapping within the same conceptual domain, while metaphor maps one conceptual domain onto another.

Signos Cardinales is the mapping of two conceptual domains, which are based on, and can be traced back to one conceptual domain. The tracing of the maps on the legs can be read as a metonymy given that both the indexical signs of traumatic experience and the cartographic symbolism represent conceptual domains that share a common experiential basis. The space, namely, the represented territory, is understood differently in this work as Posada appropriates the visual iconography of the map to reference the personal experiences of the women within a "methodology for locating the individual subject within vast psychological, interpersonal territories; [...] to draw geographical parallels between the vastness of [the journey] and the scope of the human psyche" (D'Ignazio, 2009, p. 192). In an unpublished interview with the researcher (see Appendix C), Posada points out:

I was also thinking about the idea that when you travel you make maps, you draw routes, but when these people travelled through displacement, they drew routes with their own bodies, routes guided by fear, by the need to save lives, routes that no one knew, routes that they discovered while traveling. This project of the maps, of the history of each person, of the travel route of each person from the moment they had to leave their original home, where they had everything, the trees, the river, the landscape, their identity preserved, when that is all lost, they begin to make random paths, guided by fear, and finally they end up living in Medellín. (L. Posada, personal communication, November 25, 2017)

The map is the story of each person, which bestows the external forces inscribed on the skin with a narrative that is given a sense of authenticity through the indexicality of the photographic image. The symbolism used on the maps support the harsh realities of this forced diaspora. These maps and the accompanying unconventional map key (figure 4) subvert typical cartographic semiotics to evoke their subjects' experiences, and in this sense the photographs of the mapped legs are not the usual record of a singular moment in time but a sign derived from indexical and 
metonymical elements that intimates a history that invites greater inspection of the work (for instance, see figure 25).
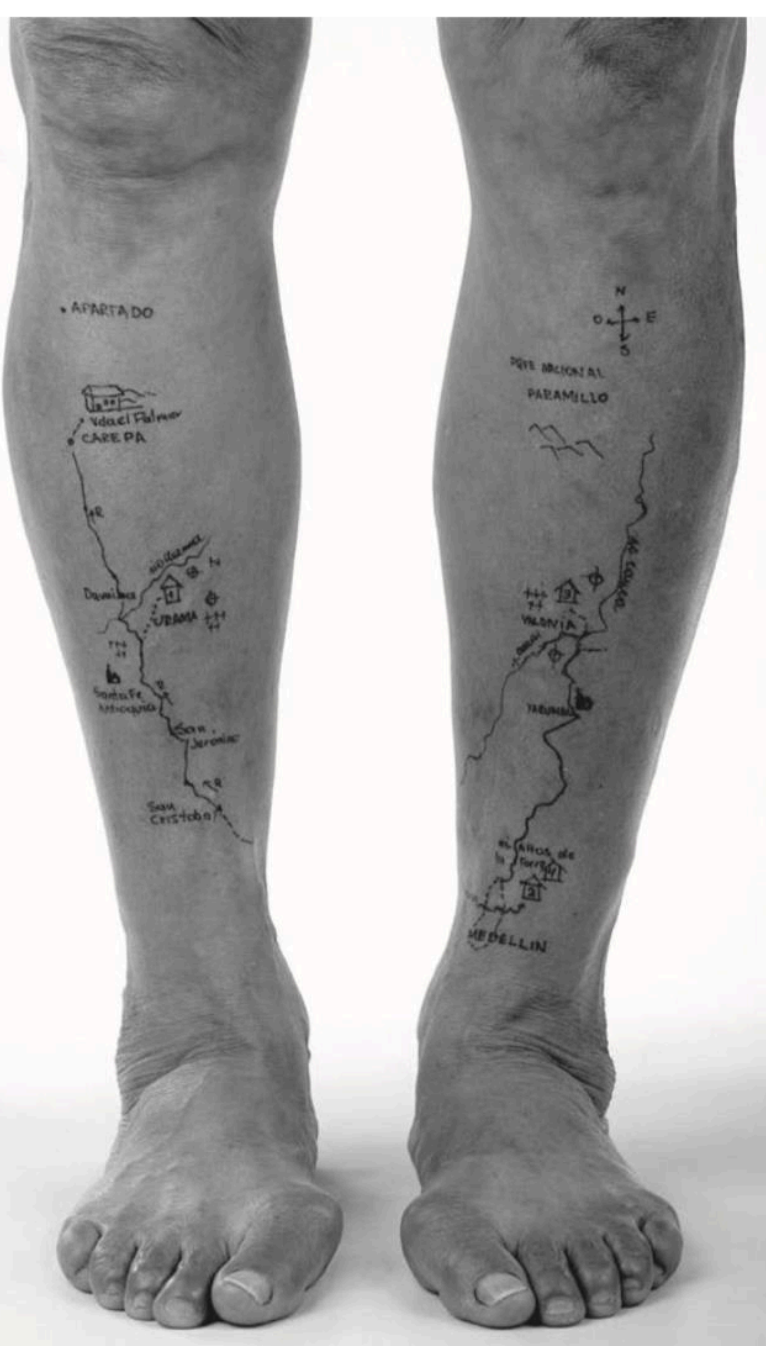

Figure 25. Posada, L. (Artist). Signos cardinales. (2008). [Photograph]. Courtesy of the artist

The maps draw the viewer in. From what at a distant first glance must seem like some strange taxonomy of legs are now testimonial documents that capture a temporality beyond that of just the decisive moment, and a geographical spatiality unrestrained by the frame that elicits a narrative. The mapped legs in figure 25 
represent a woman's forced displacement from Carepa to Medellín, and considering the apparent scale of the map it seems a significant distance (a Colombian viewer will know that the distance is approximately $300 \mathrm{~km}$ ). However, there is no explicit indication of the duration of this journey, but the cartographical icon Desplazamiento (displacement) signifies that this particular woman had to move four times, so it speaks to a long and arduous journey to find a place to finally settle. The distance not covered by Camino a mula, bus $u$ otros (the way by mule, bus or other means) is traversed on foot (Camino a pie, paso o zancada - the way by foot, step or stride) through territories that include probable areas of massacre (Zona probable de masacre) and suspected minefields (Sospecha de campo minado), While these photographs may move viewers affectively, they do not have, however, an inscribed meaning to them. But rather it is the confluence of the image and the mapped legs, the same feet that had traversed that exact route that allows the viewer to partially reconstruct their experience. The maps provide context to the circumstances of the individuals that these worn legs and feet belong in a manner that transcend typical representations of the displaced, and the reported numbers reflecting the immense scale of displacement that often accompany them. At the time Posada was conceptualising Signos Cardinales, the figures regarding forced displacement that routinely appeared in the press were already astronomical numbers. As Posada notes in the interview:

There were millions, so many millions of displaced people but the people were invisible, and one of the intentions of the work was to make the bodies visible behind the numbers. Because in medicine it happens a lot in how many statistics are handled. The many figures and the human situations that gave rise to those figures disappear behind the figure. This is a paradox because there is human suffering that generates these figures and that suffering is erased behind the figures. The numbers end up being more important figures than the people, so I wanted to make people look at the bodies that were behind those figures, such as the people, the human beings, the suffering that was being experienced. (L. Posada, personal communication, November 25, 2017)

Although Posada describes each map as the story of that person, she chose to not have their faces appear as she considered each narrative to be the story of millions of people who have been displaced within Colombia. These are stories that resonate 
with the viewer. The photographs invite the viewer to follow their indexical signs to navigate the mapped geographies of the women's forced displacement and recognise the tragedy of their circumstances. In doing so, they promote the viewer's imagined traumatic experiences of the women, such as the unfathomable thought of what it must be like to lose one's home, one's community, one's sense of self, and in many instances the loss of a loved one to violence, only then to be forced to travel long distances in the pursuit of some resemblance of peace. And, not unlike Muñoz's Aliento, through the creation of an affective space, they draw the viewer closer to a comprehension of the ongoing suffering of the conflict's victims, yet paradoxically they cannot help but reveal the distance between the viewer and those worst affected by a seemingly never ending catalogue of crimes committed against Colombia's most marginalised. Herein lies these works' power to elicit empathy and remembrance.

\subsection{Conclusion}

Although decidedly different in construction, aesthetics, and content, Oscar Muñoz's Aliento and Libia Posada's Signos Cardinales share a stated desire by the artists to bring attention to ongoing atrocities of the Colombian conflict that have been rendered near invisible by a fog of oblivion. As elaborated in this and previous chapters, mass media depictions of the conflict through shocking or repetitious imagery have rendered the disappeared, the displaced, the soldiers, and the guerrillas as anonymous and homogenous figures in the service of a hegemonic visual regime. This invisibility is not necessarily perceptual but ideological and political. With no shortage of representations of the victims today, and with those published easy to find in online news resources, paradoxically it is the existence of such representations that have historically rendered the victims unnoticed within the socio-political arena. The dominant visual regime makes it known that there are victims of the conflict, but the excessive and repetitive nature of the representations leaves the individual experiences of those who have suffered the worst of the conflict, unseen, unheard, and unfelt. As Posada suggests above, the victims become little more than figures that erase the human suffering. These images, particularly 
those explicit in their depiction of violence, for the most part only testify to the existence of victims, and the photographers' technical ability, over time elicit diminished affect and memorability.

Despite the differences in their mediatory strategies, the works discussed in this chapter share an elicitation of affect that is a function of the engagement and involvement of the viewer. As noted in this chapter, tens of thousands of Colombians have been disappeared along with millions displaced in an unrelenting asymmetric war between government forces, far right paramilitaries, criminal groups, and left wing insurgents that vacillates between conflict and post-conflict with inadequate attention paid to the individual human cost. In contrast to the excess of media representations, the two works discussed in this chapter draw in the viewer and provide an affective space generated from both proximity and distance. The process activated by breath in Aliento and the mapped Diasporas in Signos Cardinales function affectively by somewhat closing the distance between the viewer and the mediated experience through the viewer's imagination and the questions the works pose. Perhaps these are questions about the viewer's privilege, given the location of the works in well-regarded galleries, alongside their complicity in Colombia's societal oblivion. These works through their construction and the subjective choices made by the artists act as what Ricouer (2003) would describe as 'memento', that is, those objects that guard against oblivion and admonish not to forget. Both Muñoz's Aliento and Posada's Signos Cardinales mediate often overlooked traumatic events through alternative process and/or atypical representation. Consequently, they engender an affective engagement with the events and victims of the conflict that serves to counteract the apathy and oblivion that have become predominant in those who have not experienced Colombia's largely unseen rural conflict. In doing so, these works realise the artists' hopes that more people remember, and more people take notice of the human tragedy that occurs everyday to the poorest and most vulnerable members of their own country. 


\section{General Conclusion}

Through analysis of Colombian photographic works in the exegesis and the production of assisted portraiture of ex-combatants in the creative component this thesis has argued that alternative photographic approaches intended to mediate the trauma and the lived experiences of the victims and survivors of the Colombian conflict can act as a means to interrogate ideas of memory and historical identity through the subjective choices made in its production. Despite their different subjects, aesthetic strategies, materiality, and spaces of exhibition, the photographic artworks discussed throughout the preceding chapters and the creative component Recordando Excombatientes have one goal in common: to mediate the trauma of enduring political violence that disproportionately affects Colombia's most marginalised communities. The thesis has shown that artworks by noted Colombian artists Erika Diettes, Juan Manuel Echavarría, Jesús Abad Colorado, Miguel Ángel Rojas, Oscar Muñoz' and Libia Posada mediate the knowledge and memory of the armed conflict for their viewers, not by making this history explicitly visible but by eliciting an empathic response that promotes remembrance and generates an affective vigour that potentially empowers political and social activism. This objective is accomplished by the critical creation of thought provoking work that acts as an antithesis to the overused and sometimes graphically violent hegemonic mass media representations of the conflict. These photographic works, through the critical creative approaches applied to their construction and the subjective choices made by the artists, act as mementos, that is, those objects that guard against oblivion and admonish not to forget the violent past that continues to haunt the present in Colombia.

This thesis has explained theories of photographic indexicality, phenomenology of memory, and affect theory, which have been deemed essential in the analysis and understanding of the affective nature of the contemporary Colombian post-conflict art discussed, and the role these artworks have in fostering social memories that allow the silence and omitted histories of all actors within the conflict to be given spaces of memorialisation. The works discussed have been critically created with this idea about the connection between art and memory in mind. Through the use of diverse practices, which include alternative artistic and technical approaches to subject matter, image construction, photographic process and materiality, the Colombian artists discussed in this thesis have 
demonstrably shown that through the subjective choices they have made in their work, they have enabled the creation of affective art works that actively reflect on the lived experiences of a civil conflict that seemingly has no end and of the violence committed against the more vulnerable members of Colombian society. This is a violence that continues to fuel the conflict, and is responsible for many Colombians taking up arms in a cycle of retributory response, that too needs understanding.

In the remembrance of the victims and survivors of the Colombian conflict mediated by artistic practices that shun traditional methods of representation of the conflict's violence, this thesis has sought to demonstrate that it is possible to envisage the creation of memories that do not immobilise thought and action. This is realised through the production of reflective photographic works that contrast with those generated by hegemonic media depictions which fail to elicit apathy and remembrance, to manifest memories that enable understanding of the trauma experienced by the often neglected or forgotten victims and survivors of ongoing tragic circumstances. This is a memory that encourages an empathic and reflective space to help reconstruct the significant plots of the events and images of the conflict, whereby the viewer as depositories of social memories are reconfigured. To this extent, it has been argued that it is necessary to construct images within narratives, and stories that reveal a voice that makes the trauma explicit. However, it is also necessary to opt for images that, politically, help to change ways of seeing, ways of judging, and ways of narrating the course of the conflict, that allow thought and reflection on the elements that made the same images and events possible. In other words, an argument for the construction of images in situated contexts, in fields of meaning, that in addition to providing photographic evidence, help to constitute thought. Thus, it is crucial to understand that memory is not only an exercise in remembrance, but, and above all, an exercise in reflection that constitutes spaces of understanding about the present historical moment to enable the construction of a peaceful future that facilitates an empathic understanding of the plight of the other in Colombian society. 


\section{Appendix A}

\section{Fieldwork: The Act of Producing Recordando Excombatientes}

This fieldwork appendix briefly describes the production of the creative work titled Recordando Excombatientes (Remembering Ex-combatants) and the ideas that influenced its final appearance as realised in exhibition and book form. An important aspect of this project concerns participant agency, and the first section discusses the participatory role of the participants and its theoretical considerations in how the images were taken. Prior to the release of a shutter, there are numerous creative choices that precede the capture of an image, and the next section details some of the technical and creative choices, made by the film, and the participants, respectively, that are behind the work's aesthetic. An important part of post-production is editing, and the third section explains how this was performed in a way to minimise my subjective intervention in the process, followed by a final section on the exhibitions that took place in Colombia.

It should be noted that this creative work has its genesis in practice-led research.

This can be defined as:

Research which is initiated in practice, where questions, problems, challenges are identified and formed by the needs of practice and practitioners; and secondly, that the research strategy is carried out through practice, using predominantly methodologies and specific methods familiar to us as practitioners in the visual arts. (Gray, 1996, p. 3)

Creative work within the university environment can result in research insights, such as those that arise out of producing a creative work and/or in the theorisation and documentation of that work "to articulate what is crucial about one's practice, while also having the time, resources and space for critical reflection to take the practice to a higher level (at least of reflection)" (McNamara, 2012, p. 7). To this end, the work is grounded on the theories of photographic affect, social memory, and empathic affect described in the exegesis.

The ensuing work is composed of a series of assisted self-portraits of former combatants of the Colombian conflict combined with testimony of their lived experiences that took place over four trips to Colombia that totalled approximately 15 months. The first two from August 2017 - Jan 2018 and July 2018 - Jan 2019, were mostly data collection, but included two exhibitions during my second trip for this 
project, and the remaining two times I returned to Colombia in 2019 was solely to exhibit.

\section{The Participatory Role in Image Making}

Prior to traveling to Colombia, I applied for research assistance from the Agencia para la Reincorporación y la Normalización (ARN) (Agency for Reincorporation and Normalisation), the agency responsible for ex-combatants, to no avail. This was before the FARC demobilisation. I therefore travelled to Colombia in late August 2017 for six months with the hope to recruit participants locally. Through the academics, human rights lawyers, and journalists I initially met, and later with help from the project's participants, I was able to locate ex-combatants from a diverse number of armed groups, some long gone, and also former FARC who had just demobilised and were still in the Espacios Territoriales de Capacitación y Reincorporación (ECTR) (Territorial Spaces for Training and Reincorporation); the twenty-four reintegration camps throughout Colombia managed by the ARN to reintegrate close to 7000 ex-FARC. I was granted access to two of these camps by FARC leadership who could only be contacted through intermediaries initially. All participants had been provided information and consent letters in Spanish that outlined the project, and informed them that although no names or group affiliations would be used, they could be potentially recognisable in exhibited and published photographs. For their participation they would each receive one of their exhibition prints. This was a portrait that was to be made with their creative input.

Photographers make a number of subjective choices when deciding to take a photograph. The first being the decision as to what is worth photographing. Framing or composition is one of the key decisions faced by a photographer. The inclusion or omission of elements within the frame influences the potential reading of an image through the photographer's decisions of what, where, and how. Combined with the choice of focal length, depth of field, camera angle, and lighting, these choices provide a connotative element. Allowing those in front of the lens the choice of what, where, and how, in the construction of their own image provided a greater context in which to interrogate ideas of memory, historical identity, and ideology. The shift of agency from photographer to participant allowed them to assert themselves artistically and 
intellectually in the process. A shift from traditional photographer-centric documentary photography to a self-realised representation by participants is not a new idea. This participatory method to give interpretive control to the lives being represented has its origins within what is called PhotoVoice, defined by Wang and Burris (1997), as “a process by which people can identify, represent, and enhance their community [by entrusting] cameras to the hands of people to enable them to act as recorders, and potential catalysts for change" (p. 369). PhotoVoice typically has the participants take the camera home, and the resultant images become a discussion within the community. Though not strictly an example of PhotoVoice, the approach of assisted self-portraiture used here enables those pictured to decide what, where, and how in the construction of their own image. Participants would first settle on a location they found memorable or significant, such as the Universidad Nacional de Colombia (National University of Colombia), which is a symbolic location for guerrillas in Colombia because of the decidedly left-wing ideological underpinnings of the institution. Participants in the reintegration camps often chose to be photographed in front of murals of their heroes.

\section{The Productive Aspects of Recordando Excombatientes}

On location, I worked with an interpreter, and before the photography began they were interviewed in Spanish about their lived experiences, and their hopes for the future. After the interview, participants were shown examples of prints made from the film to be used to give an idea of the resultant aesthetic, and the photographic process was explained. A significant aspect of methodology requires a selection of film and equipment that can best communicate the convergence of the technical, conceptual and theoretical aspects of a project. For this, I chose to use two different kinds of photographic film: calotype and colour negative. The calotype is a negative and positive process invented by William Henry Fox Talbot in the 1840s that uses a paper negative to make a print with a much softer, less sharp image than possible with modern cellulose acetate based negatives available today. As the image is retained in the fabric of the paper rather than on the surface like modern film, the paper fibers become evident on the printed photographs. The calotype film was chosen because it is evocative of $19^{\text {th }}$ century photographic aesthetics. Although the modern Colombian conflict is often considered to have begun in the late 1940s, the conditions for 
the conflict can be traced back to the 1840s with the Guerra de los Supremos (War of the Supremes), a civil conflict caused by ambitions of various regional leaders to seize control of the country and depose of then President José Ignacio de Márquez; a pattern of civil conflict emblematic of Colombia's history to this day. The use of this film is intended to be redolent of the historical preconditions of the modern conflict, as well as suggestive of the country's exceedingly long history of internal violence. An added benefit of calotype film lies within its inherent lack of clarity, and obscuration of detail that can function as metaphor for the historically problematic memorialisation of the conflict. The resultant images also make participant identification difficult. The film is an orthochromatic film that is made by the coating of silver halide crystals, which being blue-sensitive tends to overexpose blue skies, and render reds as black, often leading to very high contrasts. In addition, a slow film speed of ISO 25, when typical daylight film is rated at ISO 100, and a hypersensitivity to exposure and development times meant that each photo was bracketed to three or four different exposures for a singular pose. The participant was also photographed using ISO 400 colour negative film, which operates well in low light as well as sunny conditions, as a contingency against poorly executed calotypes.

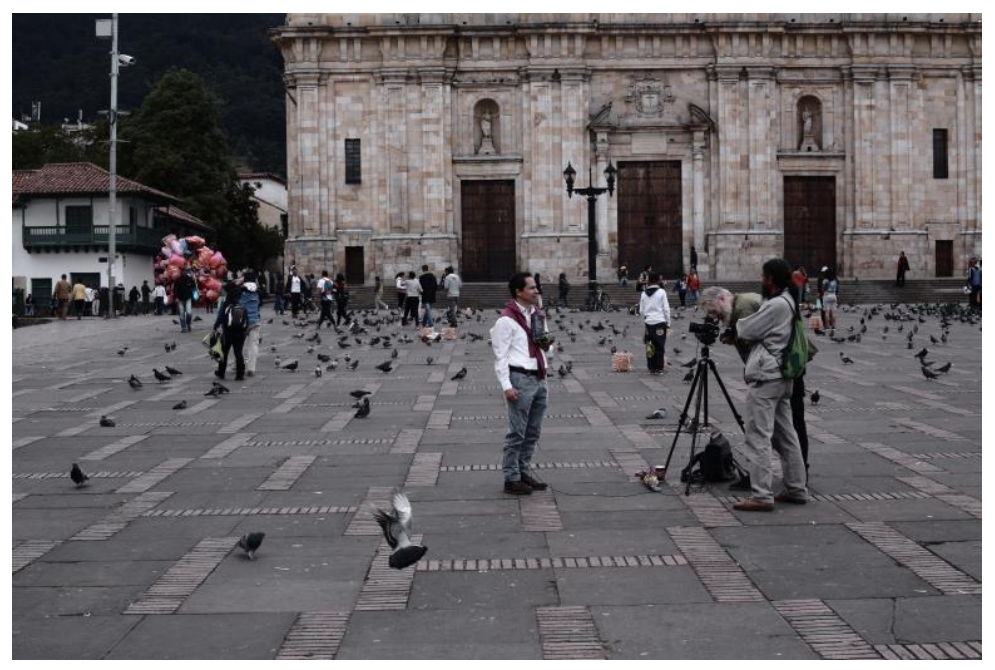

Figure 26. Caneva Akle, D. (Photographer). Assisted portraiture. (2017). [Photograph] Courtesy of the artist

The participants were photographed using a Hasselblad medium format camera, chosen for both its large and bright viewfinder to better preview images, and its associated $6 \mathrm{~m}$ long shutter cable release, mounted on a tripod (figure $26 \& 27$ ). My role here was solely to take 
care of the technical aspects of focus and exposure, which are mostly predetermined by the film's limitations. The depth of field, the zone of acceptable sharpness within a photograph that will appear in focus, was dictated by the low film speed of the calotype film at ISO 25 , which limits the image to a shallow depth of field.

At times, the slow film speed required shutter speeds of more than a second, because of the innate low light limitations of the film.

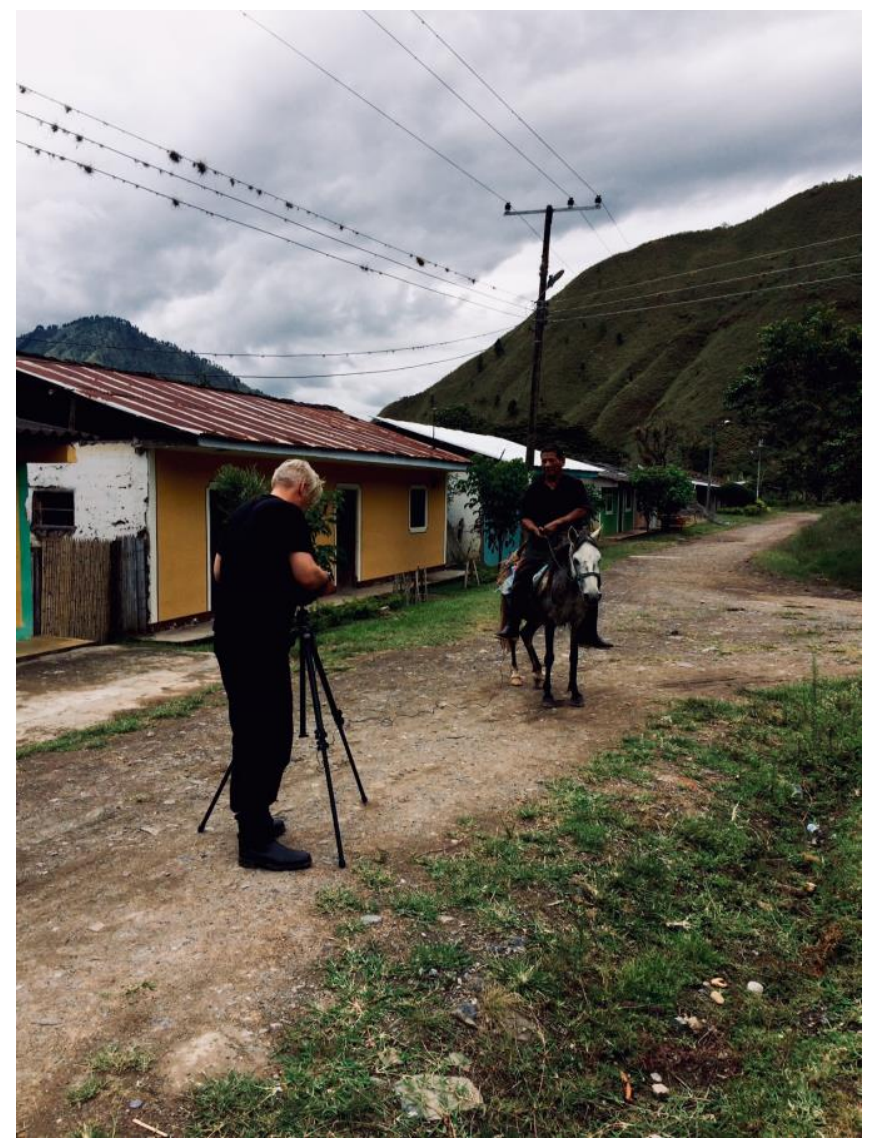

Figure 27. Galvis, G. (Photographer). Assisted portraiture. (2018). [Photograph] Courtesy of the artist

As part of portraiture, composition is an essential element in regards to how the image is framed, scaled, and the relationship of elements to each other and to the edge of frame. Here I found that participants followed general conventions of portrait photography that typically place the subject in the centre of the image. This was not unexpected, as the tropes of portraiture photography are well known, however, what was not expected was for one participant to choose to be photographed naked in the jungle. Arguably costume is 
symbolic, and it is important to note that the nude as a conventionalised type may be considered as an example of costume. This participant also chose to be pictured holding a backpack he had made as part of his training as a young man in the group. Some participants dressed in their everyday clothes, while others, both men and women, dressed up for the occasion. Even though participants had been informed that they would be deidentified in the images, some chose to either pose in front of murals, or hold objects that were symbolic of their struggle, and the armed group they formerly belonged to. There is a noticeable pride in how all participants project and represent their identities, and it was only during the interview stage when participants recounted those lost to the conflict that their trauma became evident.

\section{The Convergence of Method and Editing}

Editing forms an integral part of the creative process. In this project the editing process essentially took place in the viewfinder as participants decided what to include and exclude within the frame. As mentioned above, the camera's large focusing screen allows for effective image evaluation, as the focusing screen is the same size as the negative surface $(56 \mathrm{~mm} \times 56 \mathrm{~mm})$ for both types of film used. This camera also uses a waist level finder that allows two-eyed image evaluation. This allows the user to perform a more complete and effective evaluation of the image, observing more detail, with both eyes open: similar to viewing a small print. The participant would look through the viewfinder as someone stood in the approximate position and pose that they desired. After I had focused the camera, and set exposure parameters, the participant would use the cable release to take their own image. Given that each participant only took bracketed shots of a singular composition for both the calotype and colour negative film, there was no intervention on my behalf in postproduction selection. The image chosen was the one that was taken, and therefore the subsequent frame to be printed was solely chosen on its technical merits. The resulting images for exhibition and the book were neither cropped nor manipulated beyond what was necessary for a correctly exposed print. 


\section{Exhibiting the Work in Colombia}

During my time in Colombia the work was exhibited a total of four times. The first as part of a neighbourhood art festival known as Circuito Armenia in Barrio Armenia, Bogotá, and the second a solo exhibition at Galeria Crispeta in Chapinero, Bogotá (figure 28), both held in September 2018. The next exhibition was part of group show for FORMEMOS MEMORIA: Conversaciones y Manifestaciones Artísticas como Estrategias de Reparación Simbólica y No Repetición (FORMING MEMORY: Conversations and Artistic Manifestations as Strategies for Symbolic Reparation and Non-repetition) held at Universidad Distrital Francisco José de Caldas in Bogotá by the Faculty of Visual Arts from May 2019 to June 2019 (figure 29). And the last exhibition took place at Centro de Memoria, Paz y Reconciliación in Bogotá (Centre of Memory, Peace and Reconciliation) (figure 30), a memory museum that honours the victims of violence and war from October 2019 to November 2019. It was during this last trip that I was able to present most of the participants with one of the exhibition prints, however, some of the participants could not be reached, and the remaining photographs were held in Colombia awaiting collection (figure 31).

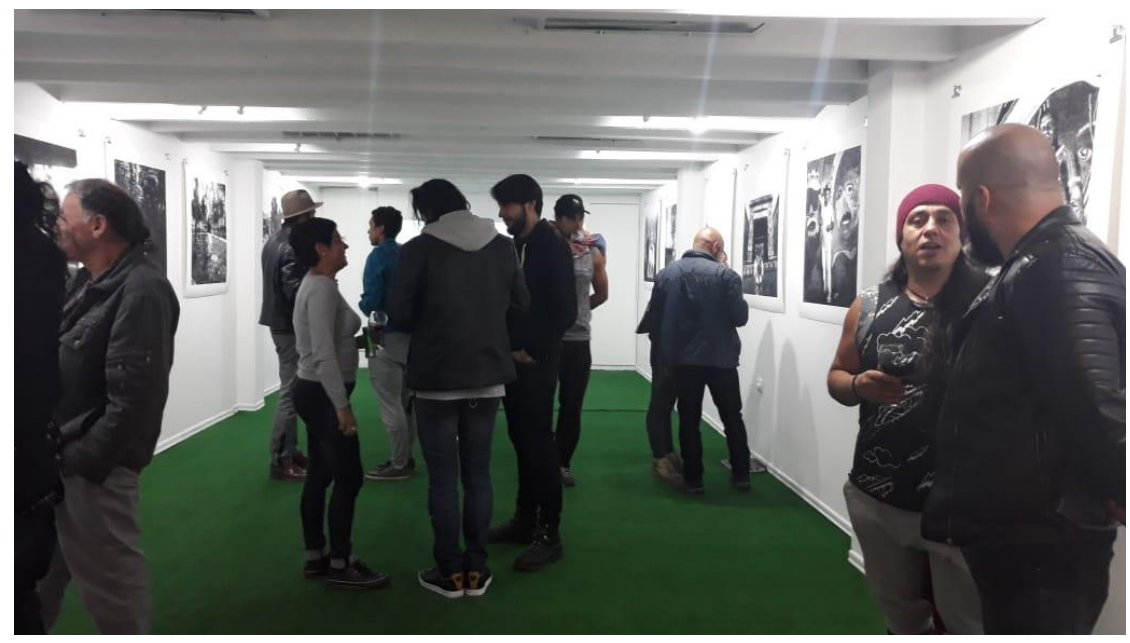

Figure 28. Caneva Akle, D. (Photographer). Recordando Excombatientes opening at Galeria Crispeta. (2018). [Photograph] Courtesy of the artist 


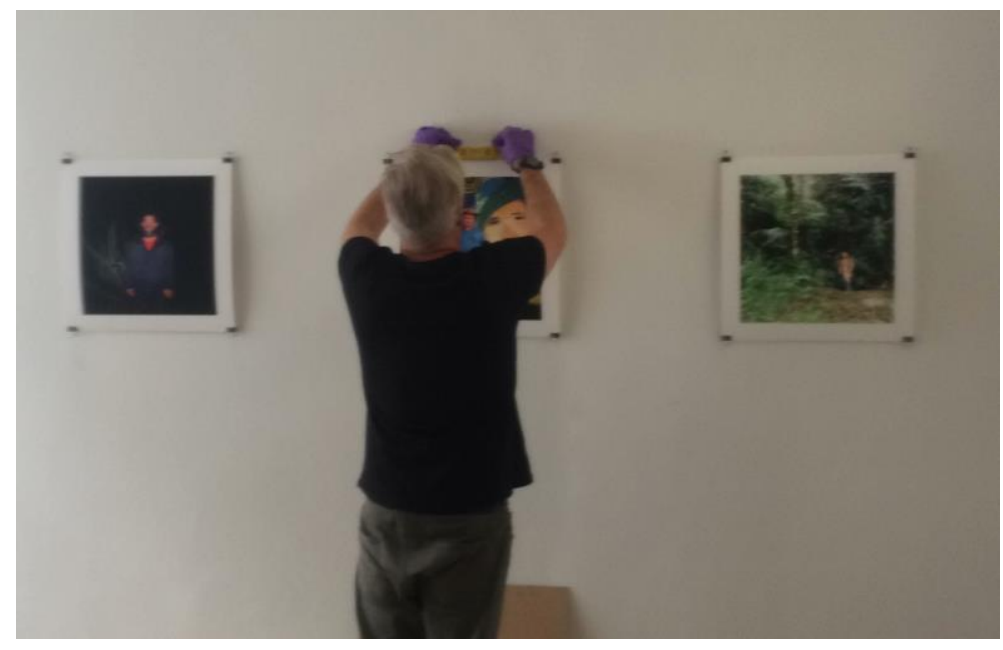

Figure 29. Caneva Akle, D. (Photographer). Installation of artwork at Universidad Distrital Francisco José de Caldas. (2019). [Photograph] Courtesy of the artist

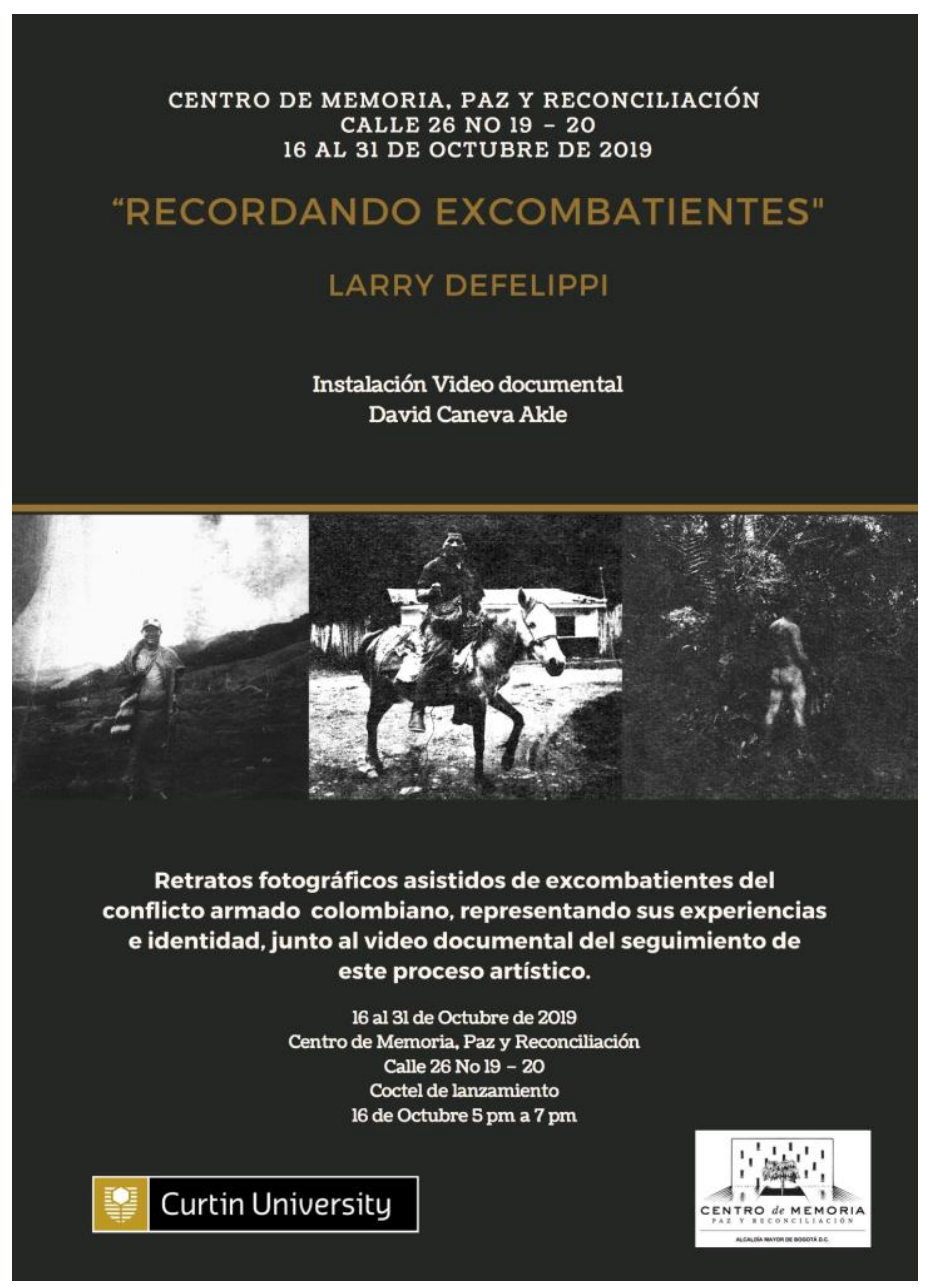

Figure 30. Postcard for Recordando Excombatientes at Centro de Memoria, Paz y Reconciliación in Bogotá, 2019. 


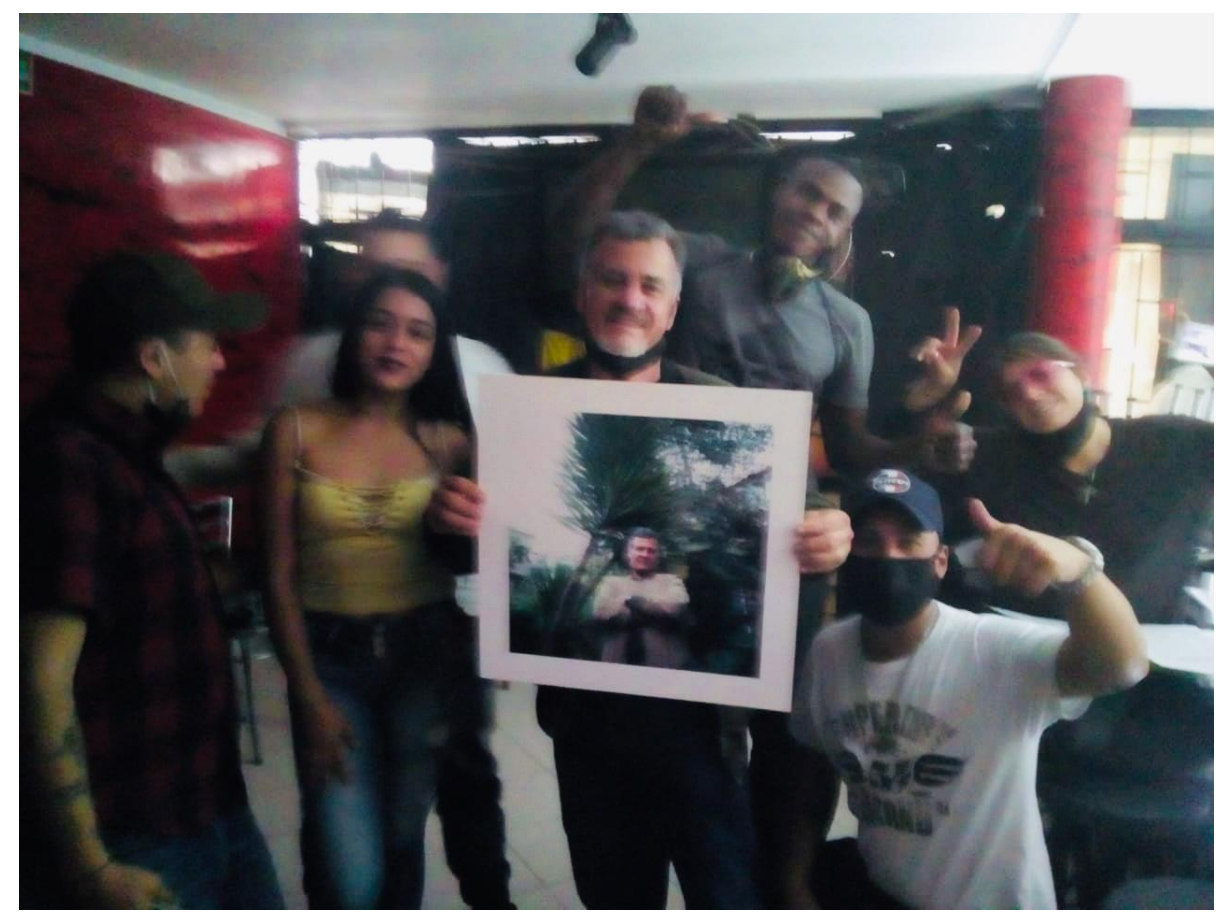

Figure 31. (Unknown photographer). Participant receives a copy of their exhibition print. (2021). [Photograph] Courtesy of the participant 


\section{Appendix B}

\section{Chronology of an Intractable Conflict}

The Colombian conflict provides important context here. However, given its long history of political violence, the conflict in its entirety will not be discussed at length. The vast and diverse Colombian landscape has been the stage for several rounds of violent political upheaval, as the country has experienced nine civil wars since its foundation in the early nineteenth century (Steele, 2017). However, the chronology of the Colombian conflict detailed here will only focus on the conflict as it occurred in the mid twentieth century to the present day. As discussed throughout the exegesis, modern Colombia's political violence is often traced back to "a notorious period of national slaughter between 1946 and 1958, known as La violencia" (Oslender, 2008, p.78, original italics). An upheaval "generated by the rupture between the nation's two grand political parties bequeathed from the 19th century, the Liberals and Conservatives" (Sherman, 2015, p. 454), and sparked by the assassination of Jorge Eliezer Gaitán in 1948, a liberal party populist. This assassination led to a violent riot known as El Bogotazo, "well inscribed in collective memory through images and narratives dealing with the massacres, and the horrendous tortures and dismembering of bodies that characterised it" (Cabrera, 2009, p. 203). This triggered a decade of bloodletting as political parties in Bogotá feuded while the countryside degenerated into cycles of vicious retributory killings that continue to this day.

\section{6}

Violence erupts in the countryside between followers of the Conservative Party and the Liberal Party over land ownership.

\section{8}

The assassination of the left-wing Mayor of Bogotá, Jorge Eliécer Gaitán, leads to a period of civil strife known as La violencia that lasts until 1957. An estimated 250,000 300,000 people are killed. 
Liberal peasants organise self-defence groups against those responsible for violent land grabs. The chaos that followed La violencia, particularly the violent seizure of land by the Pájaros, a conservative paramilitary group, gave rise to Marxist peasant defence groups which led to the emergence of a peasant based left wing insurgency (Brittain, 2009). The landowning elites recognised the threat posed by the existence of peasant based defence groups, and realised "they were not a sign of relative equilibrium in the class balance, but a manifestation of class struggle. Particularly, as these groups began to present a defensive front against the state sanctioned violence of landowning elites with the creation of autonomous self defence communities that were able to resist the military. Consequently, a plan of aggression against these zones began to be elaborated [...]" (Brittain, 2009, p. 11).

\section{8}

The Liberal and Conservative Parties agree to share power in a negotiated peace. This arrangement is called the National Front and lasts for 16 years. The two parties alternate in power; all other political actors are excluded. The Liberal - Conservative violence is contained but there is renewed struggle by the excluded groups.

\section{4}

The government bombs the Marquetalia Republic, a rural enclave held by communist peasant guerrillas during the aftermath of La violencia, to eliminate an independent republic. The offensive receives the assistance of the U.S military, which allegedly presents the opportunity to evaluate napalm. Some of the survivors reunited elsewhere and later became part of the Bloque Sur (Southern Bloc) guerrilla group in 1964, a precursor to the official foundation of the FARC two years later.

\section{6}

The Fuerzas Armadas Revolucionarias de Colombia (FARC) (Revolutionary Armed Forces of Colombia) is founded, becoming the leading guerrilla threat to the Colombian state. A second guerrilla group, the Ejército de Liberación Nacional (ELN) (National 
Liberation Army), emerges following Cuban-style foco theory. Ejército Popular de Liberación (EPL) (Popular Liberation Army), a third guerrilla group inspired by Maoism is formed. Both the ELN and EPL have currently active members.

Liberal President Carlos Lleras Restrepo orders the destruction of the archives of La violencia in an attempt to erase the painful past.

1970

Formation of the left-wing guerrilla group M-19 (Movimiento 19 de Abril / 19th of April Movement). The M-19 traced its origins to the allegedly fraudulent presidential elections of 19 April 1970, in which former President Gustavo Rojas Pinilla was denied electoral victory. The M-19 demobilise in 1990.

\section{4}

On March 28, conservative president Belisario Betancur Cuartas had peace talks with the FARC under a bilateral truce. The initiative broke down in 1987 after right-wing paramilitaries assassinate a presidential candidate from a party allied to the FARC. Further peace efforts collapse in 1991 and 2002. Since the 1980s, there had been "a strategic attempt $[\ldots]$ to paint the FARC as an ideologically empty political-military organization [and] embellish, without credible evidence, the insurgency's relation to the coca industry" (Brittain, 2009, p. 89). Likewise, it has been suggested that the FARC's longevity cannot be explained by a relation to the drug trade, but rather to historic conditions of exploitation and inequality (Molano, 2000).

Movimiento Armado Quintin Lame (MAQL) (Quintin Lame Armed Movement) was also founded in 1984 as an indigenous guerrilla movement that operated in the department of Cauca, a province in south central Colombia that is approximately $40 \%$ indigenous. MAQL was initially formed as a movement to defend indigenous communities from hostile attacks from landowners, paramilitaries, the military, and other guerrilla movements. The MAQL demobilised in May 1991. 
On November 6, 1985, the guerrilla group M-19 stormed Colombia's Palace of Justice and held all 25 of the country's Supreme Court justices and hundreds of civilian hostages. The palace was retaken by the army using heavy weapons during a 27 hour battle that left the palace in ruins and more than 100 people dead, including several judges.

The Unión Patriotica (UP) (Patriotic Union), the political arm of the FARC, is founded to seek political power. The UP wins 14 political posts in 1986 and, within a month, three of its legislators are assassinated. (Within a decade, 3,000 UP activists are killed, decimating the movement.)

\section{6}

Drug traffickers subject to extortion and kidnappings by insurgents form their own defence groups with the acquiescence of the military. The military, in turn, use their legal right to arm civilians and form paramilitary groups as a counterinsurgency strategy.

The self-defence groups and the paramilitaries carry out massacres against union members and civilians accused of supporting the guerrillas. In discussing the role of paramilitary groups, Grajales states:

Paramilitary groups are pivotal in the protection of their allies' property rights against landless peasants' demands and rebel movements threats. Moreover, they participate in processes of spoiling, using violence and corruption to accumulate rural land. Their role in securing some people's property rights and denying others is not merely extra-institutional [...] [but] supported by large bureaucratic and political networks that allow the legalization of profits from violence. (p. 771)

This mission to maintain power and privilege, and to further enrich oneself by the corrupt and violent acquisition of land, is described by Hristov as "the heart that keeps the war alive" (2009, p. 202).

\section{6}

The Mondoñedo massacre took place on September 6 and 7, whereby four students from the Francisco José de Caldas District University of Bogotá, members of the Patriotic 
Union (UP) at the time, were abducted and murdered by the police. Two further murders of alleged urban guerrilla members by the government were included as all those killed were alleged FARC.

1997

The paramilitary groups form a federation led by Carlos Castaño and funded by his drug trafficking activities. It is called the Autodefensas Unidas de Colombia (AUC) (United Self-Defence Forces of Colombia). The group was a consolidation of numerous paramilitary groups that used tactics such as kidnappings and assassinations that led to a sharp increase of the forced displacement of civilian populations in the countryside.

2000

The Clinton Administration proposes a $\$ 1.3$ billion dollar military aid package for the Andean Region, and Congress approves this package. Plan Colombia receives $\$ 860$ million, mostly for military and police activities. The plan commences with the training of Colombian soldiers by U.S. Special Forces. In an article discussing American involvement, Avilés (2001) examines Colombian military policy in the late twentieth century, particularly Colombia's political and military relationship with the United States. Avilés argues that the "landowning elites and the United States have penetrated the state, the power structure of the state, and restrained the decision- making powers of elected officials" (p. 32). Similarly, Palacios (2006) argues there is a marked international involvement with the wars on drugs and terror directed externally by American policymakers having strategic influence within Colombia.

$2003-2006$

The government of President Álvaro Uribe began talks with the AUC with an aim to eventually dismantle the organization and reintegrate its members to society. In 2006, approximately 30,000 AUC demobilised. Since this demobilisation in 2006, however, individuals and small groups have carried out attacks claiming to be the AUC. Furthermore, while some 30,000 paramilitaries demobilised, many remained at large or abandoned the process and have since been implicated in serious human rights 
violations, drug trafficking, extortion, kidnappings and numerous other criminal acts that continue to the present day.

2005

President Álvaro Uribe Vélez sets the Justice and Peace Law that reduces punishments for guerrilla and paramilitary members if they surrender their arms, renounce violence, and return illegal assets.

2007

The AUC mutually benefited from extensive ties to Colombian lawmakers and public officials, and these connections between the paramilitary group and several congressmen came to light, creating the parapolítica (para-political) scandal, resulting in the conviction of dozens of congressmen and hundreds of public officials with proven ties to the AUC. The scandal became a prominent aspect in Colombian politics, with politicians at all levels of government accused of using paramilitary support for political gain and benefits.

2008

Falsos positivos (False positives) scandal, in which the government and army is accused of colluding in the murder of up to 6000 civilians who were then presented as guerrillas killed in combat.

2010

In June, Colonel Alfonso Plazas Vega who led the army assault in 1985 during the Palace of Justice siege was convicted of the forced disappearance of 11 people who survived the raid on the building but were taken away by the army afterward and never seen again.

2011

Alfonso Cano, the top commander of the FARC is killed in a raid by the Colombian army on November 4 . The current leader Timoleon Jimenez, who reaches out to the 
government for peace talks, replaces Alfonso Cano. Two other top leaders, Raul Reyes and Jorge Briceno, were previously killed in 2008 and 2010.

2012

On October 4, the government of President Juan Manuel Santos launches new peace talks with the FARC, weakened by the loss of its top leaders.

2016

On June 23, the FARC and the government sign a definitive ceasefire and disarmament agreement.

2017

The FARC demobilised close to 7,000 combatants. However, an estimated number of more than 2000 members, known as the Disidencias de las Farc (FARC dissidents), refused to demobilise, and remain active to the present day.

2019

Since 1985, government figures reveal that conflict related violence has displaced more than 8.2 million Colombians, out of a population of 49 million. More than 75,000 people were displaced in 2019 (Human Rights Watch, 2021a).

2021

Since the peace agreement signed by the FARC in 2016, a total of 253 ex-combatants have been killed, including four as of mid January 2021 (Aljazeera, 2021).

Furthermore since 2016, over 400 rural human rights activists have been killed in Colombia's remote communities as remaining armed groups fight for control over territory for coca production and other illegal activities (Human Rights Watch, 2021b).

An inescapable fact from this timeline is the longevity of the Colombian conflict. This raises questions about the role culture plays, and Waldmann (2007) addresses this question in an interrogation of the cultural causes of intractable violence. He seeks to 
explain Colombia's persistent violence, and discuss the historical and cultural precursors that permit or facilitate the creation of a violent culture. He arrives at the conclusion that "economic factors alone cannot explain violence; rather, cultural factors must be taken into account" (p. 593). The study identifies the indicators of a culture of violence as "high homicide rates, the existence of institutionalised violent actors, the prevalence of certain norms such as those of the macho and of revenge, and the absence of other norms, taboos, and prohibitive rules" (p. 596). The ubiquity of violence is not conceivable unless a propensity to violence is socio-culturally anchored, and this hypothesis that cultural predisposition to violence exists can be seen as a causal factor. To what extent culture plays a role in violence is debatable, and Waldmann's theorisation of cultural violence, fails to acknowledge the ongoing desire for peace in Colombia via numerous peace initiatives. In more recent years, research on political violence has taken what can be described as a 'processual turn', whereby, instead of focusing on socio-structural conditions ('root causes') or individual predispositions, violence has been analysed as part and outcome of processes of radicalisation and escalation that emerges from strategic interactions between protest movements, militant groups, governments, and security forces, rather than being a mere behavioral response to socio-structural tension or deprivation (Malthaner, 2017).

Given the longevity of the conflict, no discussion about Colombian society seems complete without mentioning the conflict, given the degree to which its "sociocultural structures and symbols ... [connect] with, [produce], and perpetuate violence", and how it "[has made] thinking in terms of friend and foe ... a matter of course [that] permeates social discourse on all social planes" (Waldmann, 2007, p 596 -597). In Colombia, it is suggested:

No urban district, region, or village [exists] without a sworn enmity between two or three main actors, be they individuals, family clans, or organized groups, that shapes the life of society and compels the remaining actors to take sides and fall into line. (p. 597)

This enmity provides some explanation for how sides are chosen. For instance, when interviewed, "most demobilized individuals [AUC] state[d] that they agreed with the paramilitary ideology and that they wanted to fight against the guerrilla for the sake of the country" (Nussio, 2012, p. 374). Similarly, insurgents also joined and fought for 
ideological reasons (Nussio, 2012; Ugarizza and Craig, 2012). With most involved believing that rivals acted negatively, while 'they' were somehow righteous in 'their' fight. The decades long nature of the Colombian conflict has only exacerbated this "socio-psychological basis needed to meet the enormous challenges that an intractable conflict demands" (Nets-Zehngut, 2014, p.105). The result has been a complicated weaving of memory and oblivion, where memories are remembered, omitted, or silenced, and violence has become central in the production of collective identity, where the conflict's continuous but irregular nature have transformed normality (Pécaut, 2003). In the report Basta Ya! (Grupo de Memoria Histórica, 2013), the Grupo de Memoria Histórica (Group for Historical Memory) argues Colombian society's incapacity to confront the war is a symptom of generalised collective trauma, and a normalisation of violence that has led to desensitisation and apathy. Irrespective of the fact that this has been one of the bloodiest conflicts in contemporary Latin America history exacerbated by complex social dynamics, the multiplicity of armed actors, the large number of victims, and the brutality of forced displacement, sexual violence, kidnapping, extrajudicial murders, forced disappearance, massacres, forced recruitment of minors, and terrorist attacks that continue to the present day. 


\section{Appendix C}

\section{Interview With Colombian Artist Libia Posada (English translation)}

The work of Libia Posada (b. Medellín, 1959) arises from the intersection between medicine and art, two disciplines in which she studied at the University of Antioquia in Medellín. She first graduated as a physician-surgeon in 1989, and later completed a degree in Artes plásticas (Plastic arts, otherwise known as visual arts) in 1996. As a physician she has cared for patients suffering physical and psychological trauma from the Colombian conflict including violent crime, narco-trafficking, forced displacement, and epidemic gender violence. Her art, through diverse mediums such as drawing, photography, video, installation and action-research projects in specific communities are collaborative, and responsive to community concerns. The synthesis of these two disciplines through different artistic techniques represents a questioning of the models of thought and action of each one, whereby Libia develops her work in a dialogical exercise between medicine and art to interrogate commonalities amid the two around themes of ethnicity, gender, and class in both clinical and artistic environments. She has exhibited extensively at home in Colombia, and abroad in such countries as Brazil, Chile, Cuba, France, Switzerland, Cuba, the United States, and Venezuela.

Libia Posada was interviewed to specifically discuss her work Signos Cardinales (Cardinal Signs, 2008) on forced displacement, to inform the analysis of this work found in Chapter 3. This interview took place in person at her artist studio in Medellín in November 2017. The interview involved a set of open questions, and was conducted in Spanish. A native Spanish speaker transcribed the audio, whereas I translated the subsequent transcription into English. The interview in the original Spanish can be found in Appendix D.

\section{Let's start by talking about your early life, where were you born?}

I was born in Andes, Antioquia, it is a small town in the southwest of Antioquia, and it is a region where a lot of coffee is traditionally grown. 


\section{What was your experience like growing up in Colombia?}

I come from a peasant family. Both my father and my mother were coffee growers for a long time, then they migrated to the city when I was very little, and basically I grew up in the city, in Medellín, or in towns near Medellín, but I always had contact with the countryside because my vacations were spent with my relatives, with my uncles, on the farms where coffee was grown.

\section{What were your first experiences with art and photography?}

I studied some arts, drawing, some painting while I was in high school. When I was studying medicine, I also studied art in a non-formal way, and then I asked to re-enter the University of Antioquia to study art in a more formal way, let's say that was like an approach to academic training, but I also had training with an external teacher who opened his library for me, and for me it was like a door. I gained a knowledge of art in a disciplined way, and the other part is like one of a lot of self-taught training, a lot of reading, visits to galleries, museums, trips, well, and with photography, photography has been a necessity, it has appeared in my work as an artist, as a necessity. I am not a photographer all the time. I do not label myself as a photographer. I think I am an artist who uses photography when I need it, when I needed it. Sometimes I work with other people who help me. They work on the technical side, that is, they solve any technical problems, but when I feel that a project needs photography, then photography is there.

\section{What do you feel is integral to your work as an artist?}

For me, art has been a tool to think, to understand the world, to survive, it is an exercise in survival, it is an exercise of understanding, it is an exercise of understanding the world, basically also an exercise of communication, of being able to speak with others about issues that interest me. 


\section{What themes do you pursue in your work?}

I have, let's say there are several areas of work, there are some, as I said before. For me art is basically a tool for understanding the world, of reality. In what I do I work on issues that have to do with human beings, concerns that have to do with human affairs, right?

Definitions about what humanity is, what it is to be a human being, about what death is, what life is, struggle, let's say that they occur while one lives through situations that are expressed often in people's bodies as disease. As a doctor, I have to see these types of situations, so when I see, when I face a sick body, I think of the subject who is expressing a situation in this body. That situation or a certain situation has to do with culture, with society, with the historical moment, with the economy, because that disease made a body speak to us about a historical and socio-cultural moment, and that seems to me very important, very interesting. So what I do in my work as an artist, it is like reflecting, producing thoughts, reflections on issues that have to do with how the human is connected, let's say, to a whole series of situations that have to do with the environment.

\section{Where did the project Signos Cardinales (Cardinal Signs) come from? What made it necessary or compelling to do this work?}

Signos Cardinales came about as a result of an invitation to a great project called Destierro y reparación (Exile and Reparation, 2008) an exercise in reflection with sociologists and anthropologists, which also included an art exhibition about the problem of the loss of territories in Colombia, of the dispossession of the lands in Colombia by the war, by the armed conflict. That was done in 2008; it was a great collaboration that took place in the Museum of Antioquia, here in Medellín. I was asked to produce a work and I had already made other maps in other projects as I am very interested in the idea of geography as a representation of human situations, but I am also interested in a geography that returns again. That is let's say backwards, that they turn towards people, that they become compressible maps of human situations. For that project, I was working for several months on the idea of territory, of the earth, of what the loss of land means, what the conflict over land means, and dispossession, and after a lot of work, with a significant number of ideas I came to this project of Signos Cardinales. I wanted to work on the idea of the earth, to arrive at the idea that the earth is also a body and that the body is also territory, and that the 
body is a territory that moves over another. In that it is a territory that transits over another territory, that affect each other, and has a close interdependent relationship in that the territory cannot be affected without affecting people, and that people cannot be affected without affecting the territory. That there are differences between territory and land, that for the people who live in the countryside, which have lost their arable land, this also contributes to a loss of their identity. Because it is not a piece of land, it is not a piece of territory, for those who see it solely as an economic interest, a fragment of territory for exploitation, but for the people who originally owned the land, the peasants, the land is part of their vital structure. Their corporeality, even then, let's say from reflections with this line of thought, the idea that one cannot speak of territory but speak of the body was born according to this perception. At the time I was seeing many figures that appeared in the press, we were already talking about forced displacement and there were millions, so many millions of displaced people but the people were invisible, and one of the intentions of the work was to make the bodies visible behind the numbers. Because in medicine it happens a lot in how many statistics are handled. The many figures and the human situations that gave rise to those figures disappear behind the figure. This is a paradox because there is human suffering that generates these figures and that suffering is erased behind the figures. The numbers end up being more important figures than the people, so I wanted to make people look at the bodies that were behind those figures, such as the people, the human beings, the suffering that was being experienced, that was already appearing in hospitals as individuals made unwell. I think such trauma is not individual but informative about a group and a society when it appears. I came to this project to think about the body, to think about the idea of the portrait, to make some portraits, to also question the idea of the portrait, to wonder what a portrait was, and how to do portraits of the displaced, of the dispossession of the lands. I also question the idea of the portrait because that typically will start from the head along the body and reach the feet. If there is someone who is mobile, who can traverse territory, it is because they have legs and feet. Before I had also done a project called Lección de Anatomía (Anatomy Lesson, 2005) where we talked about the loss of legs due to anti-personnel mines. For that project then I had already thought how the war changed bodies, modified them, that those bodies were being modified in Colombia because of the many anti-personnel mines that were appearing in the territories, and that polluted, 
poisoned, mined geography undermines the bodies, damages them, deteriorates them, and mutilates them. At the time, I had already been thinking about the loss of legs, and with that line of thought and the need to make portraits based on people's forced displacement, I thought that legs should tell the story of those displacements. I was also thinking about the idea that when you travel you make maps, you draw routes, but when these people travelled through displacement, they drew routes with their own bodies, routes guided by fear, by the need to save lives, routes that no one knew, routes that they discovered while traveling. This project of the maps, of the history of each person, of the travel route of each person from the moment they had to leave their original home, where they had everything, the trees, the river, the landscape, their identity preserved, when that is all lost, they begin to make random paths, guided by fear, and finally they end up living in Medellín. Then each map is the story of that person, but the story of that person is also the story of millions of people past, and that is why no faces appear, only legs appear, as if they were of anonymous people. Because they really represent the millions of people who have been displaced from this country.

\section{How did those who were represented in Signos Cardinales feel about the project?}

I found people with the help of an anthropologist here in Medellín. I would propose the project to those displaced. Participants chose to take part voluntarily. The project is not only the photography, but included many encounters, first with each person, individually. We worked a lot on the idea of the trip, not on the idea of recreating the violent events, but on the idea of the trip, and on the idea that the trip they had made was a heroic journey, a historical journey, a journey that no one else had made. They had made maps, and they had drawn a geography, which was an absolutely real geography, but one not in book. It is another geography, the geography of others, and that in tracing that geography their bodies had lost all their identity, and they were now only victims with a number. Those bodies were very important, the bodies of heroes, the body of the survivors, so they work on that idea, and for them it was very important. The photographs took place after several conversations, workshops, and preparation for the lines, a tracing session, and drawing on the legs, all prior to the photography session. Going to a photography studio was a very important place, which they had never visited, then seeing their legs in the museum in a 
significant exhibition, taking their children, their nephews, their grandchildren, for them that was very important. What they told me was that they did not know that they were important, and that their feet, so ugly, so abused, so dirty, were so important. Well, there is a kind of conscience that the project achieves in them at a certain level, a certain sense of pride, not of shame, because in addition to being displaced they had been made to feel ashamed. Because to be displaced is to be a thief, a criminal, a pejorative figure, but here they could feel proud and feel heroic.

\section{How do you feel this work has contributed to the expanding social memory work being done in Colombia?}

I have not thought too much about it, because I do what I do, and exhibit. But actually this project has been published in several books since it was exhibited for the first time. Numerous sociologists and anthropologists, who had extensively studied displacement, have seen it. For them it was important because they thought that this project provided images that had been able to picture what they wrote, such as the image of what forced displacement, and what displacement due to war can look like. So the project has been published in several different studies in sociology and anthropology, and used by different researchers, not only in the field of art, but let's say, it has become a project that has persisted. Which is, let's say, they are recurring images when thinking about the Colombian conflict and its consequences, these images from Signos Cardinales are often used, but I also think that in that sense, it has contributed to making memory in the various memory projects in which they have appeared.

\section{What role does the artist have in Colombian society?}

I do not know, I think that the voice of the artist is another voice; it is not a single voice. In the case of my work, it interests me, because of what happens to people, and how the situations that happen in the country affect people. In that sense I think that my work contributes to the discussion, contributes thoughts, and contributes to reflections on the different situations represented by the project. If it is the case for example about the issue of traditional botanical medicine, and how this knowledge is being lost, or how it is in danger of being lost through social inequalities, or in the case of Signos Cardinales, the issue of 
displacement and unofficial geographies, or the problem of antipersonnel mines that we have in this country, or another project such as Evidencia Clínica (Clinical Evidence, 2006) that has to do with gendered violence, so I think that, in each of the projects in which I get involved, I am reflecting on situations that are real and that concern us as a society, not only for Colombian society, but as something that transcends even Colombian borders.

\section{How do you feel your work comments on current social or political issues in}

\section{Colombia?}

It is current, it is as if it had been done today, because this project has not aged, because the situation continues, the situation has not been fixed; the situation has not been solved. At this time that we are in the peace process, there is a large amount of displacement. There are many people who are being displaced; there are many people who are being dispossessed of their territories. There is a great conflict over the land, these are lands that were stolen and those who took them don't want to return them. The problem of displacement, the problem of these atrocious horrifying geographies, like the geographies of horror, of the pain of trauma, they are here, then the project is current, it is still current, although I did it in 2008, it remains fully current. 


\section{Appendix D}

\section{Entrevista a la artista colombiana Libia Posada (Interview With Colombian Artist}

Libia Posada) (Spanish transcription)

\section{Comencemos hablando de tu vida temprana, ¿dónde naciste?}

Yo nací en Andes, Antioquia, es una pequeña población del suroeste de Antioquia, es una región donde se cultiva tradicionalmente mucho café.

\section{¿Cómo fue tu experiencia al crecer en Colombia?}

Yo vengo de una familia campesina. Tanto mi padre como mi madre, fueron caficultores por mucho tiempo, después migraron a la ciudad, cuando yo estaba muy pequeña y básicamente crecí en la ciudad, pero en Medellín, o en poblaciones cercanas a Medellín, pero siempre tuve contacto con el campo porque mis vacaciones las pasaba donde mis familiares, donde mis tíos, en las fincas donde se cultivaba café.

\section{¿Cuáles fueron tus primeras experiencias con el arte y la fotografía?}

Yo estudié mientras estaba en mi secundaria. Estudiaba algo de artes, dibujo, algo de pintura, luego mientras estudiaba medicina, estudié primero medicina, estudiaba también arte de una manera no formal, y luego pedí reingreso a la universidad de Antioquia para estudiar arte de una manera más formal, digamos eso fue como el acercamiento a una formación académica, pero también tuve formación con un profesor por fuera quien me abrió su biblioteca y para mi fue como una puerta. Digamos, el conocimiento del arte de una manera más seria y la otra parte es mucha formación autodidacta, mucha lectura, visitas a galerías, a museos, viajes, bueno, y con la fotografía pues la fotografía ha sido una necesidad, ha aparecido en mi trabajo como artista, como una necesidad. Yo no soy fotógrafa todo el tiempo. No me rotulo a mi misma como fotógrafa, creo que soy una artista que usa la fotografía cuando la necesita, o cuando la necesitaba. Algunas veces soy yo quien toma las otras personas que me ayudan en la parte técnica, o sea que me solucionan como problemas técnicos, pero cuando siento que un proyecto necesita la fotografía pues ahí está la fotografía. 


\section{¿Qué crees que es parte integral de tu trabajo como artista?}

Para mí, el arte ha sido una herramienta para pensar, para entender el mundo, para sobrevivir, es un ejercicio de sobrevivencia, es un ejercicio de comprensión, es un ejercicio de entendimiento del mundo, básicamente también un ejercicio de comunicación, de poder hablar con otros acerca de asuntos que me interesan.

\section{¿Qué temas persigues en tu trabajo?}

Yo tengo, digamos hay como varias áreas de trabajo, hay unas como decía anteriormente.

Para mí, el arte es básicamente una herramienta de comprensión del mundo, de la realidad. Yo en lo que hago trabajo asuntos que tienen que ver con los seres humanos, preocupaciones que tienen que ver con asuntos humanos, ¿cierto? en definiciones sobre lo que es la humanidad, un ser humano, sobre lo que es la muerte, lo que es la vida, los combates, digamos que se dan mientras uno vive, situaciones que se expresan muchas veces en los cuerpos de las personas como enfermedad. Como médica, me toca ver este tipo de situaciones, entonces cuando yo veo, cuando me enfrento a un cuerpo enfermo, pienso en el sujeto que está expresando en su cuerpo una situación. Esa situación equis o una situación determinada tiene que ver con la cultura, con la sociedad, con el momento histórico, con la economía, pues esa enfermedad hecha cuerpo nos está hablando es de un momento histórico, y socio-cultural, y eso a mi me parece muy importante, muy interesante. Entonces lo que yo hago en mi trabajo como artista, es como reflexionar, producir pensamientos, reflexiones sobre asuntos que tienen que ver con lo humano y lo humano está conectado digamos a toda una serie también de situaciones que tienen que ver con el entorno.

\section{¿De dónde surgió el proyecto Signos Cardinales? ¿Qué hizo necesario o convincente realizar éeste trabajo?}

$\mathrm{Si}$, Signos Cardinales surge a raíz de una invitación a un gran proyecto que se llama: “Destierro y Reparación” un ejercicio de reflexión con sociólogos, antropólogos, que tenían también un componente expositivo de arte acerca del problema de la pérdida de los territorios en Colombia, del despojo de las tierras en Colombia por la guerra, por el conflicto armado. Eso se hizo en el 2008, fue un gran encuentro que se hizo en el museo de 
Antioquia, acá en Medellín. A mi se me comisionó una obra, y yo pues ya había hecho otros mapas en otros proyectos porque me interesa mucho la idea de la geografía como representación de situaciones humanas, pero me interesa mucho la idea de la geografía como representación de situaciones humanas, pero me interesa también una geografía que vuelva otra vez hacia atrás, que se vuelva hacia lo humano, que se vuelvan mapas compresibles de las situaciones humanas. Entonces para ese proyecto yo estuve trabajando varios meses sobre la idea de territorio, de la tierra, de lo que significa la pérdida de la tierra, de lo que significa el conflicto por la tierra, el despojo y después de mucho trabajar, pues digamos alrededor de una cantidad importante de ideas fui llegando a este proyecto de Signos Cardinales.

Escogí trabajar pues cuando tuve claro que quería trabajar sobre la idea de la tierra, llegar a la idea de que la tierra también es cuerpo y el cuerpo es tierra, que el cuerpo es territorio, que el cuerpo es un territorio que se desliza sobre otro, que es un territorio que transita sobre otro territorio, que se afectan mutuamente, que tienen una relación de estrecha interdependencia, que no se puede afectar al territorio sin afectar a la gente, y que no se puede afectar a la gente sin afectar el territorio. Que hay diferencias entre territorio y tierra, que para la gente que vive en el campo, la gente que ha perdido la tierra, sus tierras cultivables pierden también la identidad. Pues no es un pedazo de tierra, no es un pedazo de territorio digamos para alguien que no ve, sino un interés económico en la tierra puede ser simplemente un fragmento de territorio que necesita para transitar, pero para las personas que son propietarios de la tierra, los campesinos, por ejemplo, la tierra es parte de su estructura vital. Entonces de su corporalidad, incluso, entonces nace digamos de reflexiones a estas con esa línea de pensamiento la idea de que no se puede hablar de territorio sino hablar de cuerpo, según mi percepción. Yo estaba viendo en ese momento muchas cifras que aparecían en la prensa, ya se estaba hablando de desplazamiento forzado y aparecían millones, tantos millones con números, cifra de personas desplazadas pero las personas eran invisibles, entonces yo, pues una de las intenciones del trabajo era como hacer visibles los cuerpos detrás de los números. Porque en medicina pasa mucho que se manejan muchas estadísticas. Muchas cifras y las situaciones humanas que dieron origen a esa cifra desaparecen detrás de la cifra. Es como una paradoja porque hay un sufrimiento humano 
que genera cifras y ese sufrimiento se borra detrás de las cifras. Terminan siendo más importantes los números, las cifras que las personas, entonces yo quería hacer ver buscar los cuerpos que estaban detrás de esas cifras, como las personas, los seres humanos, el sufrimiento que realmente se estaba viendo, ya estaba apareciendo en los hospitales como enfermos, pero la enfermedad pienso yo que no es individual, sino que siempre nos habla de un colectivo y de una sociedad. Entonces aparece, pues aparece no, voy llegando decantando, resumiendo, sintetizando y llego a este proyecto a pensar en el cuerpo, a pensar en la idea del retrato, de hacer unos retratos, de cuestionar también la idea del retrato, de preguntarme ¿qué era un retrato?, ¿cómo podría yo hacer retratos del desplazamiento, del despojo de las tierras? Y cuestiono también la idea del retrato porque eso va a bajar desde el rostro a lo largo del cuerpo y llego a los pies. Si hay alguien que se desplaza o si hay alguien que puede desplazarse, es porque puede desplazarse porque tiene pies y tiene piernas. Pero antes había hecho también un proyecto que se llama "Lección de Anatomía" donde hablaba de la pérdida de las piernas por las minas antipersonas, por unas minas. Entonces había pensado ya en que la guerra cambiaba los cuerpos, los modificaba, que esos cuerpos no habían podido ser modificados que se estaba modificando la anatomía humana en Colombia porque estaban apareciendo muchas minas antipersonas en los territorios, en la geografía, y esa geografía como contaminada, envenenada, minada, minaba los cuerpos, los daña, los deteriora, los mutila.

Entonces, yo ya venía pensando en la pérdida de piernas, y sigo como un poco en esa línea de pensamiento y aparece la necesidad de hacer unos retratos basados en las piernas de las personas, y esas piernas debían contar la historia de esos desplazamientos. Estaba pensando también en la idea de que cuando uno viaja hace mapas, traza rutas, pero estas personas cuando viajaron por el desplazamiento, trazaron rutas con sus propios cuerpos, rutas guiadas por el miedo, por la necesidad de salvar las vidas, unas rutas que nadie conocía, unas rutas que inventaron mientras viajaban. Entonces, surge todo este proyecto de los mapas, de la historia de cada persona, de la ruta de viaje de cada persona desde el momento en que tiene que abandonar su casa originaria, donde tenía todo, los árboles, el río, el paisaje, la identidad preservada, cuando pierde todo eso y empieza a hacer caminos azarosos, guiados por el miedo, y termina viviendo en Medellín, entonces cada mapa es la 
historia de esa persona, pero la historia de esa persona es la historia de millones de personas atrás, por eso no aparecen los rostros, aparecen las piernas, como si fueran de personas anónimas, porque representan realmente millones de personas que han sido desplazadas de este país

\section{¿Cómo se sintieron los representados en Signos Cardinales sobre el proyecto?}

Encontré a la gente con la ayuda de una antropóloga aquí en Medellín. Ellos estaban recibiendo asesoría legal, en torno al desplazamiento, yo voy, les propongo el proyecto cuando ya lo tengo pensado, ellos deciden participar voluntariamente. Cuando el proyecto no son sólo las fotografías, sino que tuvimos muchos encuentros, primero con cada persona, individualmente. Trabajamos mucho en la idea del viaje, no en la idea de recrear los hechos violentos, sino en la idea del viaje, y en la idea de que el viaje que ellos habían hecho era un viaje heroico, un viaje histórico, un viaje que nadie más había hecho, que ellos habían hecho mapas, y habían trazado una geografía, que era una geografía absolutamente real y verdadera, pero que no estaba en los libros. Es la otra geografía, la geografía de los otros, y que en el trazar de esa geografía los cuerpos de ellos que habían perdido toda esa identidad y ahora eran sólo unas víctimas con un número. Esos cuerpos eran súper importantes, que eran los cuerpos de los héroes, los cuerpos de los sobrevivientes, entonces ahí se trabaja sobre esa idea, y para ellos fue muy importante. Cuando se terminaron las fotografías, después de varias conversaciones, de talleres, de preparación para los trazos, de una sesión de trazado, el dibujo en las piernas, de la sesión de fotografia. Ir a un estudio de fotografía que era un sitio muy importante, que nunca habían visitado, después ver sus piernas en el museo, en una exposición muy importante, llevar sus hijos, sus sobrinos, sus nietos, para ellos eso fue muy importante. Lo que me decían era que ellos no sabían que ellos fueran importantes, y que sus pies tan feos, tan maltratados, tan sucios fueran tan importantes. Pues hay como una especie de conciencia que logra el proyecto, en ellos como cierto nivel, cierto sentido de orgullo, no de vergüenza; porque además de ser desplazados tenían que sentir vergüenza, porque ser desplazado es ser ladrón, delincuente, pues se los asemeja muchas veces a cosas negativas, y aquí se podían sentir orgullosos y se podían sentir héroes, pero siguen siendo lo mismo de pobres que eran en ese momento. 


\section{¿Cómo cree que este trabajo ha contribuido a la expansión del trabajo de memoria social que se está realizando en Colombia?}

Yo no lo he medido, porque yo hago lo que hago y lo suelto. Pero realmente este proyecto ha sido publicado en diferentes libros. Cuando se exhibió por primera vez. Lo vieron los sociólogos y los antropólogos, que habían hecho muchos estudios sobre desplazamientos, sobre migraciones; para ellos fue importante porque pensaban que este proyecto proporcionaba imágenes que ellos no habían logrado dar en lo que escribían, como la imagen de lo que puede ser el desplazamiento forzado, desplazamiento por la guerra. Entonces el proyecto se ha publicado en estudios de diferentes áreas, sociología, antropología, las fotografías han servido para diferentes investigadores, no solamente en el campo del arte, pero también digamos que este proyecto se ha vuelto un proyecto que ha quedado. Es digamos como unas imágenes recurrentes cuando se piensa en el conflicto colombiano y en las consecuencias, secuelas, efectos, muchas veces se recurre a estas imágenes de Signos Cardinales, pero también pienso que en ese sentido ha contribuido como a hacer memoria y se ha usado varios proyectos en torno a la memoria.

\section{¿Qué rol tiene el artista en la sociedad colombiana?}

No se, yo pienso que la voz del artista es otra voz, no es una única voz. En el caso de mi trabajo, a mi me interesa, pues como lo que le pasa con la gente, lo que pasa con las

personas, la manera como las situaciones que pasan en el país afectan a las personas. En ese sentido pienso que mi trabajo aporta a la discusión, aporta pensamientos, aporta reflexiones en torno a situaciones distintas de acuerdo al proyecto. Si es el caso por ejemplo de hierbas de sal y tierra en torno al asunto de la medicina tradicional botánica, y como se está perdiendo este conocimiento, o como está en peligro de perderse y las inequidades, las desigualdades sociales, o en el caso de "Signos Cardinales" el asunto del desplazamiento de las otras geografías no oficiales, bueno el caso de "Lección de Anatomía” de cómo, del problema de minas antipersonas que tenemos en este país, o si es el caso de otro proyecto como el de "Evidencia Clínica" es un asunto que tiene que ver con la violencia de género, entonces pienso que, en cada uno de los proyectos en los que yo me meto en general estoy reflexionando sobre situaciones que son reales y que nos competen a nosotros como 
sociedad, no solamente como sociedad colombiana, sino que es una cosa que trasciende incluso las fronteras colombianas.

\section{¿Qué opinas de los comentarios de tu trabajo sobre la actualidad social o política en}

\section{Colombia?}

Es actual, es como si lo hubiera hecho hoy, porque este proyecto no ha envejecido, porque sigue la situación, la situación no se ha curado, la situación no se ha solucionado. En este momento que estamos en proceso de paz, hay una gran cantidad de desplazamientos; hay muchas personas que están siendo desplazadas, hay muchas personas que están siendo despojadas de sus territorios. Hay un gran conflicto por la tierra, hay tierras que fueron robadas y no quieren ser devueltas. El problema del desplazamiento, el problema de los sujetos, de las personas desplazadas, el problema de estas geografías atroces, horrorosas, como las geografías del horror, del dolor del trauma, están aquí, están aquí, entonces el proyecto es vigente, sigue vigente, así lo haya hecho yo en el 2008, pero es totalmente vigente. 


\section{References}

Aljazeera. (2021). Killings of Colombia ex-FARC fighters persist amid peace process. Retrieved from:

https://www.aljazeera.com/news/2021/1/18/killings-of-colombia-ex-farcfighters-persist-amid-peace-process

Acosta López, M.R. (2014). Memory and fragility: Art's resistance to oblivion (Three Colombian cases). CR: The New Centennial Review, 14(1), Writing/Violence/Latin America, 71-98. Retrieved from: https://doi.org/10.14321/crnewcentrevi.14.1.0071

Arango-Domínguez, A.M. (2009). Colombia's landmine crisis. Humanitarian Practice Network. Retrieved from: https://odihpn.org/magazine/colombia\%C2\%92s-landmine-crisis/

Avilés, W. (2001). Institutions, military policy, and human rights in Colombia. Latin American Perspectives, 28(1), 31-55.

Barrios, A. (n.d.). Palabras de artistas: Miguel Ángel Rojas. Retrieved from: https://proa.org/esp/exhibicion-proa-daros-latinamerica-textos.php\#165

Barthes, R. (1980/2000). Camera lucida: Reflections on photography. London: Vintage.

Bazin, A. (1960). The ontology of the photographic image. Film Quarterly, 13(4), 4-9.

Becker, H. (1978), Do photographs tell the truth? Afterimage, 5, 9-13.

Bell, D. (2009) Introduction: Violence and memory. Millennium - Journal of International Studies, 38, 345-360. doi: 10.1177/0305829809347541

Bennett, J. (2000). Theorizing trauma through the visual arts. In Kaltenbeck, F., \& Weibel, P. (Eds.) Trauma und Erinnerung/Trauma and Memory: Cross-Cultural Perspectives. (pp. 75-89) Vienna: Passagen Verlag.

Bennett, J. (2002). Art, affect, and the "bad death": Strategies for communicating the sense memory of loss. Signs, 28(1), 333-351.

Bennett, J. (2005). Empathic vision: Affect, trauma, and contemporary art. Stanford, California: Stanford University Press.

Berger, J. (1974), Understanding a photograph, the look of things. In A. Trachtenberg (Ed.) (1980), Classic Essays on Photography. (pp. 291-294) New Haven: Leete's Island Books.

Berger, J. (1977). Ways of seeing. London: Penguin books. 
Birksted, J. (2000). Landscapes of memory and experience. London: Spon Press.

Blocker, J. (2009). Seeing witness: visuality and the ethics of testimony. Minneapolis: University of Minnesota Press.

Bojayá: La guerra sin límites. (2010). Comisión Nacional de Reparación y Reconciliación. [Report]. Retrieved from: http://www.centrodememoriahistorica.gov.co/descargas/informes2010/informe_ bojaya.pdf

Brittain, J.J. (2009). Revolutionary social change in Colombia: The origin and direction of the FARC-EP. London: Pluto Press.

Burgin, V. (Ed.). (1977). Thinking Photography. London: Macmillan.

Butler, J. (2004). Precarious life: The powers of mourning and violence. London: Verso.

Butler, J. (2007). Torture and ethics of photography. Environment and Planning D: Society and Space, 25(6), 951-966.

Butler, J. (2009). Frames of war: When is life grievable? London: Verso.

Cabrera, M. (2007). Representing violence in Colombia: Visual arts, memory and countermemory. Brújula, 6(1), 37-56.

Cabrera, M. (2009). Impossible histories: Violence, identity, and memory in Colombian visual arts. In L. Plate \& A. Smelik (Eds.), Technologies of memory in the arts (pp. 203-215). New York: Palgrave Macmillan.

Campany, D. (2003). Safety in numbness: Some remarks on problems of 'late photography'. In D. Green (Ed) Where is the Photograph? (pp. 123-132).

Brighton: Photoforum and Photoworks.

Cardona, L. (2017). Silencios. Memoria visual del Holocausto en Colombia. Rev. Colomb. Soc., 40(1), 133-160.

Carter, E., Donald, J., \& Squires, J. (Eds.). (1993). Space \& place: Theories of identity and location. London: Lawrence \& Wishart.

Cavarero, A. (2009). Horrorism: Naming contemporary violence. (W. McCuaig, Trans.). New York: Columbia University Press. 
Centro Nacional de Memoria Histórica. (2015). Una nación desplazada: Informe nacional del desplazamiento forzado en Colombia. Bogotá: Centro Nacional de Memoria Histórica. Retrieved from:

https://www.centrodememoriahistorica.gov.co/descargas/informes2015/naciondesplazada/una-nacion-desplazada.pdf

Chaparro, S.R. (2015). Anti-war: The mother's party. Retrieved from: http://www.amphibiousaccounts.org/\#!/en/publicacion/anti-war-themothers--party

Colombia Reports. (2019). Forced disappearances. Retrieved from: https://colombiareports.com/forced-disappearances-statistics/

Comité Internacional de la Cruz Roja. \#AquíFaltaAlguien, campaña por los desaparecidos en Colombia. Retrieved from: https://www.icrc.org/es/desaparecidos-en-colombia

Cross, K., \& Peck, J. (2010). Editorial: Special issue on photography, archive and memory. Photographies, 3(2), 127-138. doi: 10.1080/17540763.2010.499631

Crowder-Taraborrelli, T. (2013). Exhumations and double disappearance: Silvio Caiozzi's Fernando ha vuelto and ¿Fernando ha vuelto a desaparecer? Social Identities, 19(4), 386-402. doi: 10.1080/13504630.2013.819157

D’Ignazio, C. (2009). Art and cartography. In R. Kitchim \& N. Thrit (Eds.), International encyclopedia of human geography, vol 1. (pp. 191-206). Oxford: Elsevier Science.

da Silva Catela, L. (2001). No habrá flores en la tumba del pasado: la experiencia de reconstrucción del mundo de los familiares de desaparecido. Argentina: Ediciones Al Margen.

Debrix, F., \& Barder, A. (2012). Beyond biopolitics: Theory, violence, and horror in world politics. Florence: Routledge.

Değirmenci, K. (2017). Photographic indexicality and referentiality in the digital age. Proceedings of the European society for aesthetics, 9, 89-115.

Delbo, C. (1995). Auschwitz and after. New Haven and London: Yale University Press.

Deleuze, G. (1964/2000) Proust and signs. Minnesota: University of Minnesota Press.

Dessingué, A. (2011). Towards a phenomenology of memory and forgetting. Études Riccuriennes / Riccur Studies, 2(1), 168-178. doi: 10.5195/errs.2011.42

Diéguez, I. (2016). Cuerpos sin duelo: Iconografías y teatralidades del dolor. Nuevo León: Universidad Autónoma de Nuevo León. 
Diéguez, I. (n.d). Survival through images. Retrieved from: https://erikadiettes.com

Diettes, E. (n.d). A punta de sangre. Retrieved from: https://erikadiettesweb.squarespace.com/apunta

Doane, M.A. (2007) Imaging contingency: An interview with Mary Ann Doane. doi: http://dx.doi.org/10.25025/hart02.2018.06

Dong-Yeon Koh (2015) "Late photography" in South Korea: Heungsoon Im, Onejoon Che, Suyeon Yun, Photography and Culture, 8(1), 81-106.

Donoso Macaya, A. (2020). The insubordination of photography: Documentary practices under Chile's dictatorship. Gainesville: University of Florida Press.

Dueñas, G.P., \& Rueda, M.H. (2011). Meanings of violence in contemporary Latin America. New York: Palgrave Macmillan.

Echavarría, J.M. (2007). Death and the river. Virginia Quarterly Review: A National Journal of Literature and Discussion, 83(4), 291-300.

Echavarría, J.M. (2010). Requiem NN. Retrieved from: http://www.jmechavarria.com/requiemnn/requiemnn_exhi.html

Enciso-Noguera, A.M. (2019) Al Día: Pulses of the soul: The photography of Jesús Abad Colorado. Retrieved from: https://aldianews.com/articles/culture/pulsessoul-photography-jesus-abad-colorado/55705

Fals-Borda, O. (1987). Application of participatory action research in Latin America. International Sociology, 2(4), 329-347.

Feldman, A. (1991). Formations of violence: The narrative of the body and political terror in Northern Ireland. Chicago: University of Chicago Press.

Foster, A. (2013). Erika Diettes. Retrieved from: https://culturaldevelopmentconsulting.com/2013/12/02/8996/

Foster, H. (1996). The return of the real. Cambridge, Mass: The MIT Press.

Freud, S. (1961). Beyond the pleasure principle. W. W. Norton \& Company, Inc.

Garcia, E.C. (2010). Photography as fiction. Los Angeles: Getty Publications.

Gatti, G., \& Blanes, J.P. (2021). The Deviated Mourning of the Disappeared: Reimagining Disappearance and Transcending its Tropes. Bulletin of Latin American Research, 40(1), 54-68. 
Gibbons, J. (2007). Contemporary art and memory: Images of recollection and remembrance (1st ed.). London: I.B. Tauris.

Gibson, R. (2010). Changescapes. In J. Rutherford \& B. Holloway (Eds.), Halfway house: the poetics of Australian spaces. (pp. 17-33). Crawley, W.A.: UWA Publishing.

Giraldo, D. (2013). On art, compassion, and memory. Proceedings of the European Society for Aesthetics, 5, 498-513.

Giunta, A. (2014). Feeling the past: Display and the art of memory in Latin America. Journal of Curatorial Studies, 3(2), 321-345. doi: 10.1386/jcs.3.2-3.320_1

González-Combariza, A. (2019). El tiempo: Jesús Abad Colorado, más que un fotógrafo un compañero de las víctimas. Retrieved from: https://www.eltiempo.com/cultura/artey-teatro/jesus-abad-colorado-el-fotografo-de-las-victimas-en-colombia-317176

Gordon, E. (2017). Post-conflict" Reconstruction, the crimes of the powerful and transitional justice. State Crime Journal, 6(1), 132-155.

Grajales, J. (2011). The rifle and the title: paramilitary violence, land grab and land control in Colombia. The Journal of Peasant Studies, 38(4), 771792. doi: $10.1080 / 03066150.2011 .607701$

Gray, C. (1996). Inquiry through practice: developing appropriate research strategies. Retrieved from: http://carolegray.net/Papers\%20PDFs/ngnm.pdf

Gregg, M., \& Seigworth, G. J. (Eds.). (2010). The affect theory reader. Retrieved from: http://ebookcentral.proquest.com

Grundberg, A. (1999). Crisis of the real: Writings on photography. New York: Aperture Foundation.

Grupo de Memoria Histórica (2013). Basta ya! Colombia, memorias de guerra y dignidad. Bogotá: Centro Nacional de Memoria Histórica. Retrieved from: https://www.centrodememoriahistorica.gov.co/descargas/informes2 013/bastaYa/basta-ya-colombia-memorias-de-guerra-y-dignidad-2016.pdf

Guerin, F., \& Hallas, R. (2007). The image and the witness: Trauma, memory and visual culture. New York: Wallflower Press.

Halbwachs, M. (1950/1992). On collective memory. Chicago, The University of Chicago Press.

Haley, S. (2008). Double exposure: post-photographic practice. Photofile, (84), 38-47. 
Haustein, K. (2012). Regarding lost time: Photography, identity and affect in Proust. London: Routledge.

Head On. (2014). Retrieved from: https://www.headon.com.au/blog/erika-diettes-writingabout-her-work-sudarios-exhibited-st-canice-church-featured-head-show\#_ftnref6

Head, C.G. (1991) Mapping as Language or Semiotic System: Review and Comment. In D.M. Mark \& A.U. Frank (Eds.), Cognitive and linguistic aspects of geographic space, vol 63. (pp. 237-262). Dordrecht: Springer. https://doi.org/10.1007/978-94-011-2606-9_14

Herschdorfer, N. (2011). Afterwards: Contemporary photography confronting the past. London: Thames and Hudson.

Herzog, H. M. (2004) Colombian songs/stories: Contemporary Colombian art. Zurich: Daros-Latinamerica.

Hirsch, M. (1992). Family pictures: Maus, mourning, and post-memory. Discourse, 15(2), 3-29.

Hirsch, M. (2008). The generation of postmemory. Poetics Today, 29(1), 103-128.

Hristov, J. (2009). Blood and capital: The paramilitarization of Colombia. Toronto: Center for International Studies.

Human Rights Watch. (2021a). Colombia: Events of 2020. Retrieved from: https://www.hrw.org/world-report/2021/country-chapters/colombia

Human Rights Watch. (2021b). Left undefended: Killings of rights defenders in Colombia's remote communities. Retrieved from: https://www.hrw.org/report/2021/02/10/left-undefended/killings-rightsdefenders-colombias-remote-communities

Humphrey, M. (2018). The political lives of the 'disappeared' in the transition from conflict to peace in Colombia, Politics, Religion \& Ideology, 19(4), 452-470. doi: $10.1080 / 21567689.2018 .1538671$

Ibáñez, A.M., \& and C.E, Vélez. (2003). Forced displacement in Colombia: Causality and welfare losses. Retrieved from: https://www.researchgate.net/profile/Carlos_Velez9/publication/2286040 29_Forced_displacement_in_Colombia_Causality_and_welfare_losses/ links/54cf90080cf298d656640dce/Forced-displacement-in-ColombiaCausality-and-welfare-losses.pdf

Jakobsen, R. (2003). The metaphoric and metonymic poles. In Dirven, R \& Pörings, R. (Eds.), Metaphor and metonymy in comparison and contrast. (pp. 41-48). Berlin: Mouton de Gruyter. 
Kansteiner, W. (2002). Finding meaning in memory: A methodological critique of collective memory studies. History and Theory, 41, 179-197.

Kaplan, B.A. (2001) Pleasure, memory, and time suspension in Holocaust literature: Celan and Delbo. Comparative Literature Studies, 38(4), 310-329

Kear, A. (2005). The anxiety of the image, Parallax, 11(3), 107-116.

Kövecses, Z. (2013). The Metaphor-metonymy relationship: Correlation metaphors are based on metonymy. Metaphor and Symbol, 28(2), 75-88. doi: $10.1080 / 10926488.2013 .768498$

Kratochvil, A., \& Persson, M. (2001). Photojournalism and documentary photography: They are identical mediums, sending different messages. Niemen Reports, 55(3), 27-31.

Kulasekara, D. (2017). Representation of trauma in contemporary arts. Athens Journal of Humanities \& Arts, 4(1), 35-60.

Lazzara, M.J. (2009). Filming loss: (Post-)memory, subjectivity, and the performance of failure in recent Argentine documentary films. Latin American Perspectives, 36(5), 147-157. doi: 10.1177/0094582X09341978

Leichter, D.J. (2012). Collective identity and collective memory in the philosophy of Paul Ricoeur. Ricoeur Studies, 3(1), 114-131.

Lisle, D. (2011). The surprising detritus of leisure: Encountering the late photography of war. Society and Space, 29(5), 873-90.

Malagón-Kurka, M.M. (2019). The art object as mirror or screen. Third Text, 33(6), 761-787. doi: 10.1080/09528822.2019.1667633

Malthaner, S. (2017). Processes of political violence and the dynamics of situational interaction. International Journal of Conflict and Violence, 11, 110. doi: $10.4119 / \mathrm{UNIBI} / \mathrm{ijcv} .627$

McNamara, A. (2012). Six rules for practice-led research. Text, 14. Retrieved from: http://www.textjournal.com.au/speciss/issue14/content.htm

Medina, A. (2019). La política, la violencia y sus repercusiones en el arte colombiano, 1948-1956. Revista Letral, 22. 285-316. ISSN 1989-3302

Mendes-Flohr, P. R. (Ed.). (1983). A Land of Two Peoples: Martin Buber on Jews and Arabs. New York: Oxford University Press.

Miller, S.B. (2016). 'Sudarios' shows moving portraits of women devastated by war. Retrieved from: https://search.proquest.com/docview/1824854741 
Milech, B. H., \& Schilo, A. (2004). 'Exit Jesus': Relating the exegesis and creative/production components of a research thesis. TEXT, (3). Retrieved from: http://link.library.curtin.edu.au/p?cur_dspace_dc20.500.11937/48409.

Mitchell, W. J. (1992). The reconfigured eye: Visual truth in the post-photographic era. Massachusetts: The MIT Press.

Molano, A. (2000). The evolution of the FARC. NACLA Report on the Americas. 34(2), 23-31.

Montenegro Rosero, A.D. (2018). Uma e três aproximações teóricas à série David de Miguel Ángel Rojas. $H-A R T$, (2), 107-126.

Moore, N., \& Whelan, Y. (Eds.). (2007). Heritage, memory, and the politics of identity: New perspectives on the cultural landscape. Hampshire: Ashgate Publishing

Mzali, I. (2010). Wars of representation: Metonymy and Nuruddin Farah's links. College Literature, (37)3, 84-105.

Nets-Zehgnut. (2014). The Israeli and Palestinian collective memories of their conflict: Determinants, characteristics, and implications. Brown Journal of World Affairs, (20)11, 103-121.

Newhall, B. (1964). The history of photography. New York: The Museum of Modern Art.

Nora, P. (1989). Between Memory and History: Les Lieux de Mémoire. Representations. 26, Special Issue: Memory and Counter-Memory, 7-24.

Nowrojee, B. (2005). Making the invisible war crime visible: Post-conflict justice for Sierra Leone's Rape Victims. Harvard Human Rights Journal, 18, 87-105.

Nussio, E. (2012). Emotional legacies of war among former Colombian paramilitaries. Peace and Conflict: Journal of Peace, 18(4), 369-383.

Olick, K. (1999). Collective memory: The two cultures. Sociological Theory, 17(3), 333-348.

Olick, K. (2008). Collective memory: A memoir and prospect. Memory Studies Sage Publications, 1(1), 23-29. doi: 10.1177/1750698007083885

Oslender, J. (2008). Another history of violence: The production of "geographies of terror" in Colombia's pacific coast region. Latin American Perspectives, $35(5), 77-102$. 
Oyala, V., \& Herrera, M.C. (2014). Fotografía y violencia: la memoria actuante de las imagines. Cuadernos de Música, Artes Visuales y Artes Escénicas, 9(2), 89-106. ISSN 1794-6670

Oyola, S. (2015). Religion, social memory and conflict: The massacre of Bojayá in Colombia. UK: Palgrave Macmillan

Pacifista. (2015). Las cuatro paredes. [Video file]. Retrieved from: https://pacifista.tv/notas/pacifista-presenta-las-cuatro-paredes/

Pacifista. (2019). 'Este país no ha llorado lo suficiente todavía': Jesús Abad Colorado. Retrieved from: https://pacifista.tv/notas/jesus-abad-colorado-testigofotografia-periodismo-entrevista/

Padilla, C. (2007). A punte de sangre. Retrieved from: https://static1.squarespace.com/static/54918f84e4b0b437af2bbcf0/t/5494cae3e4b07 bc5777ffb25/1419037411395/ApuntaCPadilla_eng.pdf

Palacios, M. (2006). Between legitimacy and violence: A history of Colombia, 1875 2002. Durham and London: Duke University Press. Parallax, 13(4), 16-25. DOI: 10.1080/13534640701682743

Pécaut, D (2003). Violencia y política en Colombia: elementos de reflexión. Medellín: Hombre Nuevo, Univalle.

Peirce, C. S., Hartshorne, C., Weiss, P., \& Burks, A. W. (1965). Collected papers of Charles Sanders Peirce. Cambridge, Mass: Belknap Press of Harvard University Press.

Pollock, G. (2009). Art/trauma/representation. Parallax, (15)1, 40-54.

Pollock, G. (2012). Photographing atrocity: Becoming iconic? In G. Batchen, M. Gidley M, \& N. Miller (Eds.), Picturing atrocity: Photography in crisis (pp. 65-78). London: Reaktion.

Pollock, G. (2013). Visual politics and psychoanalysis: Art and the image in posttraumatic cultures (1st ed.). London: I.B. Tauris.

Project Video. (2013). Retrieved from: http://prod-images.exhibite.com/www_sicardi_com/2013ProjectVideoMailer.pdf

Raffles, H. (2002). In Amazonia. A natural history. Princeton: University of Princeton Press.

Ramírez Mejía, E.C. (2013). Libia Posada: Cartografías del sentir. Arte y diseño, 11(1), 38-41. ISSN: 1692-8555 
Ray, G. (2005). Terror and the sublime in art and critical theory: From Auschwitz to Hiroshima to September 11. New York: Palgrave Macmillan

Reid, C. (2000). Juan Manuel Echavarría by Calvin Reid. [blog post] Retrieved from: http://bombmagazine.org/article/2276/juan-manuel-echavarr-a

Riaño-Alcalá, P. (2002). Memory, representations and narratives: Rethinking violence in Colombia. The Journal of Latin American Anthropology, 7(1), 222-225.

Riaño-Alcalá, P. (2016). Historical memory [blog post]. Retrieved from: http://blogs.ubc.ca/priano/memoria-historica/

Riaño-Alcalá, P., \& Uribe, V. (2016). Constructing memory amidst war: The historical memory group of Colombia. International Journal of Transitional Justice, 10, 6-24. doi: $10.1093 / \mathrm{ijt} \mathrm{j} / \mathrm{ijv} 036$

Ricoeur, P. (2004). Memory, history, forgetting. Chicago: The University of Chicago Press.

Robben, Antonius C. G. M. (2007). Political violence and trauma in Argentina, Pennsylvania: University of Pennsylvania Press.

Rosenberg, E., \& Saltzman, L. (2006). Trauma and visuality in modernity. Lebanon: University Link Press of New England.

Rubiano, E. (2017). Réquiem NN, de Juan Manuel Echavarría: Entre lo evidente, lo sugestivo y lo reprimido. Cuadernos de Música, Artes Visuales y Artes Escénicas, 12(1), 33-45.

Schlichtmann, H. (1985). Characteristic traits of the semiotic system 'map symbolism'. The Cartographic Journal, 22(1), 23-30. doi:

10.1179/caj.1985.22.1.23

Sekula, A. (1982). On the invention of photographic meaning. In V. Burgin (Ed.), Thinking photography. Communications and culture. Palgrave, London. https://doi.org/10.1007/978-1-349-16716-6_5

Sekula, A. (1984). Dismantling modernism, Reinventing documentary: Photography against the grain: Essays and works 1973-1983. Nova Scotia: Press of the Nova Scotia College of Art and Design.

Sherman, J.W. (2015). Political violence in Colombia: Dirty wars since 1977. History Compass, 13(9), 454-465. doi:10.1111/hic3.12258

Silver, B. (1998). The ascent of science. New York: Oxford University Press. 
Solomon-Godeau, A. (2017). Photography after photography: Gender, genre, history. Retrieved from: http://ebookcentral.proquest.com.

Sontag, S. (1977). On photography. New York: Farrar, Straus and Giroux.

Sontag, S. (2003). Regarding the pain of others. New York: Farrar, Straus and Giroux.

Steele, A. (2017). Democracy and displacement in Colombia's civil war. Cornell: Cornell University Press.

Taussig, M. (2003). The language of flowers. Critical Inquiry, 30(1), 98-131.

Tello, V. (2014) The aesthetics and politics of aftermath photography, Third Text, 28(6), 555-562. doi:10.1080/09528822.2014.970775

Ugarriza, J.E., \& Craig, M.J. (2012). The relevance of ideology to contemporary armed conflicts: A quantitative analysis of former combatants in Colombia. Journal of Conflict Resolution, 57(3), 445-477.

Uribe, M. (2009). Memory in times of war. Public Culture, 21(1), 3-7. Retrieved from: https://law.utexas.edu/humanrights/events/speaker-seriespapers/Uribe_PublicCulture21.pdf

Uribe, M. (2012). Reflections on aesthetics and violence in Colombia. Retrieved from: http://jwtc.org.za/resources/docs/salon-volume-5/Uribe_English_3008.pdf

Vélez-Torres, I. (2013). Reflections on a participatory documentary process: constructing territorial histories of dispossession among Afro-descendant youth in Colombia. Area, 45(3), 299-306. doi: 10.1111/area.12032

Waldmann, P. (2007). Is there a culture of violence in Colombia? Terrorism and Political Violence, 19(4), 593-609. doi: 10.1080/09546550701626836

Wang, C., \& Ann Burris, M. (1997). Photovoice: Concept, methodology, and use for participatory needs assessment. Health Education \& Behavior, 24, 369-387.

Ware, M. (2002). Luminescence and the invention of photography. History of Photography, 26(1), 4-15.

Wills, M. (2011). Entrevista retrospectiva a Oscar Muñoz. Banrepcultural. Retrieved from: https://www.banrepcultural.org/oscar-munoz/entrevistaformas-de-la-imagen-en-movimiento.html

Yepes, R. (2012). (In)visible warriors: Juan Manuel Echavarría's the war we have not seen. Retrieved from: https://independent.academia.edu/YepesRuben 


\section{List of Illustrations}

Figure

Page

1. María Marcela Patiño Upegui. Carte Desaparecido Sebas

(Missing Poster Sebas). (2021). [Poster] Courtesy of the artist

2. Avedon, R. (Photographer). (1963). William Casby, born in Slavery,

9

Algiers, Louisiana, March 24, 1963. [Photograph]

(Richard Avedon Foundation (1963) (C) The Richard Avedon Foundation)

3. Adams, E. (Photographer). (1968). Brigadier General Nguyen Ngoc Loan

15 shooting a Viet Cong prisoner. [Photograph] Retrieved from:

https://www.bbc.com/news/world-us-canada-42864421

4. Anonymous. (Artist). (2008). Civilian massacre by the paramilitaries

15 in Vergel. [Painting] Retrieved from: https://laguerraquenohemosvisto.com /en/civilian-massacre-by-the-paramilitaries-in-vergel/

5. Diettes, E. (Photographer). (2005). Silencios. [Photograph]

Courtesy of the artist

6. Unknown photographer. Purported guerrilla killed in Urabá, Antioquia. (2011). [Photograph] Retrieved from:

https:/www.semana.com/nacion/articulo/lentos-positivos/234804-3/

7. Ferry, S. (Photographer). A young girl passes the body of a man assassinated in Cucuta. (2011).

[Photograph] Retrieved from: https://time.com/3782831/

8. Diettes, E. (Photographer) Rio Abajo. (2008). [Photograph]

Courtesy of the artist

9. Diettes, E. (Photographer) A Punta de Sangre. (2008). [Photograph]

Courtesy of the artist

10. Bouguereau, W.A. (Painter). Pietà. (1876). [Painting]

Retrieved from: https://commons.wikimedia.org/wiki/File:William-

Adolphe_Bouguereau_(1825-1905)_-_Pieta_(1876).jpg (Public domain)

11. Diettes, E. (Photographer) Sudarios. (2011). [Photograph]

Courtesy of the artist

12. Echavarría, J.M. (Photographer). Retratos \#5. (1996). [Photograph]

Courtesy of the artist 
13. Echavarría, J.M. (Photographer) Corte de Florero. (1997). [Photograph]

Retrieved from: http://www.amphibiousaccounts.org/\#!/en/publicacion/anti-war-themothers--party (C) Jesús Abad Colorado)

19. Rojas, M.A. (Photographer) David. (2005). [Photograph]

Retrieved from: https://www.arte-online.net/Notas/La_coleccion_Daros_

Latinamerica_hace_pie_en_Proa

20. Muñoz, O. (Artist). Aliento. (1995). [Photo-serigraph]

Courtesy of the artist

21. Muñoz, O. (Artist). Aliento. (1995). [Photo-serigraph]

Courtesy of the artist

22. Posada, L. (Artist). Signos cardinales. (2008). [Photograph]

Courtesy of the artist

23. Posada, L. (Artist). Signos cardinales. (2008). [Map key]

Courtesy of the artist

24. Posada, L. (Artist). Signos cardinales. (2008). [Photograph] 


\section{RECORDANDO DXCOMBATIDNIDS}

LARRY DEFELIPPI 
Front and back cover: Río Magdalena / Magdalena river 


\section{RECORDANDO EXCOMBATIENTES}

LARRY DEFELIPPI 
Dedicado a todos los que hicieron posible este libro 


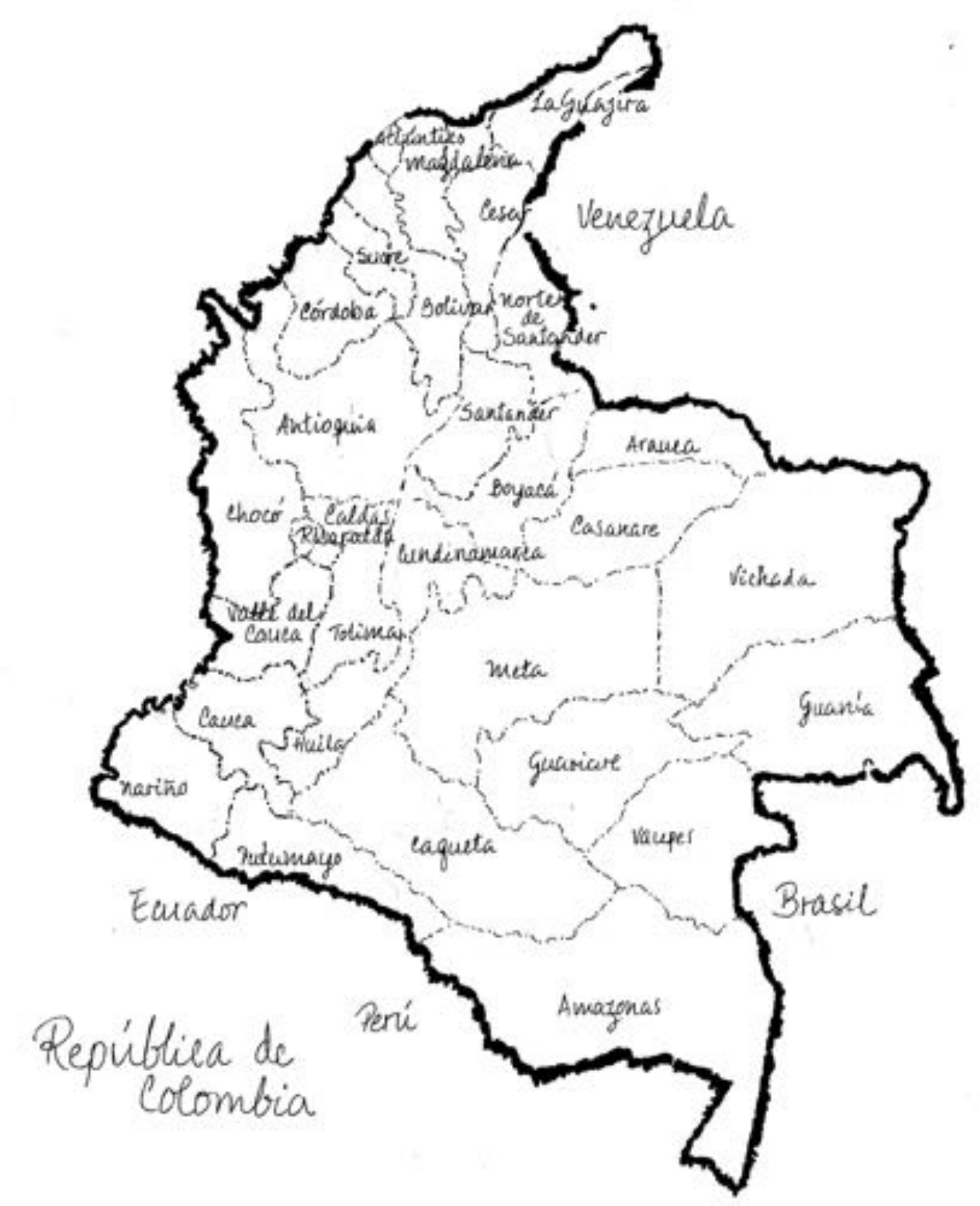


Durante la mayor parte del siglo XX hasta la actualidad, Colombia ha experimentado un conflicto interno ininterrumpido e incapacitante "cuyo estado actual combina elementos tanto del conflicto como del posconflicto"1. Una década de derramamiento de sangre conocido como La Violencia, un levantamiento "generado por la ruptura entre los dos grandes partidos políticos de la nación legados desde el siglo XIX, los liberales y los conservadores" ${ }^{2}$, y provocado por el asesinato de Jorge Eliezer Gaitán en 1948, un partido liberal populista. El asesinato de Eliezer Gaitán desembocó en un violento motín conocido como El Bogotazo, “bien inscrito en la memoria colectiva a través de imágenes y narrativas sobre las masacres, y las horrendas torturas y desmembramientos de cuerpos que lo caracterizaron" ${ }^{3}$, desencadenando una década de derramamiento de sangre como partidos políticos en Bogotá pelearon mientras el campo degeneró en ciclos de crueles asesinatos por represalias. El caos que siguió a la Violencia dio lugar a una insurgencia de izquierda que comenzó en la década de 1960 utilizando iniciativas culturales y militares para el cambio revolucionario ${ }^{4}$. Esto involucró a numerosos grupos, incluidos las FARC-EP (1964-2017) (Fuerzas Armadas Revolucionarias de Colombia - Ejército del Pueblo), el EPL (Ejército Popular de Liberación), M- 19 (1964-1990) (Movimiento 19 de Abril), y MAQL (1984-1991) (Movimiento Armado Quintin Lame). Durante el transcurso del conflicto, ha habido numerosos intentos de paz transicional que impliquen la desmovilización de sus actores armados, tanto insurgentes de izquierda como paramilitares de derecha. Sin embargo, el grupo guerrillero más grande, las FARC-EP, no desmovilizó a sus siete mil combatientes estimados hasta más de cinco décadas después de su creación, lo que resultó en el fin de la insurgencia más larga del mundo.

Las fotografías de este libro son autorretratos asistidos de excombatientes, excombatientes del conflicto colombiano de diversos grupos armados desmovilizados. Las fotografías se toman en un lugar elegido por el participante, donde el participante decide cómo desea representarse a sí mismo. Con ayuda para el uso del equipo fotográfico, los participantes toman la fotografía con un cable disparador. Permitir a quienes están frente a la lente la elección de qué, dónde y cómo, en la construcción de su propia imagen, proporciona un contexto más amplio en el que interrogar las ideas de la memoria, la identidad histórica y la ideología. El cambio de agencia del fotógrafo al participante les permite formas de afirmarse artística e intelectualmente. Este enfoque se basa en la discusión de la crítica de arte estadounidense Abigail Solomon-Godeau sobre lo que ella ha denominado Inside / Outside. Por lo que se entiende que la posición de insider implica una posición de compromiso, participación y conocimiento privilegiado. Mientras que la distancia entre sujeto y objeto se intensifica por la posición voyeurista y alienada ocupada por el forastero. Gran parte del debate relacionado con la ética o la política de varias formas de práctica fotográfica depende de este binarismo, y Solomon-Godeau postula que en la representación del otro, el punto de vista del forastero es por definición una visión parcial, si no distorsionada sujeto a ser representado ${ }^{5}$. Para ello, los participantes son los agentes impulsores del contenido y composición de sus propias imágenes en este libro. Sus autorretratos utilizan negativos de calotipo, un proceso fotográfico temprano introducido a mediados del siglo XIX utilizando papel recubierto con una capa sensible a la luz de yoduro de plata, una tecnología fotográfica heredada del siglo XIX, similar al conflicto en sí. 
For the better part of the twentieth century up to the present day, Colombia has experienced an uninterrupted, and incapacitating internal conflict "whose current status combines elements of both conflict and post conflict"1. A conflict typically described as beginning in the 1940s with a decade long bloodletting known as La violencia, an upheaval "generated by the rupture between the nation's two grand political parties bequeathed from the nineteenth century, the Liberals and Conservatives" 2 , and sparked by the assassination of Jorge Eliezer Gaitán in 1948, a Liberal party populist. Eliezer Gaitán's assassination led to a violent riot known as El Bogotazo, "well inscribed in collective memory through images and narratives dealing with the massacres, and the horrendous tortures and dismembering of bodies that characterized it" ${ }^{3}$, triggering a decade of bloodletting as political parties in Bogotá feuded while the countryside degenerated into cycles of vicious retributory killings. The chaos that followed La violencia gave rise to a left wing insurgency beginning in the 1960s utilising cultural and military initiatives for revolutionary change ${ }^{4}$. This involved numerous groups including the FARC-EP (1964-2017) (Fuerzas Armadas Revolucionarias de Colombia-Ejército del Pueblo/ Revolutionary Armed Forces of Colombia-People's Army), the EPL (Ejército Popular de Liberación/Popular Liberation Army), M-19 (1964-1990) (Movimiento 19 de Abril/The 19th of April Movement), and MAQL (1984-1991) (Movimiento Armado Quintin Lame/Quintin Lame Armed Movement). During the course of the conflict, there have been numerous attempts at a transitional peace involving the demobilisation of its armed actors, both left wing insurgents and right wing paramilitaries. However, the largest guerilla group, the FARC-EP, did not demobilise its estimated seven thousand fighters until more than five decades after its creation, resulting in an end to the world's longest insurgency.

The photographs in this book are assisted self-portraits of ex-combatientes, former combatants of the Colombian conflict from various demobilised armed groups. The photographs are taken in a location chosen by the participant, where the participant decides how they wish to represent themselves. Given assistance to use the photographic equipment, the participants take the photograph with a cable shutter release. Allowing those in front of the lens the choice of what, where, and how, in the construction of their own image provides a greater context in which to interrogate ideas of memory, historical identity, and ideology. The shifting of agency from photographer to participant allows them ways to assert themselves artistically and intellectually. This approach is informed by American art critic Abigail Solomon-Godeau's discussion of what she has termed Inside / Outside. By which the insider's position is understood to imply a position of engagement, participation, and privileged knowledge. Whereas the distance between subject and object is intensified by the voyeuristic and alienated position occupied by the outsider. Much of the debate concerned with either the ethics or the politics of various forms of photographic practice hinges on this binarism, and Solomon-Godeau posits that in the representation of the other, the outsider's viewpoint is by definition a partial if not distorted view of the subject to be represented ${ }^{5}$. To this end, participants are the driving agents to the content, and composition of their own images in this book. Their self-portraits use calotype negatives, an early photographic process introduced in the mid nineteenth century using paper coated with a light-sensitive layer of silver iodide, a photographic technology handed down from the 19th century, not unlike the conflict itself. 
En el pasado, la sociedad colombiana ha tendido hacia una práctica de amnistía y amnesia colectiva que dificultan la construcción de la memoria social ${ }^{6}$. Aunque en los últimos años se han realizado grandes esfuerzos para promover la memoria social como un medio para generar nociones de rendición de cuentas, perdón y reconciliación, al tiempo que se aborda potencialmente el relativismo moral que existe entre víctimas, perpetradores y espectadores ${ }^{7}$. Sin embargo, la memorialización social a través de un proceso de inclusión y exclusión también puede promover la difamación de los adversarios tradicionales. Por lo tanto, es importante que todas las partes afectadas por la trágica historia en curso del conflicto tengan la oportunidad de ser vistas y escuchadas, y con este espíritu en mente, este trabajo presenta narrativas previamente omitidas, silenciadas o desconocidas de las experiencias individuales de ambos exguerrilleros. y paramilitares, y su ruta hacia la paz. Las imágenes y el texto resultantes se exhibieron en El Centro de Memoria, Paz y Reconciliación en Bogotá en octubre de 2019 .

\section{NOTAS}

1. Maria Victoria Uribe, "Memory in Times of War", Public Culture 21, (2009), 3.

2. John W Sherman, “Political Violence in Colombia: Dirty Wars Since 1977", History Compass 13, (2015), 454.

3. Marta Cabrera, "Impossible histories: Violence, Identity, and Memory in Colombian Visual Arts" In Technologies of Memory in the Arts, ed. Liedeke Plate \& Anneke Smelik, 203 (New York: Palgrave Macmillan, 2009).

4. Garry Leech, FARC, the Longest Insurgency. (London and New York: Zed Books, 2011).

5. Abigail Solomon-Godeau, Photography after photography: Gender, genre, history. (North Carolina: Duke University Press, 2017).

6. Maria Victoria Uribe (2009).

7. Sandra Milena Rios Oyola, Religion, Social Memory and Conflict: The Massacre of Bojayá in Colombia. (UK: Palgrave Macmillan, 2015).

8. A los efectos de la desidentificación, no se han utilizado nombres ni afiliaciones de grupo para describir las fotografías presentadas en este libro. 
In the past, Colombian society has tended towards a practice of amnesty, and collective amnesia that make the construction of social memory difficult ${ }^{6}$. Though in recent years there have been strong efforts to promote social memory as a means to create notions of accountability, forgiveness, and reconciliation, while potentially addressing the moral relativism that exists between victims, perpetrators, and onlookers ${ }^{\text {? }}$. Social memorialisation through a process of inclusion and exclusion, however, can also promote the vilification of traditional adversaries. Therefore it is important that all parties affected by the ongoing tragic history of the conflict have the opportunity to be seen and heard, and with this spirit in mind, this work presents previously omitted, silenced or unknown narratives of the individual experiences of both former guerillas and paramilitaries, and their route to peace. The resulting images and text were exhibited at El Centro de Memoria, Paz y Reconciliación (The Center of Memory, Peace and Reconciliation) in Bogotá in October $2019^{8}$.

\section{NOTES}

1. Maria Victoria Uribe, “Memory in Times of War", Public Culture 21, (2009), 3.

2. John W Sherman, "Political Violence in Colombia: Dirty Wars Since 1977", History Compass 13, (2015), 454.

3. Marta Cabrera, "Impossible histories: Violence, Identity, and Memory in Colombian Visual Arts" In Technologies of Memory in the Arts, ed. Liedeke Plate \& Anneke Smelik, 203 (New York: Palgrave Macmillan, 2009).

4. Garry Leech, FARC, the Longest Insurgency. (London and New York: Zed Books, 2011).

5. Abigail Solomon-Godeau, Photography after photography: Gender, genre, history. (North Carolina: Duke University Press, 2017).

6. Maria Victoria Uribe (2009).

7. Sandra Milena Rios Oyola, Religion, Social Memory and Conflict: The Massacre of Bojayá in Colombia. (UK: Palgrave Macmillan, 2015).

8. For the purposes of de-identification, no names or group affiliations have been used to describe the photographs presented in this book. 


\section{Desmovilizaciones durante el conflicto colombiano Demobilisations during the Colombian Conflict}

\author{
$1953-1957$ \\ Gobierno:* Gustavo Rojas Pinilla \\ Grupo armado: Guerrillas liberales \\ Desmovilizados: $8000-20000$
}

\author{
$1982-1986$ \\ Gobierno: Belisario Betancur \\ Grupo armado: FARC, EPL y ADO \\ Desmovilizados: N/D
}

\begin{tabular}{|c|c|}
\hline 198 & - 1990 \\
\hline Gobierno: & Virgilio Barco \\
\hline Grupo armado: & $M-19$ \\
\hline Desmovilizados & 900 \\
\hline
\end{tabular}

*Government:

Armed Group:

Demobilised:

\begin{tabular}{ll}
\multicolumn{2}{c}{$1990-1994$} \\
Gobierno: & César Gaviria \\
Grupo armado: & PRT, EPL, MAQL y CRS \\
Desmovilizados: & PRT: 204 / EPL: 2520 / \\
& MAQL: 157 / CRS: 747
\end{tabular}

$1990-1994$

MAQL: 157 / CRS: 747 


\author{
$2003-2006$ \\ Gobierno: $\quad$ Álvaro Uribe Vélez \\ Grupo armado: AUC \\ Desmovilizados: 31689
}

\section{7}

Gobierno: Juan Manuel Santos

Grupo armado: FARC

Desmovilizados: 6804

FARC: Fuerzas Armadas Revolucionarias de Colombia / The Revolutionary Armed Forces of Colombia

EPL: Ejército Popular de Liberación / The Popular Liberation Army

ADO: Movimiento de Autodefensa Obrera / The Workers Self-Defense Movement

M-19: $\quad$ Movimiento 19 de abril / The 19th of April Movement

PRT: $\quad$ Partido Revolucionario de los Trabajadores / The Workers' Revolutionary Party

MAQL: Movimiento Armado Quintín Lame / The Quintin Lame Armed Movement

CRS: $\quad$ Corriente Renovación Socialista / The Stream of Socialist Renewal

AUC: $\quad$ Autodefensas Unidas de Colombia / The United Self-Defences of Colombia 
Hay varias maneras de llegar a ser guerrillero y formar parte del segmento armado: por su conciencia, por la falta de oportunidades, por el hambre, por ascender en la escala social o por aprender cosas nuevas, o simplemente por que la violencia te lleva allí. Muchos casos se deben a la violencia, han desapa recido hermanos, padres e hijos, y esta violencia los llevó a ser parte de este proceso.

There are several ways that you get to be a guerrilla and become part of the armed segment: because of your conscience, because of a lack of opportunity, because of hunger, to climb the social ladder, or to learn new things, or simply because violence takes you there. A lot of cases are because of violence, brothers, parents, and children have been disappeared, and this violence led them to be part of this process. 


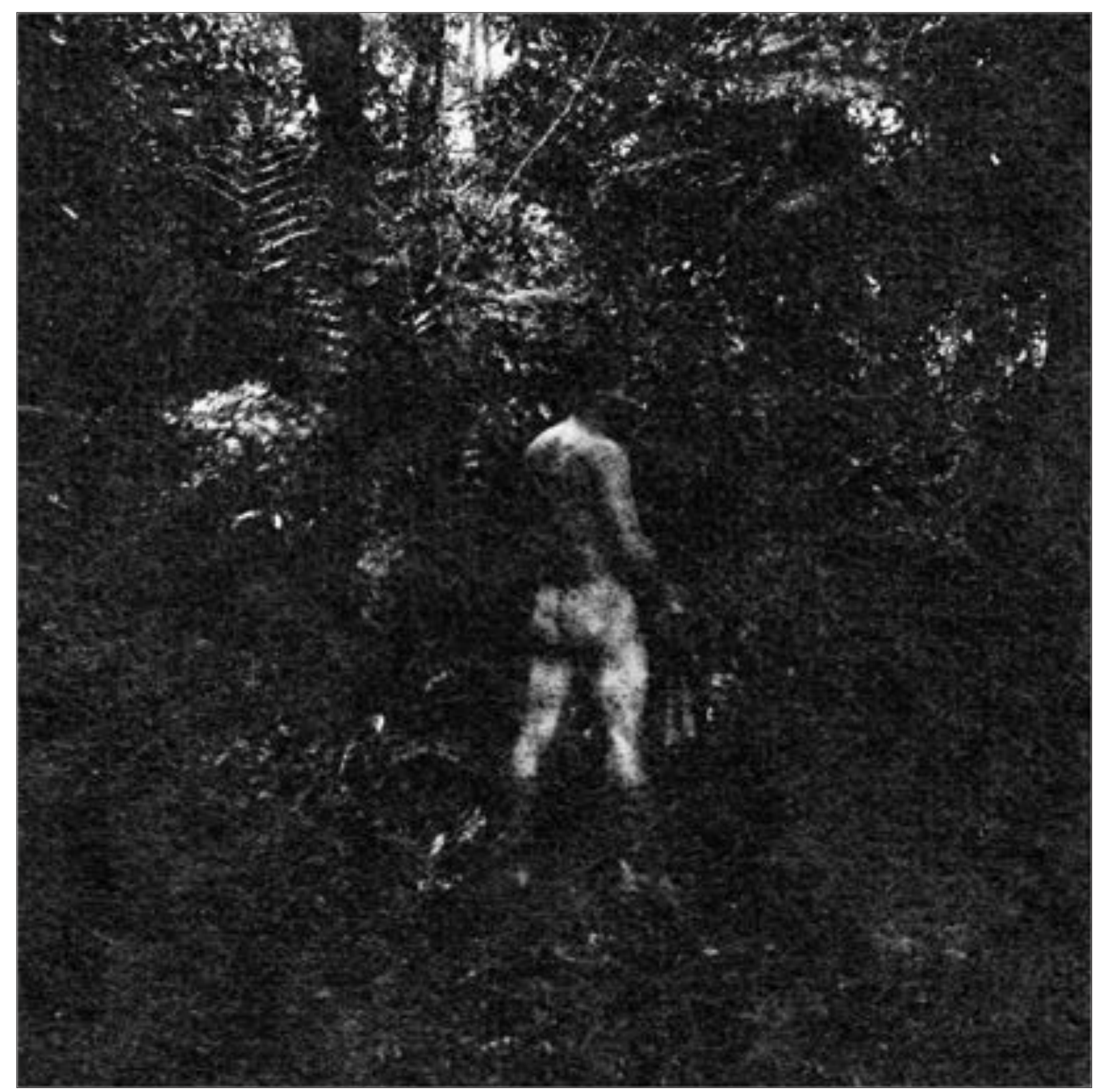

Sin título/Untitled \#1, Cauca, 2017. [Calotipo/Calotype] 
Llegué por mis propios medios. Solicité la admisión porque realmente quería hacerlo. Fue una decisión difícil para mí. Quería saber por qué lucharon las guerrillas. No lo sabía, no lo entendía ... y quería saber ... Le pregunté a mis padres y nunca tuvieron una respuesta verdadera. Pero quería averiguar ... dijeron que la guerrilla era mala. Más de una vez los escuché hablar así. Tal vez no sería bueno para mí unirme a ellos ... peligroso y matar gente y todo eso ... fue lo que me dijeron, así que quería saber.

I arrived, by my own means. I applied for admission because I really wanted to. It was a difficult decision for me. I wanted to know why the guerrillas fought. I didn't know that, I didn't understand ... and I wanted to know ... I asked my parents and they never had a true answer. But I wanted to find out ... they said that the guerrillas were bad. More than once I heard them talk like that. Maybe it would not be good for me join with them ... dangerous and killing people and all that ... was what they told me, so I wanted to know. 


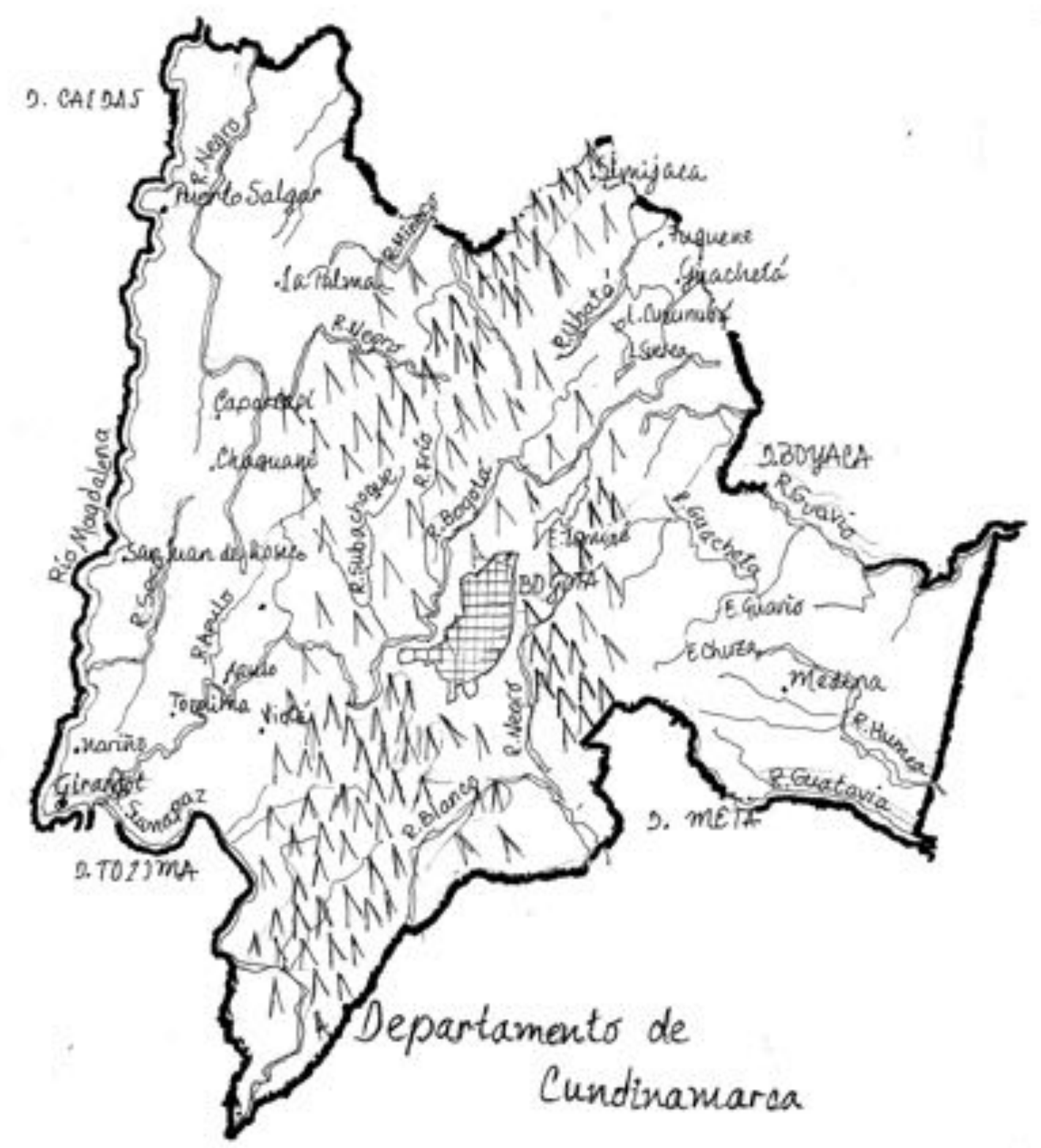


Cuando cumplí doce años, me pusieron en un equipo de mulas, conduje las mulas ... Cuando cumplí catorce años me dieron mi primer rifle ... Tenía un curso militar básico y mi primer combate estaba en ... Tenía catorce años antiguo ...

When I turned twelve, they put me on a mule team, I drove the mules ... When I turned fourteen years old they gave me my first rifle ... I had a basic military course and my first combat was in ... I was fourteen years old ... 


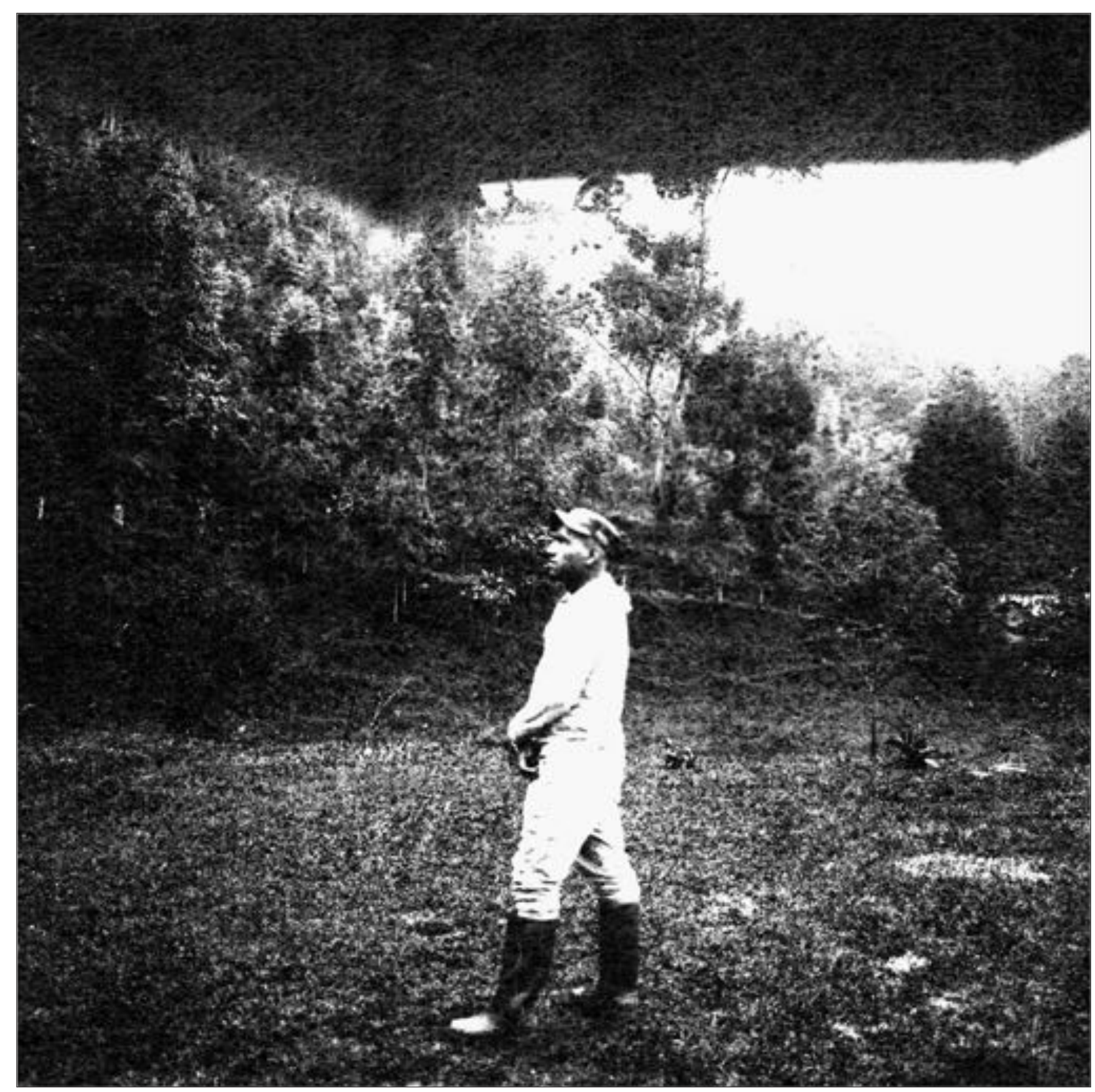

Sin título/Untitled \#2, Cauca, 2017. [Calotipo/Calotype] 
Bueno, a la edad de 22 años, decidí unirme a un grupo guerrillero armado ... en ese momento era un estudiante universitario en la Universidad Nacional, estaba estudiando, estaba en medio de un título de Ingeniería de Sistemas, soy Ingeniero de Sistemas de la Universidad Nacional. Y decidí unirme, porque consideraba que el estado colombiano me había cometido una afrenta, es decir, la toma y recuperación del tribunal en 1985, un hecho en el que el tribunal fue aniquilado y donde no había posibilidad de diálogo, entre grupo insurgente y el gobierno en el poder, una recaptura que tuvo como trasfondo algunos acuerdos de paz violados, no cumplidos por el estado, y hubo aproximadamente 100 muertos, y hubo 11 personas desaparecidas, una de ellas era mi hermana.

Well, at the age of 22, I decided to join an armed guerrilla group ... at that time I was a university student at the National University, I was studying, I was in the middle of a Systems Engineering degree, I am a Systems Engineer from the National University. And I decided to join, because I considered that the Colombian state committed an affront to me, that is, the seizure and recapture of the courthouse in 1985, a fact where the court was annihilated and where there was no possibility of dialogue, between the insurgent group and the government in power, a recapture that had as a background some violated peace agreements, not complied with by the state, and there were approximately 100 dead, and there were 11 missing persons, one of them was my sister. 


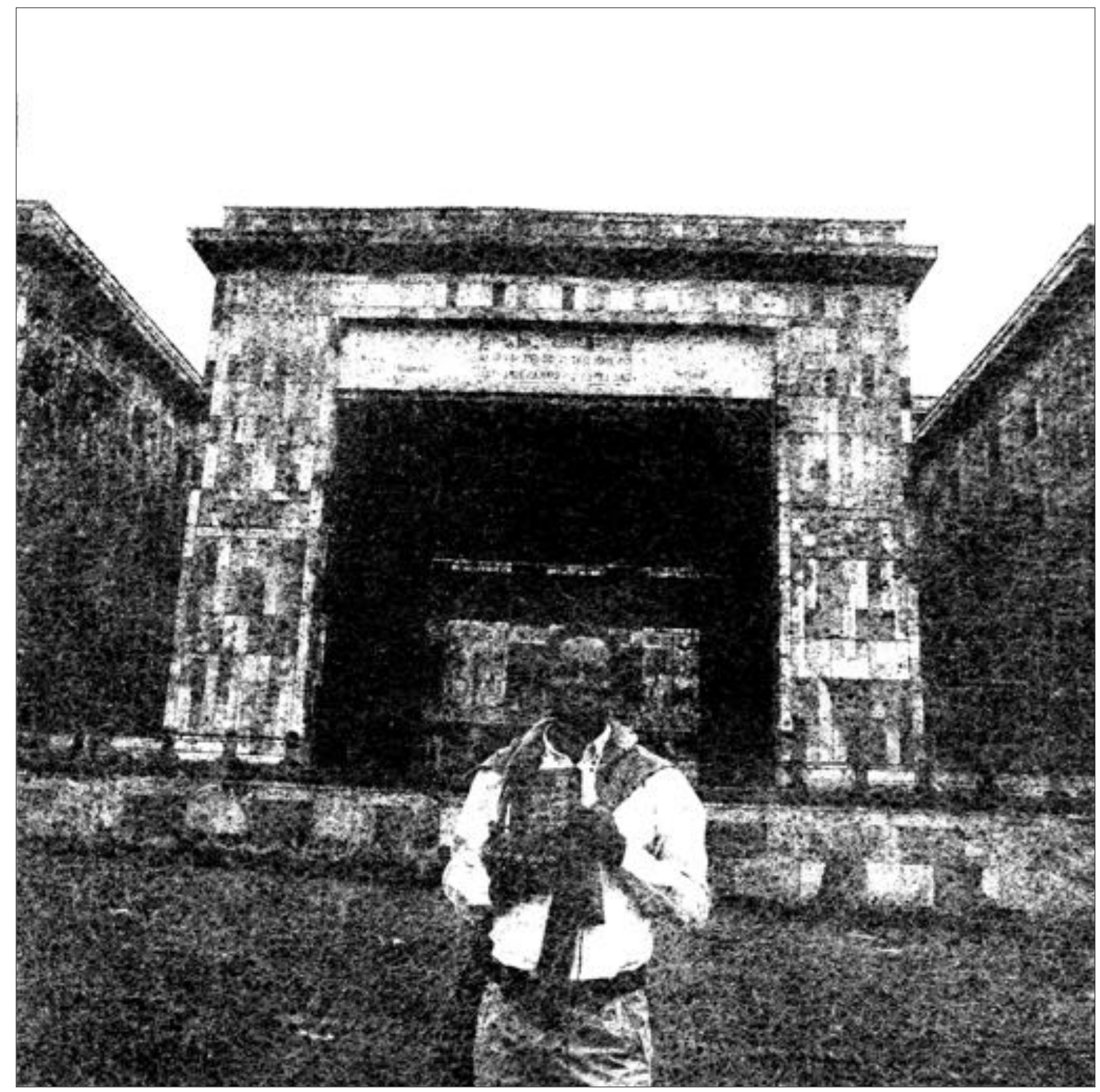

Sin título/Untitled \#3, Palacio de Justicia de Colombia, Bogotá, 2017. [Calotipo/Calotype] 
Los recuerdos oficiales manipulan el olvido para ocultar personas o sectores sociales e imponen su versión legitimadora. Pero los excluidos también pueden construir recuerdos que convoquen las muchas formas de poder. Hoy en día, los sectores tradicionalmente invisibles para la mayoría del país, como las mujeres, los negros, los indios, los jóvenes y las personas sin hogar, han propuesto llenar sus silencios con palabras y recuperar sus historias como parte de un proceso de construcción de identidad y la búsqueda del reconocimiento social. La memoria rescata del pasado las huellas de identidad que necesita con respecto al presente; allí radica su potencial de cambio.

Official memories manipulate forgetting to hide people or social sectors and impose their legitimising version. But the excluded can also construct memories that summon the many forms of power. Nowadays sectors traditionally invisible for the majority of the country like women, Blacks, Indians, youth and the homeless - have proposed filling their silences with words and recovering their stories as part of a process of identity-construction and the search for social recognition. Memory rescues from the past the traces of identity that it needs with respect to the present; therein lays its potential for change. 


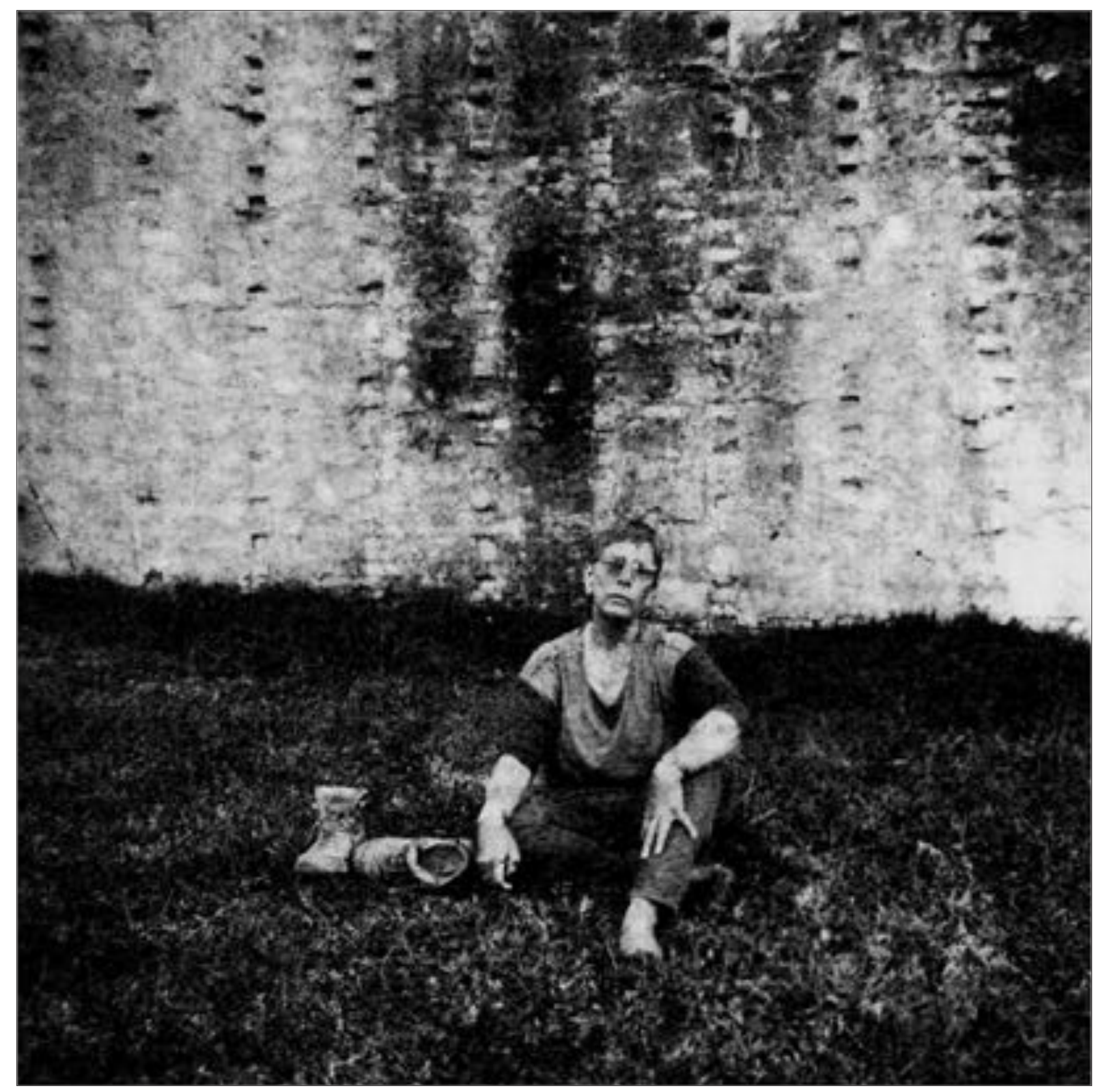

Sin título/Untitled \#4, Centro de Memoria, Bogotá, 2017. [Calotipo/Calotype] 
Comencé la actividad política a una edad muy temprana ... tal vez alrededor de los 15 años, cuando ya era un líder estudiantil, poco tiempo después ya era un líder comunitario. Como líder juvenil, comienzo a sentir la persecución. Entonces, después de las protestas, porque debemos recordar que en ese momento las protestas estaban prohibidas y penalizadas. Recordando lo que recordaba de todas las personas que ya sabía que habían desaparecido, que habían sido víctimas de tortura ... para mí fue bastante difícil continuar.

I started political activity at a very early age ... maybe around 15 years old, when I was already a student leader, a short time later I was already a community leader. As a youth leader, I begin to feel the persecution. So after the protests, because we must remember that at that time protesting was prohibited and penalized. Remembering what I remembered about all the people that I already knew that had been disappeared, who had been victims of torture ... for me it was quite difficult to continue. 


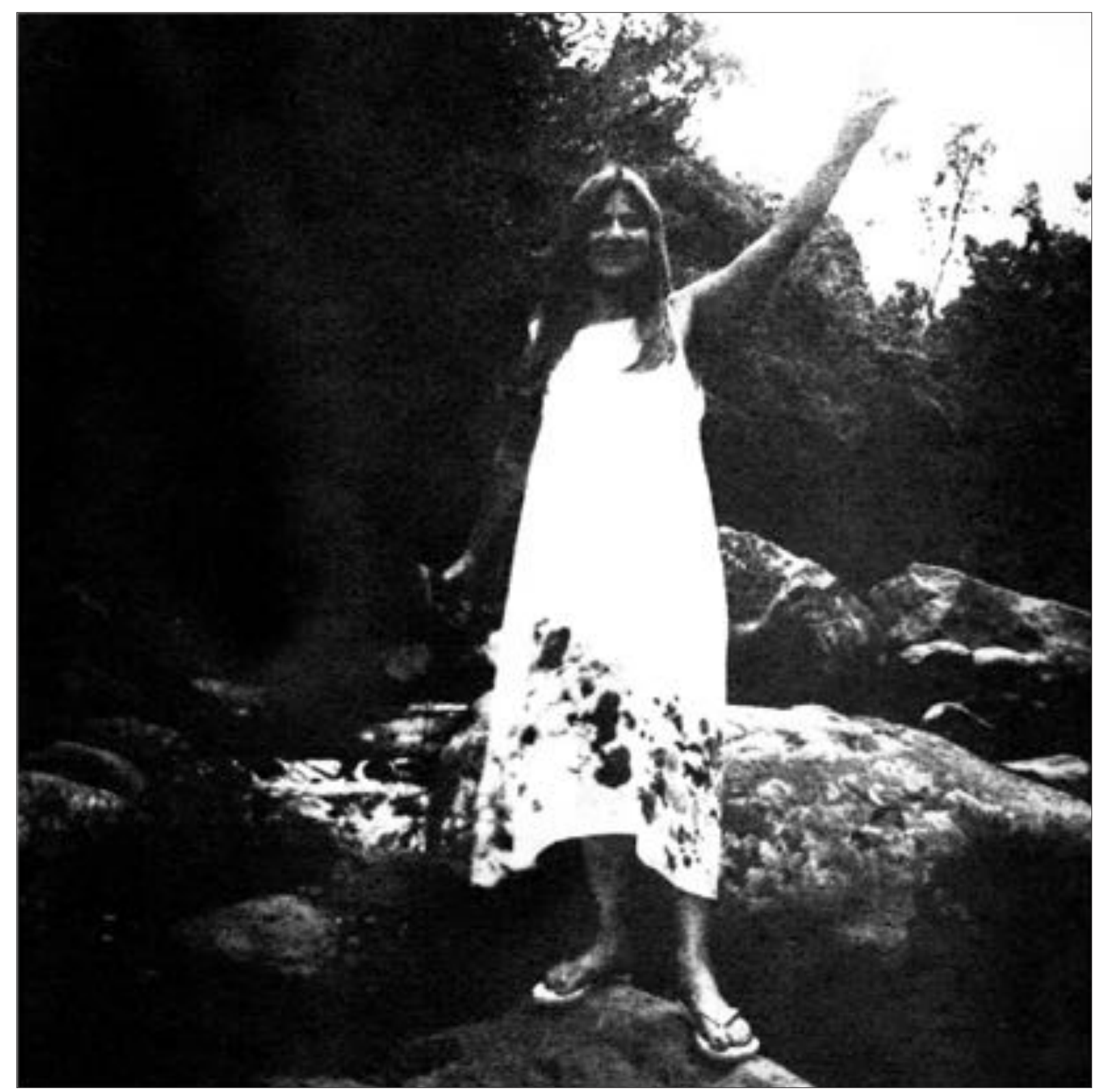

Sin título/Untitled \#5, La Calera, 2019. [Calotipo/Calotype] 
Cuando tenía cinco años, vivíamos en el centro urbano de Santa Rosa y las guerrillas de las FARC atacaron una patrulla del ejército y la policía, quiero decir, en medio de la confrontación, mi hermana de 10 años fue asesinada.

When I was five years old, uh, we lived in the urban center of Santa Rosa and, uh, the FARC guerrillas attacked, uh, a patrol of the army and the police, uh, in I mean, in the middle of the confrontation, my 10-year-old sister was killed. 


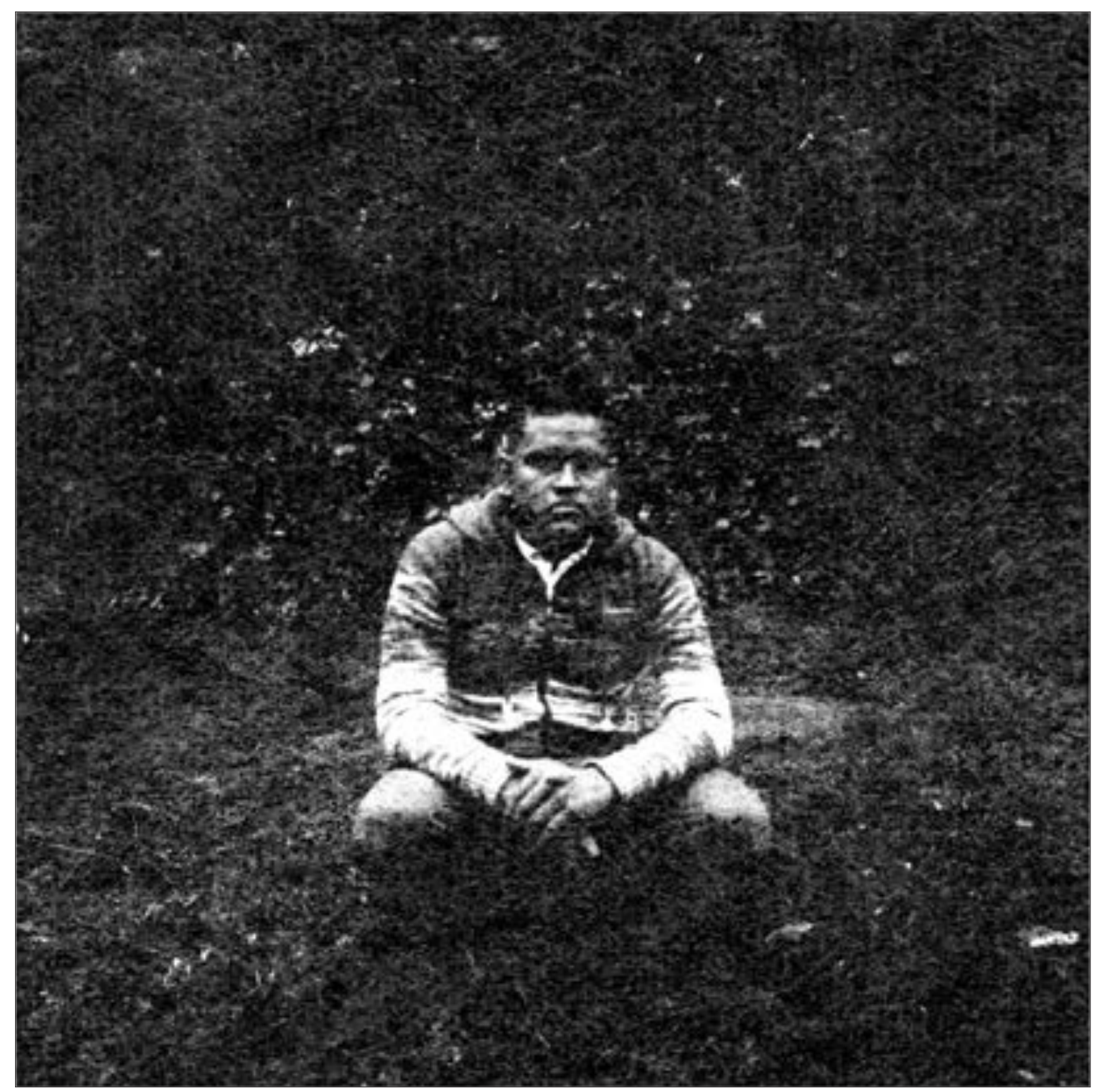

Sin título/Untitled \#6, Parque Renacimiento, Bogotá, 2017. [Calotipo/Calotype] 


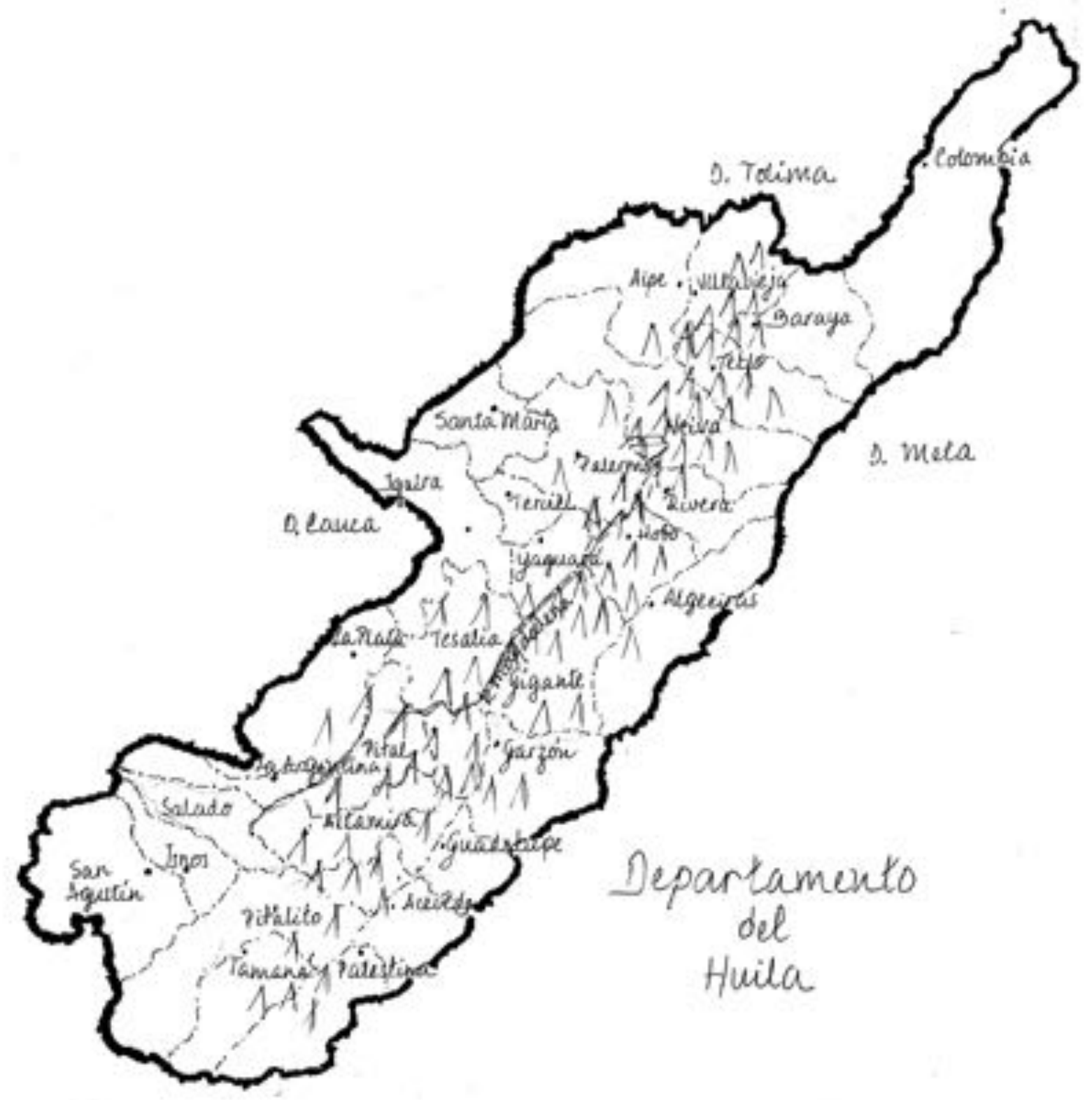




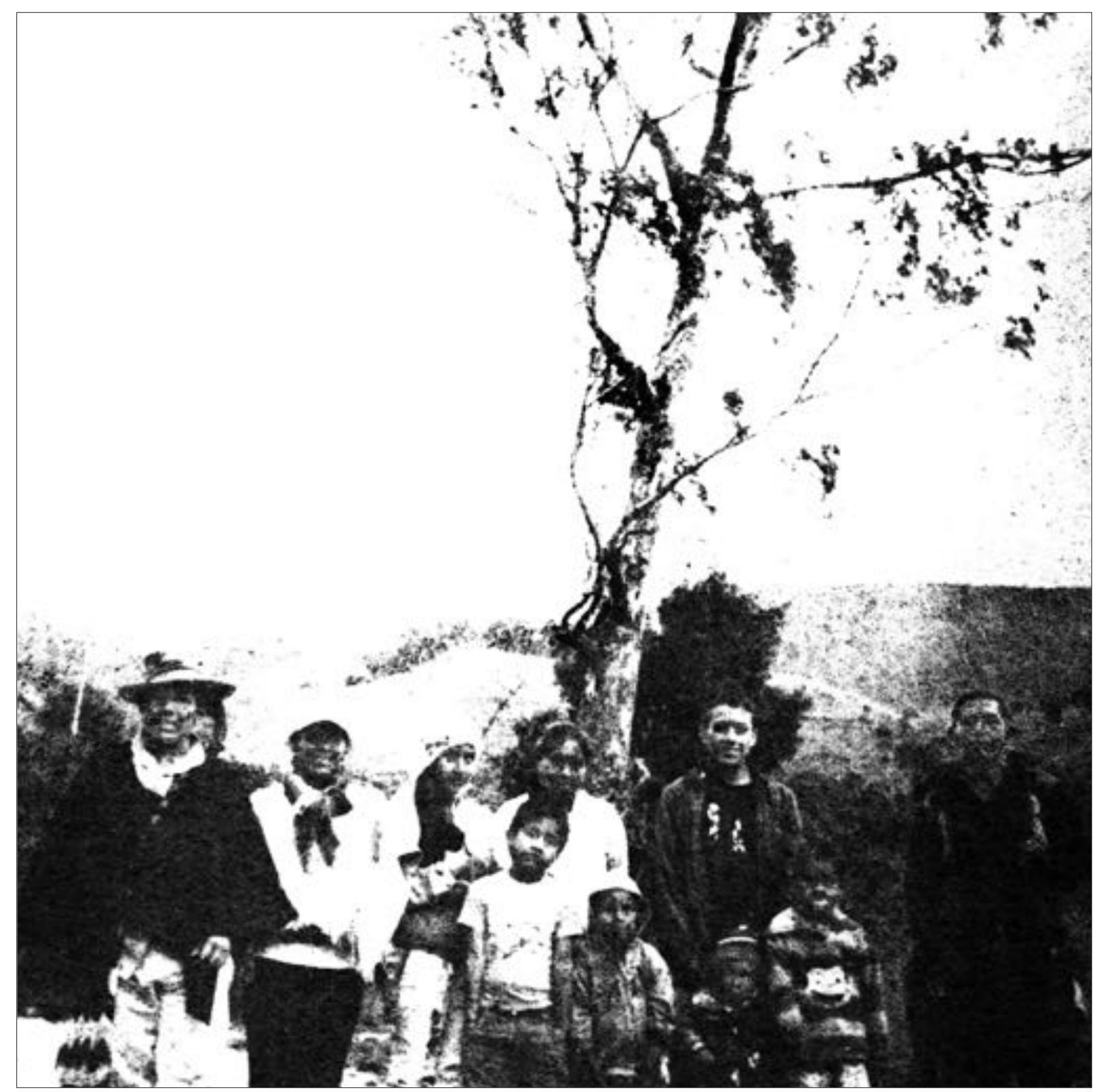

Sin título/Untitled \#7, Paispamba, Cauca, 2018. [Calotipo/Calotype] 
Los campesinos me salvaron la vida muchas veces. Me escondieron del ejército, me dieron agua cuando tenía sed ... me salvaron la vida varias veces, muchas veces ... Me escondieron en combate ... Bueno, en una pelea que tuvimos en un pueblo $X$, me abrigaron mientras el ejército pasaba.

The peasants saved my life many times. They hid me from the army, they gave me water when I was thirsty ... they saved my life several times, many times ... They have hidden me in combat ... Well, in a fight that we had in X town, they sheltered me while the army passed. 


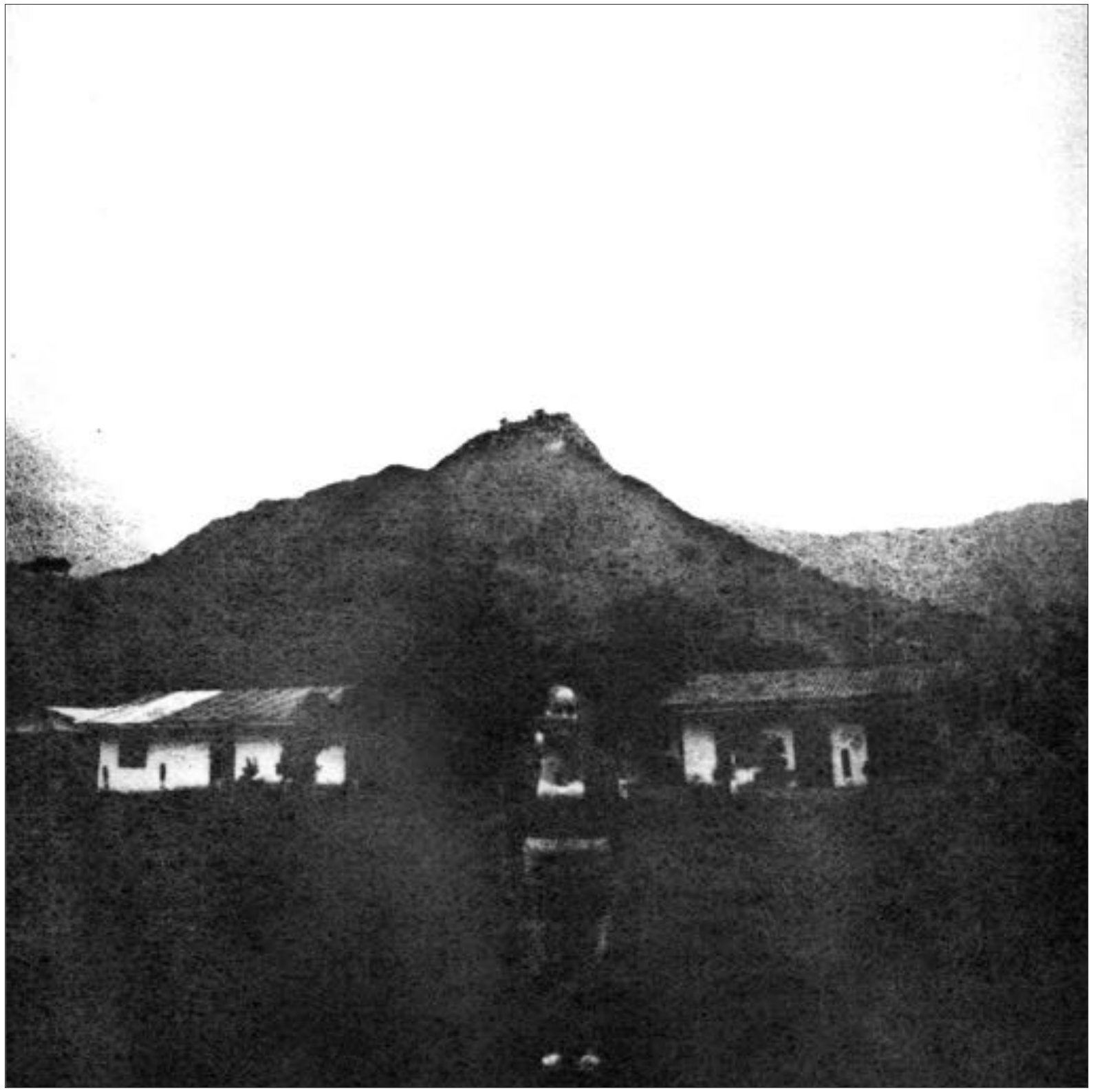

Sin título/Untitled \#8, La Mesa de Togoima, Cauca, 2018. [Calotipo/Calotype] 
¿Después de que me fui? Empecé a enseñar, ya que soy músico, así que comencé en el área de la música, el arte y lo más importante, los derechos humanos. Hoy en día, en los barrios de Bogotá, desde la administración de Gustavo Petro, he estado trabajando en el campo de los derechos humanos, apoyando su causa hasta el punto en que es posible apoyar, transmitiendo a las personas lo que son los derechos humanos, el conocimiento, los talleres. Combino con la parte musical. Eso es más o menos así.

After I left? I got into teaching, since I am a musician, so I started in the area of music, art and most importantly, human rights. Nowadays, in the neighborhoods of Bogotá, from within the administration of Gustavo Petro I have been working in the field of human rights, supporting their cause to the point where it is possible to support, transmitting to people what human rights are, knowledge, workshops I combine with the musical part. That is pretty much it along those lines. 


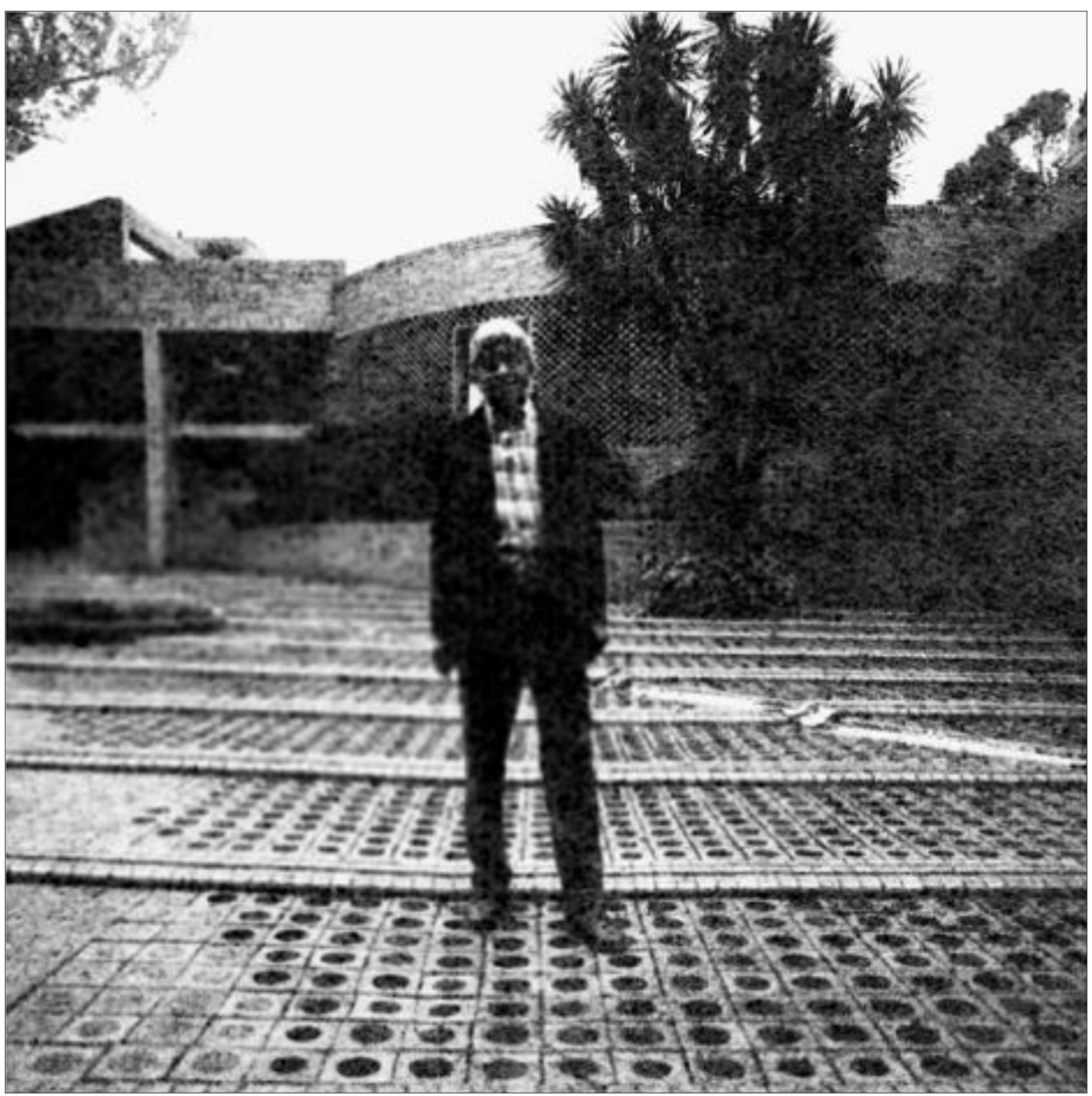

Sin título/Untitled \#9, Universidad Nacional de Colombia, Bogotá, 2017. [Calotipo/Calotype] 
En el '64 lo que pedíamos era participación política, lo que se pedía era escuelas, carreteras, vivienda, educación, hospitales, eso era lo que se quería. Y, pero nunca tuvimos el gobierno, dada la oportunidad a nuestros líderes, hasta que aprovechamos la oportunidad, y la paz es lo que buscamos. Hemos luchado por la paz por muchos, durante 53 años, y hoy nos dan la oportunidad, vamos por la paz.

In 64 what we were asking for was political participation, what was asked for was schools, roads, housing, education, hospitals, that was what was wanted. And, but never had the government, given the opportunity to our leaders, until we grasped the opportunity, and peace is what we seek. We have fought for peace for so many, for 53 years, and today they give us the opportunity, we are going for peace. 


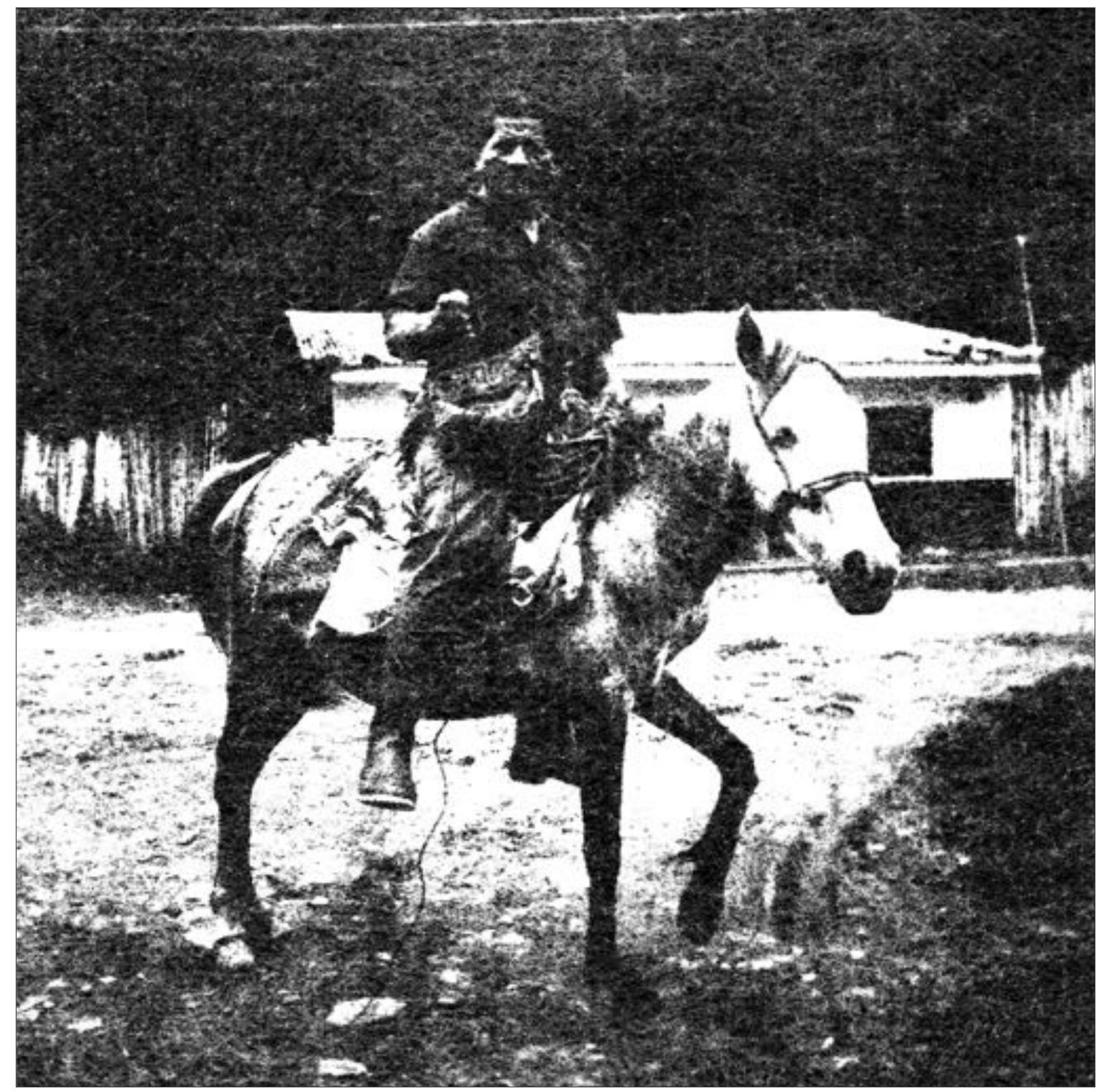

Sin título/Untitled \#10, La Mesa de Togoima, Cauca, 2018. [Calotipo/Calotype] 
Mis otros camaradas que formaban parte de la milicia fueron capturados ... Fueron más secuestrados que capturados por un grupo llamado Armados Ilegales Dependientes de la DIJIN de Bogotá, ¿sabes? La policía, quienes fueron los secuestradores, los torturó y luego los mató, y arrojó sus cuerpos a un vertedero de basura llamado Mondoñedo, ubicado en las afueras de Bogotá. Esto se conoce como la masacre de Mondoñedo. Fueron asesinados, torturados, y las familias apenas podían reconocer sus restos, si no fuera por su ADN.

My other comrades who were part of the militia, were captured ... They were more like kidnapped than captured by a group called Armados Ilegales Dependientes de la DIJIN de Bogotá, you know? The police, who were the ones that did the kidnapping, tortured them and then killed them, and dumped their bodies into a garbage landfill called Mondoñedo, located in the Bogota outskirts. This is known as the Mondoñedo massacre. They were murdered, tortured, and the families could hardly recognise their remains, had it not been for their DNA. 


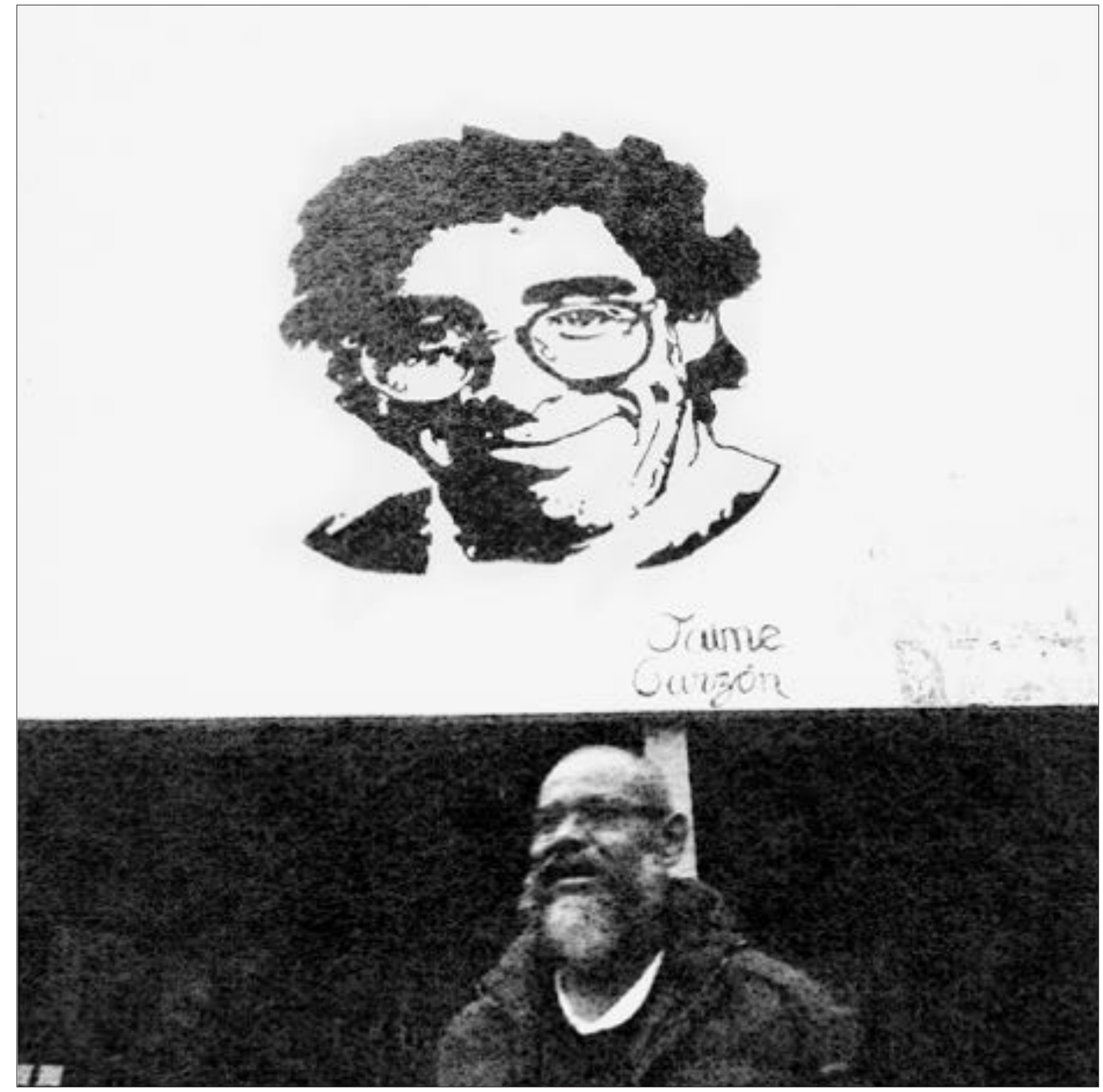

Sin título/Untitled \#11, Universidad Nacional de Colombia, Bogotá, 2017. [Calotipo/Calotype] 
¿Cómo me uno a la sociedad? ... Volver a unirse es ... es decir, no hay adjetivo, en mi opinión. En mi opinión, no hay sustantivo ni adjetivo para lo que estamos haciendo. Es simplemente un paso que estamos dando, porque no estamos siendo reintegrados, reincorporados o adaptados, ni estamos siendo sanados, no estamos y no estamos enfermos ... somos más bien ... parte de la sociedad en otro camino. Tampoco marginal. Somos un actor en esta sociedad.

How do I rejoin society? ... To rejoin is ... that is, there is no adjective, in my opinion. In my opinion, there is no noun or adjective for what we are doing. It is simply a step that we are taking, because we are not being reintegrated, reincorporated, or adapted, nor are we being healed, we are not and we are not sick ... we are rather ... part of society in another way. Not marginal, either. We are an actor in this society. 


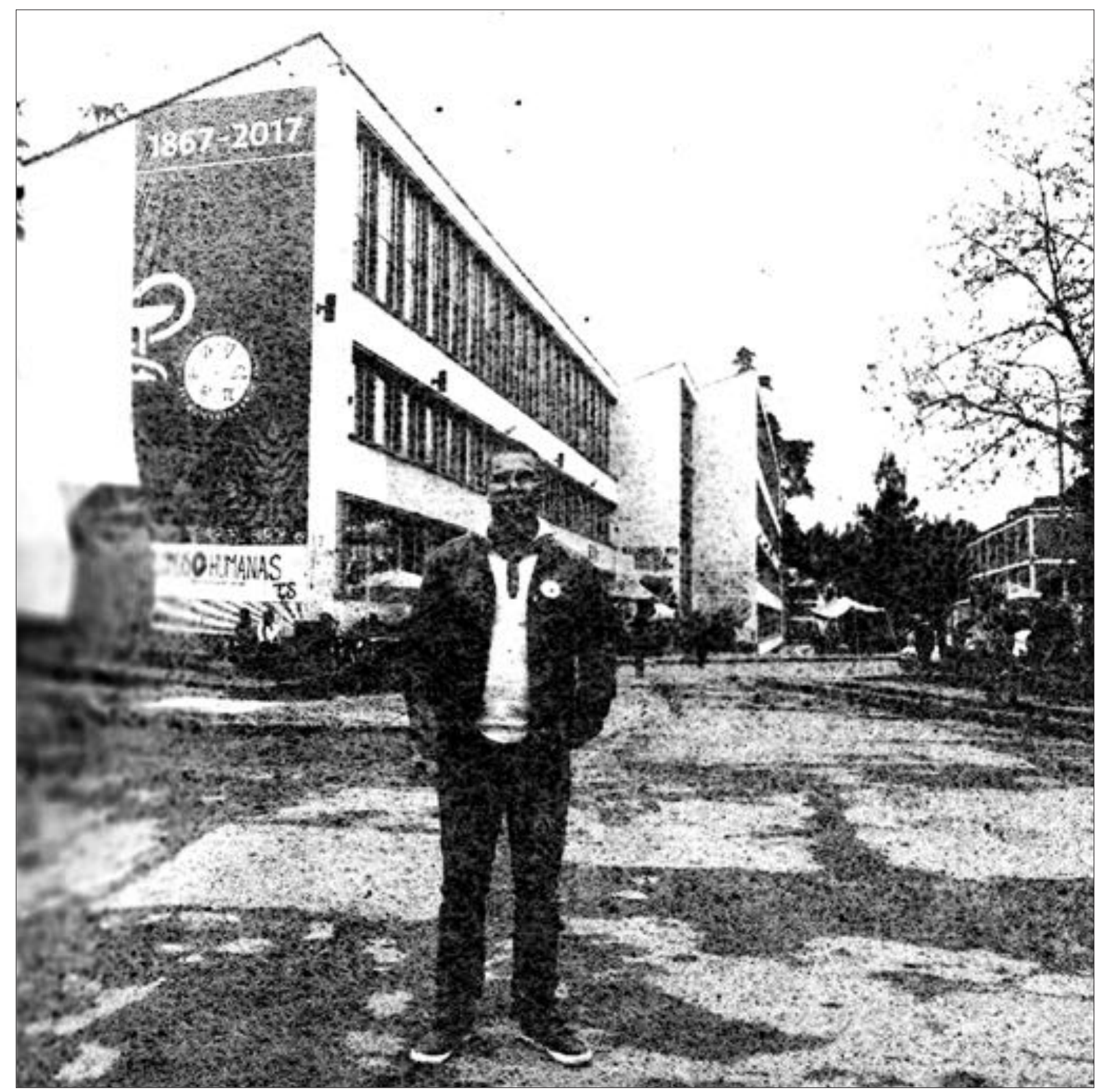

Sin título/Untitled \#12, Universidad Nacional de Colombia, Bogotá, 2017. [Calotipo/Calotype] 
unto del valle

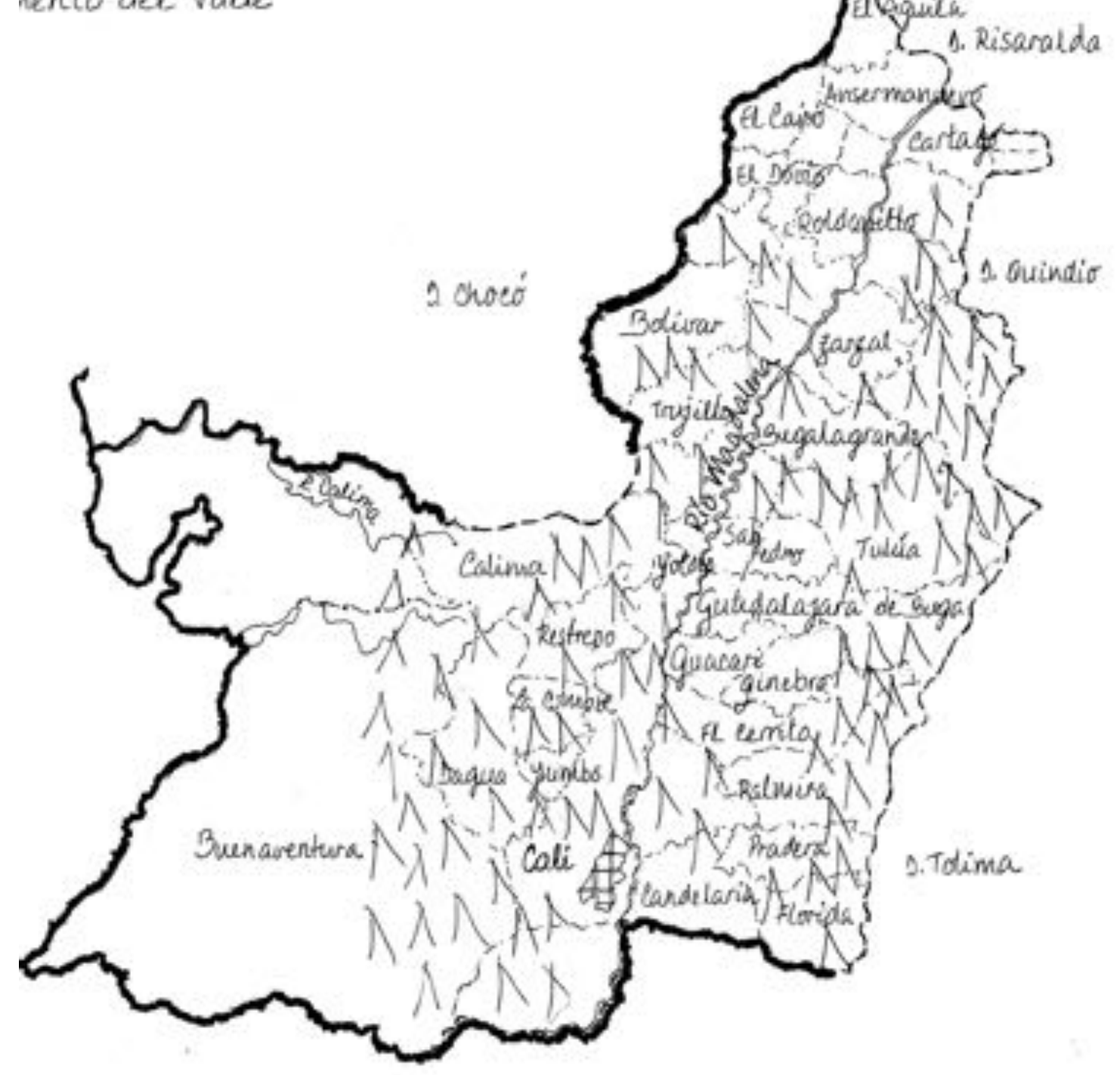




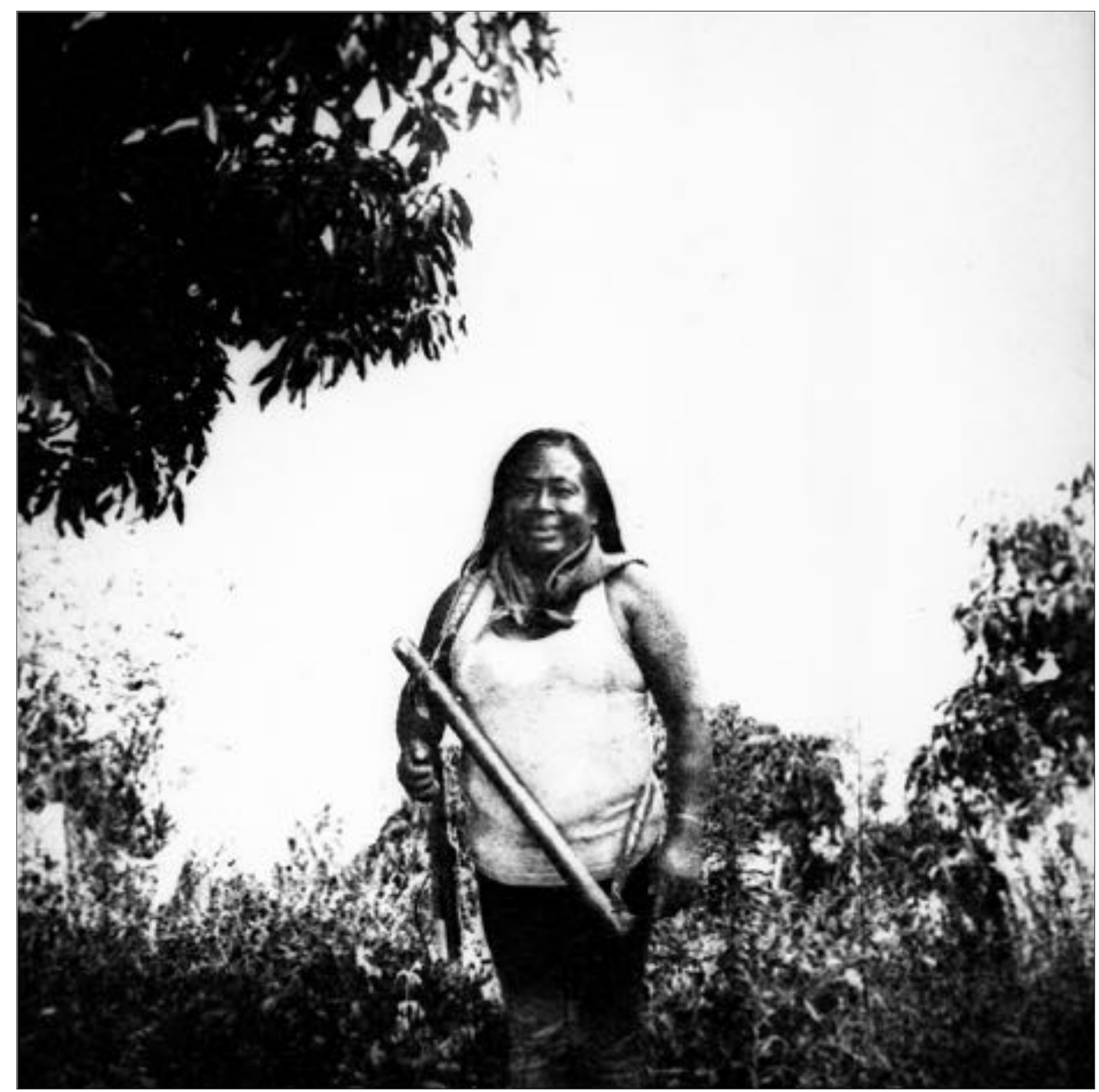

Sin título/Untitled \#13, La Mesa de Togoima, Cauca, 2018. [Calotipo/Calotype] 
Esta no es una guerra entre dos bandos. Esta es una guerra entre la vida y la muerte. No es una guerra entre comunismo, socialismo, capitalismo, ¡no! Es una guerra entre la vida y la muerte. Entre los que quieren vendernos la cultura capitalista occidental, que como un zombi ... su modelo ... es una analogía que hago ... con los seres humanos ... a la que no queremos dejar comernos el cerebro, el alma o el cuerpo.

This is not a war between two sides. This is a war between life and death. It is not a war between communism, socialism, capitalism, no! It is a war between life and death. Among those who want to sell us Western capitalist culture, which like a zombie ... their model ... is an analogy that I make ... with human beings ... with which we do not want to let eat the brain, the soul, or the body. 


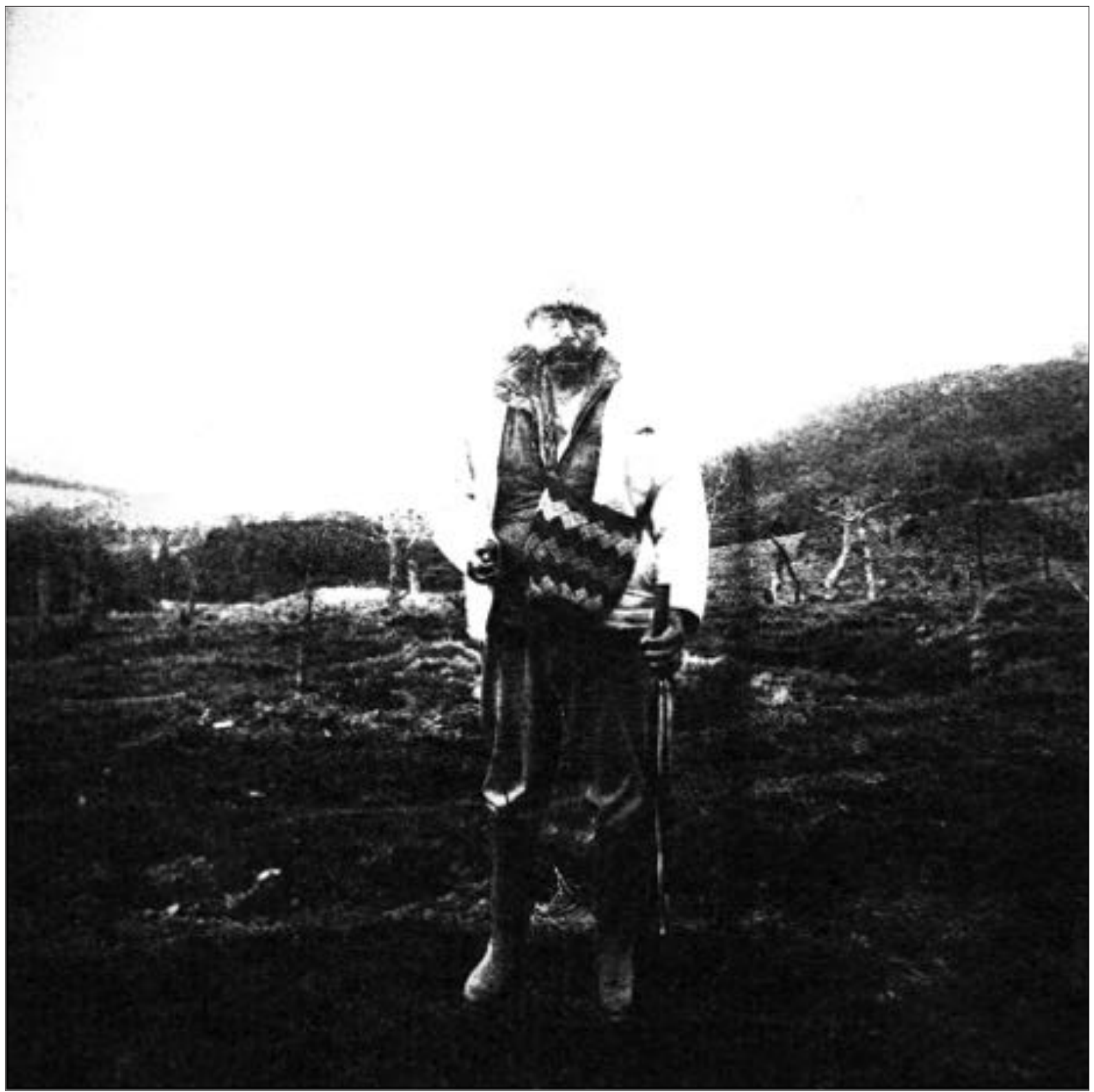

Sin título/Untitled \#14, Paispamba, Cauca, 2018. [Calotipo/Calotype] 
Mi sueño es obtener una educación ... Por el futuro de mi hijo. Todo lo que hago es por mi hijo. He tenido que hacer todo por mi cuenta. Su padre fue asesinado. Murió en un bombardeo. Mi hijo nunca lo conoció. Entonces, tuve que criarlo yo sola. Ha sido muy difícil pero lo he logrado. Um, como auxiliar de enfermería. Gracias a Dios que estoy bien. Bueno, recién estamos comenzando. Llevo cuatro meses yendo a la escuela y es un programa de dos años. Sí, ir a la escuela, estudiar y todo ... lo estoy haciendo por mi hijo, por su futuro.

My dream is to get an education ... For my son's future. Everything I do is for my son. I have had to do everything on my own. His father was killed. He died in a bombing raid. My son never even met him. So, I had to bring him up by myself. It's been very hard but I have managed. Uhm, as an assistant nurse. Thank God I am doing okay. Well, we are just starting out. l've been going to school for four months now and it's a two year program. Yeah, going to school, studying and everything ... I'm doing it for my son - for his future. 


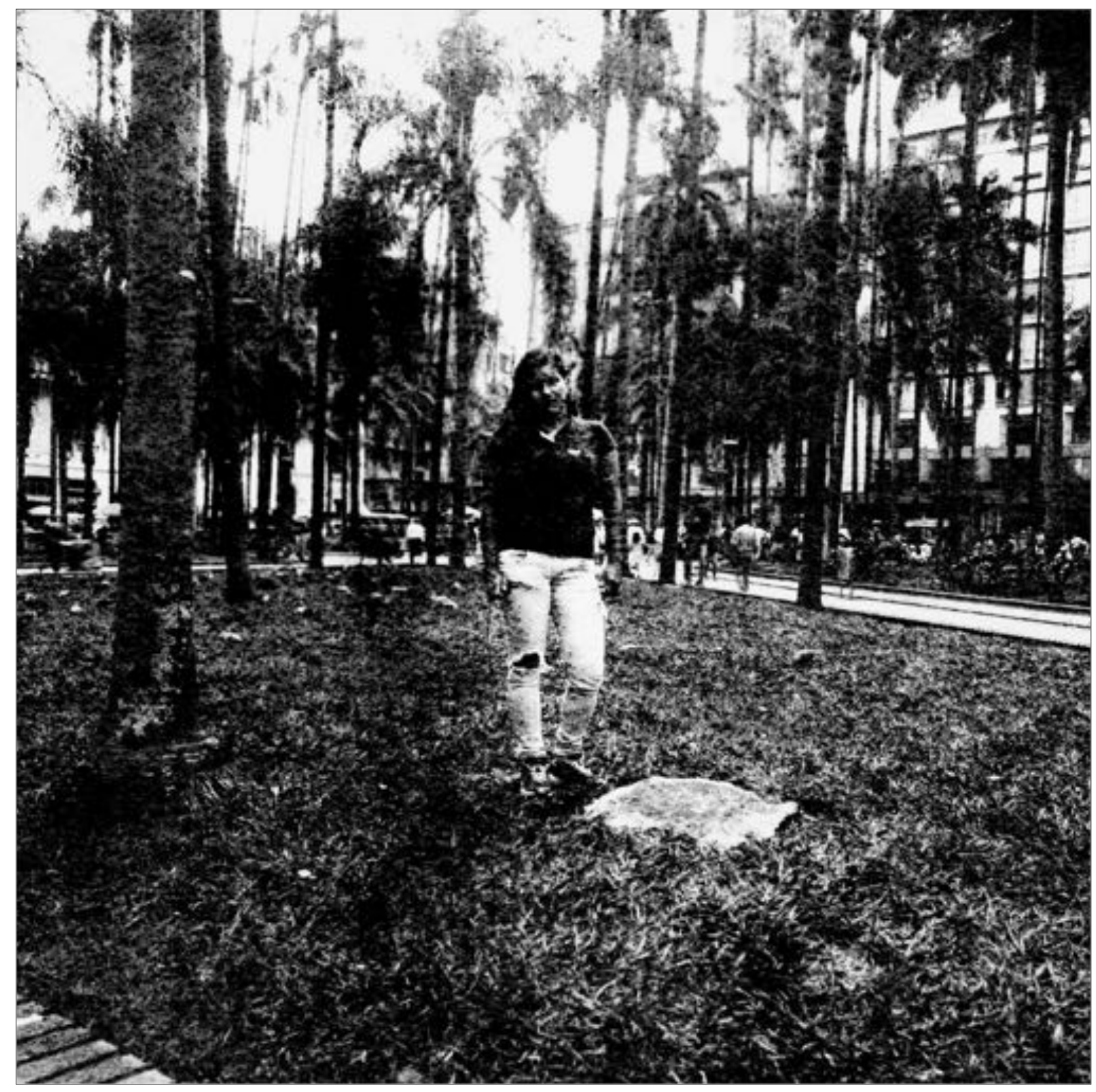

Sin título/Untitled \#15, Plaza de Caicedo, Cali, 2017. [Calotipo/Calotype] 
Siempre hemos buscado la salida a través del diálogo, y cuando llegó este momento, y para avanzar en el acuerdo de paz, ese es uno de los gestos que mostramos, que realmente queremos la paz. Vi que era una forma necesaria, es decir, era la forma de lograr la paz.

We have always looked for the way out through dialogue, and as this moment came, and to advance the peace agreement, then, that's one of the gestures that we show, that we truly want peace. I saw that it was a necessary way, that is, it was the way to achieve peace. 


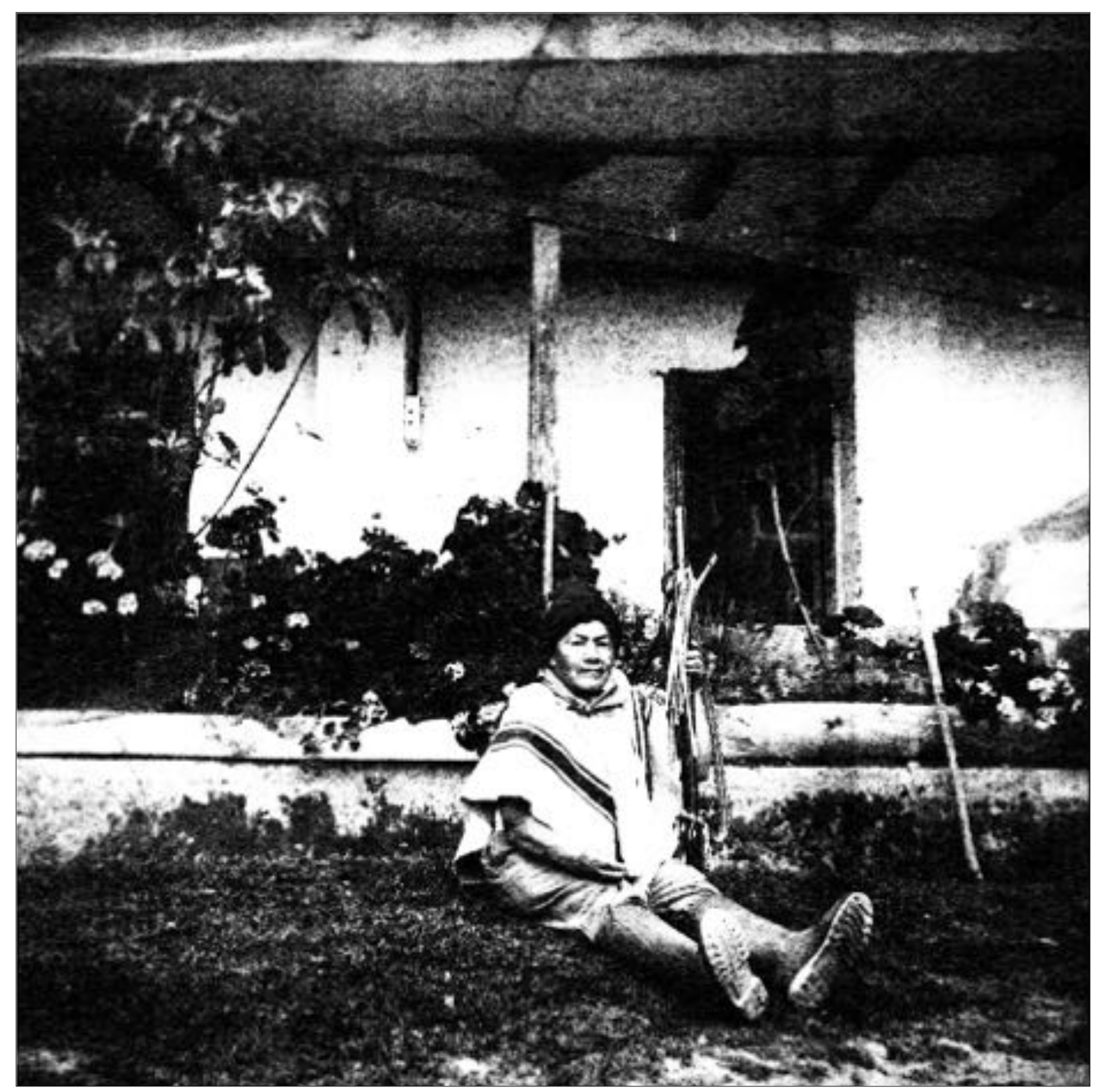

Sin título/Untitled \#16, Paispamba, Cauca, 2018. [Calotipo/Calotype] 


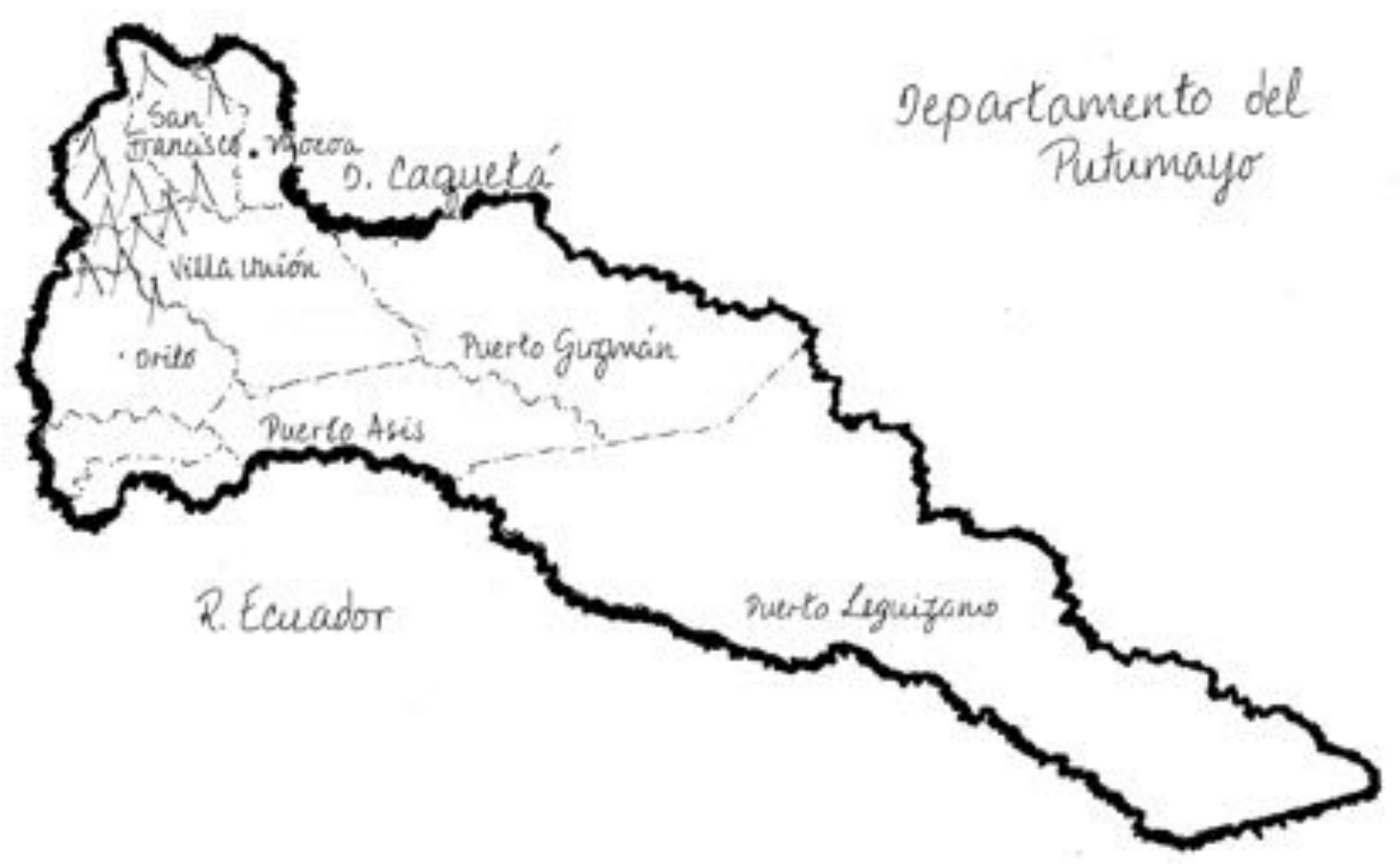




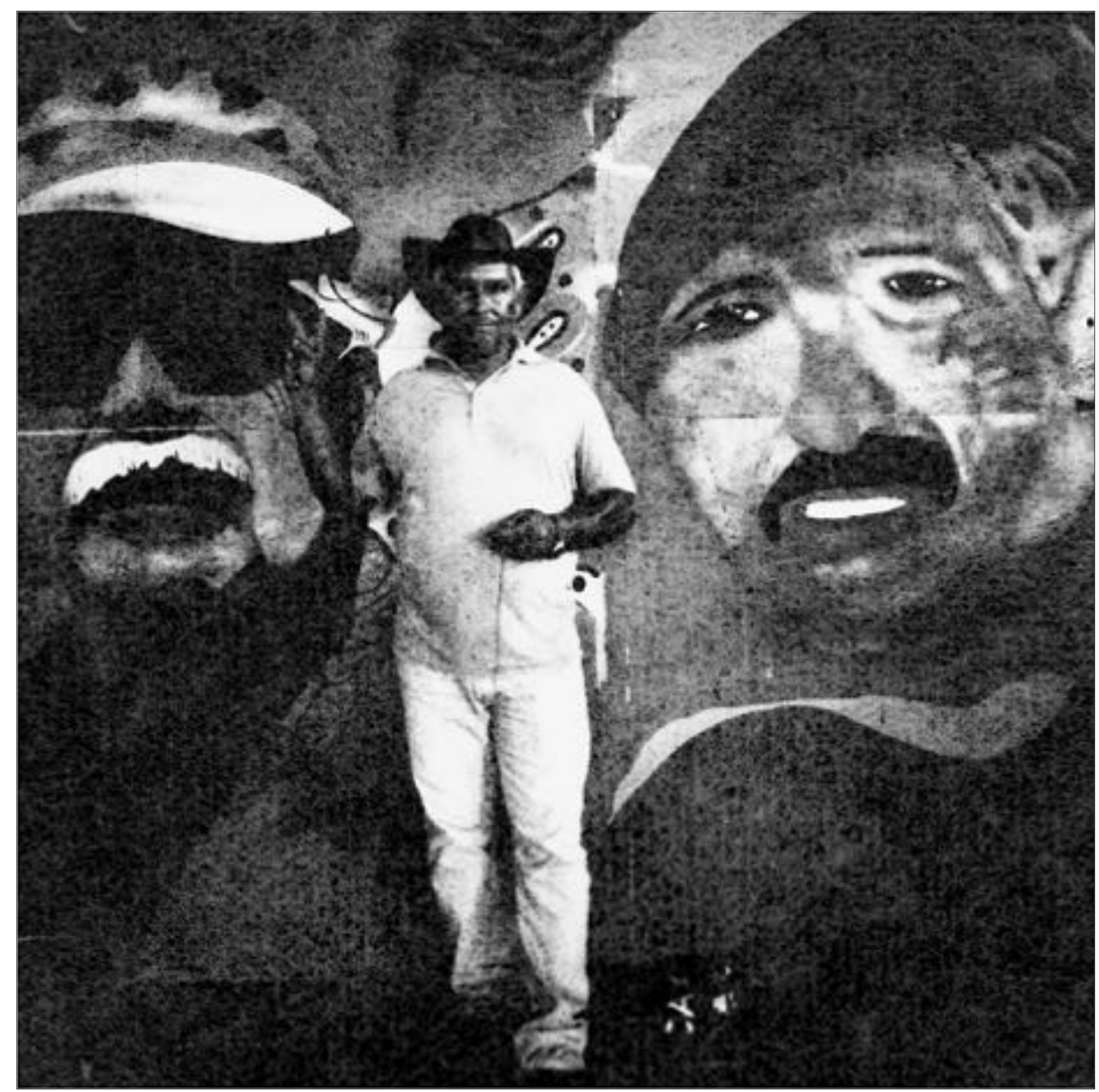

Sin título/Untitled \#17, Puerto Asis, 2017. [Calotipo/Calotype] 
Creo que Colombia debe caminar hacia la paz, la paz total, la paz total, no repetir la historia que hemos tenido durante más de 50 años, que es la historia de la guerra, la historia del conflicto armado, dejando sangre y dejando dolor, dejando viudas, dejando huérfanos, dejando muchos problemas.

I believe that Colombia must walk towards peace, full peace, total peace, not repeat the history that we have had for more than 50 years, which is the history of war, the history of armed conflict, leaving blood and leaving pain, leaving widows, leaving orphans, leaving many problems. 


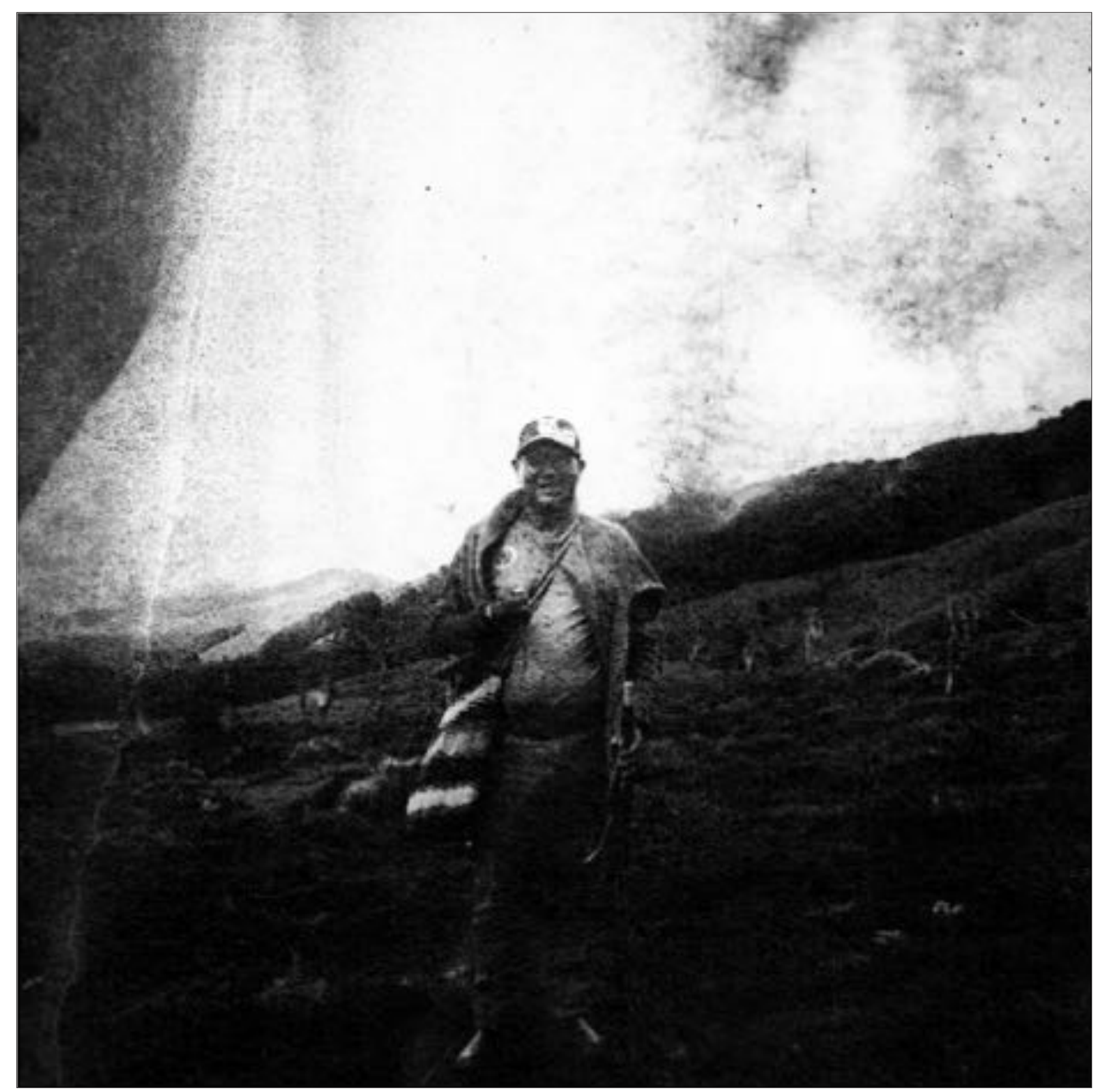

Sin título/Untitled \#18, Paispamba, Cauca, 2018. [Calotipo/Calotype] 


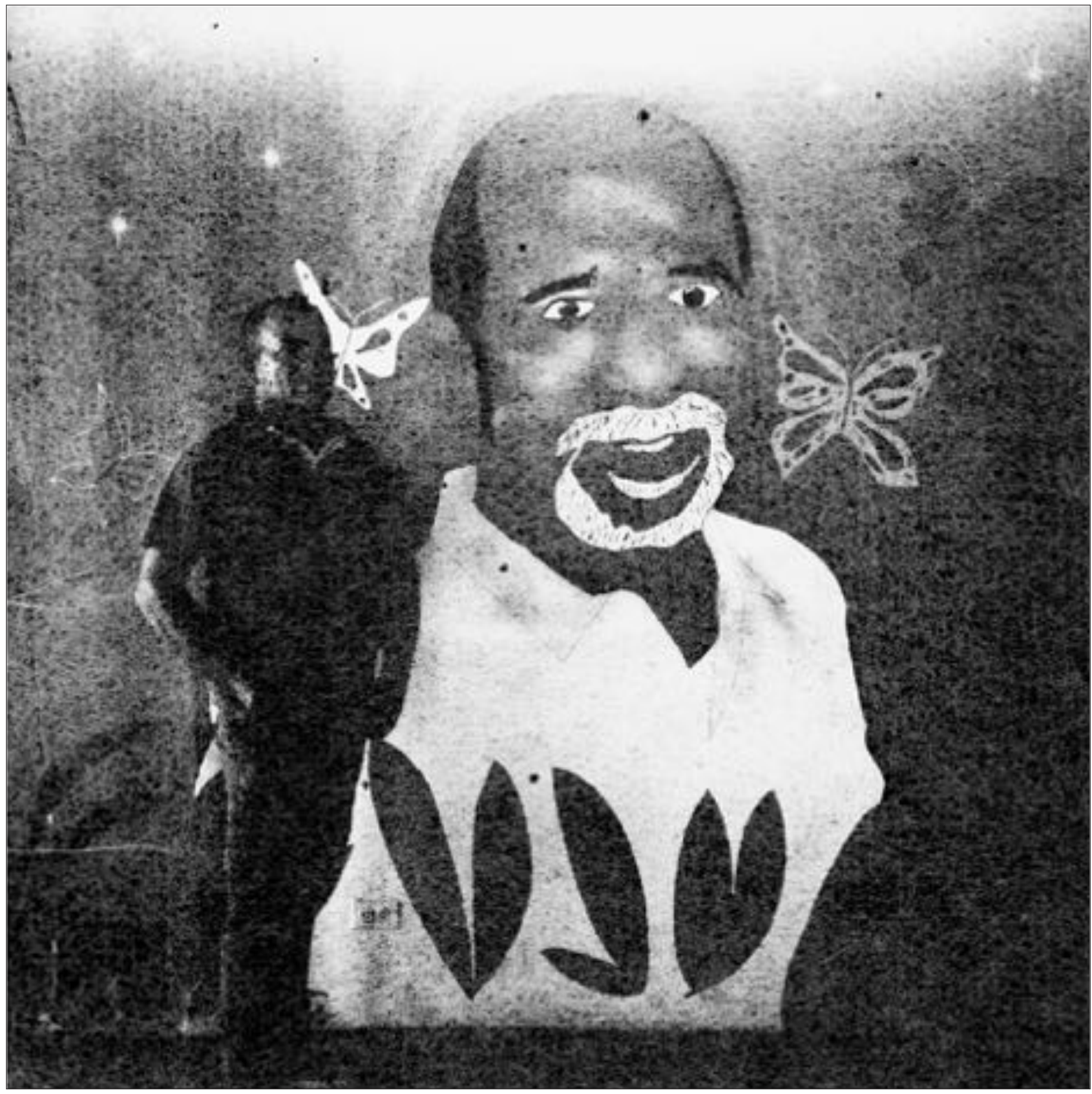

Sin título/Untitled \#19, Puerto Asis, 2017. [Calotipo/Calotype] 


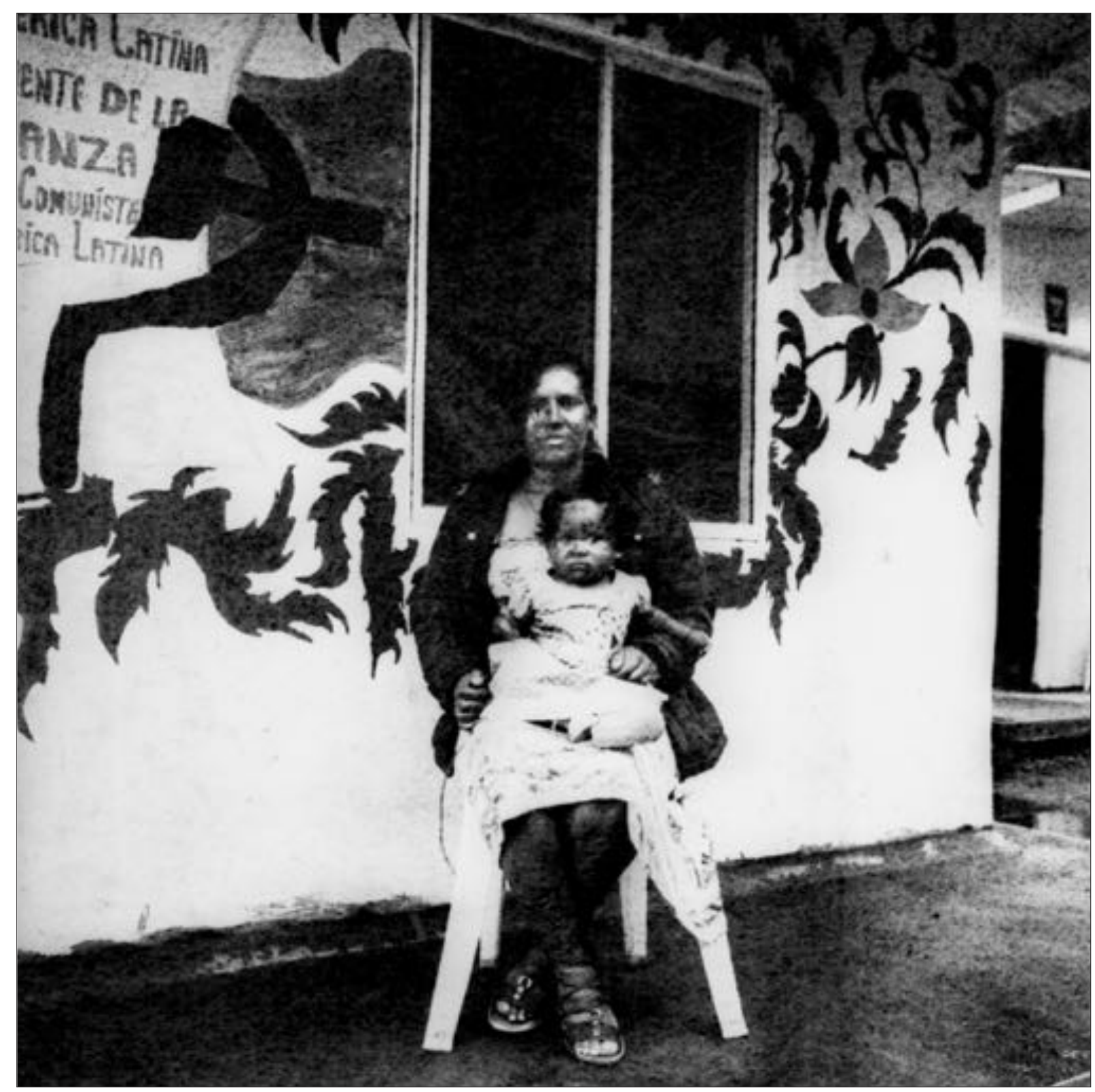

Sin título/Untitled \#20, Cauca, 2017. [Calotipo/Calotype] 
Diría que casi 90 , más de 90 de mis camaradas en toda Colombia han sido asesinados en los últimos 27 años, y bueno, todavía no tengo armas, pero sigo contribuyendo con mi grano de arena, de modo que en Colombia haya paz total, justicia social, y haya una Colombia más amable, como diríamos en tiempos de guerra, una Colombia del tamaño de nuestros sueños.

I would say almost 90 , more than 90 of my comrades in all of Colombia have been assasinated over the last 27 years, and well, I am still without weapons, but I continue to contribute my grain of sand, so that in Colombia, there is full peace, social justice, and there is a kinder Colombia, as we would say in times of war, a Colombia the size of our dreams. 


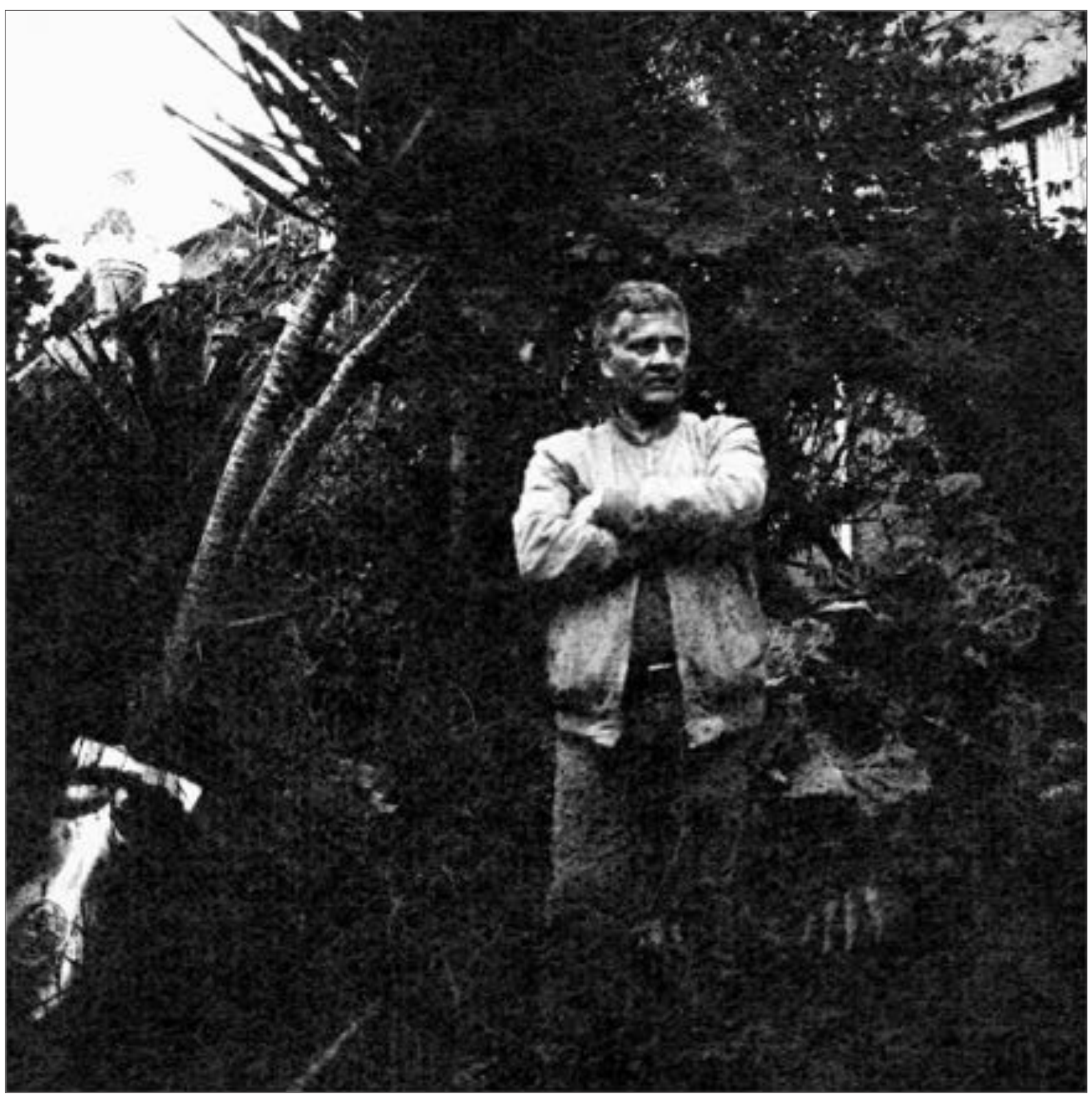

Sin título/Untitled \#21, San Luis, 2017. [Calotipo/Calotype] 
Mi sueño es que Colombia tenga que cambiar. Colombia tiene que ser un gran país para todos, donde todos vivamos con dignidad. Donde todos tenemos los mismos derechos. Donde todos participamos. Donde los recursos naturales pertenecen a las personas, y no solo a las multinacionales. Que son de nuestro pueblo ... que recuperamos nuestra cultura agrícola, donde se hacen productos agrícolas, maíz, arroz, que hay maquinaria para aprovechar esto, tener machimbradoras para procesar la madera que pertenece a los agricultores, que donde no hay escuelas, que construyan escuelas, para hacer todo eso, pero para todos. ¡No solo para nosotros, no! ¡Para todo el mundo!

My dream is that Colombia has to change. Colombia has to be a great country for all, where we all live with dignity. Where we all have the same rights. Where we all participate. Where natural resources belong to the people, and not just multinationals. That they are of our town... that we recover our agricultural culture, Where agricultural products are made, corn, rice, that there is machinery to, to take advantage of this, to have machimbradoras to process the wood that belongs to the farmers, that where there are no schools, that they build schools, to do all that, but for everyone. Not just for us, no! For everyone! 


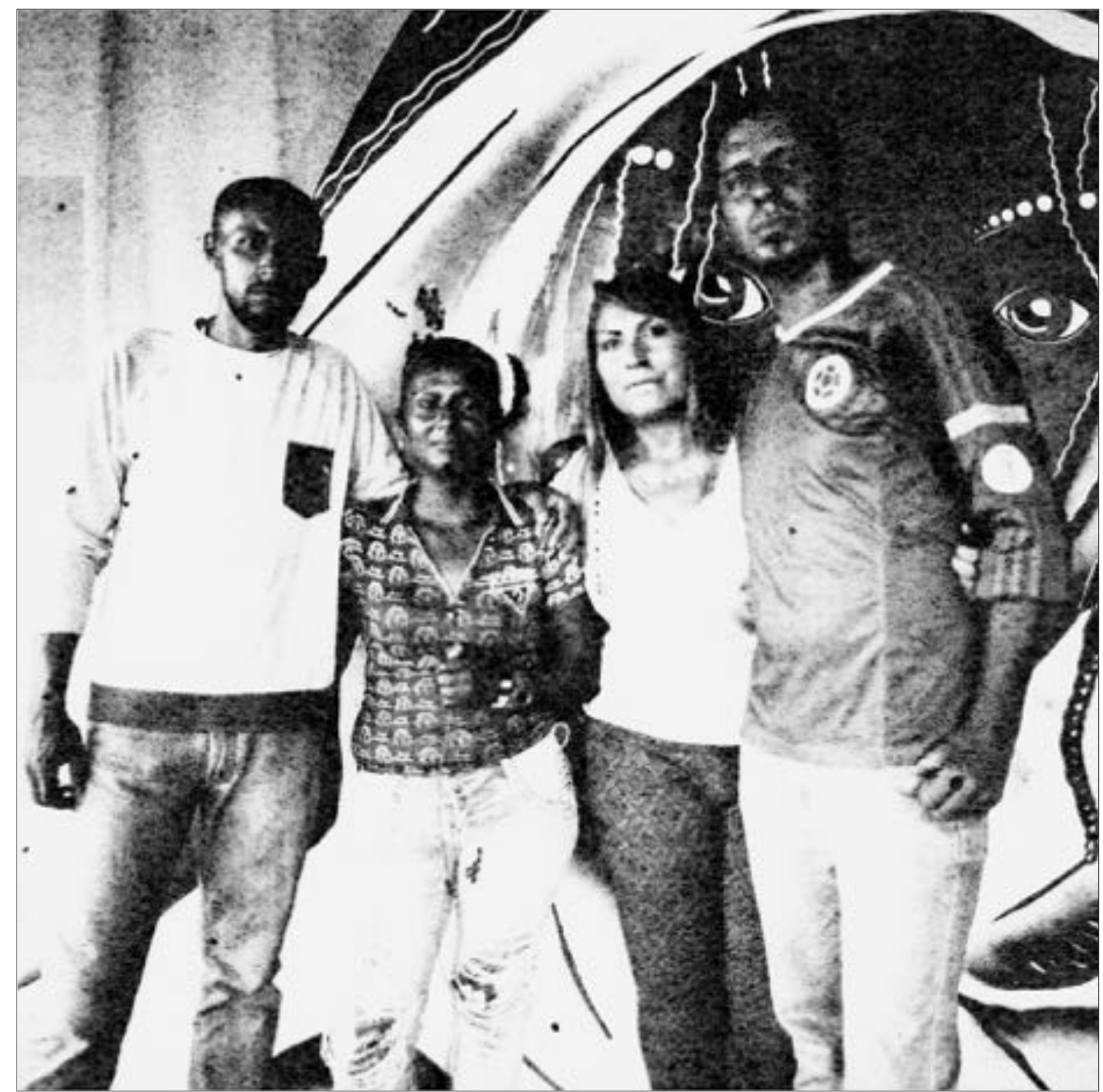

Sin título/Untitled \#22, Puerto Asis, 2017. [Calotipo/Calotype] 


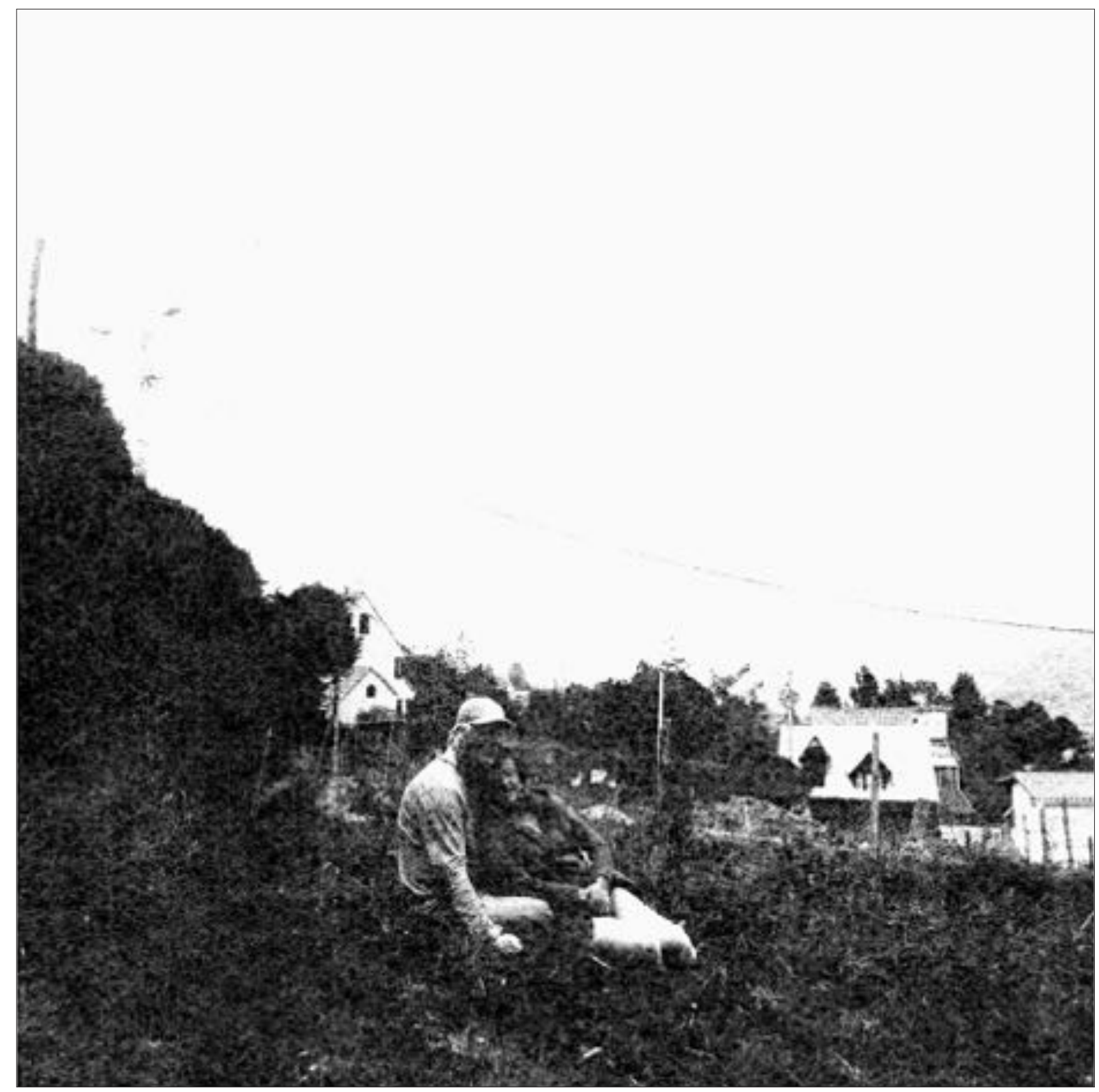

Sin título/Untitled \#23, San Luis, 2017. [Calotipo/Calotype] 


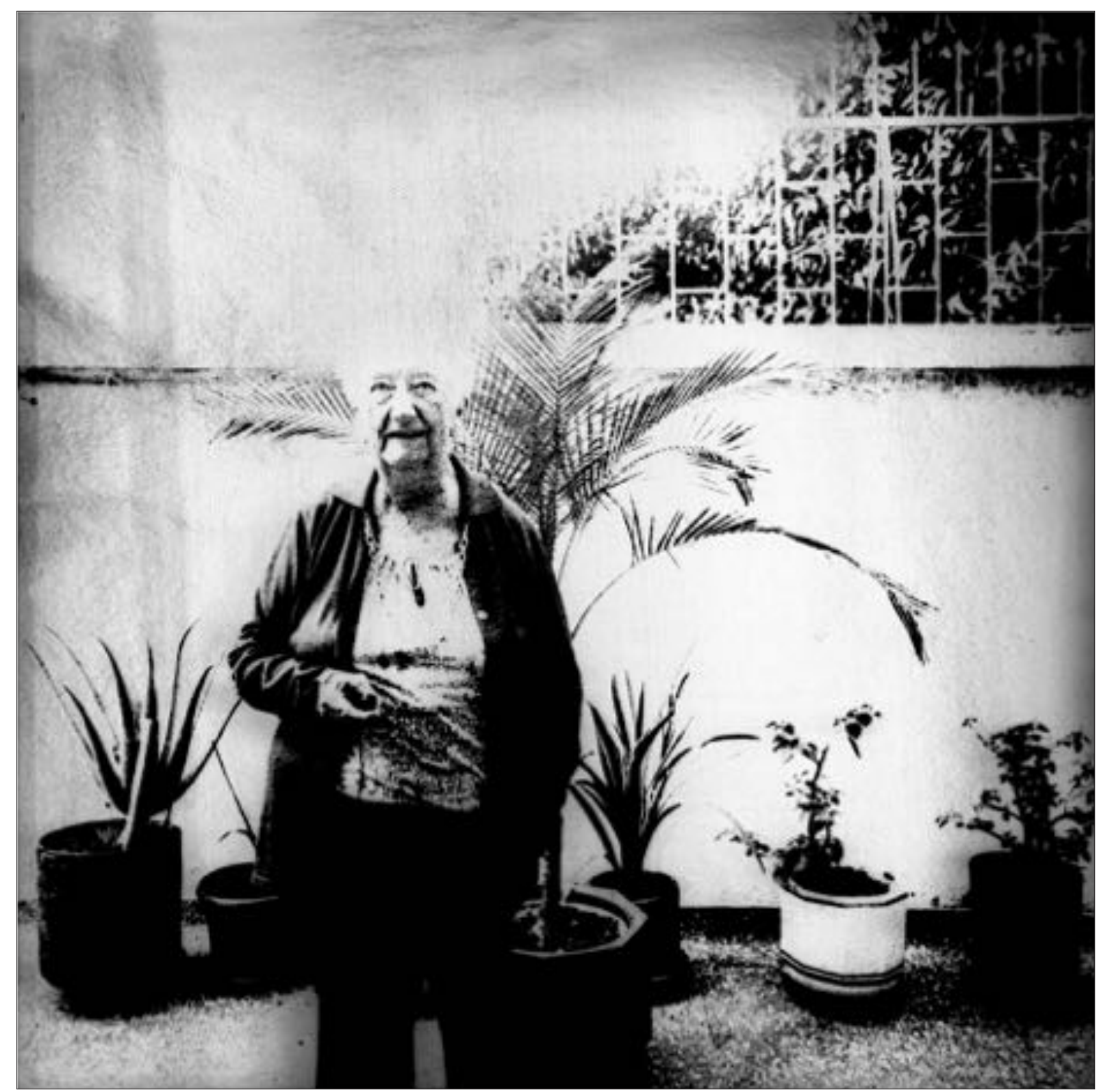

Sin título/Untitled \#24, Medellin, 2018. [Calotipo/Calotype] 
Fotografías de Color Negativo

Colour Negative Photographs

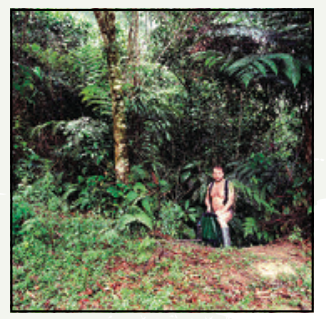

Sin título/Untitled \#1

Cauca, 2017.

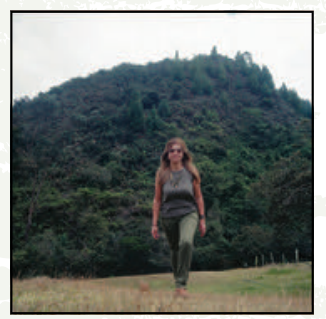

Sin título/Untitled \#5.

Color negativo/Colour negative

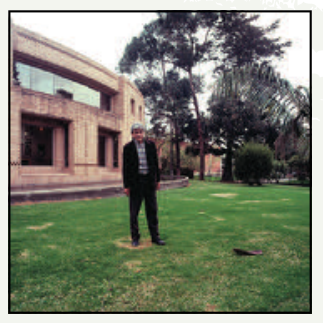

Sin titulo/Untitled \#9

cional de Colombia.

Bogotá, 2017.

[Color negativo/Colour negative]

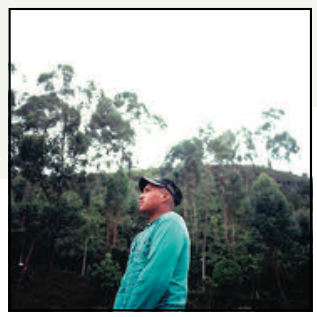

Sin título/Untitled \#2.

Cauca, 2017.

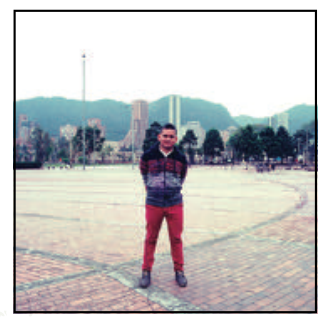

Sin título/Untitled \#6.

Parque Renacimie
Bogotá. 2017.

[Color negativo/Colour negative]

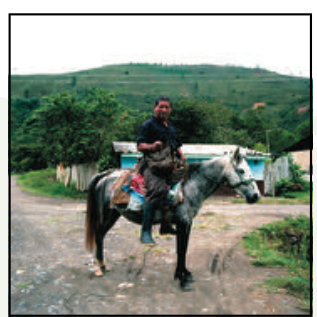

Sin título/Untitled \#10

Cauca, 2018.

[Color negativo/Colour negative]

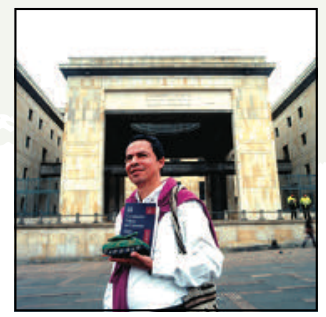

Sin titulo/Untitled \#3.

Bogotá, 2017.

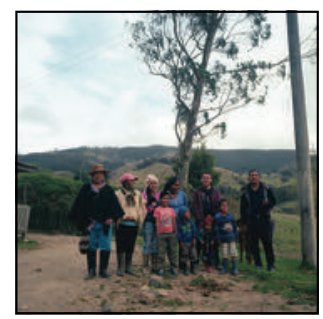

Sin titulo/Untitled \#7,

[Color negativo/Colour negative]

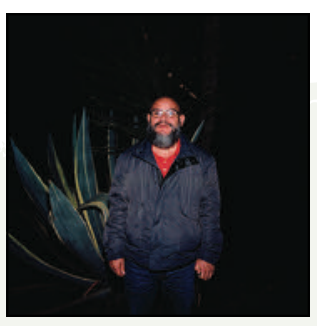

Sin titulo/Untitled \#11

Parque Armenia, Bogotá, 2017.

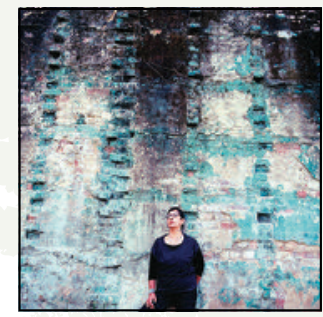

Sin titulo/Untitled \#4.

Centro de Memoria.

Bogota, 2017.
[Color negativo/Colour negative]

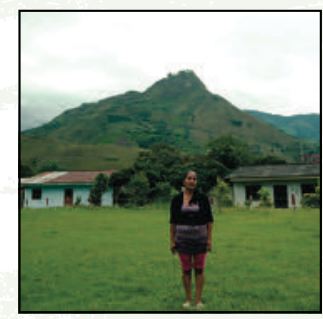

Sin título/Untitled \#8

Cauca, 2018.
[Color negativo/Colour negative]

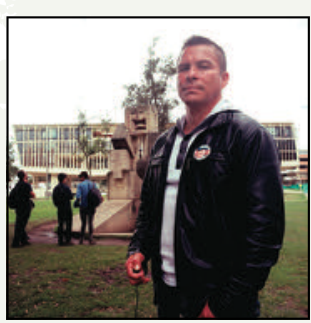

Sin titulo/Untitled \#12

Sin titulo/Untitled \#12,
Universidad Nacional de Colombia Bogotá, 2017.

[Color negativo/Colour negative] 
Fotografías de Color Negativo

Colour Negative Photographs

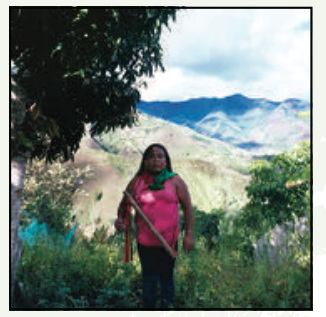

Sin título/Untitled \#13,

La Mesa de Togoima, Cauca, 2018

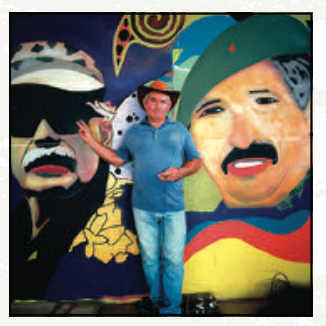

Sin título/Untitled \#17.

[Color negativo/Colour negative]

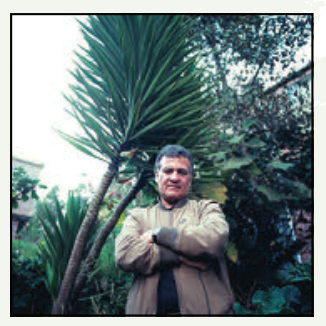

Sin título/Untitled \#21.

[Color negativo/Colour negative

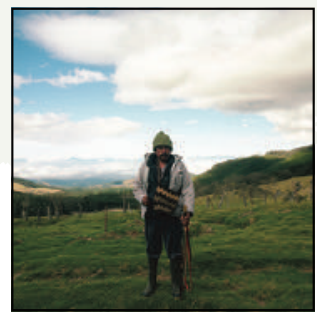

Sin titulo/Untitled \#14.

La Mesa de Togolma, Cauca, 20

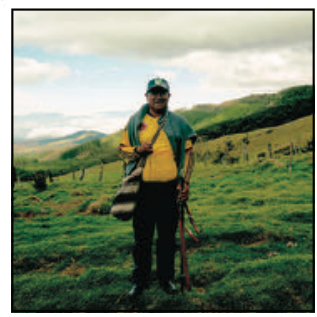

Sin titulo/Untitled \#18.

[Color negativo/Colour negative]

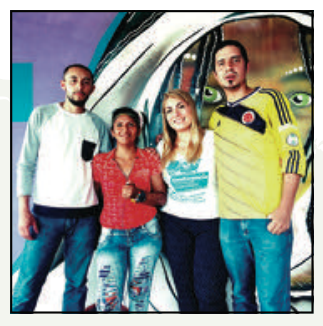

Sin titulo/Untitled \#22.

[Color negativo/Colour negative]

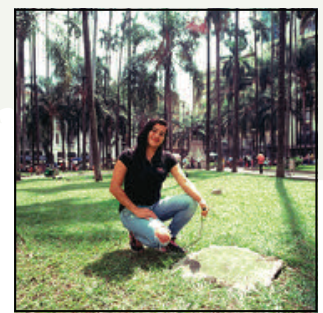

Sin título/Untitled \#15.

[Color negiatedo, Cali, 2017.

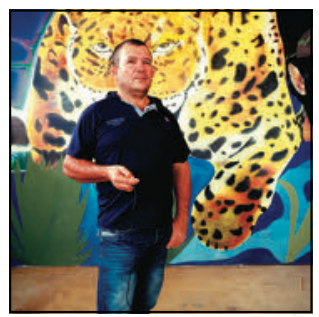

Sin titulo/Untitled \#19.

[Color negativo/Colour negative]

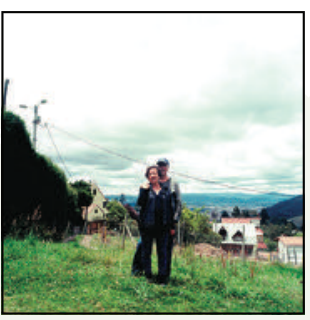

Sin título/Untitled \#23. San Luis, 2017.

[Color negativo/Colour negative]

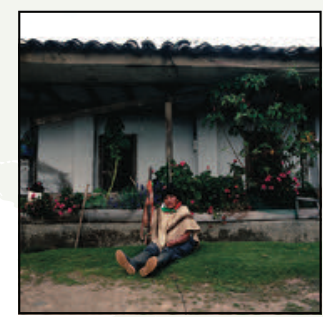

Sin título/Untitled \#16. [Color negativo/Colour negative]

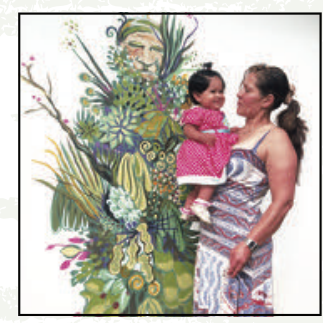

Sin título/Untitled \#20.

Cauca, 2017

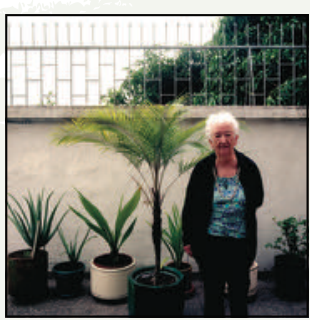

Sin título/Untitled \#24.

Sin titulo/Untitis.

[Color negativo/Colour negative] 
